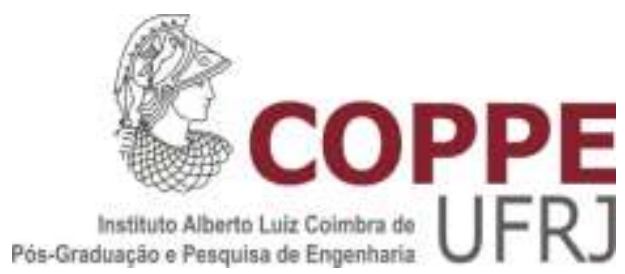

\title{
WATER-ENERGY-FOOD NEXUS OF SUGARCANE ETHANOL PRODUCTION IN THE STATE OF GOIÁS, BRAZIL: AN ANALYSIS WITH REGIONAL INPUT- OUTPUT MATRIX
}

Rodrigo Augusto Bellezoni

Tese de Doutorado apresentada ao Programa de Pós-graduação em Planejamento Energético, COPPE, da Universidade Federal do Rio de Janeiro, como parte dos requisitos necessários à obtenção do título de Doutor em Planejamento Energético.

Orientador: Amaro Olimpio Pereira Junior Marcos Aurélio Vasconcelos de Freitas

Rio de Janeiro Maio de 2018 
WATER-ENERGY-FOOD NEXUS OF SUGARCANE ETHANOL PRODUCTION

IN THE STATE OF GOIÁS, BRAZIL: AN ANALYSIS WITH REGIONAL INPUT-

OUTPUT MATRIX

Rodrigo Augusto Bellezoni

TESE SUBMETIDA AO CORPO DOCENTE DO INSTITUTO ALBERTO LUIZ COIMBRA DE PÓS-GRADUAÇÃO E PESQUISA DE ENGENHARIA (COPPE) DA UNIVERSIDADE FEDERAL DO RIO DE JANEIRO COMO PARTE DOS REQUISITOS NECESSÁRIOS PARA A OBTENÇÃO DO GRAU DE DOUTOR EM CIÊNCIAS EM PLANEJAMENTO ENERGÉTICO.

Examinada por:

Prof. Amaro Olimpio Pereira Junior, Ph.D.

Prof. Deepak Sharma, Ph.D.

Prof. Marcos Aurélio Vasconcelos de Freitas, Ph.D.

Dr. Alberto Arruda Villela, Ph.D.

Prof. Carlos Eduardo Frickmann Young, Ph.D.

RIO DE JANEIRO, RJ - BRASIL

MAIO DE 2018 
Bellezoni, Rodrigo Augusto

Water-energy-food nexus of sugarcane ethanol production in the state of Goiás, Brazil: An analysis with regional input-output matrix/ Rodrigo Augusto Bellezoni.

- Rio de Janeiro: UFRJ/COPPE, 2018.

$\mathrm{XV}, 180$ p.: il.; $29,7 \mathrm{~cm}$.

Orientador: Amaro Olimpio Pereira Junior

Marcos Aurélio Vasconcelos de Freitas

Tese (doutorado) - UFRJ/ COPPE/ Programa de Planejamento Energético, 2018.

Referências Bibliográficas: p. 131-148.

1. Sugarcane Ethanol. 2. Input-Output. 3. WEF Nexus.

4. Energy Planning and Policy. I. Pereira Jr., Amaro Olimpio et al. II. Universidade Federal do Rio de Janeiro, COPPE, Programa de Planejamento Energético. III. Título. 
À minha família,
à minha companheira,
aos meus amigos,
e a todos que me acompanharam nessa longa e importante jornada.

“Talvez não tenha conseguido fazer o melhor, mas lutei para que o melhor fosse feito. Não sou o que deveria ser, mas Graças à Deus, não sou o que era antes." (Martin Luther King) 


\section{Acknowledgements}

Firstly, I thank my family for everything.

I would like to thank my supervisors, Prof. Amaro Olimpio Pereira Jr. and Prof. Deepak Sharma, whom kindly welcomed me to take part of my research in the Centre for Energy Policy, at the University of Technology, Sydney - UTS.

I could not be so grateful to work with Alberto A. Villela for the thoughtful queries and comments, which helped me to improve the thesis, which would be harder to be done without his working experience.

I would like to express my gratitude to professors, researchers and administrative staffs of the Energy Planning Program (PPE) at COPPE, especially the academic secretary Sandra Bernardo do Reis and, also to researchers and administrative staffs of the Faculty of Engineering and Technology Information - FEIT at UTS, especially the Graduate Research Engagement Administrator Jing Zhao and my personal colleague, Evan Ramalli.

I am also thankful to Prof. Marcos Aurélio V. de Freitas and Prof. Carlos Eduardo Fickmann Young for accepting to be part of the examining board.

I am glad to have worked at IVIG, where I had great moments together with the IVIG "crew", especially the Solid Waste and the Waste-to-Energy groups. I would like to thank Vania Lourenço, Graciela Diniz, Nathália Barbosa, Thales do Carmo, Pedro Magalhães, Gabriel Goulart, Breno Tostes, Conrado Versiani, Fernando Frickmann, Pablo Mendes, Alexandre Lopes, Julian Hunt and AlbertoVillela for the conversations, working environment and experiences provided.

My sincere thanks to PRH-ANP, FINEP, MCTIC and CAPES for funding this work.

Thanks a lot, to my friends for the enjoyable and extremely necessary moments having fun together, as well as important working conversations.

And at last but not least, I am grateful for every word, gesture and attitude of companionship of my beloved partner Maíra Manzan, along all those moments the doctorate brought to our lives. This work would not be done without her tenderness and strength, which have supported me all the time. Life would be quite different without the existence of such special soul. Thank you all! 
Resumo da Tese apresentada à COPPE/UFRJ como parte dos requisitos necessários para a obtenção do grau de Doutor em Ciências (D.Sc.)

\title{
NEXO ÁGUA-ENERGIA-ALIMENTOS NA PRODUÇÃO DE ETANOL DE CANA- DE-AÇÚCAR NO ESTADO DE GOIÁS, BRASIL: UMA ANÁLISE COM MATRIZ INSUMO-PRODUTO REGIONAL
}

\author{
Rodrigo Augusto Bellezoni
}

\section{Maio/2018}

\section{Orientador: Amaro Olimpio Pereira Junior \\ Marcos Aurélio Vasconcelos de Freitas}

Programa: Planejamento Energético

O crescimento da produção de biocombustíveis enfatiza a importância do planejamento na expansão de culturas energéticas, considerando os recursos água, energia e terra, além de emissões de gases do efeito estufa (GEE). O presente estudo analisa os impactos da expansão do etanol de cana-de-açúcar na bacia do Paranaíba (estado de Goiás), visando entender se a demanda futura por etanol pode afetar indicadores socioeconômicos, ambientais e energéticos na região. Um modelo econômico-ecológico de Insumo-Produto (IP) foi aplicado para avaliar o nexo águaenergia-alimentos (NAEA) na produção de etanol. Resultados mostram que a expansão da cana-de-açúcar aparentemente causaria um impacto pouco significativo na disponibilidade de água e terras na bacia do Paranaíba, quando considerados apenas os efeitos diretos dessa expansão na região. A análise do NAEA é uma ferramenta valiosa para orientar a gestão sustentável de recursos naturais, considerando uso da água, terra e energia e emissões de GEE como metas de uma mesma política. Portanto, a abordagem híbrida NAEA-IP é útil no desenvolvimento de políticas para biocombustíveis, por coletivamente abordar impactos ambientais, sociais e econômicos, em um contexto local ou mais amplo. 
Abstract of Thesis presented to COPPE/UFRJ as a partial fulfillment of the requirements for the degree of Doctor of Science (D.Sc.)

\title{
WATER-ENERGY-FOOD NEXUS OF SUGARCANE ETHANOL PRODUCTION IN THE STATE OF GOIÁS, BRAZIL: AN ANALYSIS WITH REGIONAL INPUT- OUTPUT MATRIX
}

\author{
Rodrigo Augusto Bellezoni
}

May/2018

\begin{abstract}
Advisor: Amaro Olimpio Pereira Junior
Marcos Aurélio Vasconcelos de Freitas
\end{abstract}

Department: Energy Planning

Concerns about impacts of biomass growth for biofuel production emphasize the importance of planning energy crops expansion considering water, energy and land resources, as well as greenhouse gas emissions (GHG). This study analyses the impacts of first-generation sugarcane ethanol expansion in the Paranaíba basin (Goiás State), focusing on how future demand for ethanol could affect socio-economic, energy and environmental indicators in the region. An economic-ecological Input-Output (IO) framework was applied to develop a water-energy-food nexus (WEFN) analysis on ethanol production. Results show that sugarcane expansion would apparently cause little significant impacts on land and water availability in the Paranaíba basin, when analysing only the direct impacts of this expansion in the region. The WEFN analysis is a valuable tool on guiding the sustainable management of natural resources considering water, energy, land use and GHG emissions as goals to the same policy. In particular, the hybrid extended IO-WEFN framework is useful to design effective biofuel policies, collectively addressing impacts on environmental, social and economic spheres, in a local or broader context. 
Contents

1 Introduction ......................................................................................................... 1

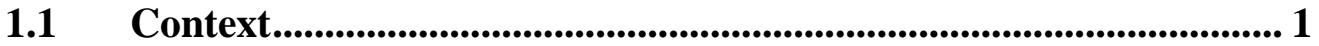

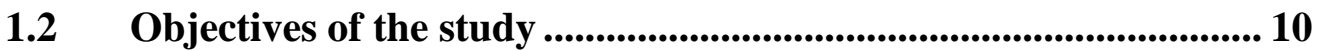

2 Biofuel Policy in Brazil............................................................................... 14

2.1 Motivations for the National Biofuel Policy .................................. 17

2.1.1 The Brazilian biofuel market ........................................................ 17

2.1.2 External dependence on oil products........................................... 18

2.1.3 Observed growth in ethanol imports ........................................... 18

2.1.4 Risks to the national fuel supply ............................................ 21

2.1.5 Volumetric targets for biofuels ............................................... 23

2.2 The National Biofuel Policy scheme.............................................. 25

2.2.1 Biofuels production certification ................................................. 25

2.2.2 Biofuel decarbonisation credits (CBIO) .................................... 27

2.2.3 RenovaBio impact estimates ...................................................... 29

2.3 Biofuels and the Brazilian Forest Code ......................................... 30

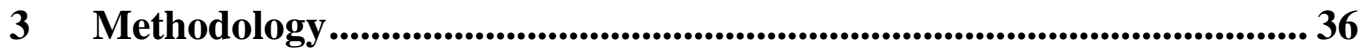

3.1 Methodology and scope of the study ................................................. 38

3.1.1 The water-energy-food nexus ..................................................... 38

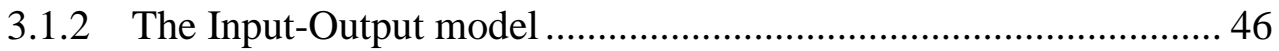

3.1.3 Inter-regional Input-Output matrix .............................................. 53

3.1.4 Goiás’ economic-ecological Input-Output model ......................... 58

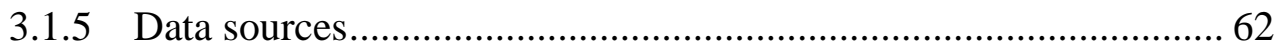

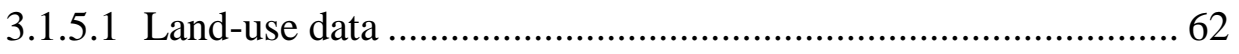

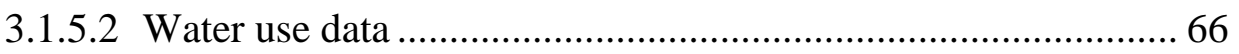




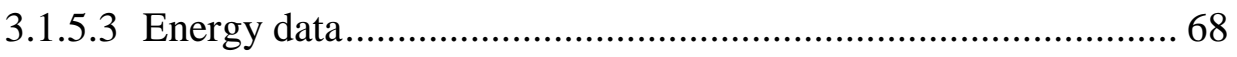

3.1.5.4 GHG emissions data............................................................... 70

$4 \quad$ Case Study .............................................................................................................. 72

4.1 Sugarcane industry and environmental concerns in Brazil .......... 72

4.2 Ethanol policy scenarios....................................................................... 87

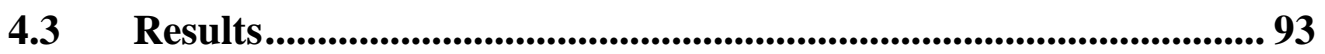

4.3.1 Concerns on local water resources ............................................. 102

4.3.2 Indirect land-use change impacts ............................................... 105

4.4 Discussion .................................................................................................. 108

4.4.1 Managing local water resources .................................................. 113

4.4.2 Indirect land-use change impacts ................................................. 115

4.4.3 Integrated biofuel policy............................................................... 118

4.5 Work limitations ................................................................................. 123

5 Conclusions ........................................................................................................... 126

6 References........................................................................................................... 131

Appendix I: Goiás' Original Input-Output table ............................................. 149

Appendix II: Aggregated Input-Output table for the state of Goiás and the rest of Brazil .................................................................................................................... 158

Appendix III: Goiás and rest of Brazil technical coefficients....................... 159

Appendix IV: Goiás and rest of Brazil $(I$ - A) matrix .................................... 160

Appendix V: Goiás and rest of Brazil Leontief inverse matrix.................... 161

Appendix VI: Goiás economic-ecological hybrid Input-Output matrix ... 162

Appendix VII: Useful volume of hydropower reservoirs............................... 163

Appendix VIII: Useful monthly volume ............................................................... 164

Appendix IX: Polynomials for reservoirs calculation ...................................... 165

Appendix X: Relative quota ..................................................................................... 166 
Appendix XI: Average monthly area

Appendix XII: Water-use coefficients, total production and total water-use by sector. 168

Appendix XIII: Evaporation coefficients 172

Appendix XIV: Net evaporation of reservoirs 173

Appendix XV: Water footprint of power plants in the region of study .... 174 Appendix XVI: GHG emissions references............................................ 175

Appendix XVII: Goiás' GHG emissions....................................................... 179 


\section{List of Figures}

Figure 1. Sugarcane crops and ethanol plants' influence areas in Brazil. .................... 6

Figure 2. Brazilian ethanol exports $x$ imports ............................................................. 19

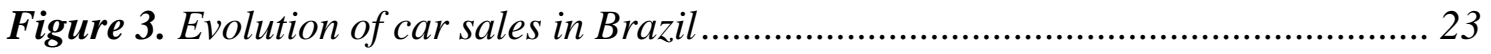

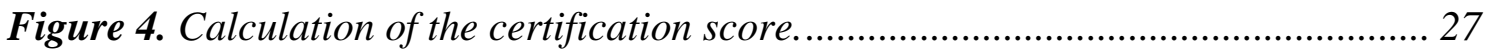

Figure 5. Hypothetical example of certification score calculation for a) plant 1 and $b$ )

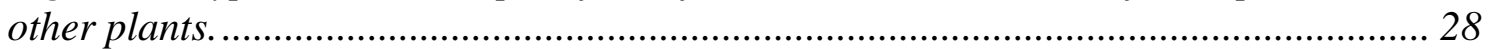

Figure 6: Environmental liabilities after the Brazilian Forest Code revision. .............. 33

Figure 7: Available pasturelands suitable for agriculture production for each Brazilian state, without considering climate restrictions.............................................................. 34

Figure 8. Justification for the nexus approach. Examples of vicious cycles due to isolated

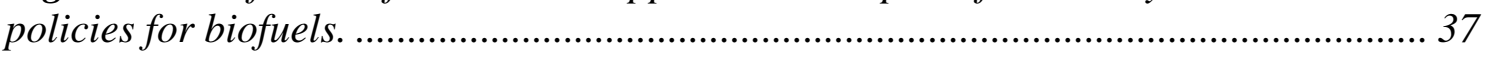

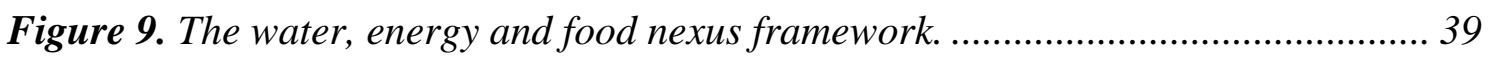

Figure 10. Example of the Climate, Land, Energy and Water System diagram............ 40

Figure 11. The electricity-water nexus in Australia. .................................................. 42

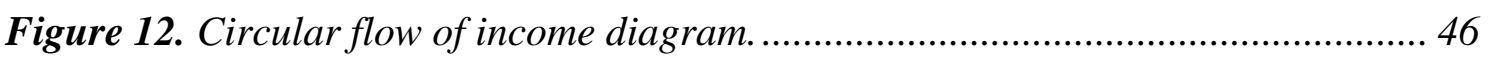

Figure 13. Basic Input-Output model relationships. .............................................. 47

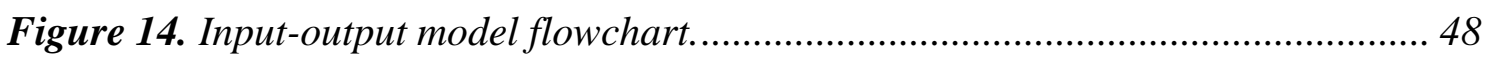

Figure 15. Input-Output relationships in an inter-regional system............................. 54

Figure 16. Goiás' agriculture land-use, by crops in $\mathrm{km}^{2}$ (2008)................................63

Figure 17: Spatial distribution of agricultural activities in Brazilian biomes in 2000. a) Livestock production, b) Croplands. ..................................................................... 73

Figure 18: Protected areas and deforestation in Brazil. a) Protected areas in Brazilian biomes. b) Deforestation in Cerrado and Amazon between 2001-2015, in km²............ 74

Figure 19. Goiás' Sugarcane Agro-ecological Zoning. Suitable areas for sugarcane expansion, by land-use in 2008.

Figure 20. Crop area in Centre-South region of Brazil, highlighting the Paranaíba basin (dotted) and the states of São Paulo (SP) and Goiás (GO) in a) 2003 and b) 2011..... 77

Figure 21. Crop area (columns) $)^{a}$ and sugarcane (dotted line) $)^{b}$ sugar (black line) ${ }^{c}$ and ethanol (dashed line) d production in Goiás State........................................................... 78

Figure 22. Geographical limits of the Paranaíba basin and its land-use .................... 79

Figure 23. Paranaiba's basin Water Management Units.......................................... 80

Figure 24. Paranaiba's basin WMU location versus sugarcane agro-ecological zoning.

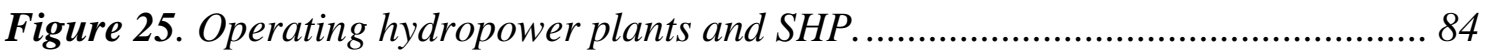

Figure 26. Hydropower plants and SHP in planning stage .......................................... 85 
Figure 27. Centre-West ethanol producers' location. 85

Figure 28. GHG emissions in the state of Goiás, by sector, in 2016. 86

Figure 29. Share of GHG emissions in Goiás State in 2016, by a) major categories, $b$ ) land-use and c) agricultural activities.

Figure 30. Additional ethanol production required, according to each policy scenario.

Figure 31. Evolution of GHG emissions in Goiás, highlighting the role of land-use change GHG emissions, 2005-2016.

Figure 32. 2008 Goiás' a) agricultural area, b) land-use, c) water use and d) GHG

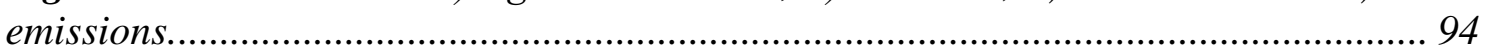

Figure 33. 2008 Goiás' GHG emissions, by major categories..................................... 95

Figure 34. 2008 Goiás' GHG emissions, by sector .................................................... 95

Figure 35. Additional water, energy and land-use requirements, ethanol production, job creation and GDP for all 2030 scenarios. .............................................................. 99

Figure 36. Additional GHG emissions for all 2030 scenarios. .................................. 99

Figure 37. Changes in water and land requirements, GHG emissions, job creation and GDP, from $1 \%$ changes in final demand for ethanol in the state of Goiás. 100

Figure 38. Share of ethanol policy scenarios regarding Brazilian government ethanol expansion forecasts. 100

Figure 39. Additional land-use estimates regarding Goiás 'sugarcane crop area, in 2015. 101

Figure 40. Total energy demand and the share of 2015 Goiás' internal energy supply. 102

Figure 41. Additional water, energy and land-use requirements, job creation and GDP for scenario $2 e$. 103

Figure 42. Share of irrigated crops, livestock production and in relation to the whole Paranaiba basin, by WMU. 105

Figure 43. Lack of integration between energy, water and land policies. 122 


\section{List of Tables}

Table 1. Basic structure of economic-ecological Input-Output models. 43

Table 2. IO table for a 2 sectors economy. 48

Table 3. List of 26 sectors from the Goiás' original IO table (GUILHOTO, 2010) and the resulting 13 aggregated sectors. 53

Table 4. General structure of an Input-Output table with hybrid units*...... 58

Table 5. Economic-ecological commodity flows: Matrix definitions. . 59

Table 6. Land-use in the state of Goiás (2008), by economy sectors. 64

Table 7. Maximum, minimum and useful water volume for the major hydro plants in the study area, in $\mathrm{hm}^{3}$.

Table 8. Total water-use in Brazil and in the state of Goiás by sector, in 2008. 67

Table 9. Summarized 2008 Goiás' energy balance (in $10^{3}$ toe) .....................................6 69

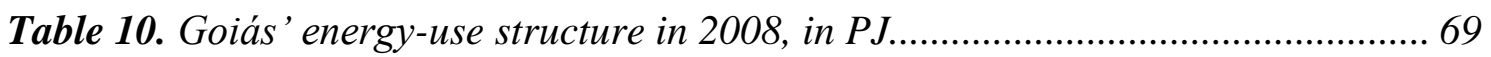

Table 11. Goiás' GHG emissions, in 2008 (in $\mathrm{TgCO}_{2 e}$ GWP-AR5).................................... 71

Table 12. Suitable areas for sugarcane expansion in Brazil, by agricultural potential and land-use, in 2008.

Table 13. Sugarcane crop area and outputs in Brazil. 78

Table 14. Surface water availability, water withdrawals and water balance in the Paranaíba basin, by Water Management Unit.

Table 15. Surface water availability for granting rights to water use, water withdrawal and annual surface water availability in the Paranaíba basin, by WMU.

Table 16. Ethanol production scenarios considering Goiás' internal demand, exports to other states, meeting 2030 demand and different levels of gasoline substitution for ethanol. 90

Table 17. Summary of the estimates for water energy and land uses, as well as GHG emissions, employment and GDP changes for each ethanol prospective scenario. 96

Table 18: Estimates of GHG emissions from expanding Goiás sugarcane crops. ...... 106

Table 19. Groundwater resources in the Paranaiba basin. Active reserves and water availability, by WMU. 


\section{List of Abbreviation and Acronyms}

\begin{tabular}{|c|c|}
\hline AEZ & Agro-ecological zoning \\
\hline ANA & National Water Agency \\
\hline ANP & National Agency for Petroleum, Natural Gas and Biofuels \\
\hline BTL & Biomass-to-liquids \\
\hline $\mathrm{C} 4$ & C4 carbon fixation pathway (plants) \\
\hline CAPEX & Capital Expenditure \\
\hline $\mathrm{CBIO}$ & Biofuel Decarbonisation Credit \\
\hline CGE & Computational General Equilibrium \\
\hline CGEE & Centro de Gestão de Estudos Estratégicos \\
\hline CLEWS & Climate, Land, Energy, and Water System \\
\hline $\mathrm{CMBC}$ & Committee for the Monitoring of Biofuels and Fuels \\
\hline $\mathrm{CNI}$ & National Industry Confederation \\
\hline CNPE & National Energy Policy Council \\
\hline $\mathrm{CO}_{2 \mathrm{e}}$ & Carbon Dioxide Equivalent \\
\hline CONAB & National Supply Company \\
\hline COP 21 & $21^{\text {st }}$ Conference of Parties \\
\hline CRA & Environmental Reserve Quota \\
\hline DLUC & Direct Land-use Change \\
\hline EMBRAPA & Brazil's federal agricultural research agency \\
\hline $\mathrm{EPE}$ & Brazilian Energy Research Company \\
\hline FAO & Food and Agriculture Organization of the United Nations \\
\hline FUNARBE & Federal University of Viçosa Support Foundation \\
\hline GCM & General Circulation Models \\
\hline GDP & Gross Domestic Product \\
\hline GHG & Greenhouse Gases \\
\hline $\mathrm{GO}$ & Goiás State \\
\hline GWP & Global Warming Potential \\
\hline HLPE & High Level Panel of Experts \\
\hline $\mathrm{hm}^{3}$ & Cubic hectometre \\
\hline IAEA & International Atomic Energy Agency \\
\hline IBGE & Brazilian Institute of Geography and Statistics \\
\hline ICIMOD & International Centre for Integrated Mountain Development \\
\hline IEA & International Energy Agency \\
\hline IIASA & International Institute for Applied Systems Analysis \\
\hline IISD & International Institute for Sustainable Development \\
\hline ILUC & Indirect Land-use Change \\
\hline IMB & Mauro Borges Institute \\
\hline INPE & National Institute for Space Research \\
\hline
\end{tabular}




$\begin{array}{ll}\text { IO } & \text { Input-Output } \\ \text { IPCC } & \text { Intergovernmental Panel on Climate Change } \\ \text { IRENA } & \text { International Renewable Energy Agency } \\ \text { J } & \text { Joules } \\ \text { km } & \text { Square kilometre } \\ \text { LCA } & \text { Life-cycle Assessment } \\ \text { LEAP } & \text { Long-range Energy Alternatives Planning } \\ \text { LHV } & \text { Lower Heating Value } \\ \text { LR } & \text { Legal Reserve } \\ \text { LUC } & \text { Land-use Change } \\ \text { MAPA } & \text { Ministry of Agriculture and Food Supply } \\ \text { MAPBIOMAS } & \text { Annual land-use and coverage mapping in Brazil } \\ \text { MCTI } & \text { Ministry of Science, Technology and Innovation } \\ \text { MME } & \text { Ministry of Energy and Mines } \\ \text { MSA } & \text { Multi-sectoral Systems Analysis } \\ \text { MUSIASEM } & \text { Multi-Scale Integrated Assessment of Society and Ecosystem } \\ \text { NDC } & \text { Nationally Determined Contribution } \\ \text { NWRP } & \text { National Water Resources Policy } \\ \text { OECD } & \text { Organization for Economic Co-operation and Development } \\ \text { OPEX } & \text { Operational Expenditure } \\ \text { PDE } & \text { Ten Year Energy Plan } \\ \text { PNPB } & \text { Brazilian Biodiesel Production Program } \\ \text { PPA } & \text { Permanent Preservation Area } \\ \text { PROALCOOL } & \text { Brazilian National Alcohol Program } \\ \text { QAV } & \text { Aviation kerosene } \\ \text { PSA } & \text { Payment for Environmental Services } \\ \text { RBP } & \text { River Basin Plan } \\ \text { SEEG } & \text { Emission Estimating System for GHG } \\ \text { SEI } & \text { Stockholm Environment Institute } \\ \text { SHP } & \text { Small Hydroelectric Plant } \\ \text { SIRENE } & \text { National Emissions Record System } \\ \text { Tg } & \text { Tera grams } \\ \text { UNCTAD } & \text { United Nations Conference on Trade and Development } \\ \text { UNEP } & \text { United Nations Environment Programme } \\ \text { UNFCCC } & \text { United Nations Framework Convention on Climate Change } \\ \text { UNICA } & \text { Sugarcane Industry Association } \\ \text { US } & \text { United States of America } \\ \text { WEAP } & \text { Water Evaluation and Planning System } \\ \text { WEFN } & \text { Water, Energy and Food Nexus } \\ \text { WMU } & \text { Water Management Unity } \\ \text { ZAE Cana } & \text { Sugarcane Agro-ecological Zoning } \\ & \end{array}$




\section{Introduction}

\subsection{Context}

Debates on energy security, oil price variability and the growing global commitment to address climate change have intensified throughout the $21^{\text {st }}$ century, motivating increasing investments in renewable energy resources, although fossil fuel still dominates the global energy market. Since the transport sector heads up the oil consumption worldwide and the air, marine and heavy freight transport rely on liquid fuels' high energy density the transportation sector is on the lookout for alternative renewable fuel sources.

On a global scale, biofuels have accounted for about $3 \%$ of the fuel consumed by the transport sector in 2014 (IEA, 2016), and the United States and Brazil lead the world biofuel production. Brazil accounted for $22.5 \%$ of global biofuel production in 2016, which represents $83 \%$ of South \& Central America's total output. Researchers and planners have focused on liquid biofuels, which in Brazil have long contributed to reduce greenhouse gas emissions (GHG) from the transport sector, besides contributing to agricultural development and reducing oil imports dependency.

Besides energy and environmental aspects, traditional biofuels production may have many social benefits that can help developing countries grow in a more sustainable way. Some studies have highlighted the employment and income generation related to biofuel programs in developing countries and their positive effects on living conditions (LYND and WOODS, 2001; MORAES et al., 2010). Thus, as technological improvements emerge, the potential environmental and economic benefits of biofuels are becoming more evident, making them a promising renewable energy source.

It is noteworthy that biofuels can be produced from different raw materials, generating sources of energy with distinct characteristics. Traditional biofuels use conventional food and feed crops as feedstocks, also known as "flex-crops" or "flexcommodities". Flex-crops are agricultural crops that can be used for food, feed, fuel and industrial material. First-generation biofuels $(I G)$ usually refers to ethanol produced from sugar-rich (e.g., sugarcane, sugar beet, sweet sorghum) and starch-rich flex-crops (e.g. corn, wheat, cassava, rice), and to biodiesel made from oilseed crops (e.g. soybeans, rapeseed, sunflower, palm) or animal fat (GASPARATOS and STROMBERG, 2012; 
OECD/IEA, 2010). Most of the current global biofuel production comes from targets and incentives that players such as Brazil, the United States and European Union, have set up to diversify transport fuel supplies, improve energy security and reduce GHG emissions (IRENA, 2016).

Biofuels made from non-edible biomass and cellulose, hemicellulose and lignin, biomass-to-liquids (BTL), and bio-synthetic natural gas are called second-generation biofuels (2G) (FAO, 2008b; OECD/IEA, 2010). Typical lignocellulosic feedstocks are agricultural by-products (e.g. cane bagasse, corn stover, husks, stalks), forestry residues (e.g. thinning, treetops and branches), perennial grasses (e.g. switchgrass and miscanthus), short rotation coppice (e.g. eucalyptus, willow, poplar, acacia) and municipal waste (HLPE, 2013). Lignocellulosic feedstocks often do not compete for high-quality land with food crops due to their high yields and growing capacity on land poorly suited for food crops. Before converting sugars into ethanol through well-known fermentation and distillation stages, firstly the cellulose and hemi-cellulose components of the biomass must be broken down into sugars, typically in a so-called biochemical conversion route (OECD/EIA, 2010; HLPE, 2013; IRENA, 2016). Feedstocks can also be submitted to a high-temperature process (gasification/pyrolysis) to be converted into a synthesis gas, in the thermochemical route. This gas can then be transformed into different types of liquid or gaseous fuel, so-called "synthetic fuels" (OECD/IEA, 2010). Most biochemical and thermochemical technologies are currently in a pilot or demonstration phase.

Because of its current early-stage of development, third-generation biofuels ( $3 G)$ are not yet cost-effective and typically refers to algae-based biofuels. They usually refer to biofuels grown on much less land than $1 G$ and $2 G$ biofuels, not competing with food crops nor with arable lands, while producing a variety of useful co-products. Conversion of algae to biofuel (biodiesel and jet fuel) involves the same steps to convert oilseeds to biodiesel, such as extraction of oil, purification and transesterification of lipids. Nowadays, several countries have intensified their research and development efforts on both $2 G$ and $3 G$ biofuels, due to their technical, economic and environmental potential (IRENA, 2016).

Considering the range of possibilities to biofuel production, which includes different raw materials, biofuel crop considered, scale of production, land category considered, cultivation practices, water availability, fertilizer application, conversion 
technologies, region or country of production, and also considering climate change in future scenarios, conclusions on socio-economic and environmental implications of biofuels are, therefore, likely to vary largely (RAVINDRANATH et al., 2011). In this regard, traditional biofuels have been criticised because they may compete with food crops for land, water, nutrients and other resources, besides impacting the agriculture itself, the security, food prices, local environment and economy (FAO, 2008), which frequently offsets positive impacts from reduced GHG emissions.

First-generation biofuel production may result in both direct and indirect land-use change. Direct land-use change (DLUC) occurs when feedstocks for biofuel production represent new crops directly established on arable land, forest or grasslands. Indirect landuse change (ILUC) occurs when the feedstocks for biofuel production are not triggering land-use change on-site, but elsewhere due to the need to compensate foregone production now used for biofuels (LAPOLA et al., 2010; 2014; HLPE, 2013). Native ecosystems deforestation to biofuel production may drastically harm the desired GHG emission reductions, besides threatening biodiversity (TILMAN et al., 2009; FARGIONE et al., 2010; LAPOLA et al., 2010; KARP and RICHTER, 2011; FAO, 2013; DHILLON and WUEHLISCH, 2013).

A study conducted by the World Bank targeting land investments by resourcepoor, capital-rich countries, has shown a weak correlation with cultural affinity between the countries of origin and destiny. On the other hand, a strong correlation was observed between high levels of land investment intentions and "weak land governance and protection of local land rights" (AREZKI et al., 2011). According to the International Water Management Institute, water is in fact the key resource behind these investments (WILLIAMS, 2012). Water and land resources are subject to independent regulatory systems and different government responsibilities, and this lack of interlinks between agencies and policies has been leading to land deals without considering water implications of large-scale projects, which can lead to water being overdrawn and to the diversion and the drying up of water sources (HLPE, 2013).

Besides the lack of an integrated governance framework, much of the impact of biofuels and policies on water, energy and food securities arises from the choice of feedstock and technology for biofuel production. It determines the form of competition for food, feed and land, with diverse land and water needs depending on the feedstock (HLPE, 2013). Therefore, governments shall assess the amount of biofuel that can be 
produced sustainably, giving priority to approaches that complement rather than compete with water use and food production, and which use available land without direct and indirect land-use change (IRENA, 2016).

Regarding the feedstock chosen, Brazil is the biggest sugar producer in the world, the biggest sugar exporter (respectively $21 \%$ and $58 \%$ of the world total) (FAO, 2017) and the second largest producer of fuel ethanol, with a record production of $30.23 \mathrm{hm}^{3}$ in 2015 (UNICA, 2017). Global bioethanol output is mainly concentrated in Brazil and in the United States, which combined account for 85\% of total production (MME, 2017b). While Brazilian ethanol is produced from sugarcane, US ethanol is produced mainly from corn, with competitive production costs, but its energy balance is not as high as sugarcane-based ethanol, as well as having lower productivity in terms of area. Considering the country's still wide availability of land for energy crops, Brazilian sugarcane ethanol is a well-known success story of commercial use of biomass for energy purposes, given its low "well-to-wheels" GHG emissions, the crop's very high yield (typical of $\mathrm{C} 4$ plants), low water footprint and its low induced deforestation (GOLDEMBERG, 2008; PEREIRA et al., 2008; LA ROVERE et al., 2011).

The use of ethanol as an alternative fuel in Brazil expanded after the first oil crisis, with the PROALCOOL ${ }^{1}$ Program in 1975 . First it was employed as an octane booster to gasoline and later as a complete substitute in properly adapted engines. The program has attracted significant investments in agricultural and industrial processes related to $1 \mathrm{G}$ ethanol production, stimulating sugarcane growing and the construction of ethanol plants in the country. Additionally, an important domestic ethanol market was consolidated through a huge investment cycle focusing on promoting flex-fuel engines, which gives to consumers the choice of fuelling their car with petrol or ethanol in any proportion, according to their selling prices. Brazilian ethanol can be produced both in autonomous distilleries and in the most common mixed-sugar ethanol plants.

\footnotetext{
1 The Brazilian National Alcohol Program - PROALCOOL - was based on several interventions by the federal government. "Phase 1 (1975 - 1979): Government effort launched with an initial target to blend anhydrous ethanol to gasoline up to $22.4 \%$ (by volume). Phase 2 (1979 - 1986): Government support to strong ethanol production increase. Industry agreement to start producing ethanol powered cars. Phase 3 (1986 - 1989): Ethanol production stopped increasing in 1986. Major supply crisis in 1989 reduced the share of ethanol fuelled cars. Phase 4 (1989-2003): Ethanol is mixed up to 24\% with gasoline. Phase 5 (from 2003 on): New and huge investment cycle. High oil prices, energy security, and climate change concerns stimulate world demand, increasing export opportunities. Domestic demand growth thanks to flex-fuel cars" (LA ROVERE et al., 2011).
} 
Brazilian ethanol production rose from $10.6 \mathrm{hm}^{3}$ in $2000 / 01$ to $17.8 \mathrm{hm}^{3}$ in $2006 / 07$, and then to $27.3 \mathrm{hm}^{3}$ in $2016 / 17$, with significant increases in agricultural and industrial productivity (UNICA, 2017). In 2016, sugarcane biomass energy accounted for $17.5 \%$ of Brazil's internal energy supply, whereas ethanol had a 5.6\% share of the final energy consumption (MME, 2017). When considering all liquid fuels used in the road transport sector alone, the share of ethanol accounted for $18 \%$ of total in 2016 , led by diesel oil (45.4\%) and gasoline (31.2\%) (MME, 2017). Currently, anhydrous ethanol is employed as an oxygenated additive to gasoline (from $18 \%$ to $27 \%$ blending - this blend gasoline-ethanol is also called gasohol). Hydrous ethanol is employed in dedicated engines or in flex-fuel engines (up to E100).

As stated by Brazil's National Agency of Petroleum, Natural Gas and Biofuels ANP (ANP, 2017), as of February 2017, the country had 384 ethanol mills, producing $333,919 \mathrm{~m}^{3}$ a day, with sugarcane being the feedstock used in $97 \%$ of authorized mills (ANP, 2017). According to ANP (2016), 36.7\% of all ethanol produced in the country between 2008 to 2015 was anhydrous ethanol, while the hydrous ethanol share was $63.3 \%$. In the same period, $95 \%$ of all ethanol consumed was for energy purposes (ANP, 2016).

Sugarcane is cultivated in many Brazilian states, being the top crop in terms of raw biomass production and third in terms of area, after soybeans and corn (IBGE, 2017). The largest sugarcane-producing area is the Centre-South region, accounting for more than $90 \%$ of the country's production (Figure 1), led by São Paulo State with $56 \%$ of the total (IBGE, 2017; UNICA, 2017). Sugarcane is also the most irrigated crop in the country (30\% of total), with about $17,000 \mathrm{~km}^{2}$ (ANA, 2012), and the National Irrigation Policy (enacted in 2013) (BRASIL, 2013) encourages the expansion of irrigated areas. However, $98 \%$ of that is the so-called salvage irrigation, i.e. $20-80 \mathrm{~mm} /$ year irrigation aiming to partially reduce the water stress in the dry season, which corresponds to the application of vinasse in the soil. Vinasse is a potassium-rich ethanol distillation byproduct produced in large amounts (about 10 litres for each litre of ethanol) and diluted with water recycled from the process (when necessary) (ANA, 2017). Therefore, despite the significant share of sugarcane in the total irrigated area, it is noteworthy that the water demand by $\mathrm{km}^{2}$ is much lower than other crops mainly due to low application levels (salvage irrigation) and high-water reuse of industrial processes (vinasse application). 


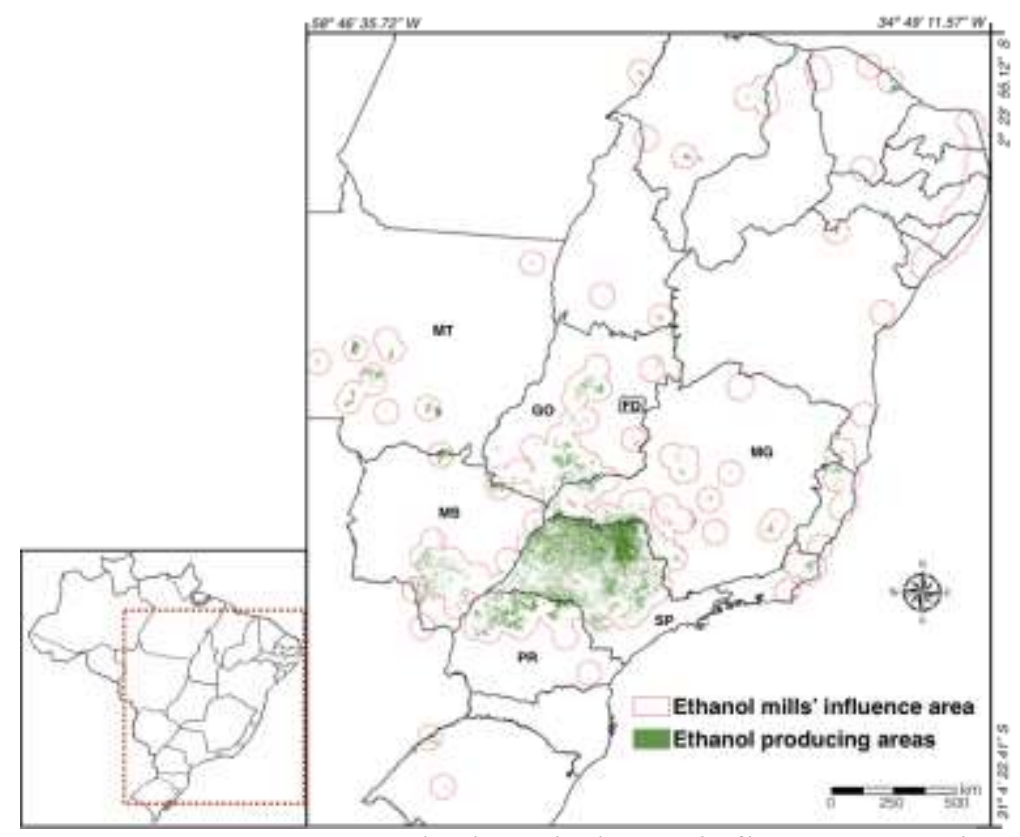

Figure 1. Sugarcane crops and ethanol plants' influence areas in Brazil. Note that the current study focuses on sugarcane expansion in Goiás State (GO), Centre-West region.

Source: Author's elaboration from CONAB (2017).

The projected increase in ethanol consumption in the transport sector over the next decade (about $54 \mathrm{hm}^{3}$ ) (EPE, 2017) is inducing the expansion of sugarcane production to areas such as the Brazilian Cerrado (a Savannah-type biome, located mainly in the CentreWest region) (MANZATTO et al., 2009; FACHINELLI and PEREIRA, 2015). There has been a rapid growth of sugarcane crop in this region, from about $3,700 \mathrm{~km}^{2}$ in 2000 to about 19,600 km² in 2015, a 5-fold increase (UNICA, 2017). Goiás (50\%) and Mato Grosso do Sul (38\%) states were the main drivers behind this increase, accounting for $88 \%$ of the region's current production (UNICA, 2017). The growing demand for new production sites has led to the exploration of water-stressed areas and it justifies further analysis on the Paranaíba basin, a river basin located in the state of Goiás which has recently raised concerns on water and land resources availability.

In this sense, biofuel production has attracted the attention of policymakers and the current debate is largely focused on the environmental and socio-economic implications of first-generation biofuel crops, since they impact food production, water security and biodiversity (IEA, 2007; Barker et al., 2007; RFA, 2008; FAO, 2008; FARGIONE et al., 2008; DE FRAITURE et al., 2008; LAPOLA et al., 2010; LA ROVERE et al., 2011; WALTER et al., 2011; RAVINDRANATH et al., 2011; HOWELLS et al., 2013; RULLI et al., 2016). 
Regarding the important role of Brazil in the global biofuel market and the natural controversy of perspectives on biofuels' sustainability assessment, many authors have been investigating socio-economic and environmental issues related to Brazilian biofuels production (MACEDO et al., 2004, 2005, 2008; COELHO et al., 2006; POUSA et al., 2007; GOLDEMBERG et al., 2008; GARCEZ and VIANNA, 2009; GOLDEMBERG and GUARDABASSI, 2009; HALL et al., 2009; LEHTONEN, 2009; PACCA and MOREIRA, 2009; KOHLHEPP, 2010; RATHMANN et al., 2010, 2011; TAKAHASHI and ORTEGA, 2010; BORZONI, 2011; LA ROVERE et al., 2011; NOGUEIRA, 2011; CGEE, 2012; GALDOS et al., 2013; NOGUEIRA and CAPAZ, 2013; HLPE, 2013; HERRERA, 2013, 2014; LAPOLA, 2010, 2014; MAROUN, 2014; WILKINSON, 2015; UNCTAD, 2016; CARVALHO et al., 2016; WATANABE et al., 2016; OBERMAIER et al., 2017). However, sustainability analysis frequently shows different methodologies and conclusions due to their complexity, which involve a great number of dependent and independent variables, directly impacting results.

Thus, there is no consensus on a specific methodology to analyse water, energy and land issues related to biofuel production. In this regard, authors have been studying biofuels through a range of perspectives and by applying distinct methodologies, such as water footprint assessment (GERBENS-LEENES et al., 2009, 2012; YANG et al., 2011; HERNANDES et al., 2013; FACHINELLI and PEREIRA, 2015), energy balances (MACEDO et al., 2005; SHAPOURI et al., 2002, 2008), land-use changes (FARGIONE et al., 2005; RATHMANN et al., 2010; LAPOLA et al., 2010, 2014; RAVINDRANATH et al., 2011; WALTER et al., 2011; HOWELLS et al., 2013), GHG emissions (MACEDO et al., 2004, 2008; GOLDEMBERG, 2008; WALTER et al., 2011; MCTI, 2016), and biofuels' sustainability concerns (UNEP, 2009; SHEEHAN, 2009; LA ROVERE, et al., 2011; SCHAEFFER et al., 2011; MATA et al., 2013; FAO, 2013; CASTANHEIRA et al., 2014; RULLI et al., 2016; OBERMAIER et al., 2017).

Therefore, concerns about the impacts of biofuel production emphasize the importance of planning the expansion of energy crops considering all the resources involved (BERNDES, 2008; GERBENS-LEENES et al., 2009; IEA, 2012). In this context, a water, energy and food nexus approach is currently quite popular in environmental management, finding fertile ground in policy-making and science (HOFF, 2011; BAZILIAN et al., 2011; FINGERMAN et al., 2011; YANG and GOODRICH, 2014; AL-SAID and ELAGIB, 2017). 
Focusing on water, energy and food security simultaneously is often referred in the literature as the water-energy-food nexus (WEFN). The logic behind the WEFN concept is that it shifts attention from a one-sector view to a more integrated one (ALSAID and ELAGIB, 2017). Overall, the concerns expressed in the literature emphasize the relevance of water-energy-food interlinkages in different time scales for activities that have limited access to water, energy and land resources and for fast-developing regions with rapidly growing demand for all elements of the WEFN (HOFF, 2011; BAZILIAN et al., 2011; ICIMOD, 2012; WEF, 2011, RULLI et al., 2016).

Two-sector nexus thinking is also not new, particularly when linking water-food, water-land, and land-food. Since irrigated agriculture is the major water demanding activity worldwide, knowledge on the water-food linkage is particularly important for water and food policies, especially in countries such as Brazil. Much less has been done on the land-energy, energy-land, energy-water, and energy-food linkages (RINGLER et $a l ., 2013)$. The energy-land linkage is mostly defined by fertilizer applications on land and by the fuel-use in agricultural machinery. The energy-water and water-energy nexuses have been increasingly investigated as water (i.e. good quality water) is becoming scarcer and the energy is becoming less affordable, impacting each other's development (PATE et al., 2007). At the same time, growing water scarcity is increasingly affecting energy production (VAN VLIET et al., 2012; MIARA et al., 2013).

Despite its rising recognition and the existence of a number of examples worldwide, the understanding to take solid actions on how to conduct assessments and tackle complex relationships between WEFN elements is relatively limited. More innovative frameworks have been recently developed with focus on describing the interlinkages in the WEFN, as well as assisting in conducting case studies and, ultimately, identifying policies and actions (IISD, 2013).

In this sense, Brazil may become again the main player in the global ethanol industry, given its technological capacity, favourable environmental conditions and competitive costs. The country has great potential for expanding sugarcane production, as well as the logistics required for ethanol production and export in large scale (SZKLO et al., 2007). However, this expansion has raised concerns about the sector's sustainability and recently, on food security. For instance, global demands for water, energy and food are estimated to increase by $40 \%, 50 \%$ and $35 \%$ respectively by 2030 (US NIC, 2012). On this point, given growing global demands for resources directly involved in ethanol 
production, such as water, land, energy, labour and capital, the sustainability of Brazilian ethanol has been put in the centre of national policy debates.

Additionally, committed to international environmental policies, Brazil was a Kyoto Protocol signatory and recently has submitted its Nationally Determined Contribution (NDC) at the United Nations Framework Convention on Climate Change UNFCCC, through the $21^{\text {st }}$ Conference of Parties (COP 21), in Paris, France. The country has committed to reducing GHG emissions by $37 \%$ in 2025 and it has indicated $43 \%$ of reduction by 2030 , with 2005 emissions as the baseline. Such measures encompass the energy, agriculture, forest, wastes and industry sectors (EPE, 2017b).

Regarding production and use of energy, the commitments include maintaining an $18 \%$ share of sustainable bioenergy in the Brazilian final energy consumption throughout 2030. This will entail an expansion of biofuels production and consumption, including raising the share of advanced biofuels (e.g. second-generation ethanol) and increasing the biodiesel content in the diesel blending. The additional biomass is also intended to expand the share of non-hydro renewable sources in power generation to at least $23 \%$ by 2030 (EPE, 2017b).

Specifically, the Brazilian NDC aims to achieve $45 \%$ share of renewable energy in the national energy matrix by 2030 , targeting raising $1 G$ ethanol production to about 50 billion litres (i.e., $50 \mathrm{hm}^{3}$ of ethanol), significantly increasing $2 G$ ethanol production, to 2.5 billion litres $\left(2.5 \mathrm{hm}^{3}\right)$ from 2023 , and tripling the power generation from biomass, with emphasis on sugarcane by-products (EPE, 2017b).

Despite this incentive to sugarcane growth, the crops impact the soil and water through erosion and pollution, and its irrigation can reduce the water availability to irrigate food crops, meet human consumption, as well as industrial and power generation demands. Water, energy and land are basic resources to any production process, but the intensity by which they are being exploited has led to growing environmental impacts. Nevertheless, it is noteworthy that the use of each of these resources affect demand for the others (IAEA, 2009). Hence, water, energy and land uses affect the climate, inducing a negative cycle, since climate changes will amplify the challenges in balancing elements of the WEFN (BAZILIAN et al., 2011; WAUGHRAY, 2011; IISD, 2013).

The relationship between water-energy-land resources and their respective policies can be shortly explained. Water policies, for example, are commonly based on 
water analysis alone (elaborated and regulated by a specific agency) and they might have adverse unforeseen effects specially on energy and land resources and the climate. The same happens to energy/land resources, where policies are also based only on analysis of energy/land issues. Since the current policies are based on existing models which usually focus on one resource and ignore interconnections with other resources, better methods and models are needed considering all the interlinkages among water, energy and land (IAEA, 2009). Thus, WEFN could be a major opportunity for integrated solutions that respond to inter-dependencies of water, food and energy systems (IISD, 2013).

\subsection{Objectives of the study}

According to the previous section, the general objective of this study is to analyse the impacts of the ongoing sugarcane ethanol production expansion towards the Brazilian Cerrado (specifically to the Paranaíba basin, Goiás State), aiming to understand how the interlinkages between the local economic sectors may influence the availability of resources in the region and how future demand for ethanol could impact local resources availability, based on current Brazilian ethanol policies and targets.

Therefore, the main objective of the present study is to answer the following question: Is there room for ethanol expansion in the state of Goiás without hardly impacting water, land and energy resources in the region?

The analysis performed herein is based on the WEFN approach, which is carried out through Input-Output (IO) model concepts. Since there is no uniform framework to analyse the issues of WEFN (LEONTIEF, 1970; ISARD et al., 1972; VICTOR, 1972; BAZILIAN et al., 2011; FINGERMAN et al., 2011; HOWELLS, et al., 2013; YANG and GOODRICH, 2014; BIGGS et al., 2015; AL-SAID and ELAGIB, 2017), researchers have been seeking for a suitable method to analyse it. Due to its robustness, the IO model is one of the most widely applied methods in economics. It analyses the interdependence of sectors in an economy, showing how the output of a given sector is an input to another, on a national or regional level (MILLER and BLAIR, 2009). IO models can also be expanded to account for energy and environmental impacts (GAY and PROOPS, 1993; CRUZ et al., 2009), by considering a proportion between the sector's output and the corresponding impact levels. Additionally, some IO model interactions of the Brazilian ethanol sector with the national economic system has been applied to analyse the impacts of ethanol and sugar exports (BURNQUIST et al., 2004; COSTA et al., 2006), impacts 
from adding ethanol plants to the system (TERCIOTE, 2006), studies on ethanol demand forecasts (FILHO and FILHO, 2009) and socioeconomic analyses from different technological approaches for producing ethanol (CUNHA and SCARAMUCCI, 2006; 2006a; SCARAMUCCI and CUNHA, 2008). Since most of these studies have focused on economic aspects of the ethanol sector, they unfortunately could not properly address environmental issues regarding the sector itself and the Brazilian economy.

Conversely, some studies have developed IO analysis considering energy and carbon intensities of different ethanol technological routes (COMPÉAN and POLENSKE, 2011; FIGUEIREDO et al., 2008) and by integrating IO models with Life Cycle Analysis (LCA) to appraise economic and GHG emissions of $1 G$ and $2 G$ ethanol production in Brazil (WATANABE et al., 2016). Also, some studies have applied IO models coupled with linear programming approaches for distinct objectives (HRISTUVARSAKELIS et al., 2010; TAN et al., 2012). Finally, the use of hybrid IO models with multi-objective linear programming (CARVALHO et al., 2015; 2016; 2016a) focusing on the analysis of the economic-energy-environmental-social spheres coupled with LCA estimates for ethanol production in Brazil was carried out by CARVALHO et al. (2016a). These authors have concluded that hybrid IO models are useful tools to assess the impacts from changes in the output of economic sectors in ethanol prospective scenarios, highlighting the importance on analysing direct and indirect impacts from technical and political choices (CARVALHO et al., 2016a).

As stated, while IO models have many applications, there has been little investigation considering environmental commodities in hybrid IO models applied to WEFN (KARKACIER and GOKTOLGA, 2005; HRISTU-VARSAKELIS et al., 2010; LI et al., 2012; HOLLAND et al., 2015; WHITE et al., 2017). However, despite some relevant recent studies considering hybrid IO models focusing on the analysis of environmental impacts of the Brazilian ethanol system (WATANABE et al., 2016; CARVALHO et al., 2015; 2016a), they only consider GHG emissions and one single resource of the WEF nexus, i.e. excluding water and land resources. Indeed, studies on hybrid IO models considering GHG emissions and water, energy and land uses as variables to the same nexus analysis (as explored herein) are rare (see WHITE et al., 2017, which have not analysed GDP and employment indicators). In this context, we justify the use of hybrid IO models as a WEFN tool aiming to analyse $1 G$ sugarcane ethanol expansion in the Paranaíba basin, located in the Brazilian Cerrado. Additionally, 
this work overcomes the lack of integrated analysis focusing on water-energy-land resources, as well as GHG emissions and socioeconomic aspects from a river basin/state perspective, i.e. IO model concepts coupled with WEFN approach. This hybrid IOWEFN framework was chosen because of its wide potential to assess integrated impacts throughout the economy, besides being a reliable decision-making tool for planning purposes and it can also be applied to other energy commodities and target sectors, as well as economic systems and regions to promote the sustainability of biofuels and policy integration.

Since the state of Goiás (GO) is one of the leading Brazilian states in sugarcane expansion, it was selected as the case study for the development of this thesis' analysis. Also, the existence of the Water Resource Plan for an important river basin in the state (Paranaíba basin) was taken into consideration when choosing the study area. The Paranaíba basin covers about $220,000 \mathrm{~km}^{2}$ in Brazil's Centre-West region and it comprises $63 \%$ of Goiás (ANA, 2015). This basin is the second major watershed in the Paraná's hydrographic region, which demands about $30 \%$ of all national water needs for consumptive uses. However, as it has less than $7 \%$ of national water availability, there are potential water use conflicts and even shortages.

The analysis of the issues related to energy was conducted considering Brazil's current energy policies, the "Ten-year Energy Expansion Plan: 2026 - PDE" (MME, 2017b) and the "Ethanol Supply and Demand Scenarios - extended version to 2030" (EPE, 2017), both produced by Empresa de Pesquisa Energética - EPE (Brazilian Energy Research Centre, an applied research centre from the Ministry of Energy and Mines MME). Also, both Brazil’s (MME, 2017) and Goiás' Energy Balance (GOIÁS, 2010, MME, 2016) were analysed and different ethanol supply scenarios were conducted in order to identify future impacts on the availability of resources in the region of study.

Besides the overview of both energy and water regulations, the land use was also considered through analysing the "Sugarcane Agro-Ecological Zoning - ZAE Cana" (MANZATTO et al., 2009) and data from both the public (IMB, 2014; IBGE, 2017, 2017a; CONAB, 2017), private (UNICA, 2017) and third sectors (MAPBIOMAS, 2017).

The reminder of this thesis is organized as follows: Section 2 presents an overview of the Brazilian national biofuel policy - RenovaBio. Section 3 describes the WEF nexus approach; IO model concepts; the hybrid IO modelling and data sources. Section 4 covers Brazilian sugarcane industry status; study site; Brazilian ethanol outlook and prospective 
policy scenarios. Section 4.3 presents the results of Goiás State case study, and discussions about the potential impacts of sugarcane crops expansion in the region are presented in Section 4.4. Finally, Section 5 provides conclusions and final considerations on the WEFN framework applied to the sugarcane ethanol expansion in Goiás State. 


\section{Biofuel Policy in Brazil}

The use of ethanol as an alternative fuel in Brazil expanded after the first oil crisis, with the Brazilian Alcohol Program - PROALCOOL - in 1975, impelling the country to increase the production of the $1 G$ bioethanol based entirely on the fermentation of sugar juice from sugarcane and/or molasses. First it was employed as an octane booster to gasoline and later as a complete substitute in properly adapted engines. The program has attracted significant investments in agricultural and industrial processes related to $1 \mathrm{G}$ ethanol production, stimulating sugarcane growing and the construction of ethanol plants in the country. Additionally, an important domestic ethanol market was consolidated through a huge investment cycle focusing on promoting flex-fuel engines, which gives to consumers the choice of fuelling their car with petrol or ethanol in any proportion, according to their selling prices. Brazilian ethanol can be produced both in autonomous distilleries and in the most commonly found mixed-sugar ethanol plants.

The institutional restructuring of the ethanol industry was established in 1997 with the creation of two important institutions: the National Energy Policy Council (CNPE), and the National Oil Agency (ANP), later renamed National Agency of Petroleum, Natural Gas and Biofuels. The CNPE is responsible for establishing directives for specific programs for biofuels use. The ANP oversees the regulation, contracting, and inspection of biofuel-related economic activities and implements national biofuel policy, with emphasis on ensuring supply throughout the country and protecting consumer interests on product price, quality and supply.

The PROALCOOL and its subsequent policies, which are not considered as formal program, are active for over 40 years now, setting Brazil as an important ethanol producer regarding technological achievements and ethanol use. The PROALCOOL has been analysed through several comprehensive studies using different approaches, such as history (GELLER, 1985; GOLDEMBERG and MOREIRA, 1999); policy implementation (OLIVEIRA, 2002); GHG emission reductions (GOLDEMBERG et al., 2004; SZKLO et al., 2005; POUSA et al., 2007; GOLDEMBERG et al., 2008); social aspects (NARDON and ATEN, 2008; LEHTONEN, 2009); and biofuel programs (HIRA and OLIVEIRA, 2009; HALL et al., 2009; GARCEZ and VIANNA, 2009; TAKAHASHI and ORTEGA, 2010, LA ROVERE et al., 2011, NOGUEIRA and CAPAZ, 2013). 
The Brazilian Biodiesel Production Program (PNPB) was launched in December 2004, being a much more recent initiative, for which literature and experience are scarcer. In recent years, because of increasing concern about the sustainability of energy systems, as well as the evolution of biodiesel production in Europe, interest in this biofuel has expanded in Brazil. Several institutions have begun to develop activities in this field, and some governmental actions have been taken.

This program was developed to encourage small producers and farmers from the least developed regions of Brazil to become involved with biodiesel production and to set progressive targets for the mandatory use of biodiesel blends in all diesel oil sold in gas stations. Initially launched with the compulsory addition of $2 \%$ in volume to diesel oil (B2), the 2008 PNPB mandate targeted up to 5\% (B5) of biodiesel to mineral diesel. Currently, the biodiesel blend accounts for 10\% (B10) in almost all diesel oil sold in the country (EPE, 2017b).

According to the history of the two programs, it is not difficult to notice the conceptual differences regarding the motivation for the development of each program. The PROALCOOL was first conceived to reduce Brazil's dependency on oil imports and, over time, the program has become a clear effort to guarantee the sugarcane market and to seek an alternative fuel to gasoline. On the other hand, the PNPB was created mostly based on social inclusion and regional development. Despite this orientation, biodiesel production has developed in Brazil based essentially on the extensive soybean production in the Centre-West region, where the agroindustry is already well established.

Therefore, government interventions and the focus on value-chain were very important to increase ethanol and biodiesel production and use in Brazil, as well as to develop their respective technologies during all phases of both programs.

Currently, the Brazilian Energy Research Centre - EPE - annually publishes the Ten-Year Energy Expansion Plan, which considers the expansion of the Brazilian energy sector and is one of the main tools of planning demand and supply expansion for different energy sources, including biofuels. This report is an important guide from the government on developing the country's strategies in designing Brazilian energy policies. The latest report published is the PDE 2016-2026 (MME, 2017b), which shows the projected expansion of the energy sector in the decade 2016-2026. Additionally, there are specific publications from EPE/MME regarding ethanol demand and supply scenarios to 2030 
(EPE, 2017) as well as the 2050 energy demand technical report (EPE, 2016) that introduces the Brazilian long-term targets for energy policies.

Aiming to design a national biofuel policy, the Brazilian's government has been discussing strategies to implement the RenovaBio, a policy which aims to recognize the strategic role of all biofuels sources in the Brazilian energy matrix, i.e. ethanol, biodiesel, bio-methane, bio-kerosene, $2 G$ ethanol, etc. The National Biofuel Policy - RenovaBio ${ }^{2}$, focuses on energy security as well as mitigating GHG emissions from the fuel sector.

The RenovaBio does not propose the creation of carbon taxes, subsidies, credits nor volume blending mandates of biofuels into traditional fuels and it does not change the existing mandates (such of anhydrous ethanol to gasoline and biodiesel to diesel oil). The main goals of the National Biofuel Policy are:

- To promote a contribution in compliance with the Paris Agreement;

- To promote the proper expansion of biofuels in the Brazilian energy matrix, with emphasis on the regularity of fuel supply;

- To ensure predictability to the fuels market by inducing energy efficiency gains and GHG emission reductions in the production, marketing and use of biofuels.

Targeting to meet these goals, the RenovaBio has been designed to introduce two basic market mechanisms to recognize the potential of each biofuel in reducing GHG emissions, individually and by each producing unit:

- Establishment of national emission reduction targets for the fuel matrix, determined for a ten-year period, where national targets will be turned into individual targets. These targets are important to set some predictability and, therefore, enable private players to make their planning and investment analyses in an environment with less uncertainty;

\footnotetext{
${ }^{2}$ Federal Law n. 13.576, enacted in the $26^{\text {th }}$ of December 2017, "establish the National Biofuel Policy (RenovaBio) and makes other provisions". Federal Law available at: http://www.planalto.gov.br/ccivil 03/ ato20152018/2017/lei/L13576.htm?TSPD_101_R0=78070d6f3fb51e1519cb38135a4d9fd1r2z0000000000000000 9fa9deb3ffff00000000000000000000000000005aafcee000bac78138. Presidential Decree n. 9.308, enacted in the $15^{\text {th }}$ of March 2018, "provides the definition of annual compulsory GHG emission reduction targets for the fuel trade referred to the Federal Law 13.576. Presidential Decree available at: http://www.planalto.gov.br/ccivil 03/_ato2015-2018/2018/Decreto/D9308.htm.
} 
- Certification of biofuel production with different scores being attributed to each producer (the higher the producer's score, the higher the net energy produced with less $\mathrm{CO}_{2}$ emissions in the life cycle).

The connection between these two instruments will occur through the creation of CBIO - Biofuel Decarbonisation Credit, a financial asset traded on the stock exchange and issued by the biofuel producer from biofuel sales (invoices). In summary, the RenovaBio's trade scheme is based on national emission reduction targets which are transferred to individual targets (to regulated players, i.e. fuel distributors), and CBIO issuance by certified biofuel producers/importers.

\subsection{Motivations for the National Biofuel Policy}

\subsubsection{The Brazilian biofuel market}

The outlook of an increasing oil production for the next decade presented by the Ten-Year Energy Expansion Plan - PDE 2026 (MME, 2017b), associated to the maintenance of Brazilian refineries' production levels, lead Brazil to the condition of a net oil exporter. However, the balance between demand and supply of the main oil products indicates that the country is expected to continue as a net importer throughout the PDE 2026 horizon, especially due to the large imported volumes of naphtha, aviation kerosene (QAV) and diesel oil.

The balance between demand and supply for gasoline A indicates periods in which Brazil will play at the threshold of self-sufficiency or as a net gasoline importer (i.e. about $2,000 \mathrm{~m}^{3} /$ day in 2026), even considering the RenovaBio biofuel policy impacts, such as bringing important investments in the expansion of ethanol production to the Otto Cycle (EPE, 2017b). That is, to make it happen, Brazil should significantly expand its ethanol production, as well as improve sugarcane and ethanol productivities. According to the PDE 2026 (MME, 2017b), the forecasts regarding the Otto Cycle ${ }^{3}$ have already considered the impacts of the RenovaBio policy and, therefore, in order to these

\footnotetext{
${ }^{3}$ PDE 2026 (MME, 2017b) also states that electrical vehicles (EV) will account for less than $1 \%$ of total Brazilian fleet in 2026, pointing out some difficulties for the insertion of this technology in Brazil, such as high EV prices, issues on supply infrastructure, unpredictability of electrical demand, lack of tax incentives due to current budget crisis and, public policies mostly focusing on biofuels as the main source of GHG emission reductions in the transport sector.
} 
projections to be feasible, RenovaBio's mechanisms shall be implemented in the shortest possible time.

\subsubsection{External dependence on oil products}

Brazil's dependence on fuel imports has grown substantially since 2010, surpassing more than $10 \mathrm{hm}^{3} /$ year of net import (already subtracted from exported volume), reaching a maximum of $14.3 \mathrm{hm}^{3}$ in 2013 (EPE, 2017b). For comparison purposes, which indicates the significant size of this dependence, Brazil is the second largest global biodiesel producer, with $3.8 \mathrm{hm}^{3}$ produced in 2016 (EPE, 2017b).

External dependence on fuel represents, directly, transfer of resources to other countries. This consists in loss of opportunity to generate income in the country and, therefore, the net expenditure with fuel imports surpassed 10 billion US\$ annually between 2011 to 2015 . This amount, sent abroad during only six years, would be enough to build more than 500 biodiesel plants or about 130 brand new ethanol mills in the country (EPE, 2017b).

A challenge for the future is to balance the growing external dependence with the expansion of domestic fuel supply. The current deficit will tend to grow in the coming years, with the resumption of economic growth and its consequences in an increasing domestic demand. The solution will include the resumption of investments in the ethanol, biodiesel and new biofuels production. However, the lack of both specific public policy till early 2018 and the predictability of ethanol markets, coupled with the effects of oil geopolitics, brought some uncertainty to private enterprises and discourage market forces from expanding investments in biofuels.

\subsubsection{Observed growth in ethanol imports}

There was not registered any significant ethanol imports from Brazil before 2010 . However, Brazilian ethanol imports have been increasing in recent years, from $0.132 \mathrm{hm}^{3}$ in $2013 / 2014$, to $1.83 \mathrm{hm}^{3}$ in 2016/2017 (Figure 2). After a long period as a net exporter of ethanol, Brazil became a net ethanol importer in 2017 (i.e., $0.445 \mathrm{~m}^{3}$ ), just at it is for diesel oil, gasoline, QAV, etc. 


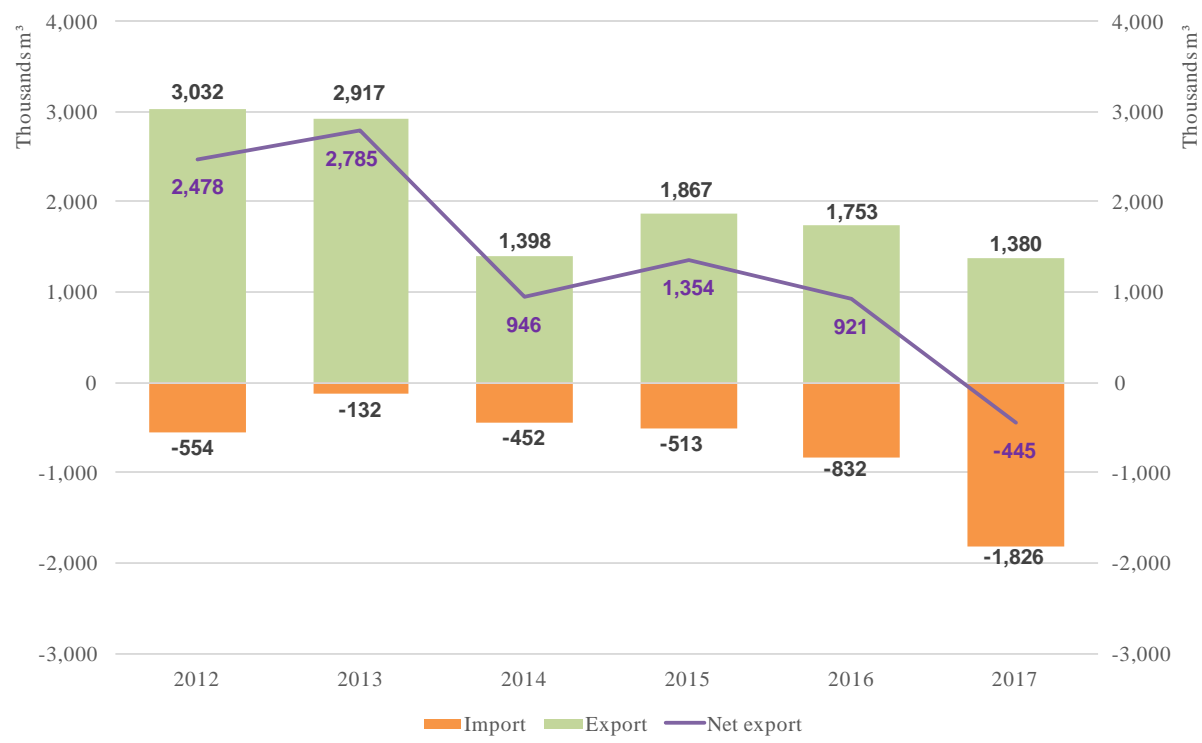

Figure 2. Brazilian ethanol exports $\mathrm{x}$ imports Source: Author's elaboration from ANP (2017b).

The excessive growth of fuel imports, which tends to increase in the coming years, both by the resumption of economic growth and by the lack of specific policies to induce both fossil fuels and biofuels production, will lead to the adoption of road transport in distributing the imported fuel. In this scenario, the country will impose higher fuel prices to society, due to inefficiency and higher logistical costs from road transportation. The option of supporting the growth of domestic biofuel supply contributes to reduce the logistic inefficiency of imports, since biofuels production is much more decentralized than oil products production.

Regarding other sources of supply, the national production is quite close to the industrial support capacity and, the country is already dependent on the foreign market for gasoline and diesel oil. Petrobras refineries, which account for most of the national production, has a high utilization factor, without forecasting new investments in capacity expansion in a short-term.

Although fuel ethanol has long contributed to slow down the growth of gasoline imports, its expansion in the energy matrix has been restricted by several factors, such as few greenfield projects, restrictions on sugarcane expansion areas, the low viability of large-scale $2 G$ ethanol plants, the international interests in Brazilian ethanol, and the economic attractiveness of hydrous ethanol. Therefore, in order to become independent from gasoline and diesel imports, the country has no alternative but to increase domestic production by means of the construction of new refineries coupled with revamping the 
existing ones, or even through expanding domestic biofuels production, i.e. ethanol and biodiesel.

However, after the 2008/2009 international financial crisis, Brazilian ethanol has experienced a reduction in the growth of sugarcane processing rate when compared to previous years. Additionally, the sugarcane productivity has varied since 2010 mostly due to producers' financial issues, from 77 t/ha in 2010/2011, to $67.1 \mathrm{t} / \mathrm{ha}$ in 2011/2012, 74.8 in 2013/2014, 76.9 t/ha in 2015/2016 and finally, to 72.6 t/ha in 2016/2017 (EPE, 2017b). There are several reasons for this, which stem largely from financial problems ${ }^{4}$. On the one hand, gasoline prices pushed down prices of hydrated ethanol, reducing its margins. This margin reduction, in an indebted sector, has jeopardized investments in the renovation of sugarcane fields - fundamental to ensure the productivity of the coming years. It also jeopardized investments in technological development and in adopting new sugarcane varieties.

Therefore, this represents a negative cycle where the deterioration of economic and financial conditions has aggravated these very conditions in the future. It should be noted that if a policy that contributes to the reversal of this negative cycle is not implemented, stagnation or declining sugarcane productivity may affect fuel prices, with negative impacts on consumers. On the other hand, there was an increase in sugarcane production costs, largely due to the introduction of compulsory mechanization, both in harvesting and planting stages. This environment of financial difficulties, besides damaging the current production and also the productivity of the next harvests, was not conducive to induce new investments in productive capacity, since only seven brand new ethanol plants were installed between 2012 to 2017 (EPE, 2017b).

\footnotetext{
${ }^{4}$ Besides financial issues, sugarcane productivity was also affected by the introduction of compulsory mechanization, both in harvesting and planting stages. For instance, producers have shown difficulties in handling machineries, which could improve both sugarcane (i.e. t/ha) and ethanol productivities (i.e. 1/t). This is because they have to set an ideal height to cut the cane, i.e. if they cut the cane too close to the ground line, the cane juice will be contaminated by the soil and this will reduce the ATR - Total Recoverable Sugar; if the cut is too far from the ground line, producers will lose a significant portion of the ATR, since there is a high concentration of ATR in the lower parts of the cane. Also, the mechanization promotes greater compaction of the soil and lower density of plants per area since the crops must conform to the specifications of the machines. Finally, climate conditions were not good enough (e.g. low rainfall volume and above average temperatures) to improve sugarcane productivity in recent years (EPE, 2015).
} 


\subsubsection{Risks to the national fuel supply}

It is important to consider that the national fuel supply is considered of public utility, under the terms of $\S 1^{\circ}$ of art. $1^{\circ}$ of Federal Law 9,847/99, being a duty of the State to ensure regularity and continuity of supply, protecting the interests of the consumer related to price, quality and products supply, among other objectives of the National Energy Policy (Federal Law 9,478/97).

The economic recession experienced in recent years has contributed to mitigating the risk of fuel shortage, by reducing fuel consumption in Brazil. On the other hand, the expected resumption of economic growth in the coming years will necessarily lead to the expansion of domestic demand for fuel. Given the positive correlation between GDP and energy consumption, which includes fossil fuels and biofuels, economic recovery will significantly increase the risk of fuel shortages. However, even under the effects of the economic recession, there are risk factors to the national fuel supply, such as:

- Limited refining capacity;

- Unfavourable scenario for investments in new refineries;

- Long maturation and construction time of new refineries (at least four years);

- Intensification of fuel transportation by road;

- Exponential increase in fuel imports, raising the country's exposure to the risks of oil geopolitics;

- Lack of both import and handling infrastructure to manage the increasing volumes of imported fuels.

In summary, fossil fuel consumption in the country has increased at high average rates but domestic production capacity has not developed at the same pace and investments in import and storage infrastructures have not been sufficient to ensure a suitable fuel supply. For biofuels, the following risks can be highlighted:

- Limited biofuels production capacity;

- Unfavourable scenario for investments in ethanol production (which has been affecting sugarcane productivity);

- Lack of predictability for new investments in biofuels; 
- Indebtedness and closing of several ethanol and biodiesel production units;

- Sugarcane production cycle;

- Decrease in sugarcane productivity;

- Increased dependence on imported ethanol to ensure the mandatory addition of anhydrous ethanol to gasoline;

- Inexistence of long-term pricing and contracting policies and mechanisms.

Considering the maturity of investments in fuels and biofuels, the inaction of the State represents a risk to society, both in terms of supply (regularity of supply) and price (external exposure and logistic inefficiencies).

Regarding energy security, the RenovaBio aims at promoting the suitable expansion of biofuels production and use in the country. Brazil seeks to establish a biofuel policy which considers that the evolution of the markets for oil and natural gas products, often influenced by exogenous issues, does not create imbalances to the biofuels industry, given its importance for energy security, GHG emission commitments and to national development.

The proper balance of the various markets to which biofuels are related, involves market failures (i.e., externalities, imperfect competition, information asymmetries and public goods), different business strategies and is also influenced by external factors such as oil geopolitics. Therefore, harmony depends on the predictable action of the State as inducer and regulator of economic activity, which requires specific public policies and planning.

Currently, biofuels account for $26 \%$ share of Brazilian fuel matrix. Part of this share has been achieved through mandates for blending biofuels into gasoline and diesel, i.e. $27 \%$ of anhydrous ethanol blending to gasoline (EPE, 2017b) and 10\% biodiesel blending to diesel oil (http://mme.gov.br). Despite the mandates, the lack of a National Biofuel Policy till early 2018, particularly in the case of ethanol (greater volumetric expression), has resulted in a large variation in its share of fuel consumption in the Otto Cycle. 


\subsubsection{Volumetric targets for biofuels}

For nearly 90 years, the Brazilian fuel sector has met mandatory targets for biofuel blends, a successful worldwide example of replacing fossils with renewables. It began in the 1930s, with the addition of anhydrous ethanol to gasoline, which was essentially imported at that time.

With PROALCOOL in the 1970s, influenced by the two oil crises and their impacts on the Brazilian economy, the production and use of ethanol was developed on a large scale, being anhydrous ethanol the first product to gain notability in terms of scale, with the increase in its content added to gasoline. As a result, for several years, the minimum of anhydrous blended to gasoline was equal to $20 \%$, a percentage that surpasses any other case in the world. Still in PROALCOOL, a new fuel appeared: hydrous ethanol. Initially, only used in cars with engines dedicated to the use of this biofuel; and, as of 2003, in flex-fuel vehicles, which can use any proportion between hydrated ethanol and gasoline. Since its release, the sales of flex-fuel vehicles have reached impressive levels, having surpassed the sales of gasoline vehicles after just 3 years (Figure 3).

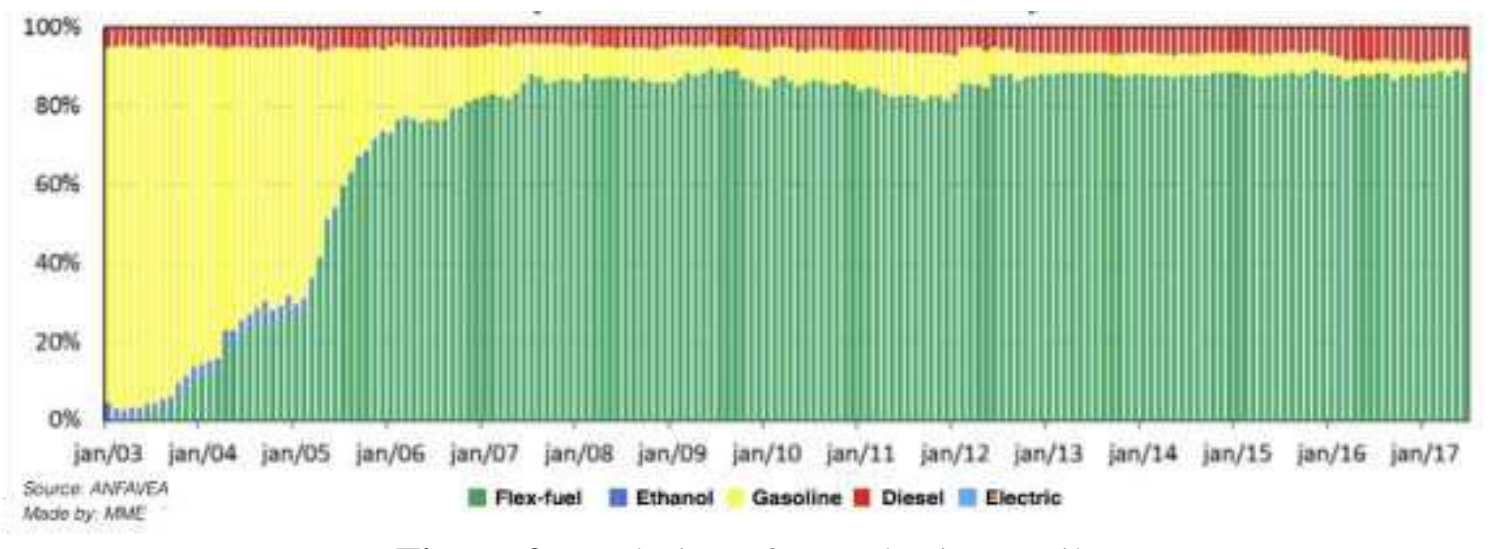

Figure 3. Evolution of car sales in Brazil Source: Elaborated by MME (2017c), from ANFAVEA data.

In December 2004, the National Program for the Production and Use of Biodiesel (PNPB) introduced biodiesel into the Brazilian fuel matrix. Taking advantage of the experience of adding anhydrous ethanol to gasoline, the PNPB set targets for blending biodiesel to all fossil diesel traded in the country, starting at 2\% (blend B2). This percentage of addition was increased, until reaching the percentage of $8 \%$ in 2017 . The Federal Law 13,263/2016, which has defined B8 (8\% blend), also established the 
schedule for the B10 blend, until March 2019, but CNPE has anticipated this 10\% blend to March 2018, i.e. currently in force.

This Brazilian experience in biofuels was largely assured, maintained and renewed over time through biofuels participation targets, as defined by law, as a legacy of different governments capable of recognizing the importance of biofuels as a State policy. As a result of these private and public initiatives, there were three moments in which the share of biofuels exceeded a quarter of all fuel traded in the country, namely, $25.1 \%$ of share in 1989, $25.5 \%$ in 2009 and, 26.4\% in 2015 (EPE, 201b). This share is not found in any other country and it consists as results of the State's strategy defined in the past for the use of sustainable fuels and linked to regional development. However, even though biofuel share has been showing high levels when compared to the rest of the world, this share is relatively small in the Brazilian energy matrix, which comprises other important renewable energy sources.

Therefore, considering the resumption of economic growth, the relative maintenance of biofuels share will require major investments in both brand-new ethanol and biodiesel plants, as well as the commercial introduction of other biofuels such as biokerosene and biogas/bio-methane.

Regarding climate commitments, RenovaBio is also in line with Brazil's commitment to the $21^{\text {st }}$ Conference of the Parties (COP21) of the UNFCCC, in Paris. The Conference adopted a new agreement with the central objective of strengthening the global response to the threat of climate change and strengthening the capacity of countries to deal with the impacts of climate change. In order to achieve the ultimate goal of the Agreement, governments were involved in building their own commitments from the socalled Nationally Determined Contributions (NDC). Through the NDCs, each country presented its contribution to reduce GHG emissions, following what each government considers suitable from their local socio-economic scenario.

Brazil has committed to reducing GHG emissions by $37 \%$ in 2025 and it has indicated $43 \%$ of reduction by 2030, with 2005 emissions as the baseline. Such measures encompass the energy, agriculture, forest, wastes and industry sectors (EPE, 2017b). To this end, among other possible measures, the country undertakes to increase the share of sustainable bioenergy in its energy matrix to approximately $18 \%$ by 2030 . This commitment assumed at COP21 offers to the Brazilian society an opportunity to use 
biofuels as a development vector that contributes to emissions reduction, among other positive externalities.

\subsection{The National Biofuel Policy scheme}

\subsubsection{Biofuels production certification}

The RenovaBio policy seeks to stimulate the improvement of biofuels' environmental performance regarding fossil fuels, focusing on energy efficiency and reducing GHG emissions. This incentive translates into the concession of decarbonisation credits to fuel distributors, according to the energy and environmental efficiency scores associated with the biofuels they trade. The energy-environmental efficiency score of a biofuel is defined as the difference between its carbon intensity and the carbon intensity of its fossil fuel substitute, established by the certification process. Certification is the process that verifies the correctness of technical data regarding the biofuel and biomass production processes that feeds RenovaCal, a support tool which calculates biofuels carbon intensity (in mass of $\mathrm{CO}_{2}$ equivalent by unit of energy $-\mathrm{gCO}_{2} / \mathrm{MJ}$ ). The adoption of a certification process aims to give credibility and transparency to the environmental performance evaluation of the RenovaBio program.

The certification takes place within the scope of the biofuel production unit (plant) and also of those biofuel importers and, in order to compare the national biofuels' carbon intensity to those of imported biofuels, GHG emissions from the distribution phase will also be accounted. In this context, foreign biofuel producers are now subject to the same verification procedures as domestic producers. The methodology for calculating GHG emissions is the same (considering import logistic effects), which is in accordance with approaches already used by international regulations. Therefore, imported biofuels have fair methodological treatment, without entailing improper demand for information.

Thus, focusing on determining the carbon intensity of biofuels, an environmental performance assessment protocol based on the Life Cycle Assessment (LCA) was developed. The LCA evaluates environmental impacts of a product throughout its life cycle, from the accounting of materials and energy consumed by the production processes and released to the environment from natural resources extraction, including manufacturing, transportation, use and product's final disposal. Although a full LCA covers several categories of environmental impacts related to the protection of natural 
resources, ecological systems and human health, RenovaBio analyses only the category "Climate Change" in its initial phase, which has as standard unit $\mathrm{gCO}_{2 \mathrm{e}}$. However, neither the Federal Law n. 13.576 nor the Presidential Decree n. 9.308 mention indirect land-use change GHG emissions in their estimates. Therefore, the RenovaCal probably will not take into account ILUC GHG emissions when analysing and certifying biofuel plants through the application of the LCA approach, so that, the RenovaBio excludes a significant source of indirect effects that may offset GHG emission reductions of biofuels.

In the first phase of the program, the following biofuels will be considered: firstand second-generation sugarcane ethanol; corn ethanol; soybean biodiesel; animal fat biodiesel; HEFA bio-kerosene (Hydro-processed Ester Fatty Acids); sugarcane SIP biokerosene (Synthesised Iso-Paraffin); bio-methane from sugarcane by-products; biomethane from meat manufacturing; and bio-methane from municipal solid waste.

A Committee for the Monitoring of Biofuels and Fuels - CMBC - will be constituted focusing on monitoring and evaluating the regularity of both national biofuel and fuel supply, and it will propose to the CNPE (National Council for Energy Policy):

- Annual compulsory targets for reducing the carbon intensity for the commercialization of fuels;

- Guidelines, criteria and parameters for accreditation of regulating companies and certification of biofuels and;

- Requirements for technical and economic regulation of decarbonisation credits.

The annual compulsory GHG emission reduction targets for the commercialization of fuels will be defined by June 2018, for a minimum period of 10 years. Carbon intensity reduction targets will be individualized by the ANP for each distributor, based on their fossil fuel market share to the total market for these fuels in the period before the mandate exercise, according to the Presidential Decree n. 9.308 and till June 2019. The share of each fuel distributor in the fossil fuel market will determine their obligation for the following year. 


\subsubsection{Biofuel decarbonisation credits (CBIO)}

The CBIO will be a financial instrument registered in book-entry form for purposes of proving the individual objectives of fuel distributors. The definition of the amount of decarbonisation credits to be issued will consider the volume of biofuel produced or imported traded by the primary issuer, considering the respective energyenvironmental efficiency score contained in the primary issuer's certificate of efficient biofuel production. The energy-environmental efficiency score consists in a score attributed to each primary emitter, based on the difference between the carbon intensity established in the certification process and the carbon intensity of its fossil fuel substitute, having as standard unit a ton of $\mathrm{CO}_{2}$.

In regulation, to determine the standard unit, the first step will define the baseline of standard fossil fuel carbon intensity (gasoline, diesel, natural gas, etc.), as well as identify the standard biofuels substitute for these fossils. The second step would be to apply the RenovaCal life cycle analysis tool (object of the certification process) to the specific biofuel production unit. The result will indicate the biofuel's carbon intensity, i.e. $\mathrm{gCO}_{2 \mathrm{e}} / \mathrm{MJ}$, for each specific plant. The certification score will then be given by the difference between the baseline of the fossil substitute and the RenovaCal result (Figures 4 and 5).

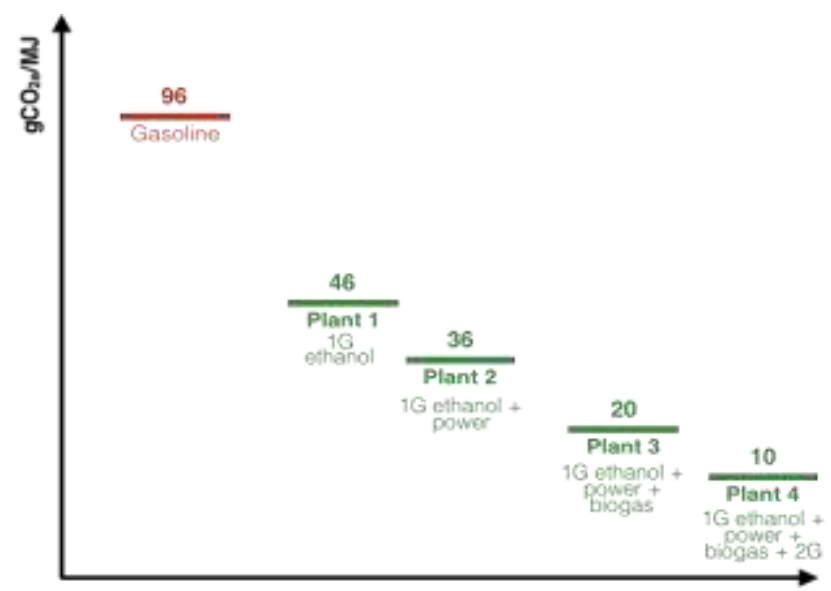

Figure 4. Calculation of the certification score.

Note: Score $=$ Fossil baseline - RenovaCal results. Hypothetical values. Source: Adapted from EPE (2017b). 

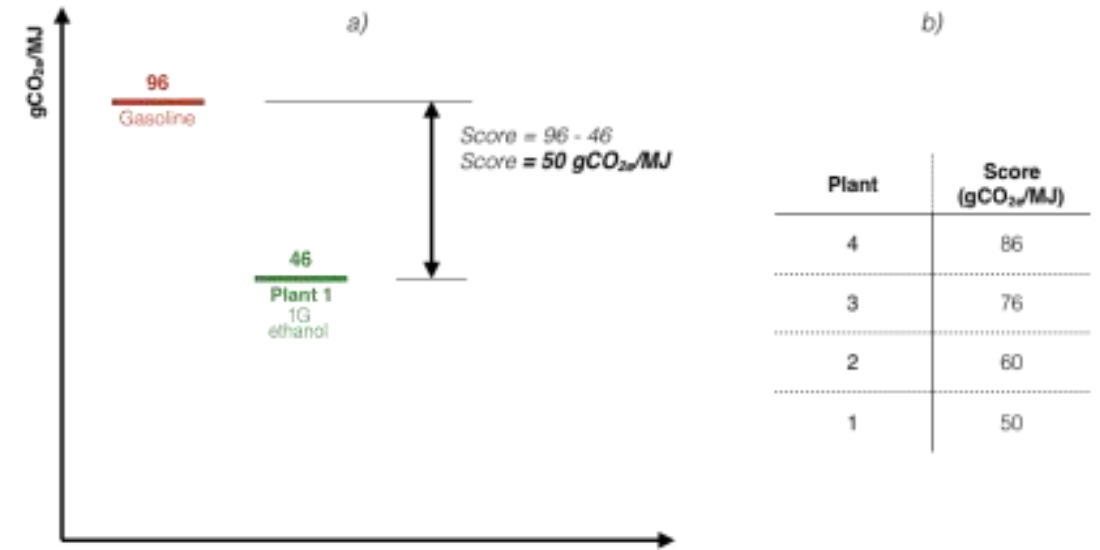

Figure 5. Hypothetical example of certification score calculation for a) plant 1 and $b$ ) other plants.

Source: EPE, $2017 b$.

Considering that, in this hypothetical example, the hydrated ethanol energy content is equal to $21.35 \mathrm{MJ}$ for each litre, it has been verified that plant 1 have sold $640,500 \mathrm{MJ}$ of energy, by trading 30,000 litres. As its certification score is 50, then multiplying 640,500 MJ by the certification score results in 32 million CBIO. The biofuel producer or importer, after trading a minimum quantity of certified biofuel (determined in specific regulations), will have the right to issue decarbonisation credits - CBIO within 60 days. The biofuel producer or importer, responsible for the issuance of bookentry decarbonisation credits, will hire a bookkeeper, bank or financial institution to issue the $\mathrm{CBIO}$ on their behalf. Although it results in higher costs, the financial institution brings more security in operations with $\mathrm{CBIO}$, which in turn attracts institutional investors (investment funds and banks) to the carbon credit market, besides discouraging the commercialization of biofuel fraudulently (without invoice) and adding transparency to operations in the fuel market.

Therefore, the organized market is an environment with computerized systems and rules for the trading of securities (stocks and other assets). The main role of the stock and over-the-counter markets is to organize, maintain, control and ensure favourable environments or systems for meeting offers and conducting business with efficient price formation, transparency and disclosure of information and security in clearing and settlement of business. Finally, the costs of the CBIO (in the financial market) will be individually negotiated with the bookkeeper and collectively with the organized market. 


\subsubsection{RenovaBio impact estimates}

RenovaBio will promote the expansion of biofuels supply in Brazil and seek efficiency and productivity. The favourable trading environment will allow the program to add 1.4 trillion $\mathrm{R} \$$ in investments by 2030 . This amount includes investments in new industrial facilities and implementing new agricultural areas (CAPEX) at 0.54 trillion R \$ by 2030. In turn, investments in OPEX will account for 0.86 trillion $\mathrm{R} \$$ (EPE, 2017b).

These investments were estimated by EPE, based on assumptions established by the MME and primary information provided by biofuel industry associations. It was considered an 3\% GDP growth per year between 2017 to 2030, nulling the national oil product imports (gasoline and diesel), CAPEX (land price plus production unit cost, sugarcane cost, biodiesel raw material cost, soy crushing units), OPEX (sugarcane fields renewal cost, replanting of soybean, operational cost).

Based on these assumptions, RenovaBio will add 24 new ethanol production units and promote the expansion of production of 31 existing plants, which will increase the national ethanol production by $25 \mathrm{hm}^{3}$. Considering only $2 G$ sugarcane ethanol, 29 new plants would be added to the system, producing $2.3 \mathrm{hm}^{3} /$ year and totalizing 84 new production units in the sugar-energy sector. The biodiesel production will increase the production units' utilization factor, from 59\% to 79\%, besides installing 27 new plants in the country. Investments are also planned in 10 soybean crushing units. RenovaBio is expected to add $7 \mathrm{hm}^{3} /$ year to national biodiesel production by 2030 .

Given these expectations, it is observed that the biofuels sector will add $22 \%$ to GDP in current values until 2030, with the implementation of RenovaBio. In addition to bringing new investments to the country and generating income, RenovaBio will employ around 1.4 million workers in constructing and operating the new production capacity added to the agricultural phase of the process. In this preliminary analysis, jobs related to the production of raw material for biodiesel, ethanol and biogas production, as well as to the construction and operation of new manufacturing plants were accounted.

Therefore, the present proposal to create a national biofuel policy will have impacts not only on the productive sector, but also on the national economy. The publication of this biofuel bill positively signals all the economic agents involved who are waiting for the implementation of an energy policy by the Government regarding the role and importance of biofuels in the energy matrix. RenovaBio is, therefore, 
characterized as a market solution, with no tax changes, with positive effects on tax collection and economic growth, without subsidies nor any other form of burden on public accounts. Finally, some RenovaBio implementation effects can be highlighted (EPE, 2017b):

- Import savings of around $13 \mathrm{hm} /$ year of gasoline, accounting for about 18 billion $\mathrm{R} \$$ per year in 2030, at today's prices;

- Under RenovaBio, increasing the share of biodiesel could generate savings that exceeds 9 billion $\mathrm{R} \$$ per year by 2030 .

Therefore, since the Brazilian government has just implemented a National Biofuel Policy which will boost domestic ethanol production in the coming years, it is important to analyse the impacts of biofuels expansion on water, land and energy uses, as well as GHG emissions related to the production process. Additionally, analyses aiming to assess the impacts of biofuels expansion through an integrated way by considering water, energy, and emission as goals to the same nexus analysis should be encouraged to evaluate the real impacts that biofuel production may cause to society, despite its obvious economic gains. In this context, we justify our choice of using a nexus approach by applying integrated tools considering socio-economic, energy and environmental aspects of biofuels production aiming to analyse the Brazilian sugarcane ethanol expansion through a case study.

\subsection{Biofuels and the Brazilian Forest Code}

The conflict between the need for increasing agricultural production (including biofuels) and the conservation of Brazilian forests has generated political pressures to revise the Brazilian Forest Code, which provides, among others, environmental conservation in private properties. The proposal for a new code, more flexible or less demanding, has been debated for more than a decade in the Brazilian Congress and society. Despite the controversies, the "New Brazilian Forest Code" (Federal Law n. 12.651) was enacted in October 2012, providing the main aspects regarding the protection of native vegetation and the national biodiversity (BRASIL, 2012).

The forest code establishes general rules on the protection of the vegetation, on Permanent Preservation Areas and areas of Legal Reserve, as well as, logging, supply of 
forest raw materials, control of the origin of forest products and, control and prevention of forest fires. Overall, it provides economic and financial instruments to achieve the following goals (BRASIL, 2012):

i) Confirm Brazil's commitment to the preservation of its forests and other forms of native vegetation, as well as biodiversity, soil, water resources and the integrity of the climate system;

ii) Reaffirm the importance of the strategic function of agricultural activity and the role of forests and other forms of native vegetation in sustainability, economic growth, improvement of Brazilian population quality of life and the country's presence in the national and international markets for food and bioenergy and;

iii) Provide governmental actions for the protection and sustainable use of forests, highlighting the country's commitment to the adjustment between the productive use of land and the preservation of water, soil and vegetation.

For the general understanding and the enforcement of the Forest Code, Permanent Preservation Area (PPA) is defined as a protected area, covered or not by native vegetation, with the environmental function of preserving water resources, landscape, geological stability and biodiversity, which facilitates the genetic flow of fauna and flora, protecting the well-being of human populations. In short, PPAs can be understood as areas of significant environmental relevance, such as margins of any natural and intermittent natural watercourse; areas around lakes and natural lagoons; areas surrounding artificial water reservoirs; areas around the springs and perennial water eyes; slopes or parts thereof with slope greater than $45^{\circ}$; restinga vegetations ${ }^{5}$, as dune fixers or mangrove stabilizers; mangroves, in all their extension; the edges of plateaus, up to the line of rupture of the relief; on top of hills, hills and mountains and; areas at an altitude greater than 1,800 meters, regardless the vegetation. Therefore, according to the protection regime established, any vegetation located in PPAs shall be maintained by the

\footnotetext{
${ }^{5}$ Restinga is a geographical space always formed by sandy deposits parallel to the shoreline, in a generally elongated form. The restinga vegetation is understood as the a of vegetation communities, physiognomically distinct, under marine and fluvio-marine influence. These communities, occur in areas of great ecological diversity and are considered edaphic communities because they depend more on the nature of the soil rather than the weather.
} 
owner of the area and, in the case of suppression of native vegetation in an PPA, the owner is obliged to promote native vegetation recovery.

For the purposes of the Forest Code, Legal Reserve (LR) is an area located inside a rural that consists in ensuring the sustainable economic use of property's natural resources, assisting the conservation and rehabilitation of ecological processes and promoting biodiversity conservation, as well as providing shelter and protection for wildlife and native flora. The Code states that all rural property shall maintain an area with native vegetation cover as a LR, without prejudice to the application of the rules on PPAs, observing the minimum percentages with regards to the area of the property, i.e. $20 \%$ when the property is located outside the Legal Amazon ${ }^{6}$. However, if the property is located in the Legal Amazon, the minimum of $35 \%$ of the area shall be kept as native vegetation in the Cerrado biome and $80 \%$ of the area shall be preserved in the case of rural properties located in forest areas (BRASIL, 2012).

In this context, LR areas must be preserved with cover of native vegetation by the owner of the rural property, although the economic exploitation of the LR is approved, as long as it occurs by the means of sustainable management. However, any activity on LR shall be previously approved by the agency in charge and, in the sustainable management of the LR forest vegetation, selective exploitation practices shall be adopted in the ways of sustainable management without commercial purpose for consumption in the property and sustainable management for commercial exploitation.

The aforementioned aspects of the Brazilian Forest Code constitute the main changes to the previous Forest Code in force before 2012 and, therefore, these aspects were and still are the most important controversial points of the "Brazilian New Forest Code" at time. Overall, the Brazilian Forest Code has been criticized for eliminating or reducing several safeguards previously in force, such as the annulment of the need for vegetation recovery in consolidated $\operatorname{areas}^{7}$ in small farms, and a reduction in the size of PPAs.

\footnotetext{
${ }^{6}$ Legal Amazon consists in an area that covers the Brazilian states of Acre (AC), Pará (PA), Amazonas (AM), Roraima (RR), Rondônia (RO), Amapá (AP) e Mato Grosso (MT) and, the regions located North of the parallel $13^{\circ} \mathrm{S}$ in the states of Tocantins (TO) and Goiás (GO) and, West of the meridian $44^{\circ} \mathrm{W}$ in the state of Maranhão (MA).

${ }^{7}$ Consolidated rural area consist in an area of rural property with anthropic occupation pre-existing on the $22^{\text {nd }}$ of July 2008, with buildings, improvements or agricultural activities (BRASIL, 2012).
} 
In this context, several studies indicate that there was a reduction in the need to recover native forests on rural properties. SOARES-FILHO et al. (2013) estimated that Brazilian forest liabilities ${ }^{8}$ were reduced by $58 \%$ (i.e. from 500,000 to $210,000 \mathrm{~km}^{2}$ ), accounting for deforestation in LR and PPAs. However, even with the reduction in reforestation obligations and other concessions introduced by the New Forest Code, Brazilian forest liabilities are still high (SOARES-FILHO et al., 2013; SOARES-FILHO, 2015; YOUNG et al., 2016). Overall, environmental liabilities are concentrated on the edges of the Amazon, for almost the entire length of the Atlantic Forest and in the southern Cerrado, where agricultural occupation is higher. Biomes with greater environmental liabilities are Amazon (i.e. $80,000 \mathrm{~km}^{2}$ ), Atlantic Forest (i.e. $60,000 \mathrm{~km}^{2}$ ) and Cerrado (i.e. $50,000 \mathrm{~km}^{2}$, of which about $7,500 \mathrm{~km}^{2}$ in the state of Goiás) (SOARESFILHO et al., 2013; 2015; YOUNG et al., 2016) (Figure 6).
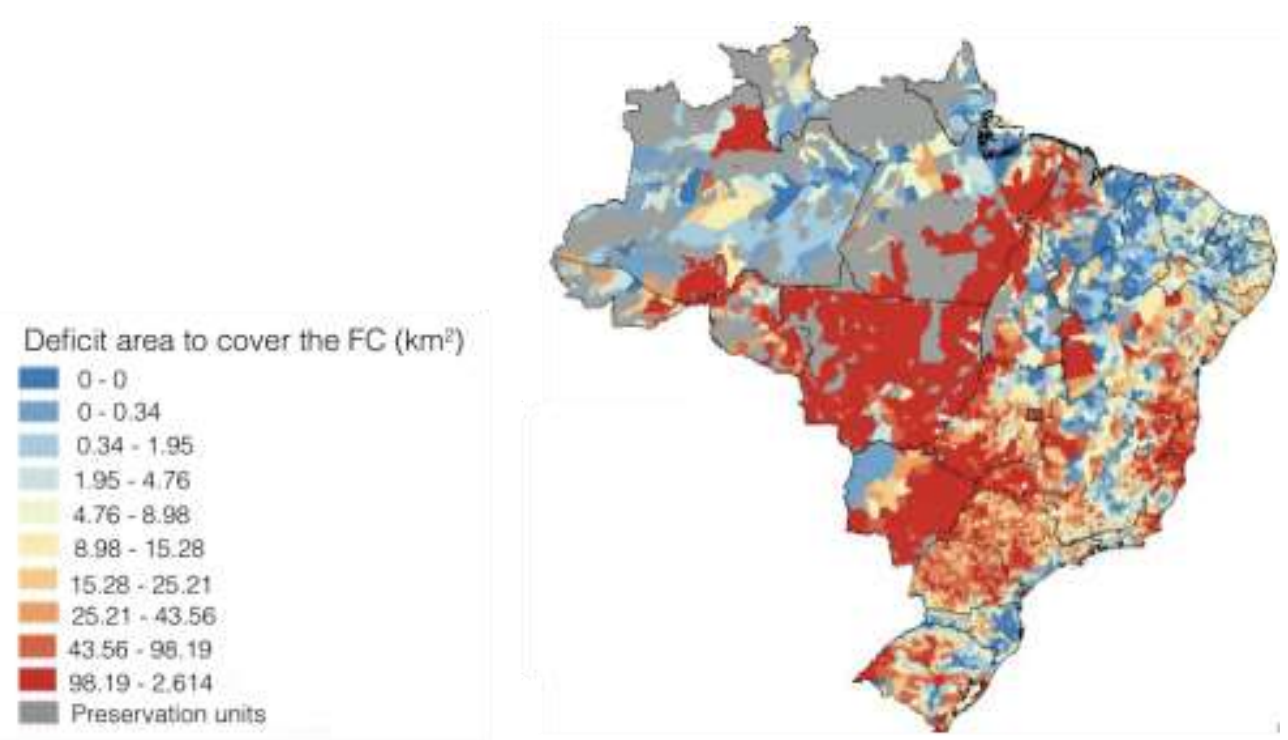

Figure 6: Environmental liabilities after the Brazilian Forest Code revision. Source: Adapted from YOUNG et al., 2016.

The revision of the Forest Code caused great loss in areas to be re-vegetated. On the other hand, it improves mechanisms that facilitate its feasibility. One of these mechanisms is the Environmental Reserve Quota (ERQ), which is a nominative title representative of an area with native vegetation or in process with surplus recovery of the Legal Reserve. The ERQ of one property can be used to offset the legal reserve deficit of another, provided that it has an area equivalence and is situated in the same biome and

\footnotetext{
${ }^{8}$ Forest liabilities refers to the area of native vegetation that a particular rural owner should add due to being below the minimum requirements required by the Forest Code.
} 
preferably in the same state. It is estimated that with the implementation of the ERQ a monetary credit market for forested land can be consolidated, thereby adding value to native forests.

SOARES-FILHO et al. (2013) have confirmed the viability of this market by pointing out the sources of forest assets (surplus) and demonstrating that it is possible to reduce environmental liabilities in LRs by $55 \%$ (i.e. about $160,000 \mathrm{~km}^{2}$ ), offsetting the deficit by the means of ERQs from the same biome and state. They state that the conflict between areas to be recomposed with current agricultural use is relatively small in the country. Overall, Brazil has about 3 million $\mathrm{km}^{2}$ occupied by agricultural activities, of which $680,000 \mathrm{~km}^{2}$ are covered by crops and the rest by pasturelands in varying degrees of occupation, productivity or degradation. From the PPAs liabilities (i.e. $48,000 \mathrm{~km}^{2}$ ), it is estimated that only $6,000 \mathrm{~km}^{2}$ may be occupied by crops, accounting for less than $1 \%$ of national agriculture (SOARES-FILHO et al., 2013). Also, of the 2.3 million $\mathrm{km}^{2}$ of pastures, $60 \%$ could be used for agriculture if climatic restrictions are not taken into account (Figure 7). Therefore, livestock production has to increase its productivity so that, the same level of meat production is maintained at the same time as land is made available for the agricultural transition.

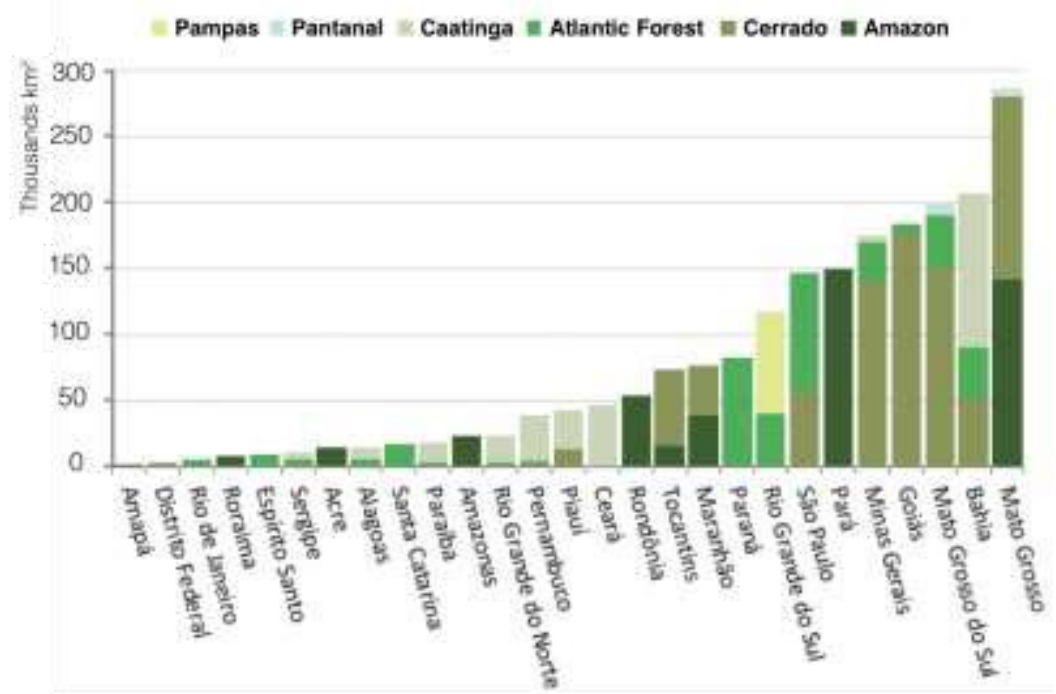

Figure 7: Available pasturelands suitable for agriculture production for each Brazilian state, without considering climate restrictions. Source: Adapted from SOARES- FILHO et al., 2013.

Although solutions exist, the costs of forest recovery are not negligible. If the opportunity costs of avoiding $\mathrm{CO}_{2}$ emissions from deforestation are low, in turn, the costs 
of recovering PPA and LR can be prohibitive, especially for small and medium-sized rural producers (SOARES-FILHO et al., 2013; YOUNG et al., 2016). Also, there is a need to enhance the recovery effort and forest preservation through the payment for environmental services (PES). Environmental services are the benefits generated by ecosystems for society and can generally be grouped into four categories: $i$ ) carbon capture and storage; $i$ ) biodiversity protection; $i i i)$ watershed protection, and; $i v$ ) scenic beauty protection. The starting point of the PES is that conservationist behaviours revert to benefits for the whole society. However, the task of pricing has enormous technical complexity and political and economic sensitivity, as it impacts groups of paying and recipient agents. In general, it constitutes an intervention mechanism in the economic domain, deliberately constructed to change the relative opportunity cost of environmental services over other possible allocations of the assets involved.

Through estimating costs and benefits from a PES policy in Brazil, YOUNG et al. (2016) have concluded that the costs to avoid deforestation per unit of preserved area is significantly lower than the costs to recover those areas with environmental deficits, mainly due to the high costs of revegetation and labour. For this reason, PES programs aimed at recovering deforested areas require payment values to owners and implementation costs that are much more expensive than those for forest conservation.

Therefore, there is a need to develop a national strategic plan to guide the responsible expansion of agriculture and biofuels as well as to invest in the conservation of the Brazilian environmental patrimony, thus transforming apparently divergent interests in complementary strategies. Solutions for agriculture encompass the engagement in environmentally sustainable agricultural production by agents that promote deforestation, by the means of the creation of international certification standards that include a ban on cultivation in newly deforested areas and areas of outstanding conservation interest, as well as compliance with local laws. As access to special markets or financial reward usually results from certification schemes, farmers, ranchers and loggers, among others, are joining together to create voluntary records, in which participants undertake to improve their socio-environmental performance. This is particularly important for the Cerrado biome due to its $400,000 \mathrm{~km}^{2}$ forest asset, which may become legal deforestation in the future most due to the increasing livestock production, as well as food and biofuels crops expansion. 


\section{Methodology}

Since assessing the use of a specific resource (e.g. water, land or energy, etc.) by any activity constitutes a complex task and, often there are lack of available data, as well as difficulties in analysing different issues together and their multiple interlinkages, there are few studies focusing on how to support decision-making at the nexus of water, energy and land (BAZILIAN, et al., 2011). Additionally, as previously mentioned, there are very few studies aiming to integrate water, energy and land concerns regarding biofuels production in Brazil, specifically $1 G$ sugarcane ethanol.

In this regard, MAROUN (2014) performed an integrated assessment in sugarcane expansion areas in the state of São Paulo, Brazil, based on the interface between the sector policies for each water, energy and land resource. By integrating all three resources and their respective policies through the methodologies proposed by DOE (2012), IAEA (2009), WELSCH et al. (2014) and HERMANN et al. (2012), the results were different as compared to analysing isolated polices for each resource, evidencing the importance of integrated analysis to the sustainable development of biofuels in the country. Therefore, biofuel-related policies shall consider the integration of individual policies.

This lack of policy integration linked to water, energy and land can create vicious cycles which impact biofuels' sustainability. When interlinkages between policies are not treated crosswise, these vicious cycles can threaten the sustainability of biofuels. Debates on sugarcane ethanol production in Brazil, for example, frequently focuses on impacts of land-use change, mainly through deforestation, which can also indirectly lead to the reduction of water availability. Water constraints in producing sugarcane would demand more irrigation and hence, energy consumption would increase, and more land would be required for power generation, resulting in more competition for land (e.g. through competition between food, biofuels and power generation; leading to deforestation; etc.).

Another indirect effect of biofuel crops is that they may induce the movement of cattle towards the Brazilian forests (e.g. mainly to the Amazon and Cerrado biomes), hence contributing to the most important source of deforestation and GHG emissions in the country (PALERMO, 2011; LA ROVERE et al., 2011; SOARES-FILHO, 2013; LAPOLA et al., 2014; MAPBIOMAS, 2017; SEEG, 2017b). Also, land competition may impact land prices, which may also lead to the use of poorer quality land for crops cultivation, requiring more irrigation and inputs, increasing energy demand. These 
changes will impact both biofuels' energy balance and emissions, increasing their production costs, pushing producers to seek even lower-quality cheaper land, thus, establishing a vicious cycle (Figure 8) (MAROUN, 2014). Therefore, if these policies are not treated through a nexus perspective, it can lead to misleading policy recommendations.
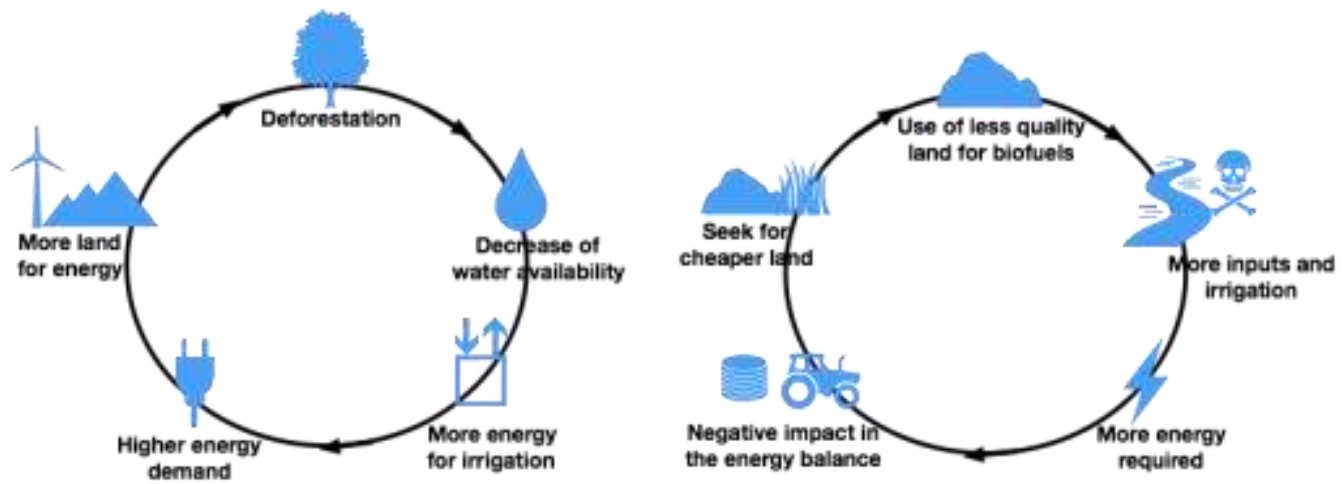

Figure 8. Justification for the nexus approach. Examples of vicious cycles due to isolated policies for biofuels. Source: Author's elaboration based on MAROUN (2014).

In fact, assessments of land use, energy and water are often carried out in isolation by disconnected institutions. An institution focusing on water resources is likely to consider food and energy systems as end users (HELLEGERS, et al., 2008). Assessments on agriculture might see energy and water as resources (KHAN and HANJRA, 2009; MUSHTAQ et al., 2009), whereas the energy sector is likely to treat biomass and water as inputs. Thus, promoting biofuel expansion through the current sector-driven approach, disregarding indirect impacts on water resources and GHG emissions could counteract one of the main objectives of biofuel policies (HOWELLS, et al., 2013).

Since there is no uniform way to analyse the interdependent resource issues of water, energy and land using an integrated framework in scientific analysis and policymaking, analyses will depend on the existing resource links in a certain region and the purpose of the analysis. The WEFN approach is conceptualized and measured using varying methods, such as macro-level assessments, life-cycle assessments (LCA), resource planning use modelling (CLEW), multi-sectoral systems analysis (MSA), among others.

Additionally, general equilibrium models (e.g. Computational General Equilibrium - CGE; Input-Output Analysis - IOA) have been recently employed as a 
decision-making tool for sustainable development and planning in models incorporating the impact of environmental aspects and energy use on a national or regional level (MILLER and BLAIR, 2009; HRISTU-VARSAKELIS et al., 2010; ZHANG et al, 2016; WANG and CHEN, 2016). Overall, IO models can appraise indirect flows besides the direct ones, to account the inputs required for producing goods and services based on sectoral interactions and exchanges in complex systems (ZHANG et al., 2016; CAZCARRO, et al., 2013). Differently from partial equilibrium models, general equilibrium models consider the interdependence between different markets of a specific economy, making them closer to the reality than the partial equilibrium ones (ELY, 2015).

Next sub-sections 3.1.1 and 3.1.2 will explore the reasons why both the WEFN and the IO framework were chosen to perform the analysis required by this thesis. The general objective of this study is to analyse the impacts of sugarcane expansion towards the Brazilian Cerrado (Goiás State), aiming to understand how future demand for ethanol could impact water, energy and land availability and what would be the environmental constraints for ethanol production in the region of study. In this regard, the state of Goiás was chosen due to its role in the Brazilian ethanol production and the historical trends of expanding sugarcane crops towards that state. Section 4 presents the state of Goiás as the case study of this thesis, justifying its choice by explaining the role of the state in the Brazilian sugarcane ethanol production.

\subsection{Methodology and scope of the study}

\subsubsection{The water-energy-food nexus}

Focusing on the promotion of inseparable links between the use of resources to provide basic rights to food, water and energy security, the 2011 World Economic Forum has first postulated the 'nexus thinking'. This approach has become an advanced tool on sector-specific governance of natural resource use (BIGGS et al., 2015) and it has been the basis for the development of alternative methodologies seeking the integration of issues related to sustainability.

Focusing on ensuring integrated water-energy-food security, the WEFN aims greater policy coherence to overcome unintended consequences of uncoordinated policy across different sectors and it constitutes a way of framing cross-sector and cross-scale interactions in a context of growing concerns about the global economic crisis and the 
WEF security (Figure 9) (HOFF, 2011; IISD, 2013; ALLOUCHE et al., 2014; WEITZ, et al., 2017).

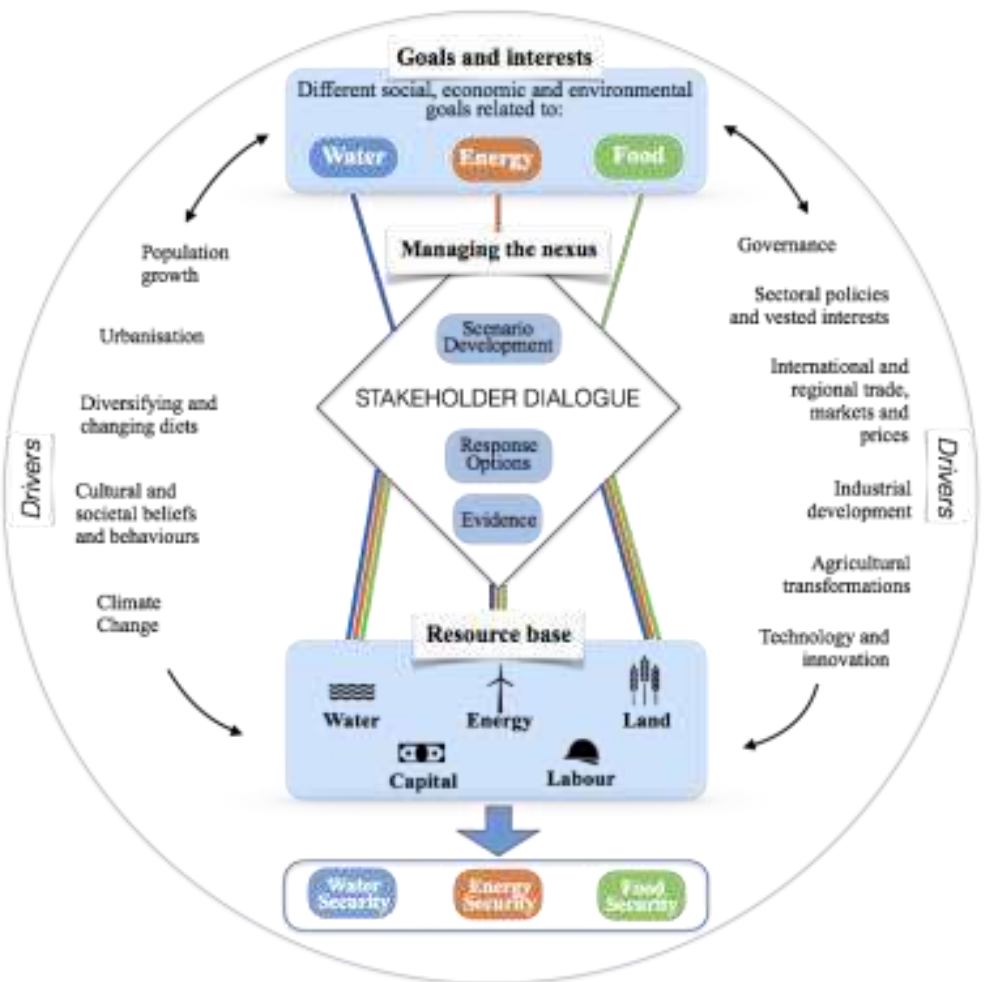

Figure 9. The water, energy and food nexus framework. Source: Author's elaboration from FAO (2014).

Several studies have pointed out that the ultimate goal of the nexus thinking focuses on promoting action by providing policy entry points exploring synergies, seeking trade-offs reduction and promoting the transition to a more sustainable future (HOFF, 2011; BAZILIAN, 2011; IISD, 2013, HOWELLS et al., 2013; WELSCH et al., 2014; Al-SAID and ELAGIB, 2017; WEITZ, et al., 2017). In this regard, biofuels are the focus of researches because they largely rely on water, land and energy to meet its growing demand and, therefore, it is noteworthy checking methodologies already applied aiming to integrate $\mathrm{WEF}$ resources.

Nevertheless, there is no standard integrated framework for assessing the issues of the WEFN in an interdisciplinary way. Thus, different methodologies seeking the integration of issues related to WEFN concerns have been applied to assist the decisionmaking process. The Climate, Land, Energy, and Water System (CLEWS), proposed by the International Atomic Energy Agency - IAEA (IAEA, 2009), consists in an evolution 
from the original nexus concept, focusing on the expansion of a systems approach to support nexus analyses and it has its origins on LCA methodology (Figure 10).

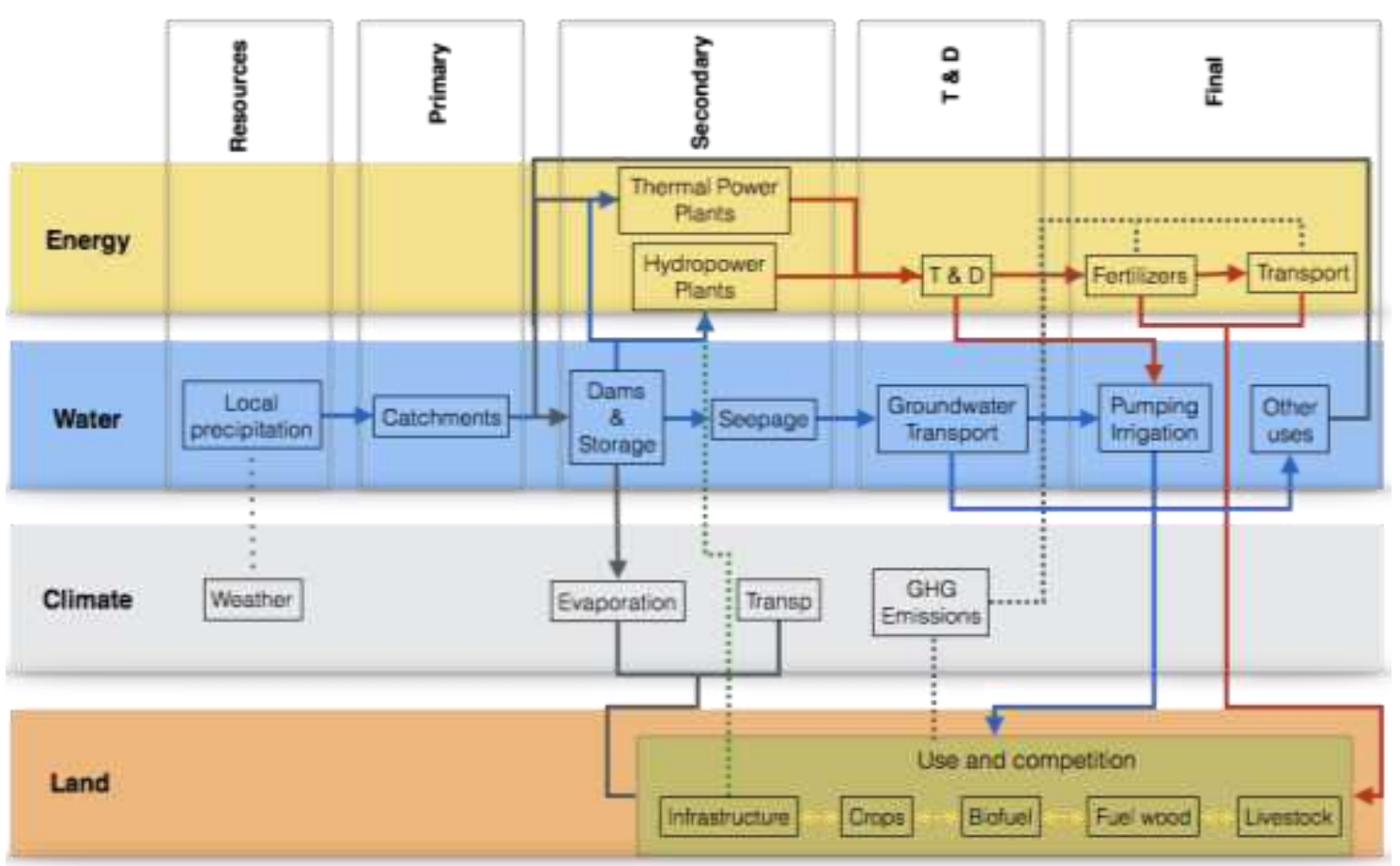

Figure 10. Example of the Climate, Land, Energy and Water System diagram. Source: Author's elaboration from IAEA (2009).

By applying CLEWS analysis, WELSCH et al. (2014) have compared isolated conclusions derived from energy planning models with those of an integrated CLEWS approach. Aiming to evaluate CLEWS strategies applied to a study case conducted for the Republic of Mauritius, HOWELLS et al. (2013) have used well-stablished tools such as General Circulation Models (GCM) to estimate weather changes (IPCC, 1990; IIASA and FAO, 2012), the Long-range Energy Alternatives Planning (LEAP) model (HEAPS, 2008), the Water Evaluation and Planning System (WEAP) (SEI, 2015), and the AgroEcological Zones (AEZ) land production planning model (IIASA and FAO, 2012). Analysing different policy scenarios, a significant difference between the results of isolated energy planning models and the CLEWS approach was found. HOWELLS et al. (2013) concluded that integrated assessment is imminently achievable, and a range of tools are available that could be adapted and used for CLEWS assessments. However, they also pointed out that "although achievable, the process of integrating individual tools into a module-based framework requires considerable effort to ensure compatibility and efficient data transfer" (HOWELLS, et al., 2013). 
KING (2014) sought to inform actions for Hawaii's sustainable water use in agriculture by applying a systems approach in a report of the University of Texas at Austin - UT Austin). The report focuses on the water and energy inputs and outputs for producing both biofuel feedstocks and food crops. This systems approach considers water as available for multiple purposes to assess how Hawaii's water resources can be used to achieve multiple sustainability objectives, after analysing different policy scenarios. The overall conclusion is that there is a significant opportunity to meet multiple sustainability goals using the same or a lesser quantity of water for large-scale farming of biofuel crops in the country.

The WEFN of $1 G$ biofuels were explored by MARTA et al., (2011), from the net energy produced standpoint, and the implications for water and food security. A longrange climatic series of meteorological data was analysed through a crop model (CropSyst) for the simulation of water requirements, crop production and cultivation techniques in Tuscany, Italy. Results have determined the real costs of producing energy crops regarding the net energy and water balances, from an integrated point of view.

In 2013, an innovative accounting framework for the WEFN was proposed by FAO (2013a), where a Multi-Scale Integrated Assessment of Society and Ecosystem Metabolism - MuSIASEM - was applied to three case studies: (i) analysis of sugarcane biofuel production in the Republic of Mauritius; (ii) future grain exports in the Indian state of Punjab; (iii) assessment of two alternative energy sources to generate power in South Africa. The MuSIASEM model was originally developed for analysing the metabolic pattern of energy of modern society and it has been extended to consider the WEFN (FAO, 2013a).

NEWELL et al. (2011) have discussed practical ways that policy makers can take up the systems challenge. They focused on resilience thinking, and the use of influence diagrams, causal-loop diagrams, and system archetypes. Through a climate-energy-water nexus standpoint, system concepts and tools were used to study the factors impacting the resilience of the Australian National Electricity Market (Figure 11). The overall recommendation is that policy makers should work to reduce reliance on conventional market mechanisms, institute continuing cross-sector dialogue, and promote basic education in system dynamics. 


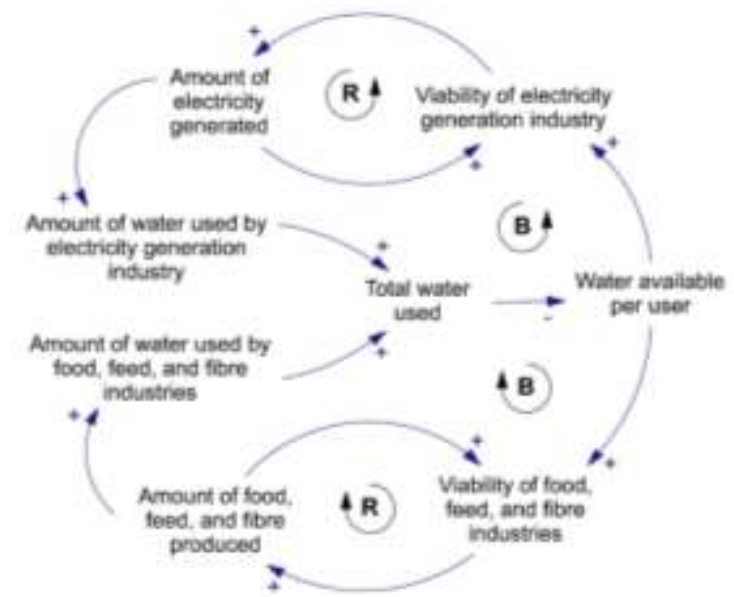

Figure 11. The electricity-water nexus in Australia.

According to the authors, this diagram illustrates the Tragedy of the Commons system archetype as applied to the competition for water between the electricity sector and other sectors that use water. Overuse of this resource leaves all users vulnerable to the effects of climate change.

Source: NEWELL et al. (2011).

Since the seminal work by $\operatorname{LEONTIEF}^{9}$ (1936), several studies have used the traditional IO framework coupled with energy and environmental data for different purposes (see ISARD et al., 1972; MILLER and BLAIR, 2009; HRISTU-VARSAKELIS et al., 2010; CAZCARRO et al., 2013; ZHANG et al., 2016; WANG and CHEN, 2016). In fact, the IO framework can be extended to estimate environmental impacts from economic activities by determining a proportionality between sector's outputs and their corresponding impact levels (Table 1). In this regard, WHITE et al. (2017), have applied a transnational inter-regional IO approach in a tele-connected WEFN analysis of the East Asia global value-chain to assess competing demands for these resources and environmental outcomes. This analysis has shown the hidden virtual flows of water, energy, and food embodied in intra-regional and transnational inter-regional trade. Results demonstrate a mismatch between regional water, energy and land availability and final resource consumption and the lack of attention for environmental impacts in national economic growth strategies.

\footnotetext{
${ }^{9}$ Wassily W. Leontief has first described the Input-Output methodology and its application to the economy in the article "Quantitative Input-Output Relations in the Economic Systems of the United States" (1936), and later in the book "The Structure of the American Economy", published in 1941. The basic Input-Output framework principle is how changes in one economic sector may affect other sectors. Input-Output analysis has been traditionally used to study the interlinkages among different sectors in the economic system, describing the relationship between the inputs used and the outputs produced. Leontief won the Nobel Committee's Nobel Memorial Prize in Economic Sciences in 1973. For Leontief's biography, see: https://www.nobelprize.org/nobel_prizes/economic-sciences/laureates/1973/leontief-bio.html.
} 
Table 1. Basic structure of economic-ecological Input-Output models.

\begin{tabular}{lll}
\hline & Industries & Ecologic process \\
\hline Industries & $\begin{array}{l}\text { Flows between economic } \\
\text { sectors }\end{array}$ & $\begin{array}{l}\text { Flows from industry to the } \\
\text { ecosystem }\end{array}$ \\
Ecologic process & $\begin{array}{l}\text { Flows from the ecosystem to } \\
\text { industry }\end{array}$ & Flows within the ecosystem \\
\hline & Source: MILLER and BLAIR (2009).
\end{tabular}

Additionally, CARVALHO et al. $(2015,2016,2016$ a) have used a hybrid IO framework focusing on assessing the trade-offs between economic, energy, environmental and social objectives in the Brazilian economic system. The traditional IO framework was reorganized to include the National Energy Balance, creating a hybrid IO framework that is extended to asses GHG emissions and the employment level.

For further examples on approaches and methodologies of the nexus of water, energy, land, GHG emissions and climate change, please refer to BAZILIAN et al. (2011), STILLWELL et al. (2011), HUSSEY and PITTOCK (2012), RINGLER et al. (2013), LAWFORD et al. (2013), IISD (2013), SEI (2014), FAO (2014), BIGGS et al. (2015), FENG et al. (2016), WANG and CHEN (2016), GARCIA and YOU (2016), WHITE et al. (2017), AL-SAID and ELAGIB (2017), WEITZ et al. (2015, 2017), ENDO et al. $(2015,2017)$, among others.

Regardless of the methodology applied, there are three main reasons for the need for WEFN debate:

a) increasing resource interlinks due to growing scarcities. As an example, many dams worldwide are primarily built for energy purposes, although their benefits extend to other issues (e.g. flood control, irrigation and drought management) (AL-SAID and ELAGIB, 2017).

b) resource supply crises. This concern lies in recent water and food crises, as well as drought and heat waves across the globe. Since 2013, Brazil has experienced a severe water crisis that has impacted large sections of the country through water rationing for agriculture and human consumption, as well as hydropower supply, resulting in high energy prices and low reservoir levels.

c) failures of sector-driven management strategies. Increasing demands for food and energy, for example, are ultimately converted into increasing pressures on water 
resources, emphasizing the natural interlinkages between resources (AL-SAID and ELAGIB, 2017).

In fact, assessments of land use, energy and water are often carried out in isolation by disconnected institutions. Taking into account the key elements of WEFN frameworks, they all focus on security challenges and consider social, economic and environmental domains, respectively by changing human behaviours, by analysing different approaches to economic growth and by promoting ecosystems services (IISD, 2013). Thus, promoting biofuel expansion through the current sector-driven approach, disregarding socio-economic and environmental indirect impacts on the resources used as inputs to bioenergy production could counteract one of the main objectives of biofuel policies, i.e., GHG emissions reduction (HOWELLS, et al., 2013).

Since there is no uniform integrated framework to analyse the issues of water, energy and land, analyses will depend on the existing resource links and the purpose of the analysis, reinforcing that the WEFN approach is conceived and measured using varying methods.

Among the usual methods to analyse the WEFN, the IO approach was chosen to be applied in our case study because of its wide potential to assess integrated impacts throughout the economy, besides being a reliable decision-making tool for planning purposes. Another reason was the data availability for the region under study. Moreover, environmental impacts have been accounted through modified IO models using three basic modelling approaches: generalized IO models (LEONTIEF, 1970); economicecological models (ISARD et al., 1972); and hybrid IO models (MILLER and BLAIR, 2009). The economic-ecological model results from extending the interindustry framework to include additional "ecosystem" sectors, where flows will be recorded between economic and ecosystem sectors along the lines of an inter-regional IO model (MILLER and BLAIR, 2009). To analyse the WEFN through a case study, this thesis applies a hybrid economic-ecological IO approach in attributing water, energy, land use and emissions to the various sectors of the economy, and in calculating the interdependence of sectors regarding changes in final demand.

IO models with hybrid units have been developed to assess the Brazilian economic system and interactions between economic, energy and environmental systems (see HILGEMBERG \& GUILHOTO, 2006; IMORI and GUILHOTO, 2010; IMORI et al., 
2011; CARVALHO et al., 2015, 2016; OBERMAIER et al., 2017). Thus, IO approach has been used as a decision-making tool for sustainable development and planning in models considering environmental and energy impacts by tracing the flows of resources from consumption activities and supported by outputs from production sectors (HRISTUVARSAKELIS et al., 2010; WANG and CHEN, 2016; CARVALHO et al., 2015, 2016).

Regardless of the methodology used to assess the WEFN, the nexus approach has tended towards technical assessments focusing on productivity, synergies and trade-offs across nexus sectors (HOWELLS et al., 2013). This corroborates to the origin of the nexus framework, mostly based on systems analysis and backed by scientific evidences, but only beginning to take hold in policy-making and planning (SEI, 2014). Therefore, when the term "security" is used in WEFN analyses aiming to ensure water, energy and food availability, it is noteworthy that this security is not solely driven by availability of resources but also by access to resources, the capacity to use resources as well as dynamics of social power relations and the strength of institutions (PRITCHARD et al., 2013; BIGGS et al., 2015).

In this context, WEITZ et al. (2017) have identified three governance gaps in the nexus literature, which indicate that governance matters to nexus approach, but it does not go into depth. According to the authors "it falls short on providing insights on (i) conditions for cross-sector coordination and collaboration; (ii) dynamics that influence the nexus beyond cross-sector interactions; and (iii) political and cognitive factors as determinants of policy change", arguing that governance theory can help to fill these gaps. Although the nexus approach can explore interlinkages between water, energy and land and hence, help to determine physical limits to the use of resources, on the other hand, governance issues has found difficult on how to implement the WEFN and deliver real world solutions (WICHELNS, 2017; LECK et al., 2015; WHITE et al., 2017). Although important to the nexus approach, governance issues are not focus of this thesis and they will be briefly discussed further, in the conclusions section (Section 5).

Therefore, integrated analyses through WEFN approach, by applying hybrid IO models aiming to better understand the interlinkages between GHG emissions and water, energy and land uses from biofuels production, although limited by governance issues, can help shape bioenergy development and highlighting the necessity of a specific policy for biofuels through the integration of basic resources for bioenergy production. 


\subsubsection{The Input-Output model}

Firstly, an IO model (also named Leontief model) consists in linear equations system and it is understood as a direct technical coefficients matrix that denotes how much a given economic activity needs to consume from other activities, so that it can produce an additional monetary unit (IBGE, 2008). In the model, the economy is constituted by sectors which produce goods and services (outputs), but to do so, they also consume goods and services from other sectors (inputs). Thus, there are monetary flows of products from a given sector to another in a given period and site (MILLER and BLAIR, 2009).

In this context, the IO approach is a simplified representation of the classical interdependence theory between economic sectors and it seeks to highlight their respective income distribution issues (GUILHOTO, 2004). Thus, the IO model can be related to an attempt of interpreting the circular flow of income between the markets for goods and services and the markets for factors of production (Figure 12).

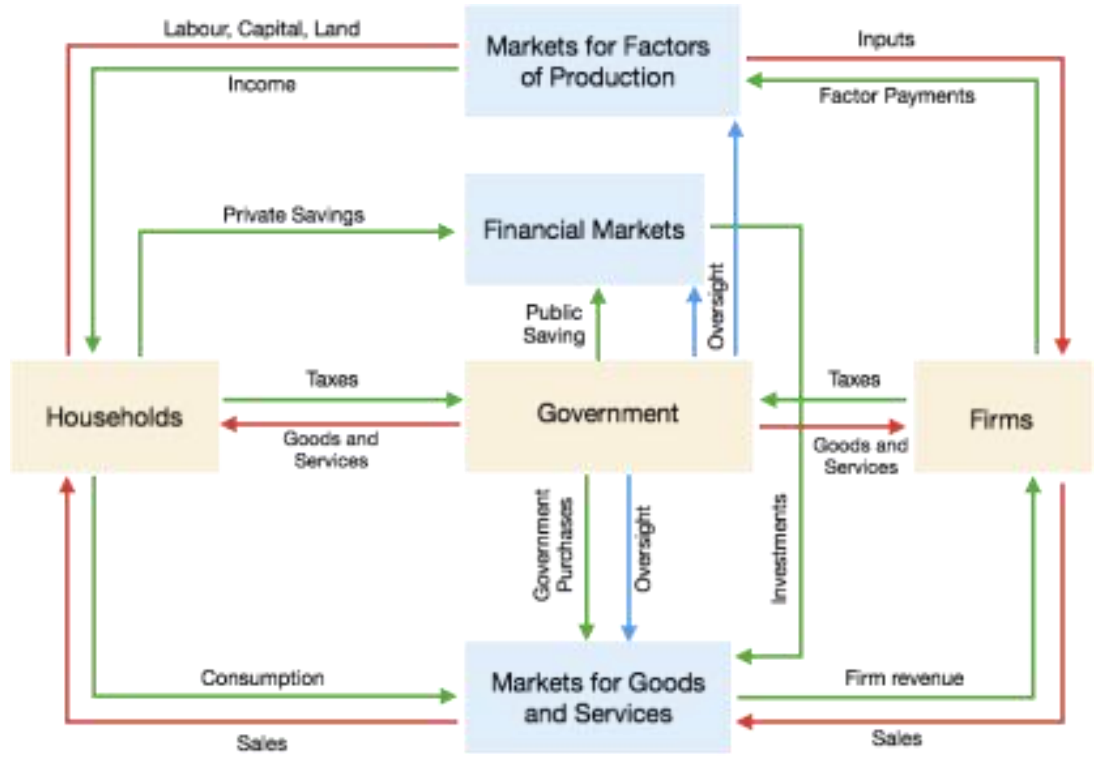

Figure 12. Circular flow of income diagram.

Source: Author's elaboration from MILLER and BLAIR (2009) and MANKIW (2010).

The Leontief model is developed from IO tables, allowing the calculation of the production of each activity, from an exogenous final demand (IBGE, 2008). Most of National Statistical Institutions are responsible for the construction of such database-type and to provide it to the public and, in general, such official tables are used as a base for estimating the others, better suiting specific research goals (ELY, 2015). By providing 
economic and environmental data in a consistent Leontief-type framework, the hybrid IO model is well suited for analytical purposes (LEONTIEF and FORD, 1971). The economic-ecological hybrid IO model, which considers environmental and energy data will be better described in Section 3.1.4.

The basic IO relationships show that sectors' sales can be used as inputs in the productive process by any sector of the economy or can be consumed by different components of final demand. On the other hand, inputs are needed to produce goods and services, taxes must be paid, products are imported, jobs are created, and value is added to the economy (Figure 13) (GUILHOTO, 2004).

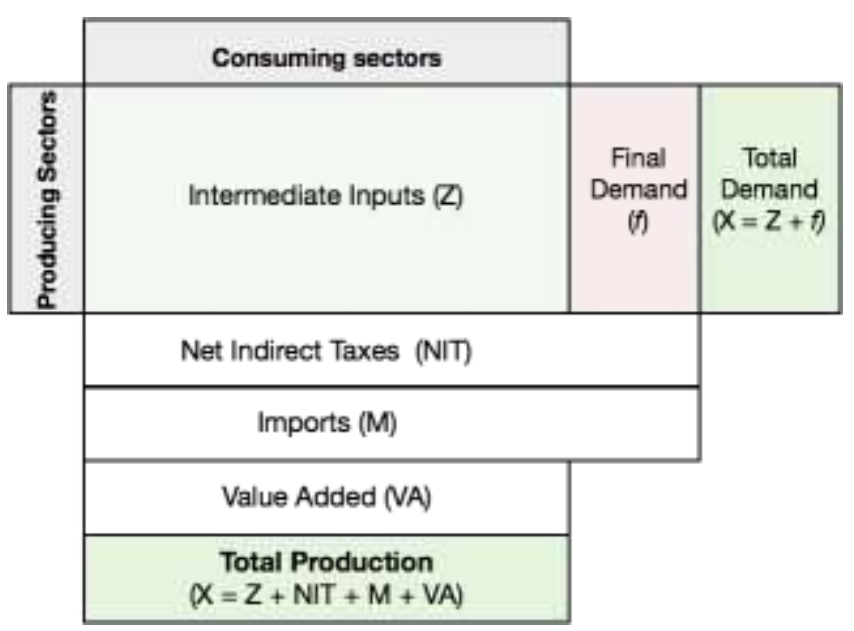

Figure 13. Basic Input-Output model relationships. Source: Author's elaboration from GUILHOTO (2004).

Note that domestic inputs (obtained from domestic production), imported inputs and primary inputs (labour, capital, land) are used in the productive process to produce domestic products. Domestic products are then used by industries as intermediate inputs or consumed as final products (exports, household consumption, govern expenditures, investments, etc.). In addition, it should be noted that imports may be intermediate inputs, which are used in the productive process, or final goods, which are directly consumed by final users (Figure 14). 


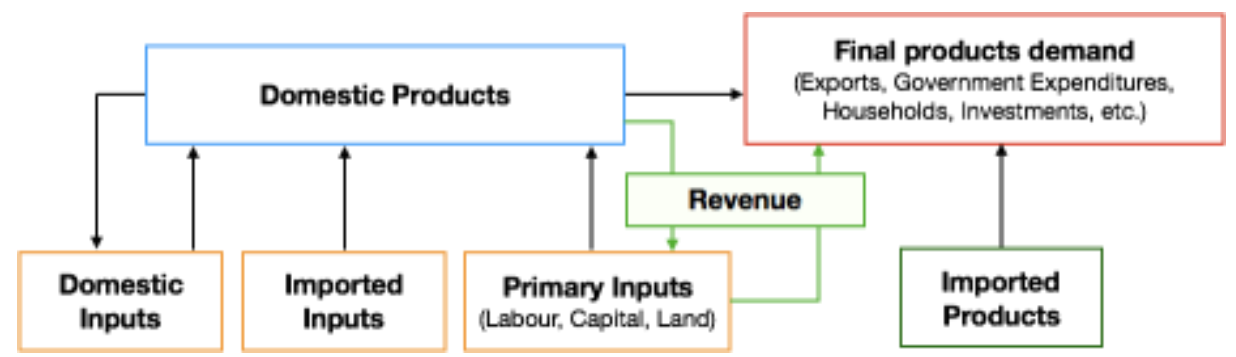

Figure 14. Input-output model flowchart.

Source: Author's elaboration from GUILHOTO (2004).

Therefore, the revenue of the economy is generated from the remuneration of labour, capital and land, which is used on consuming final goods and services - whether they are destined for consumption or investment (GUILHOTO, 2004). The government revenue is obtained through the payments of taxes by companies and individuals. Thus, the IO model assumes that there is equilibrium in all markets of the economy (corroborating thus, to Figures 12 and 13).

It is noteworthy that there are two fundamental hypotheses regarding the economic system in the IO model (MILLER and BLAIR, 2009):

1) Homogeneity: each product is supplied by a single activity (and only one technology is used to produce a product) and;

2) Proportionality: the inputs consumed by each activity are to be as a function of the production level of the activity itself.

Therefore, the constraints considered and the corresponding solutions are to be viewed as policy targets.

The system of equations of the IO model can be expressed as follows (Table 2).

Table 2. IO table for a 2 sectors economy.

\begin{tabular}{lccccccc}
\hline & Sector1 & Sector2 & Households & Government & Investment & Exports & Total \\
\hline Sector 1 & $Z_{11}$ & $Z_{12}$ & $C_{1}$ & $G_{1}$ & $I_{1}$ & $E_{1}$ & $X_{1}$ \\
Sector 2 & $Z_{21}$ & $Z_{22}$ & $C_{2}$ & $G_{2}$ & $I_{2}$ & $E_{2}$ & $X_{2}$ \\
Imports & $M_{1}$ & $M_{2}$ & $M_{c}$ & $M_{g}$ & $M_{i}$ & & $M$ \\
Taxes & $T_{1}$ & $T_{2}$ & $T_{c}$ & $T_{g}$ & $T_{i}$ & $T_{e}$ & $T$ \\
Value added & $W_{1}$ & $W_{2}$ & & & & & $W$ \\
\hline Total & $X_{1}$ & $X_{2}$ & $C$ & $G$ & $I$ & $E$ & \\
\hline
\end{tabular}

Source: Author's elaboration from GUILHOTO (2004), MILLER and BLAIR (2009). 
Where:

$Z_{i j}$ is the monetary flow between sectors $i$ and $j$;

$C_{i}$ is households' consumption from sector $i$ 's products;

$G_{i}$ is government's purchases from sector $i$;

$I_{i}$ is the demand for investments from sector $i$ 's products;

$E_{i}$ is sector $i$ 's total exports;

$X_{i}$ is sector $i$ 's total output;

$T_{i}$ is sector $i$ 's total net indirect taxes;

$M_{i}$ is sector $i$ 's imports;

$W_{i}$ is sector $i$ 's value added.

Therefore, from the table above, we can establish the following equality:

$X_{1}+X_{2}+C+G+I+E=X_{1}+X_{2}+M+T+W$

By eliminating $X_{1}$ and $X_{2}$ from both sides, we have:

$C+G+I+E=M+T+W$

Arranging differently:

$C+G+I+(E-M)=T+W$

Again, in other words, the IO table preserves macroeconomic identities. From the above example with 2 economic sectors and generalizing to $n$ sectors, we have:

$$
\sum_{j=1}^{n} z_{i j}+c_{i}+g_{i}+i_{i}+e_{i} \equiv x_{i}
$$

$$
i=1,2, \ldots, n
$$


where:

$z_{i j}$ is the sector $j$ 's demand for the products of sector $i$;

$c_{i}$ is sector $i$ 's output consumed by households;

$g_{i}$ is sector $i$ 's output consumed by the government;

$i_{i}$ is sector $i$ 's output destined to investments;

$e_{i}$ is sector $i$ 's exports;

$x_{i}$ is sector $i$ 's total domestic output.

Assuming that the intermediate flows per unit of final product are fixed, we can derive the Leontief open system ${ }^{10}$, that is,

$$
\sum_{j=1}^{n} a_{i j} \cdot x_{j}+y_{i}=x_{i}
$$

$i=1,2, \ldots, n$

where:

$a_{i j}$ is the technical coefficient which denotes the quantity of sector $i$ 's product required as input to produce a unit of sector $j$ 's final output and;

$y_{i}$ is the sector $i$ 's final demand, that is, $c_{i}+g_{i}+i_{i}+e_{i}$.

Therefore:

$a_{i j}=z_{i j} / x_{j}$

All other variables have already been defined previously.

Note that Eq. 3.5 can be written in its matrix form:

${ }^{10}$ The Leontief open system considers the final demand to be exogenous to the system, whereas in the closed system the final demand is considered as endogenous. 
$A x+y=x$

where:

$A$ is the direct technical coefficient matrix of size $(n \times n)$ and;

$x$ and $y$ are column vectors of size $(n \times 1)$.

Solving the Eq. 3.7, we obtain the total output required to satisfy the final demand, that is,

$x=(I-A)^{-1} \cdot y$

where:

$I$ is the identity matrix ${ }^{11}$ and;

$(I-A)^{-1}$ is the direct and indirect technical coefficient matrix or the Leontief inverse matrix.

We have $L=(I-A)^{-1}$, where the element $b_{i j}$ is the sector $i$ 's total output that is required to produce a unit of sector $j$ 's final demand.

The famous Leontief inverse matrix, $(I-A)^{-1}$, also called total requirements matrix, is equivalent to $\left(I+A+A^{2}+A^{3}+\ldots+A^{n}\right)$ by the power series approximation. Leontief inverse is a way of measuring the total effects caused by any $y$ components variation $(\Delta y)$ of the IO table (MILLER and BLAIR, 2009).

Considering $x=(I-A)^{-1}$. $y$ as a system of linear equations representing an economic system (with $x$ being the economic output and $y$ the final demand), we can measure any variation of $x$, (i.e., $\Delta x)$, resulted by any variation of $y$, (i.e., $\Delta y$ ), by $\Delta x=\Delta y$ $\left.+\Delta y A+\Delta y A^{2}+\Delta y A^{3}+\ldots\right)$, in which the first element of the right side of the equation is related to the initial output effect, i.e. totally computing the stimulus occurred by the $y$ matrix variation $(\Delta y)$. The second, $\Delta y A$, are the direct effects, i.e. the first order effects, directly related to the technical coefficients. Beyond the second order we find the indirect effects $\left(\Delta y A^{2}+\Delta y A^{3}+\ldots\right)$, which measure the effects caused by the variation of inputs

\footnotetext{
11 The identity matrix of size $n$ is the $(n \times n)$ square matrix with ones on the main diagonal and zeros elsewhere.
} 
demanded by such technical coefficients. We can have the total effects by summing all of them (GUILHOTO, 2004; MILLER and BLAIR, 2009; ELY, 2015). For a better understanding on IO theory, see LEONTIEF (1970), LEONTIEF and FORD (1971), HERENDEEN (1978) and MILLER and BLAIR (2009).

The Brazilian Institute of Geography and Statistics (IBGE) began to elaborate national IO tables in 1970. Its initial objectives were to create a structural framework for the National Accounts System and an instrument to guide the development of the economic statistics required to elaborate macroeconomic frameworks (IBGE, 2011). In this regard, the Brazilian IO matrix is formed by a set of tables detailing the production and consumption operations, by activity, which generate the technical coefficient matrices, resulting in tables with up to 67 economic activities and 127 products (IBGE, 2016). The IBGE has recently released the latest version of Brazilian IO matrix for the year 2010.

GUILHOTO (2010) has developed an inter-regional IO table for Goiás State and the rest of Brazil, based both on the National and Regional Accounts for the year 2000, considering 26 sectors of the economy (Appendix I). To perform it, the methodology described in GUILHOTO and SESSO FILHO $(2005,2010)$ and GUILHOTO et al. (2010) was applied. Focusing on the analysis proposed herein, these 26 Goiás' economy sectors were aggregated into 13 target sectors (Table 3 and Appendices II, III, IV, and V). Next, a nexus framework was developed by applying the Goiás' hybrid inter-regional IO model to analyse its direct and indirect relationships while considering the water, energy, land use and GHG emissions that would be required due to any change in final demand. 
Table 3. List of 26 sectors from the Goiás' original IO table (GUILHOTO, 2010) and the resulting 13 aggregated sectors.

\begin{tabular}{|c|c|c|c|}
\hline \multicolumn{4}{|c|}{ Economy sectors } \\
\hline & Original sectors & & Aggregated sectors \\
\hline $\begin{array}{l}1 \\
2\end{array}$ & $\begin{array}{l}\text { Agriculture and forestry } \\
\text { Livestock and fishing }\end{array}$ & 1 & Agricultural \\
\hline 3 & Mining & 2 & Mining \\
\hline 4 & Food, beverages and tobacco & 3 & Food, beverages and tobacco \\
\hline 5 & Textile, clothes and shoes & 4 & Textile, clothes and shoes \\
\hline 6 & Wood, paper and printing & 5 & Wood, paper and printing \\
\hline 7 & Oil refining, coke and alcohol & 6 & Biofuels ${ }^{I}$ \\
\hline 8 & Chemical and pharmaceutical products & 7 & Chemical and pharmaceutical products \\
\hline 9 & Plastic and rubber goods & & \\
\hline 10 & Machinery and equipment & & \\
\hline 11 & Electrical and electronic materials & 8 & Other industries \\
\hline 12 & Transport materials & & \\
\hline 13 & Miscellaneous industries & & \\
\hline 14 & $\begin{array}{l}\text { Cement and other non-metallic mineral } \\
\text { products }\end{array}$ & 9 & $\begin{array}{l}\text { Cement, construction and other non- } \\
\text { metallic mineral products }\end{array}$ \\
\hline 16 & Metallurgy & 10 & Metallurgy \\
\hline 17 & Power, gas, sewage and public cleaning & 11 & Power sector $^{2}$ \\
\hline 18 & Commerce & & \\
\hline 19 & Private services & & \\
\hline 20 & Financial and insurance & & \\
\hline 21 & Real estate services & & \\
\hline 22 & Accommodation and food services & 12 & Services \\
\hline 23 & Public and private education & & \\
\hline 24 & Public and private healthcare & & \\
\hline 25 & $\begin{array}{l}\text { Public administration and social } \\
\text { security }\end{array}$ & & \\
\hline 26 & Transport, storage and mail & 13 & Transport, storage and mail \\
\hline
\end{tabular}

Note: ${ }^{I}$ Biofuels sector hereafter since the state of Goiás does not produce any oil or coke. The charcoal production (from the energy balance) was also allocated into the Biofuels sector in the following sub-sections. ${ }^{2}$ It was assumed that $75 \%$ of Power, gas, sewage and public cleaning sector (from the Goiás' original IO table) was allocated into the Power sector, which represents the electricity generation in the state. The other $25 \%$ of the original sector was allocated into Other industries sector, aiming to represent sewage and public cleaning activities.

\subsubsection{Inter-regional Input-Output matrix}

The IO model concepts that was previously shown refers basically to National matrices, when working with models from a single region or models from several interconnected regions, that is, inter-regional models. In short, a regional matrix shows the same structure of a national matrix.

The inter-regional IO model, also known as "Isard model" (1951), requires a huge amount of real or estimated data. In the inter-regional system, there are exchanges 
between regions through imports and exports, which are expressed by the flow of goods destined to both intermediate consumption and final demand (Figure 15).

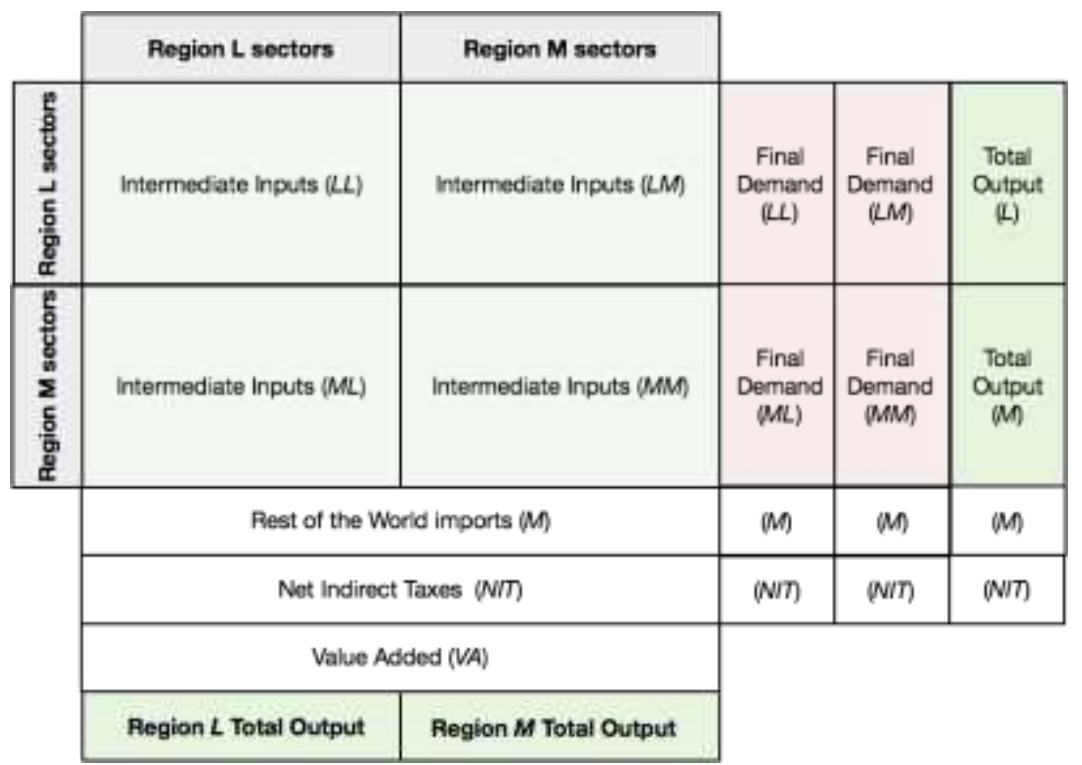

Figure 15. Input-Output relationships in an inter-regional system.

Source: Author's elaboration from GUILHOTO (2004), MILLER and BLAIR (2009).

In summary, we can present the model from a hypothetical example of intersectoral and inter-regional flows of goods to regions $L$ and $M$, as follows:

$Z_{i j}{ }^{L L}=$ monetary flow from sector $i$ to sector $j$ of region $L$;

$Z_{i j}^{M L}=$ monetary flow from sector $i$ of region $M$ to sector $j$ of region $L$.

We can set up the matrix:

$$
\mathrm{Z}=\left[\begin{array}{ll}
Z^{L L} & Z^{L M} \\
Z^{M L} & Z^{M M}
\end{array}\right]
$$

where:

$Z^{L L}$ and $Z^{M M}$ represent intra-regional monetary flow matrices;

$Z^{L M}$ and $Z^{M L}$ represent inter-regional monetary flow matrices.

Considering the Leontief equation, 
$X_{i}=z_{i 1}+z_{i 2}+\ldots+z_{i i}+\ldots+z_{i n}+Y_{i}$

where:

$X_{i}$ indicates sector $i$ 's total output;

$z_{i n}$ the money flow from sector $i$ to sector $n$ and;

$Y_{i}$ the sector $i$ 's final demand.

Thus, in a regional context:

$X_{1}^{L}=z_{11}^{L L}+z_{12}^{L L}+z_{11}^{L M}+z_{12}^{L M}+Y_{1}^{L}$

where $X_{1}{ }^{L}$ is the total product 1 produced in the $L$ region.

Considering the regional input coefficients for $L$ and $M$ regions, we have:

The intra-regional coefficients:

$$
a_{i j}^{L L}=\frac{z_{i j}^{L L}}{X_{j}^{L}} \quad \Rightarrow \quad z_{i j}^{L L}=a_{i j}^{L L} \cdot X_{j}^{L}
$$

where $a_{i j} L L$ are the technical coefficients of production, and they represent how much the sector $j$ of region $L$ demands from sector $i$ of region $L$.

$$
a_{i j}^{M M}=\frac{z_{i j}^{M M}}{X_{j}^{M}} \quad \Rightarrow \quad z_{i j}^{M M}=a_{i j}^{M M} \cdot X_{j}^{M}
$$

where $a_{i j}{ }^{M M}$ are the technical coefficients of production, and they represent how much the sector $j$ of region $M$ demands from sector $i$ of region $M$.

And finally, the inter-regional coefficients:

$$
a_{i j}^{M L}=\frac{z_{i j}^{M L}}{X_{j}^{L}} \quad \Rightarrow \quad z_{i j}^{M L}=a_{i j}^{M L .} \cdot X_{j}^{L}
$$


where $a_{i j}{ }^{M L}$ are the technical coefficients of production, and they represent how much the sector $j$ of region $L$ demands from sector $i$ of region $M$ and,

$$
a_{i j}^{L M}=\frac{z_{i j}^{L M}}{X_{j}^{M}} \quad \Rightarrow \quad z_{i j}^{L M}=a_{i j}^{L M} \cdot X_{j}^{L}
$$

where $a_{i j}{ }^{L M}$ are the technical coefficients of production, and they represent how much the sector $j$ of region $M$ demands from sector $i$ of region $L$.

These coefficients can be substitute in Eq. 3.11, obtaining:

$$
X_{1}^{L}=a_{11}^{L L} X_{1}^{L}+a_{12}^{L L} X_{2}^{L}+a_{11}^{L M} X_{1}^{M}+a_{12}^{L M} X_{2}^{M}+Y_{1}^{L}
$$

The production for other sectors can be obtained in a similar way.

By isolating $Y_{1}^{L}$ and evidencing $X_{l}^{L}$, we have:

$$
\left(1-a_{11}^{L L}\right) X_{1}^{L}-a_{12}^{L L} X_{2}^{L}-a_{11}^{L M} X_{1}^{M}-a_{12}^{L M} X_{2}^{M}=Y_{1}^{L}
$$

The final demand for other sectors can be obtained in a similar way.

Therefore, according to:

$$
A^{L L}=Z^{L L}\left(\hat{X}^{L}\right)^{-1} \text {, we can make the } A^{L L} \text { matrix for } 2 \text { sectors, }
$$

where $A^{L L}$ represents the intra-regional technical coefficients of production matrix. Note that the same formulation can be used to $A^{L M}, A^{M M}$ and $A^{M L}$.

Now, we can determine the following matrices:

$$
A=\left[\begin{array}{ccc}
A^{L L} & \vdots & A^{L M} \\
\cdots & \cdots & \cdots \\
A^{M L} & \vdots & A^{M M}
\end{array}\right]
$$




$$
\begin{gathered}
X=\left[\begin{array}{c}
X^{L} \\
\cdots \\
X^{M}
\end{array}\right] \\
Y=\left[\begin{array}{c}
Y^{L} \\
\cdots \\
Y^{M}
\end{array}\right]
\end{gathered}
$$

(Eq. 3.20)

The complete inter-regional IO system can be expressed by:

$(I-A) X=Y$,

and the matrices can be set as follows:

$$
\left\{\left[\begin{array}{ccc}
I & \vdots & 0 \\
\cdots & \cdots & \cdots \\
0 & \vdots & I
\end{array}\right]-\left[\begin{array}{ccc}
A^{L L} & \vdots & A^{L M} \\
\ldots & \cdots & \ldots \\
A^{M L} & \vdots & A^{M M}
\end{array}\right]\right\}\left[\begin{array}{c}
X^{L} \\
\cdots \\
X^{M}
\end{array}\right]=\left[\begin{array}{c}
Y^{L} \\
\cdots \\
Y^{M}
\end{array}\right]
$$

By carrying out these operations, we obtain the basic models required for the interregional analysis proposed by Isard, that is:

$$
\begin{aligned}
& \left(I-A^{L L}\right) X^{L}-A^{L M} X^{M}=Y^{L} \\
& -A^{M L} X^{L}+\left(I-A^{M M}\right) X^{M}=Y^{M}
\end{aligned}
$$

Resulting in the Leontief inter-regional model:

$$
X=(I-A)^{-1}
$$

For a deeper understanding on IO theory and inter-regional IO models, please refer to LEONTIEF (1970), HERENDEEN (1978), GUILHOTO (2004) and MILLER and BLAIR (2009). 


\subsubsection{Goiás’ economic-ecological Input-Output model}

Since the late 1960s the IO framework has been extended by many researchers to account for environmental pollution generation and abatement associated with interindustry activity. This has been occurring because of IO models consists in good analytical tools in measuring both direct and indirect impacts (GUILHOTO, 2004; MILLER and BLAIR, 2009). LEONTIEF (1970) himself provided one of the key methodological extensions that has since been applied widely and extended further.

The main goal of an environmental IO model is to analyse environmental (and energy) flows determining the total inputs (e.g. water, land, energy) used in producing a given output for consumption in the final demand sectors (MILLER and BLAIR, 2009).

To do so, the resetting of a hybrid IO table is required, in which the flows between sectors are represented in hybrid units. In other words, in a hybrid analysis, an environmental IO model shows its "environmental flows" both in monetary and in physical units (e.g. $\mathrm{m}^{3}$ of water, $\mathrm{m}^{2}$ of land, $\mathrm{J}$ of energy consumed, etc.), whereas nonenvironmental flows are described only in money terms (Table 4). Through this hybrid IO model, we can estimate the environmental (and energy) requirements of productive sectors as well as the requirements to produce goods and services in the economy, resulting in estimates of all resources used by each sector, from changes in the final demand.

Table 4. General structure of an Input-Output table with hybrid units*.

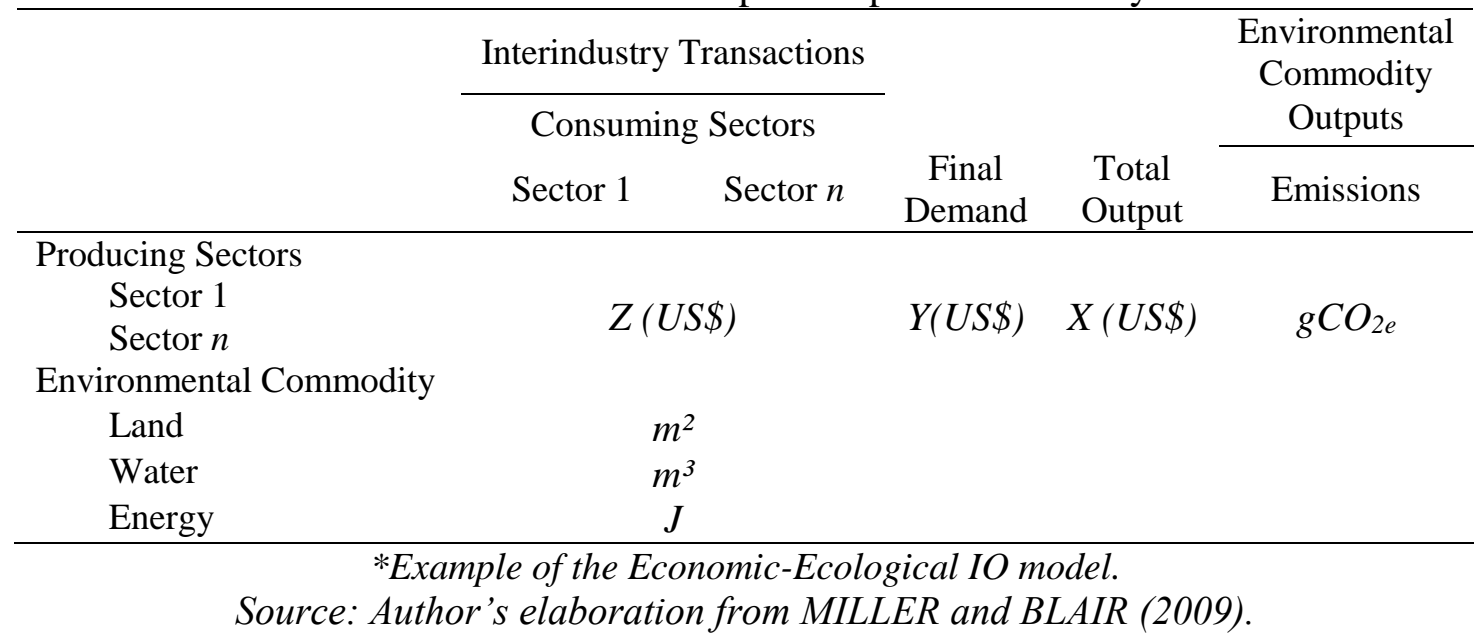

In environmental IO models, we seek an analogous set of matrices to $Z, A$, and $L$, that is, respectively, an environmental transactions or flows matrix, a direct 
environmental requirements matrix and finally a total environmental requirements matrix (MILLER and BLAIR, 2009).

To carry this out, we define a set of ecological commodity inputs and the magnitudes of which we will capture in a matrix $M=\left[m_{k j}\right]$, an element of which reflects the amount of ecological input of type $k$ used in the production of economic sector $j$ 's total output. Similarly, we define a set of ecological commodity outputs (e.g. $\left.\mathrm{gCO}_{2 \mathrm{e}}\right)$. The corresponding matrix of ecological commodity output flows is $N=\left[n_{k j}\right]$, an element of which specifies the amount of ecological commodity output $k$ associated with the output of sector $j$.

From Table 4, we can identify the matrices of ecological commodity inputs and outputs, respectively, i.e., $M$ and $N$, as well as the interindustry transactions $(Z)$, vector of total final demands $(Y)$ and the vector of total industry outputs $(X)$ (highlighted in Table 5).

Table 5. Economic-ecological commodity flows: Matrix definitions.

\begin{tabular}{|c|c|c|c|c|c|}
\hline & \multicolumn{2}{|c|}{ Interindustry Transactions } & \multirow[b]{3}{*}{$\begin{array}{c}\text { Final } \\
\text { Demand }\end{array}$} & \multirow[b]{3}{*}{$\begin{array}{c}\text { Total } \\
\text { Output }\end{array}$} & \multirow{3}{*}{$\begin{array}{c}\begin{array}{c}\text { Environmenta } \\
\text { Commodity } \\
\text { Outputs }\end{array} \\
\text { Emissions }\end{array}$} \\
\hline & \multicolumn{2}{|c|}{ Consuming Sectors } & & & \\
\hline & Sector 1 & Sector $n$ & & & \\
\hline Producing Se & & \multirow{6}{*}{ Y } & \multirow{6}{*}{$\mathrm{X}$} & \\
\hline $\begin{array}{l}\text { Sector } 1 \\
\text { Sector } n\end{array}$ & & & & & $\mathrm{~N}$ \\
\hline Environment: & & & & & \\
\hline Land & \multirow{3}{*}{\multicolumn{2}{|c|}{ M }} & & & \\
\hline Water & & & & & \\
\hline Energy & & & & & \\
\hline
\end{tabular}

Source: Author's elaboration from MILLER and BLAIR (2009).

We can now define ecological commodity input and output coefficients in much the same way we defined direct impact coefficients earlier, by first recalling that $A=Z x^{\wedge-1}$, which defines the matrix of technical coefficients; hence, similarly we define the matrices of ecological commodity input and output coefficients as:

$$
R=M x^{\wedge-1} \text {, which defines the matrix of ecological commodity input coefficients, }
$$
that is, the elements of $R=\left[r_{k j}\right]$ specify the amount of commodity $k$ required per dollar's worth of output of industry $j$; 
$Q=N^{\prime} x^{\wedge-1}$, which defines the ecological commodity output coefficients, that is, $Q=\left[q_{k j}\right]$ specifies the amount of commodity $k$ generated per dollar's worth of output of industry $j$ (MILLER and BLAIR, 2009).

Note that $N^{\prime}$ is the transpose of the matrix of ecological commodity output flows. Also, note that in matrix algebra notation, a "hat" over a vector denotes a diagonal matrix with the elements of the vector along the main diagonal, so, for example:

$$
\hat{\mathbf{x}}=\left[\begin{array}{ccc}
x_{1} & \cdots & 0 \\
\vdots & \ddots & \vdots \\
0 & \cdots & x_{n}
\end{array}\right]
$$

Thus, using $R$ and $Q$ as computed above, total impact coefficients - in this case, ecological commodity input and output coefficients as a function of final demands - can be respectively written as:

$$
R^{*}=R(I-A)^{-1} \text { and } Q^{*}=Q(I-A)^{-1},
$$

where,

$R^{*}=\left[r_{i j}^{*}\right]$ reflects the amount of ecological input $i$ required directly and indirectly to deliver a dollar's worth of industry $j$ 's output to final demand and;

$Q^{*}=\left[q_{i j}^{*}\right]$ reflects the amount of ecological output $i$ associated with delivering a dollar's worth of industry $j$ 's output to final demand directly and indirectly.

Therefore, the use of hybrid IO models aiming to analyse GHG emissions and the water, energy and land uses by the final demand is considered suitable both in verifying the direct consumption of resources by the final demand, as well as in calculating the total environmental requirements to produce the outputs required by this final demand. Aiming to analyse future changes in the use of inputs (i.e. water, energy and land) from changes in final demand for ethanol in the state of Goiás, this thesis justifies the use of the environmental analysis tool provided by the hybrid IO model.

However, there are no market transactions of environmental requirements and, therefore, they are not represented in the standard national accounts (HRISTUVARSAKELIS et al., 2010). In order to assess environmental requirements, Goiás' IO 
table was rearranged to include them into the analysis (see also MILLER and BLAIR, 2009; HRISTU-VARSAKELIS et al., 2010; CARVALHO et al., 2015; WANG and CHEN, 2016). In this regard, production and consumption of water, energy, land and emissions were incorporated into the original Goiás' IO table as an 'attached environmental account' to allocate the environmental flows between sectors (Appendix VI). This procedure generates an extended IO table with hybrid units, where environmental flows are considered in physical units (i.e., $\mathrm{hm}^{3}, \mathrm{PJ}, \mathrm{km}^{2}, \mathrm{TgCO} 2 \mathrm{e}$ ) and all non-environmental sector flows are measured in monetary units (US Dollar - US\$); assuming an average exchange rate of $3.23 \mathrm{R} \$ / \mathrm{US} \$$, for a year period (BCB, 2017). Therefore, this framework allows tracing the impacts associated with interindustry production generated in response to any new vector of final demands. To carry it out, a linear programming problem is defined aiming at maximizing the GDP (Eq. 3.26):

$$
\operatorname{Max} G D P=c^{T} X
$$

where $c^{T}=[1,1, \ldots, 1]^{T}$ (so that $c$ is the column-sum of the IO matrix). The matrix of technological coefficients (from Eq. 3.6, $A=Z x^{-1}$ ) is obtained from the IO matrix and, through some algebraic manipulation, it derives in the basic linear Leontief model ( $E q$. 3.8). Thus, the maximization of GDP was subject to the following (linear) constraints:

a) $c^{T}(I-A) X \leq c^{T}\left(Y_{\min }-M\right)$; where $M$ represents imports and $Y_{\min }$ is a lower bound on the total sum of demand met across all sectors;

b) $X \geq X_{\min }$, where $X_{\min }$ is the lower production bound;

c) $X \geq 0$, representing that gross value of production must be non-negative in every sector;

d) $R^{*} \leq R_{\min }$, where $R_{\min }$ is the current use of environmental resources, i.e. water, energy and land;

e) $N^{\prime *} \leq N_{\min }^{\prime}$, where $N_{\min }^{\prime}$ is the current GHG emissions;

f) $J^{*} \leq J_{\min }$, where $J_{\min }$ is the current employment level.

Additionally, prospective ethanol scenarios were considered as the main changing variable in the IO model. After estimating these scenarios (in terms of \% change from current levels - 2015), the new ethanol final demand requirement was incorporated into 
the extended IO model aiming to estimate the impacts on energy, environmental and economic systems to better understand whether ethanol expansion in the region would threat local environmental resources.

Thus, this work addresses the nexus approach through the application of the Goiás' hybrid IO model, considering as environmental aspects $(i)$ inputs: water withdrawal $\left(\mathrm{hm}^{3}\right)$, land use $\left(\mathrm{km}^{2}\right)$ and energy use $(P J)$; and (ii) outputs: GHG emissions (as mass of $\mathrm{CO}_{2 e}$ GWP-AR5 - in Tg). Also, since the Goiás' IO model considers official jobs data, the model can be used to estimate social impacts from future changes in final demand for ethanol. Finally, the IO tables were processed through multiple spread-sheets workbook structure (using Microsoft Excel) and the optimizations were performed through the Opensolver.

\subsubsection{Data sources}

Due to Goiás' IO table having been estimated for the year 2008, all other data required to formulate the hybrid IO model (i.e., water, energy, land use and GHG emissions) are also analysed for the same year to calibrate the model. The main purpose behind this initiative is to capture all the economic (through the Goiás' IO table) and environmental conjuncture (through analysing specific data sources, explained hereafter) for a specific year and it aims to understand the relationship between inputs and outputs on that economy, at that time. Analogous, it can be seen as a picture of the economy at the target year. Hence, it is defined a pattern (ratio) between the sectors of the economy (coefficients) to be used as a tool to estimate future impacts regarding changes in final demand by following the structure (ratio) defined to the baseline year, i.e., 2008. Despite the fixed relationship ratios between sectors, this method can be used to estimate economic and environmental impacts on the economy for any future year and, in our case study, the scenarios consider ethanol expansion in the year 2030. The issues related to the fixed nature of technical coefficients will be better discussed further.

\subsubsection{Land-use data}

Land-use data for the agriculture sector covers all the crop area used in Goiás State, i.e., mainly soybean, corn and sugarcane crops, which, altogether, accounted for $71 \%$ of the total agriculture area in 2008 (Figure 16) (IBGE, 2009, MAPBIOMAS, 
2017). Also, total area used by livestock production was estimated from IBGE (2009a, 2017) and MAPBIOMAS (2017), resulting in $155,234 \mathrm{~km}^{2}$.

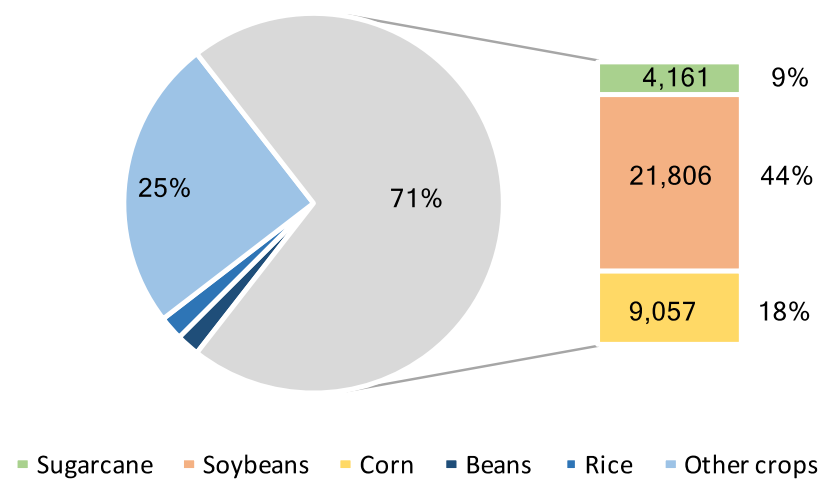

Figure 16. Goiás' agriculture land-use, by crops in $\mathrm{km}^{2}$ (2008).

Source: Author's elaboration from IBGE (2009) and MAPBIOMAS (2017).

Despite the lower land footprint compared to agriculture, data on total industry area was estimated from state government agencies such as the Secretariat of Planning and Development of the state of Goiás - SEPLAN (SEPLAN, 2009, 2010) and the Institute for Statistics and Socioeconomic Studies - IMB (IMB, 2014). All the land-use estimates are presented in the Table $\mathbf{6}$ and it was applied as a land-use input vector in the Goiás’ hybrid IO model (Appendix VI).

Finally, the land used by Goiás' Power sector (through the area occupied by water reservoirs) was estimated from the available hydropower stations and reservoirs data from the National Electrical System Operator - ONS (ONS, 2004, 2005, 2017) and by applying polynomial calculations to estimate the desired information. 
Table 6. Land-use in the state of Goiás (2008), by economy sectors.

\begin{tabular}{|c|c|c|}
\hline Economy sectors & $\begin{array}{c}\text { Land-use } \\
\left(\mathrm{km}^{2}\right)\end{array}$ & $\%$ \\
\hline Agricultural & 204,517 & 98.64 \\
\hline Livestock & 155,234 & 74.87 \\
\hline Agriculture & 49,283 & 23.77 \\
\hline Power sector & 2,755 & 1.33 \\
\hline Industry & 57 & 0.03 \\
\hline Mining & 30 & 0.02 \\
\hline Food, beverages and tobacco & 7 & 0.00 \\
\hline Textile, clothes and shoes ${ }^{1}$ & - & - \\
\hline Wood, paper and printing & 4 & 0.00 \\
\hline Biofuels ${ }^{2}$ & 0 & 0.00 \\
\hline Chemical and pharmaceutical products & 4 & 0.00 \\
\hline Other industries & 2 & 0.00 \\
\hline Cement, construction and other non-metallic minerals & 4 & 0.00 \\
\hline Metallurgy & 7 & 0.00 \\
\hline Transport $^{l}$ & - & - \\
\hline Services ${ }^{l}$ & - & - \\
\hline Total $\left(\mathbf{k m}^{2}\right)$ & 207,330 & - \\
\hline
\end{tabular}

Note: ${ }^{I}$ The land-use for Services and Textile, clothes and shoes sectors were not properly identified from the available references. There is no land-use for the Transport sector. ${ }^{2}$ Biofuels sector has shown null land-use $\left(0.09 \mathrm{~km}^{2}\right)$ when considered as part of the Industry sector. However, their land-use is accounted into the agriculture land-use.

To do so, each hydro station has at least two fourth-degree polynomial data sets with the following properties:

a) Quota-Volume polynomial: It is possible to calculate the reservoir surface in relation to the sea level, from the water volume stocked into the reservoir (in $\left.\mathrm{hm}^{3}\right)$. Thus, for each hydro plant, the parameters $a_{Q V P}, b_{Q V P}, c_{Q V P}, d_{Q V P}$ and $e_{Q V P}$ are available. The equation 3.27 shows how the reservoirs surface quota can be calculated from the reservoirs volume $(\mathrm{Vol})$.

$Q u o t a=a_{Q V P}+b_{Q V P} . V o l+c_{Q V P} . V o l^{2}+d_{Q V P} . V o l^{3}+e_{Q V P} . V o l^{4}$

b) Quota-Area polynomial: From the reservoir quota (in metres), we can calculate the reservoir surface area (in $\mathrm{km}^{2}$ ). So, from the reservoirs surface area, which depends on the volume of water stocked, we can also estimate the water lost due to evaporation. Similarly, for each hydro plant, the parameters $a_{Q A P}, b_{Q A P}, c_{Q A P}, d_{Q A P}$ and $e_{Q A P}$ are available. The equation 3.28 shows how 
the area can be estimated from the reservoirs surface quota relative to the sea level:

Area $=a_{Q A P}+b_{Q A P} \cdot$ Quota $+c_{Q A P} \cdot Q_{\text {uota }}^{2}+d_{Q A P} \cdot Q_{u o t a}{ }^{3}+e_{Q A P} \cdot$ Quota $^{4}(E q .3 .28)$

The following hydropower reservoirs located in the study area were analysed (Table 7) and the maximum, minimum and useful water volumes data for the year 2008 were obtained from the ONS - Operation history: useful volume of the main reservoirs (ONS, 2017).

Table 7. Maximum, minimum and useful water volume for the major hydro plants in the study area, in $\mathrm{hm}^{3}$.

\begin{tabular}{lrrr}
\hline Hydropower plant & Max Volume & Min Volume & Useful Volume \\
\hline UHE Batalha & 1,781 & 430 & 1,351 \\
UHE Nova Ponte & 12,792 & 2,412 & 10,380 \\
UHE Corumbá I & 1,500 & 470 & 1,030 \\
UHE Barra dos Coqueiros & 347 & 300 & 47 \\
UHE Salto & 826 & 826 & 0 \\
UHE Emborcação & 17,725 & 4,669 & 13,056 \\
UHE Cachoeira Dourada & 460 & 460 & 0 \\
Queimado & 557 & 95 & 461 \\
Corumbá IV & 3,708 & 2,936 & 771 \\
Corumbá III & 972 & 709 & 263 \\
Serra do Facão & 5,199 & 1,752 & 3,447 \\
Itumbiara & 17,027 & 4,573 & 12,454 \\
Salto Verdinho & 264 & 264 & 0 \\
Cacu & 231 & 197 & 34 \\
Espora & 209 & 71 & 138 \\
Castelo Branco II & 879 & 878 & 1 \\
Castelo Branco I & 241 & 228 & 12 \\
Miranda & 1,120 & 974 & 146 \\
São Simão & 12,540 & 7,000 & 5,540 \\
\hline
\end{tabular}

Note: Useful volume = Max volume - Min volume; Minimum volume, also called "dead volume".

Source: Author's elaboration from the ONS (2017) data.

The Power sector's total land-use area obtained from the estimates mentioned above represent $2,755 \mathrm{~km}^{2}$ of surface, as pointed out in the Table 6. Additionally, the useful volume (monthly average), the real useful volume (monthly average), the relative quota and the average monthly area for all the 19 hydropower reservoirs located in the study area can be verified through Appendices VII, VIII, X and XI. Specifically, 
Appendix IX shows all the polynomials made available by the ONS (2017), used for estimating the volume of water and the area occupied by power plant reservoirs.

\subsubsection{Water use data}

Since there is lack of available data on water use by different activities in the country, estimating water use by economy sectors is not a trivial task. Most of the analyses performed herein was based on estimates on water use, from indicators such as water footprint (in the case of agriculture sector), specific water consumption (in the livestock sector) and water-use technical coefficients (in industry sector). Additionally, after calculating the area of hydropower reservoirs presented in the previous sub-section, it was carried out an estimation of the evaporation from the reservoirs, determining so the water consumed by the power sector.

The water used by the agriculture (blue water) and livestock sectors was based on IBGE (2009, 2009a), MEKONNEN and HOEKSTRA (2011), EMBRAPA (2013) and FAO (2017). Regarding sugarcane production in Goiás State, the blue water coefficient applied was $0.075 \mathrm{~m}^{3} / \mathrm{kg}$ of sugarcane, which was found by FACHINELLI and PEREIRA (2015) through their work on irrigated ethanol in the Paranaíba basin, Goías.

Regarding water use by the industry, there is an issue to determine the sectoral technical coefficients, which ideally should be differentiated by productive sectors, micro-region and by technological process (FUNARBE, 2011). Many studies (ANA, 2002; ONS, 2005; FUNARBE, 2011; CNI, 2013) have tried to find some water use coefficients related to water withdrawals. The industrial water use coefficients applied to this study were related to water withdrawal $\left(\right.$ in $\mathrm{m}^{3}$ ) per unit of production, considering the findings of FUNARBE (2011). In this context, the total national production for 2008 was obtained from the Brazilian Industrial Research (IBGE, 2009b) and GUILHOTO (2010), by sector. All the water-use coefficients, the bulk production and the estimates of total water use by sector, can be checked through Appendix XII. Additionally, a short version of the water use data in Goiás, by economy sectors in 2008, is presented next (Table 8). 
Table 8. Total water-use in Brazil and in the state of Goiás by sector, in 2008.

\begin{tabular}{lrr}
\hline Economy sectors & $\begin{array}{r}\text { Brazil } \\
\left(\mathrm{hm}^{3}\right)\end{array}$ & $\begin{array}{r}\text { Goiás } \\
\left(\mathrm{hm}^{3}\right)\end{array}$ \\
\hline Agricultural & - & $3,721.59$ \\
Agriculture & - & $3,394.86$ \\
Livestock & - & 326.73 \\
Mining & $3,850.02$ & 200.49 \\
Food, beverages and tobacco & $1,125.77$ & 64.09 \\
Textile, clothes and shoes & 858.45 & 22.49 \\
Wood, paper and printing & 76.78 & 2.01 \\
Biofuels* & 502.47 & 13.16 \\
Chemical and pharmaceutical products & 436.12 & 1.67 \\
Other industries & 802.55 & 21.03 \\
Cement, construction and other non-metallic minerals & 6.67 & 0.17 \\
Metallurgy & 41.21 & 1.36 \\
Power sector & $2,862.33$ & 74.50 \\
Transport sector & - & 699.26 \\
Services/Human supply & - & - \\
\hline Note: ${ }^{*}$ According to Table 3, the production of charcoal was allocated into the Biofuels sector in \\
the Goiás' aggregated IO table. Therefore, the water used by the Biofuels sector considers \\
charcoal production and only the industrial phase of ethanol production. \\
Source: Author's elaboration from ONS (2004, 2017), IBGE (2009, 2009a, 2009b), \\
FUNARBE (2011), MEKONNEN and HOEKSTRA (2011), FAO (2017), EMBRAPA (2013, \\
2016), DNPM (2009), CETESB (2014), IPT (2013), GOIÁS (2010), ANA (2012, 2015), \\
FACHINELLI and PEREIRA (2015). &
\end{tabular}

Finally, the water used by Goiás' Power sector was estimated from the National Electrical System Operator data (ONS, 2004, 2005, 2017). According to the location of the reservoir and the month of the year, the evaporation causes the surface of the reservoir to be reduced. Thus, for each hydropower plant, 12 indexes of the average local evaporation are available, corresponding to the months of the year (in $\mathrm{mm}$ ). The evaporation is an important parameter in the Brazilian Power sector, since the rainy season varies widely depending on the region of the country.

To estimate the volume of water lost by the evaporation from reservoirs (EVAV), the following equation can be applied:

$E V A V=$ Area $\cdot 10^{2} \cdot E E_{A} C_{i} \cdot 10^{-5}$

where:

$E V A C_{i}$ is the evaporation coefficient of month $i$

The $10^{2}$ constant consists in converting $\mathrm{km}^{2}$ into $\mathrm{hm}^{2}$ and; 
The $10^{-5}$ constant consists in converting the evaporation coefficient given in $\mathrm{mm}$, into hm.

Thus, the volume of water lost by evaporation $(E V A V)$ will be given in $\mathrm{hm}^{3}$, the most common unit used to determine the water stocked into reservoirs. In short, the Eq. 3.29 can be rewritten as follows:

$$
E V A V=10^{-3} . \text { Area } . \text { EVAC } i
$$

The monthly average evaporation coefficient $(E V A C)$ was obtained from the ONS (2004) and it can be verified through the Appendix XIII. By applying the Eq. 3.30, the total net evaporation of the reservoirs in the region of study in 2008 have accounted for $1,219 \mathrm{hm}^{3}$ of water, as pointed out in the Appendix XIV. This value was used to estimate the water footprint of hydro plants in the Paranaíba basin (Appendix XV), from the average power generation in the basin during the year 2008 (data from ANEEL, 2017). Thus, the water footprint of the hydro plants in the Paranaíba basin was equivalent to $28.742 \mathrm{~m}^{3} / \mathrm{MWh}$. From this indicator of water used by unit of energy, we have calculated the total water consumed by power plants (i.e., $699.26 \mathrm{hm}^{3}$ ) (Table 8), from the total power generation in the state of Goiás, in 2008 (BRAZIL, 2010). All the water-use estimates presented in the Table $\mathbf{8}$ was applied as a water-use input vector in the Goiás' hybrid IO model (Appendix VI).

\subsubsection{Energy data}

Data on both Brazil's and Goiás' energy balances were obtained from Goiás State government (GOIÁS, 2010) and the Ministry of Energy and Mines (MME, 2016, 2017) (Tables 9 and 10). Ethanol and gasoline demand and supply forecasts were obtained from the Brazilian Energy Research Centre - EPE (EPE, 2017) and it will be better explained in the sub-section 4.2 . 
Table 9. Summarized 2008 Goiás' energy balance (in $10^{3}$ toe).

\begin{tabular}{|c|c|c|c|c|c|c|c|c|c|c|c|c|c|}
\hline \multirow{2}{*}{$\begin{array}{l}\text { Energy } \\
\text { source }\end{array}$} & \multicolumn{13}{|c|}{ Economy sectors ${ }^{l}$} \\
\hline & (1) & (2) & (3) & (4) & (5) & (6) & (7) & (8) & (9) & $(10)$ & (11) & (12) & (13) \\
\hline Natural gas & 0 & 0 & 0 & 0 & 0 & 0 & 0 & 0 & 0 & 0 & 0 & 0 & 957 \\
\hline Hydropower & 0 & 0 & 0 & 0 & 0 & 0 & 0 & 0 & 0 & 0 & 2,092 & 0 & 0 \\
\hline Firewood $^{2}$ & 29 & 0 & 27 & 0 & 12 & 545 & 2 & 9 & 22 & 0 & 3 & 2 & 0 \\
\hline $\begin{array}{l}\text { Sugarcane } \\
\text { products }^{2}\end{array}$ & 0 & 0 & 533 & 0 & 0 & 3,011 & 0 & 0 & 0 & 0 & 137 & 0 & 0 \\
\hline $\begin{array}{l}\text { Other } \\
\text { primary }\end{array}$ & 0 & 0 & 0 & 0 & 0 & 0 & 0 & 0 & 15 & 0 & 0 & 0 & 0 \\
\hline Diesel oil & 205 & 32 & 20 & 0 & 0 & 5 & 39 & 28 & 9 & 0 & 15 & 36 & 1,282 \\
\hline Fuel oil & 0 & 93 & 54 & 0 & 0 & 3 & 2 & 5 & 192 & 0 & 8 & 4 & 0 \\
\hline Gasoline & 0 & 0 & 0 & 0 & 0 & 0 & 0 & 0 & 0 & 0 & 0 & 0 & 713 \\
\hline LPG & 2 & 0 & 5 & 0 & 0 & 0 & 0 & 1 & 18 & 0 & 0 & 5 & 0 \\
\hline Kerosene & 0 & 0 & 0 & 0 & 0 & 0 & 0 & 0 & 0 & 0 & 0 & 0 & 40 \\
\hline Electricity & 87 & 43 & 98 & 3 & 6 & 0 & 14 & 28 & 63 & 3 & 110 & 133 & 0 \\
\hline Charcoal & 0 & 0 & 0 & 0 & 0 & 8 & 0 & 0 & 0 & 0 & 0 & 0 & 0 \\
\hline Ethanol & 0 & 0 & 0 & 0 & 0 & 0 & 0 & 0 & 0 & 0 & 0 & 0 & 435 \\
\hline Other sec oil & 0 & 0 & 0 & 0 & 0 & 0 & 0 & 0 & 45 & 0 & 0 & 0 & 0 \\
\hline Total & 323 & 168 & 737 & 3 & 18 & 3,572 & 57 & 71 & 364 & 3 & 2,365 & 180 & 3,427 \\
\hline Total (PJ) & 13.5 & 7.0 & 30.8 & 0.1 & 0.8 & 149.5 & 2.4 & 3.0 & 15.2 & 0.1 & 99.0 & 7.5 & 143.5 \\
\hline
\end{tabular}

Note: ${ }^{1}$ Economy sectors from Table 3. ${ }^{2}$ Since there is no manufacture of coke in the state of Goiás, firewood production was allocated into the Biofuels sector. Similarly, since there is no oil refining in the state, sugarcane products were also allocated into the Oil refining, coke end ethanol sector. That is the reason why this sector has been called only by Biofuels sector.

Conversion factors: 1 toe $=41.87 \times 10^{9} \mathrm{~J} ; 1 \mathrm{PJ}=1 \times 10^{15} \mathrm{~J}$.

Source: BRAZIL (2010) and MME (2016, 2017).

Table 10. Goiás' energy-use structure in 2008, in PJ.

\begin{tabular}{lr}
\hline Economy sectors & Energy use $(P J)$ \\
\hline Agricultural & 13.5 \\
Industrial processes & 208.9 \\
Mining & 7.0 \\
Food, beverages and tobacco & 30.8 \\
Textile, clothes and shoes & 0.1 \\
Wood, paper and printing & 0.8 \\
Biofuels & 149.5 \\
Chemical and pharmaceutical products & 2.4 \\
Other industries & 3.0 \\
Cement, construction and other non-metallic minerals & 15.2 \\
Metallurgy & 0.1 \\
Power sector & 99.0 \\
Transport sector & 143.5 \\
Services / Commercial & 7.5 \\
\hline
\end{tabular}

Source: BRAZIL (2010) and MME (2016, 2017). 
All the energy-use presented in the table above was applied as an energy-use input vector in the Goiás' hybrid IO model (Appendix VI). Ethanol and gasoline forecasts demand for the state of Goiás were used to create future ethanol supply scenarios, aiming to analyse future environmental impacts from changes in ethanol demand (sub-section $4.2)$.

\subsubsection{GHG emissions data}

GHG emissions for Brazil and Goiás State were obtained from the Brazilian National GHG Inventory (BRASIL, 2016), the National Emissions Record System SIRENE (SIRENE, 2017) and the Emission Estimating System for GHG - SEEG (SEEG, 2017) (Appendices XVI and XVII). After analysing the available data sources, data from SEEG (2017) was considered the best source which suits the purpose of this study, by making available the GHG emissions from the state of Goiás for all the economy sectors covered here. All direct land-use (DLUC) GHG emissions were accounted into the Agricultural sector due to the origin of the emissions (i.e. land-use change, liming and forestry residues). Indirect land-use change (ILUC) GHG emissions ${ }^{12}$ were not included in the modelling exercise due to data constraints regarding the state of Goiás for the year 2008. However, ILUC GHG emissions were estimated for the additional land required by each scenario (analysed in the results of this paper, section 4.3.2) aiming to identify ILUC GHG emissions from replacing pasturelands for sugarcane crops and, considering the cattle may be induced to move towards Brazilian forests. Additionally, due to its importance in a country such as Brazil, LUC issues were considered in this thesis's discussions and conclusion.

A summary of the GHG emissions identified for the state of Goiás in 2008 is presented next (Table 11). All the estimated GHG emissions were used as a GHG emissions output vector in the Goiás' hybrid IO model (Appendix VI).

\footnotetext{
${ }^{12}$ According to Chapter 11: Agriculture, Forestry and Other Land Use (AFOLU) of IPCC $5^{\text {th }}$ Assessment Report (2014), indirect land-use change is difficult to ascertain because the magnitude of these effects must be modelled raising important questions about model validity and uncertainty and policy implications. Available model-based studies have consistently found positive and, in some cases, high emissions from LUC and ILUC, mostly of first-generation biofuels, albeit with high variability and uncertainty in results (HERTEL et al., 2010; TAHERIPOUR et al., 2011; DUMORTIER et al., 2011; HAVLÍK et al., 2011; TIMILSINA et al., 2012; WARNER et al., 2014). However, as ILUC GHG emissions represent a significant source of emissions in Brazil, these issues will be better addressed in the results of this paper, taking into account the study case for the state of Goiás.
} 
Table 11. Goiás' GHG emissions, in 2008 (in $\mathrm{TgCO}_{2 e}$ GWP-AR5).

Economy sectors

GHG Emissions

Agricultural

89.4023

Industrial processes

4.6892

Mining

0.1894

Food, beverages and tobacco

0.5908

Textile, clothes and shoes

0.0005

Wood, paper and printing

0.0256

Biofuels

0.1540

Chemical and pharmaceutical products

0.0665

Other industries

2.4583

Cement, construction and other non-metallic minerals

0.4392

Metallurgy

0.7649

0.0736

Power sector

5.9243

Transport sector 0.0679

Services / Commercial

$\mathbf{1 0 0 . 1 5 7 3}$

Total

Note: Emissions from the Agricultural sector (41.6740 $\mathrm{TgCO}_{2 e}$ ) were added to all the emissions from land-use change in the state (47.7283 $\left.\mathrm{TgCO}_{2 e}\right)$.

Source: SEEG (2017).

With such information and by applying IO concepts, it is possible to estimate future changes related to GHG emissions, water, energy and land use, value added and job creation, when the final demand in any sector of the economy increases by a monetary unit (in this case, 1 million US\$). Therefore, the IO model helps analysing future scenarios regarding changes for ethanol demand and how it could impact the use of inputs and outputs production throughout the economy, by applying an integrated analysis considering water, energy, land and emissions as targets for a given policy goal. 


\section{Case Study}

\subsection{Sugarcane industry and environmental concerns in Brazil}

Brazil holds the greatest potential for further agricultural expansion in the $21^{\text {st }}$ century (FAO, 2012). Understanding recent LUC patterns and visualizing a sustainable land-use pathway in Brazil have become highly strategic, given that regional and global climate change, food and energy provision, and biodiversity conservation are all at stake (LAPOLA et al., 2014).

In a national context, sugarcane crops expansion verified since the seventies has apparently caused low impacts on deforestation and biodiversity loss (LA ROVERE et al., 2011). According to the Brazilian Sugarcane Industry Association - UNICA (UNICA, 2017), Brazil's 2014/2015 sugarcane planted area amounted to 103,000 km². This represents about $14 \%$ of total cultivated area in the country, $5 \%$ of pasturelands, $3 \%$ of all agricultural properties and only 1\% of Brazil's total area (IBGE, 2017, 2017a). In the last 30 years, sugarcane crops expansion was concentrated in the Centre-South of Brazil and distant from the Amazon, the Pantanal and the Atlantic forest biomes, which represents, along with the Cerrado, the main Brazilian ecosystems (LA ROVERE et al., 2011). However, agricultural activities have expanded mostly over the Cerrado biome in the last 40 years, resulting in extensive land-cover transformations and significant changes to the water cycle (HUNKE et al., 2015; SPERA et al., 2016).

Over $80 \%$ of the expansion in cropland in Brazil from 1990 to 2011 occurred in the Amazon and Cerrado regions (IBGE, 2012) and currently, agriculture covers about half of Cerrado's original extent (IBGE, 2012; LAPOLA et al., 2014). Cattle ranching is also by far the dominant land-use, but a fraction of these pastures has been replaced recently by advancing large-scale mechanized cropping of soybean and sugarcane (IBGE, 2012, MARTINELLI and FILOSO, 2008; WALTER et al., 2011). In fact, the Cerrado is Brazil's most important beef producing region, hosting the largest extent of pasturelands and about $50 \%$ of the national herd (Figure 17a). The pronounced conversion of the Cerrado into soybean monoculture over the past two decades was one of the main contributors to the expansion in total cropland area in Brazil (Figure 17b). 

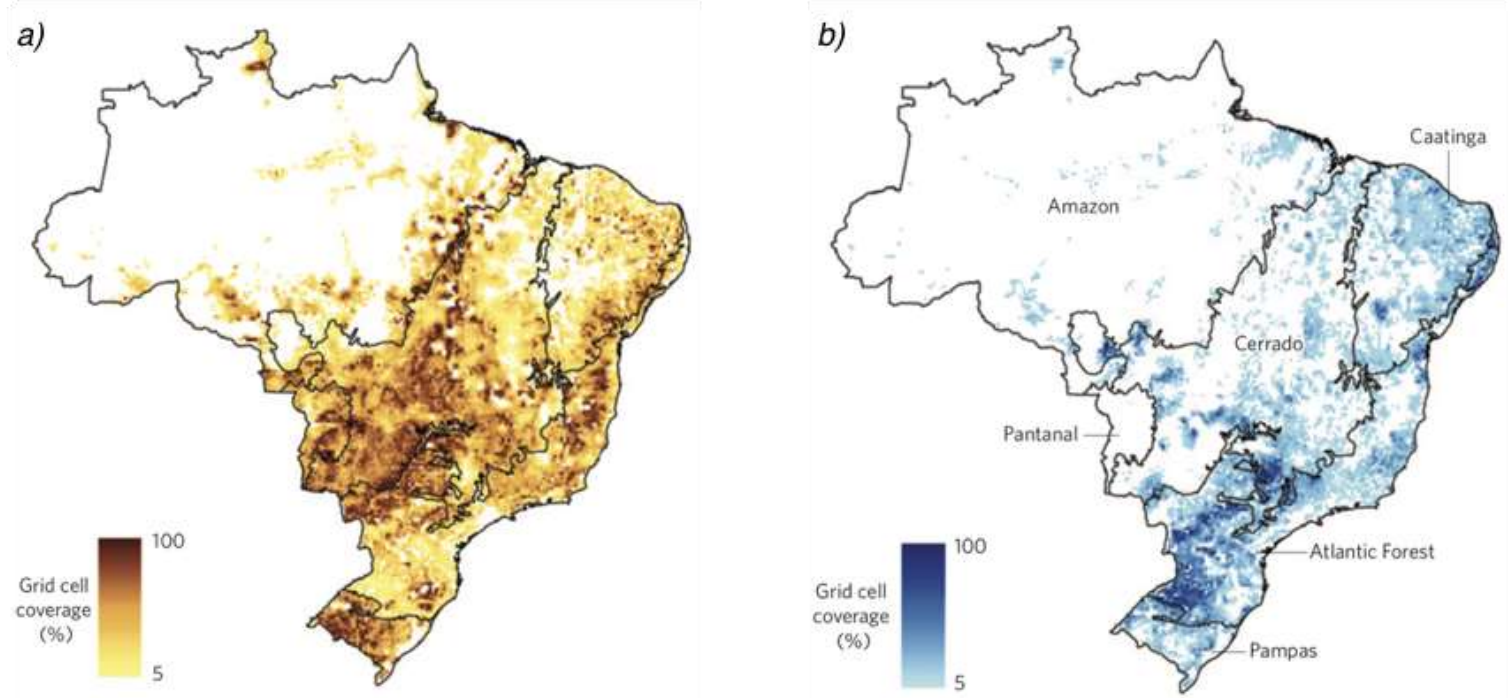

Figure 17: Spatial distribution of agricultural activities in Brazilian biomes in 2000. a) Livestock production, $b$ ) Croplands.

Source: LAPOLA et al., 2014.

Thus, the high suitability of the Cerrado topography and soils for mechanized agriculture, the reduced number and total extent of protected areas (SPAROVEK et al., 2010), the lack of a well-established and routinized deforestation surveillance program, and potential leakage pressure resulting from declining deforestation in Amazonia all indicate that the Cerrado will continue to be a principal region of LUC in Brazil (NEPSTAD, et al., 2009; LAPOLA et al., 2011, 2014; NOOJIPADY et al., 2017).

With regards to sugarcane crops, the Brazilian Sugarcane Agro-ecological Zoning $^{13}$ (ZAE Cana) indicates the Centre-West region as the one with the largest total of suitable areas for sugarcane expansion (MANZATTO et al., 2009). On the one hand, the Brazilian Cerrado represents about $10 \%$ of the total area of tropical savannahs in the world and is one of the world's biodiversity hotspots (SPERA et al., 2016), despite the small number and total extent of protected areas (Figure 18a) (LAPOLA, et al., 2014). Besides its large biodiversity, the Cerrado shows the worst deforestation record in the last 15 years in Brazil (i.e. 236,000 km²), even more than Amazonian forests (i.e. 208,000 $\mathrm{km}^{2}$ ) (Figure 18b) (REIS et al., 2017; MMA, 2018 ${ }^{14}$ ). Only in 2015, the Cerrado lost about $9,400 \mathrm{~km}^{2}$ of native forests, $52 \%$ higher than the Amazon for the same year,

\footnotetext{
${ }^{13}$ Presidential decree n. 6.961, enacted in the $17^{\text {th }}$ of September 2009, "Approves the sugarcane agroecological zoning and it determines to the National Monetary Council the establishment of financing operation norms for the sugarcane industry, under the terms of the zoning”. Presidential decree available at: http://www.planalto.gov.br/ccivil_03/_ato2007-2010/2009/decreto/d6961.htm.

${ }_{14}$ Brazilian Ministry of Environment, Deforestation Prevention and Control. Federal Deforestation Prevention and Control Plan, available at: http://combateaodesmatamento.mma.gov.br.
} 
obviously raising concerns about conservation efforts in the biome (MMA, 2018). Therefore, land-use in the region (also but not only by sugarcane) should be based on sustainable practices regarding biodiversity, water resources, and soil preservation, maximizing, on the other hand, economic and social gains.

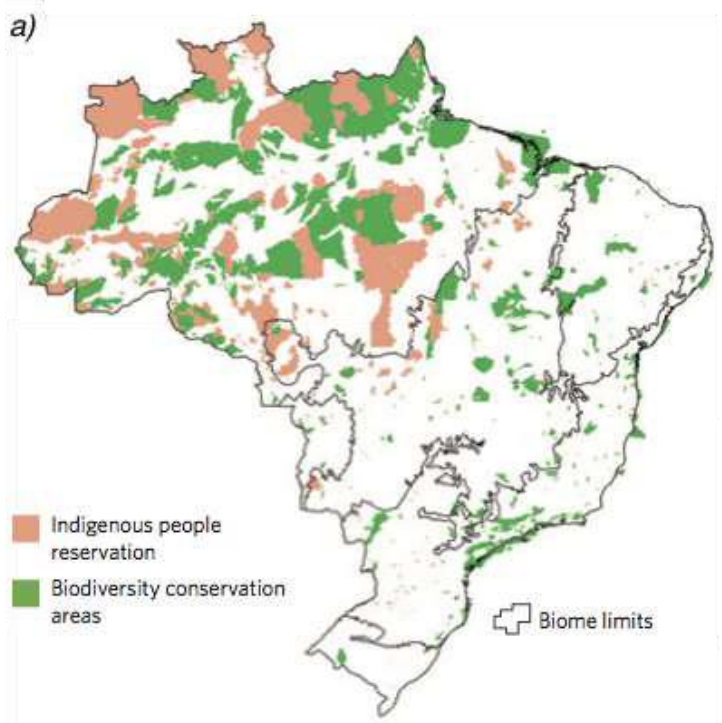

b)

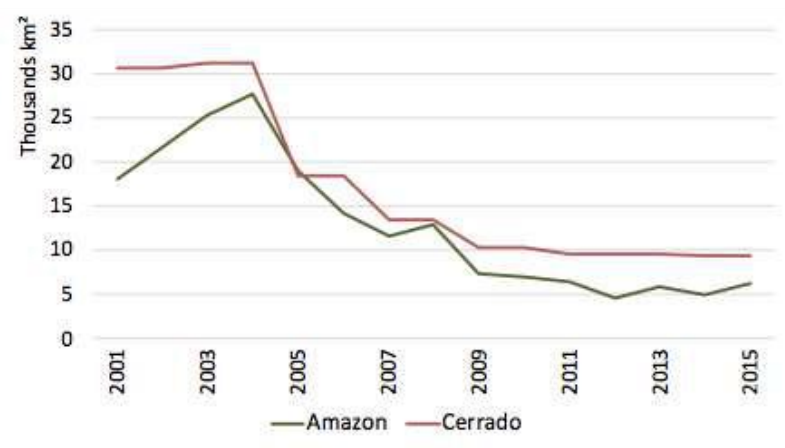

Figure 18: Protected areas and deforestation in Brazil. a) Protected areas in Brazilian biomes. b) Deforestation in Cerrado and Amazon between 2001-2015, in $\mathrm{km}^{2}$. Source: a) LAPOLA et al., 2014, b) MMA (2018).

As a measure to control unsustainable ways of producing sugarcane, the Brazilian government created the ZAE Cana to protect environmentally sensitive areas and the native vegetation, besides guiding the sugarcane expansion in the country. Overall, the zoning promotes the sugarcane sustainable development and it constrains the expansion of sugarcane crops and the licensing of ethanol mills towards biomes such as the Amazon and the Pantanal.

The ZAE Cana consists in a comprehensive product from renowned Brazilian institutes and researchers and its main goal is to determine suitable areas for large-scale sugarcane growing in the country. Also, it represents an incipient initiative towards the formulation of biofuel policies in Brazil by providing technical support to the sustainable sugarcane production and expansion. In this regard, the ZAE Cana focuses on sugarcane production under rain-fed conditions by analysing the chemical, physical and mineralogical characteristics of the soils, relating them to the sugarcane crop's requirements. The development of the ZAE Cana has also considered indicators such as land vulnerability, climate risk, the potential for sustainable agricultural production and 
environmental regulations, aiming to determine suitable areas (MANZATTO et al., 2009). These areas were classified according to their potential for sugarcane growing (i.e., low, medium and high) and to their current land-use (i.e., Ap: Pasture; Ac: Agriculture; Ag: Agriculture and pasture) (Table 12).

Table 12. Suitable areas for sugarcane expansion in Brazil, by agricultural potential and land-use, in 2008.

\begin{tabular}{llrrrr}
\hline \multirow{2}{*}{ Site } & Potential & \multicolumn{4}{c}{ Suitable areas by land-use $\left(\right.$ in $^{\left.\mathrm{km}^{2}\right)}$} \\
\cline { 3 - 6 } & & $\begin{array}{c}\text { Pastureland } \\
(\text { Ap })\end{array}$ & $\begin{array}{c}\text { Agriculture } \\
(\text { Ac })\end{array}$ & $\begin{array}{r}\text { Agricultural } \\
(A g)\end{array}$ & Ap+Ac+Ag \\
\hline Goiás & High $(H)$ & 7,832 & 2,208 & 0 & 10,040 \\
& Medium $(M)$ & 69,985 & 45,980 & 0 & 115,965 \\
& $H+M$ & 77,817 & 48,188 & 0 & $\mathbf{1 2 6 , 0 0 5}$ \\
Centre-West & $H$ & 62,093 & 10,368 & 0 & 72,461 \\
& $M$ & 104,021 & 104,713 & 0 & 208,734 \\
& $H+M$ & 166,114 & 115,081 & 0 & $\mathbf{2 8 1 , 1 9 5}$ \\
Brazil & $H$ & 113,023 & 73,603 & 6,008 & 192,634 \\
& $M$ & 228,639 & 164,967 & 21,264 & 414,870 \\
& $H+M$ & 341,662 & 238,570 & 27,272 & $\mathbf{6 0 7 , 5 0 4}$ \\
\hline
\end{tabular}

Note: Low potential areas were excluded because we consider that the use of low-quality land may induce vicious cycles, as already mentioned (Figure 8). In short, the total low-quality land represented 21,649 $\mathrm{km}^{2}$ and 42,555 $\mathrm{km}^{2}$, in the Centre-West region and in Brazil, respectively. There was no data for low-quality land for the state of Goiás.

Source: Adapted from MANZATTO et al., (2009).

According to the ZAE Cana, only $82 \%$ of Goiás' suitable areas would be able to support the 2015 total sugarcane planted area, i.e., 103,000 km². Also, both the high and medium potential suitable areas in the state of Goiás represent $45 \%$ of Centre-West's region high and medium potential suitable areas and $21 \%$ of Brazil's. Additionally, the Centre-West region accounts for $46 \%$ of the whole country's suitable areas for growing sugarcane crops. However, these data must be carefully analysed, since the ZAE Cana also covers the area already occupied by sugarcane crops in 2008, which makes difficult to analyse the real amount of suitable areas available and whether sugarcane crops expansion would impact food crops. On the other hand, about half of suitable areas (either medium or high potential) are currently used as pasturelands, indicating opportunities to higher cattle densification and growing sugarcane in old or idle pasturelands. For instance, the Brazilian state of Rondônia shows higher densification rates (i.e. between 1.23 to 3 cattle heads/ha) when compared to the Brazilian average (i.e. about 1 cattle 
head/ha ${ }^{15}$ ) (SOARES-FILHO et al., 2009; CSR, 2018), therefore, the intensification of livestock production with the objective of freeing up space for both regular and flex-crops is the most likely outcome to happen in the coming years in the country.

However, this is not that simple since even considering the potential for cattle densification this pasturelands replacement for sugarcane crops may also cause ILUC negative impacts. As previously mentioned in the section about the "Brazilian New Forest Code" and its implications for the reduction of protected areas in Brazilian biomes (section 2.3), the state of Goiás shows a deficit of Legal Reserves that amounts to about $7,500 \mathrm{~km}^{2}$ of forest to be recovered, especially in its South-Western section (SOARESFILHO et al., 2013) and another 16,300 $\mathrm{km}^{2}$ are projected to be deforested in the coming years in the state (YOUNG et al., 2016). Overall, there is a significant shortage of Legal Reserve surplus in certain parts of the country, especially in regions where there is a significant expansion of agricultural activities, such as the state of Goiás. Therefore, we cannot ensure that there will not be deforestation and competition between sugarcane and food crops in the state, for example, from just analysing the ZAE Cana maps and estimates. The total suitable areas in Goiás amounted to $126,000 \mathrm{~km}^{2}$, of which $62 \%$ was used by livestock production and the remaining 38\%, by agricultural activities, in 2008 (Figure 19).

The "Agribusiness Outlook in Brazil, 2015/16 to 2025/26", elaborated by the Ministry of Agriculture - MAPA (MAPA, 2016), estimates an expansion of 19,000 km² of sugarcane crops in the country by $2026,8,000 \mathrm{~km}^{2}$ of which in the Centre-West region. The states of Mato Grosso do Sul (45.6\%) and Goiás (34.3\%) are projected to present the highest growth rates regarding sugarcane planted area, which confirms the sector's tendency in expanding near traditional producing areas (see Figures 1 and 20). However, the Brazilian Cerrado is typified by water shortage periods and watersheds with economic, social and environmental conflicts related to multiple water uses. Thus, the expansion of sugarcane crops towards Centre-West region may trigger a water constraint on ethanol production.

\footnotetext{
${ }^{15}$ The area unit $\mathrm{km}^{2}$ is used throughout this paper. However, to facilitate understanding, the indicator cattle heads $/ \mathrm{km}^{2}$ was replaced by cattle heads/ha because the latter is easier to imagine and measure. That is, 0.01 $\mathrm{km}^{2}=1$ hectare (ha), therefore, 0.03 cattle heads $/ \mathrm{km}^{2}$ is equal to 3 cattle heads $/$ ha.
} 


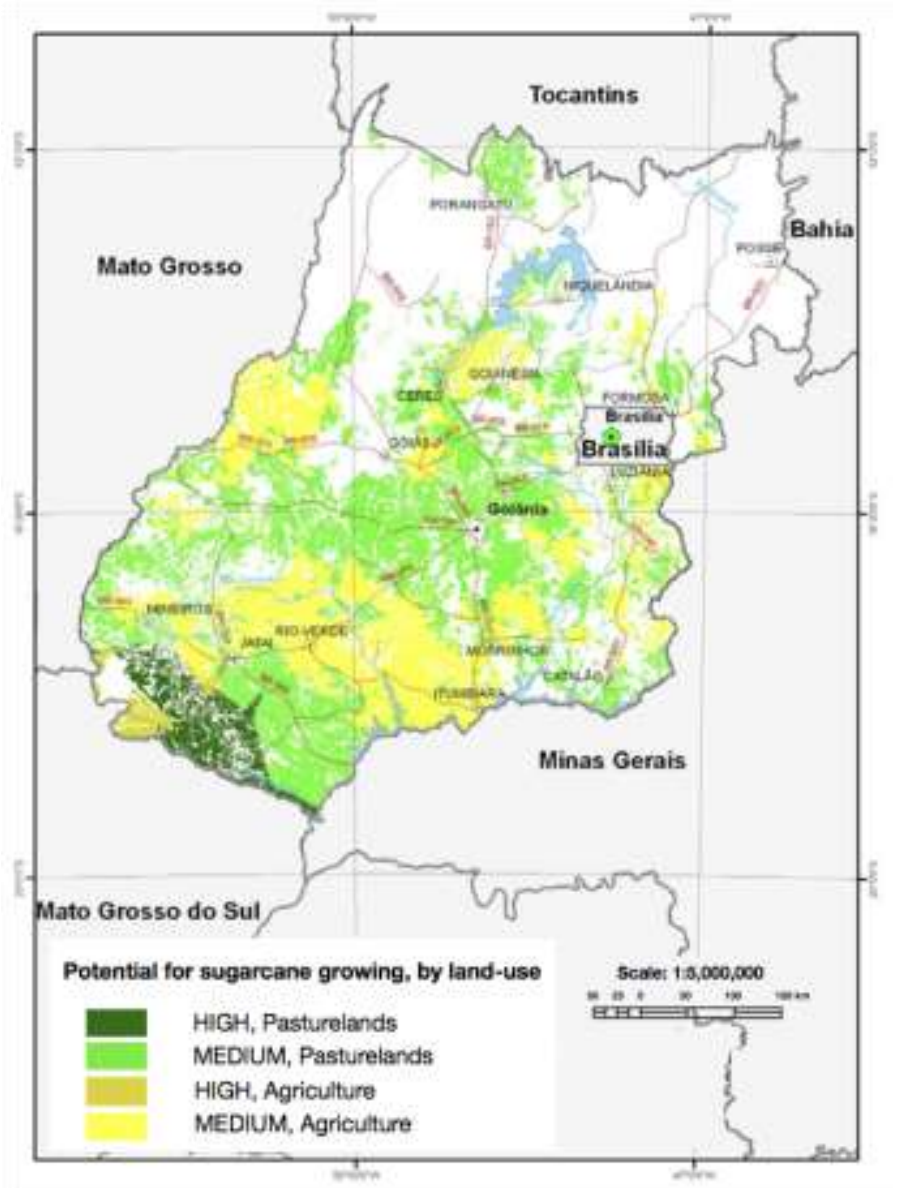

Figure 19. Goiás' Sugarcane Agro-ecological Zoning. Suitable areas for sugarcane expansion, by land-use in 2008.

Source: Adapted from MANZATTO et al. (2009).

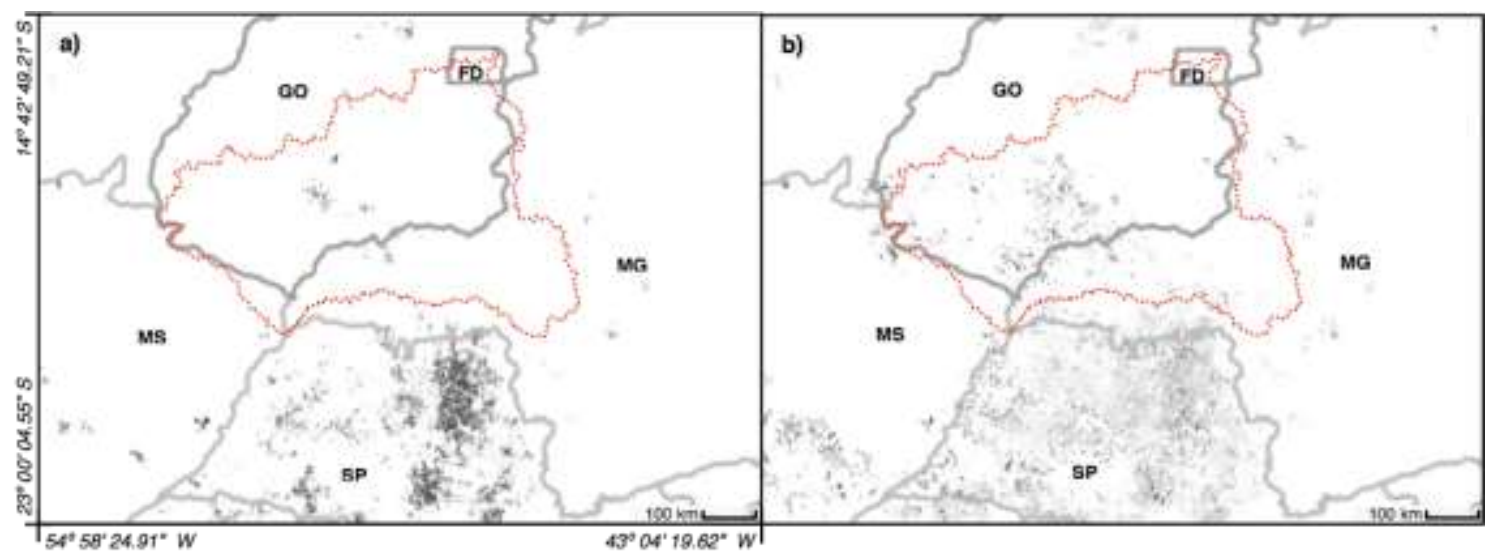

Figure 20. Crop area in Centre-South region of Brazil, highlighting the Paranaíba basin (dotted) and the states of São Paulo (SP) and Goiás (GO) in a) 2003 and b) 2011. Note: Different grey scales represent different crop growth stages, unimportant to the current analysis.

Source: Author's elaboration from INPE (2013). 
While São Paulo State has shown less available areas for expansion, sugarcane area in Goiás State soared 18\%, twice the Centre-West region's growth rate (Table 13 and Figure 20). Also, Goiás' sugarcane accounts for about half the entire Centre-West's sugarcane area and production.

Table 13. Sugarcane crop area and outputs in Brazil.

\begin{tabular}{lcccccc}
\hline \multirow{2}{*}{ Site } & \multicolumn{3}{c}{ Crop area $\left(\mathrm{km}^{2}\right)$} & \multicolumn{3}{c}{ Output (million $\mathrm{t})$} \\
\cline { 2 - 7 } & 2013 & 2014 & $(\%)$ & 2013 & 2014 & $(\%)$ \\
\hline Brazil & 102,230 & 106,457 & 4.1 & 588.48 & 651.29 & 10.7 \\
São Paulo State & 54,150 & 54,174 & 0.0 & 329.92 & 367.45 & 11.4 \\
Centre-West region & 17,864 & 19,479 & 9.0 & 106.38 & 120.50 & 13.3 \\
Goiás State & 8,605 & 10,183 & 18.3 & 52.73 & 62.02 & 17.6 \\
\hline
\end{tabular}

Source: Author's elaboration from UNICA (2017) and IBGE (2017).

Currently, sugarcane crops have been covering about $9,600 \mathrm{~km}^{2}$ in the state of Goiás, with an output of 67.6 million tonnes of sugarcane, resulting in 2.1 million tonnes of sugar and about $4.4 \mathrm{hm}^{3}$ of ethanol (UNICA, 2017; CONAB, 2017). The growth rate of sugarcane planted area in the state accounted for a massive growth of $416 \%$ from 2000 to 2010 and for $170 \%$, from 2010 to 2015 , emphasizing the tendency of sugarcane expansion towards that region (Figure 21).

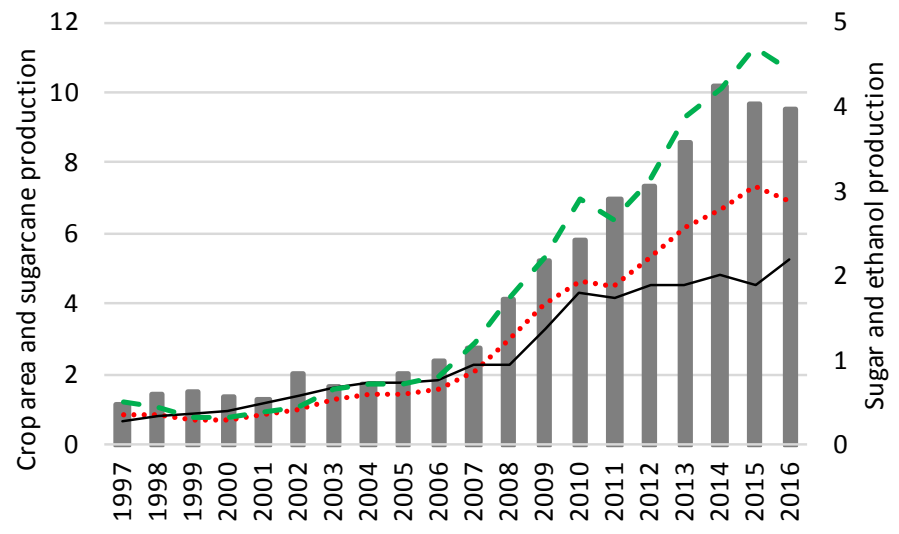

Figure 21. Crop area (columns) ${ }^{\mathrm{a}}$ and sugarcane (dotted line) ${ }^{\mathrm{b}}$, sugar (black line) ${ }^{\mathrm{c}}$ and ethanol (dashed line) ${ }^{\mathrm{d}}$ production in Goiás State. Note: ${ }^{a}$ in $10^{3} \mathrm{~km}^{2} ;{ }^{b}$ in 10 million $t ;{ }^{c}$ in million $t$; and ${ }^{d}$ in $\mathrm{hm}^{3}$. Source: Author's elaboration from UNICA (2017) and CONAB (2017).

Therefore, as one of the leading states in sugarcane expansion, this work focuses on the Goiás State (Figures 1 and 20), situated in Brazil's Centre-West region. The state embraces an important river basin from both an energy and agricultural point of view, i.e. 
Paranaíba basin, which was used here as proxy to determine the impacts on land and water resources. The Paranaíba basin covers about $220,000 \mathrm{~km}^{2}$ in this region (Figures 22 and 23), of which $141,000 \mathrm{~km}^{2}$ in the state of Goiás (63\%), and the remaining $80,000 \mathrm{~km}^{2}$ divided into the states of Minas Gerais (32\%), Mato Grosso do Sul (3.5\%) and the Federal District (1.5\%) (ANA, 2015).

Current land use in the basin shows the predominance of livestock (35\%) and agriculture (34\%), with emphasis on soybeans, corn and sugarcane. The basin still has about $25 \%$ of native vegetation coverage, mainly located at the Northeast section of the basin, according to estimates from the National Water Agency - ANA (ANA, 2015).

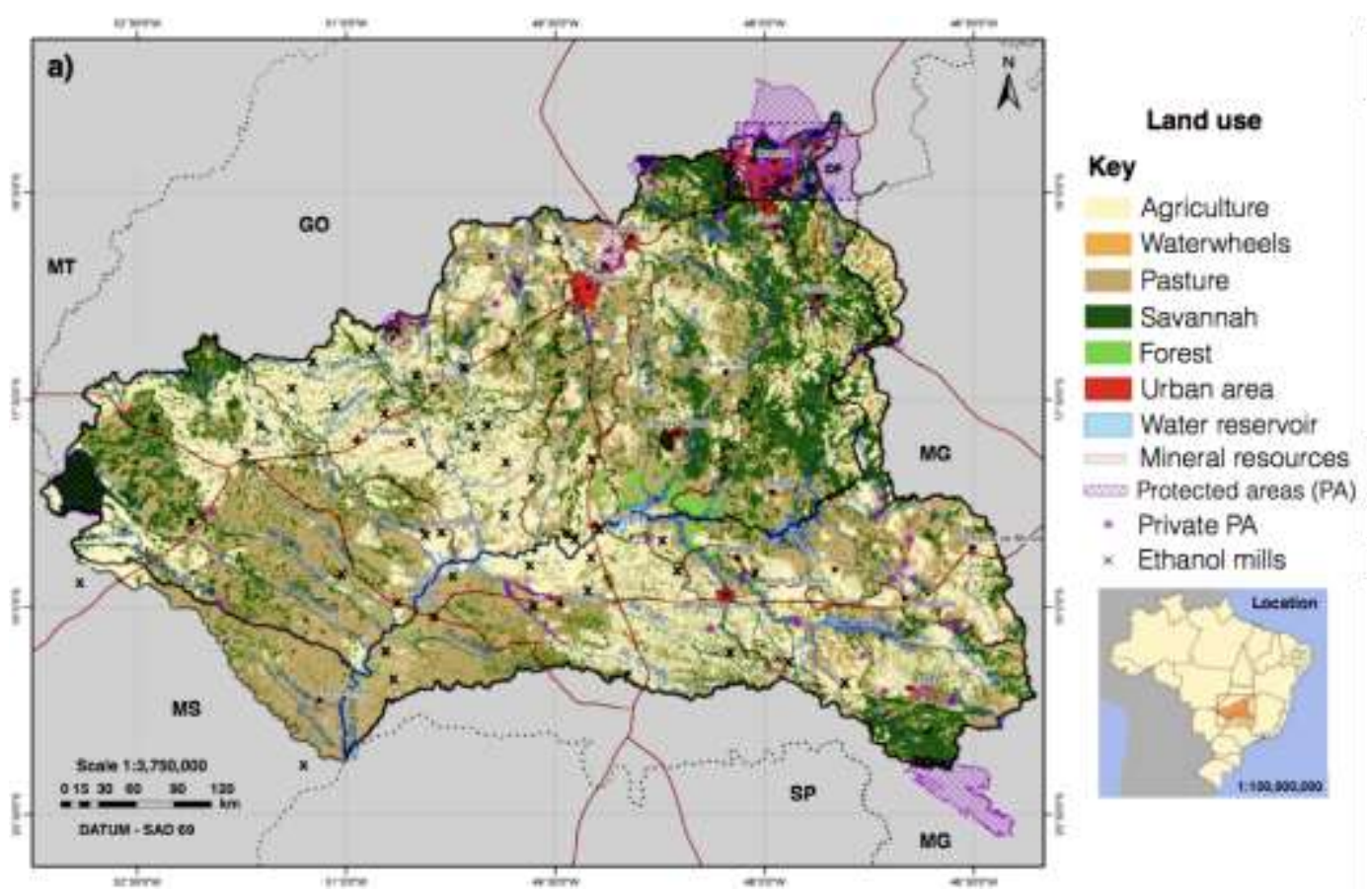

Figure 22. Geographical limits of the Paranaíba basin and its land-use. Source: Adapted from ANA (2015).

The activities developed in the Paranaíba basin result in growing water demand for consumptive uses, $89.5 \%$ of which for irrigation. Moreover, most industrial water demand $(3.5 \%)$ comes from agribusiness, specifically the sugarcane industry (ANA, 2015). The basin has been undergoing rapid agricultural expansion, with sugarcane replacing pasturelands, corn and soybean crops. Irrigated sugarcane has expanded 2,300 $\mathrm{km}^{2}$ since 2010; overall, irrigated area in the basin rose from $2,100 \mathrm{~km}^{2}$ in 1995 to 6,100 $\mathrm{km}^{2}$ in 2010 , virtually tripling the area in 15 years (ANA, 2015). However, as previously mentioned, most of the irrigated sugarcane in the region is the so-called salvage irrigation 
which corresponds to the application of vinasse in the soil. Conversely, although about $3,800 \mathrm{~km}^{2}$ of irrigated sugarcane crops were identified in Goiás in 2016 through analysing recent geospatial images, the National Water Agency - ANA - states that the water used in irrigated sugarcane is relatively unknown (ANA, 2017).

It is noteworthy mentioning that the National Water Resource Plan (NWRP), a Federal Law enacted in 1997 (BRASIL, 1997), reinforces that water resources management should be decentralized and include the participation of the government, users and local communities. The NWRP determines the River Basin Plans (RBP) which must be implemented by the ANA and approved by the River Basin Committees. The River Basin Committees, composed by representatives from government, civil society and water users, are considered the basis of a participatory and integrated water management, and have a deliberative role. Thus, the RBP set out data regarding water quality, priority uses, water availability and demand, etc. According to the Paranaíba's RBP (ANA, 2015), the basin is divided into 10 Water Management Units - WMU (Figure 23).

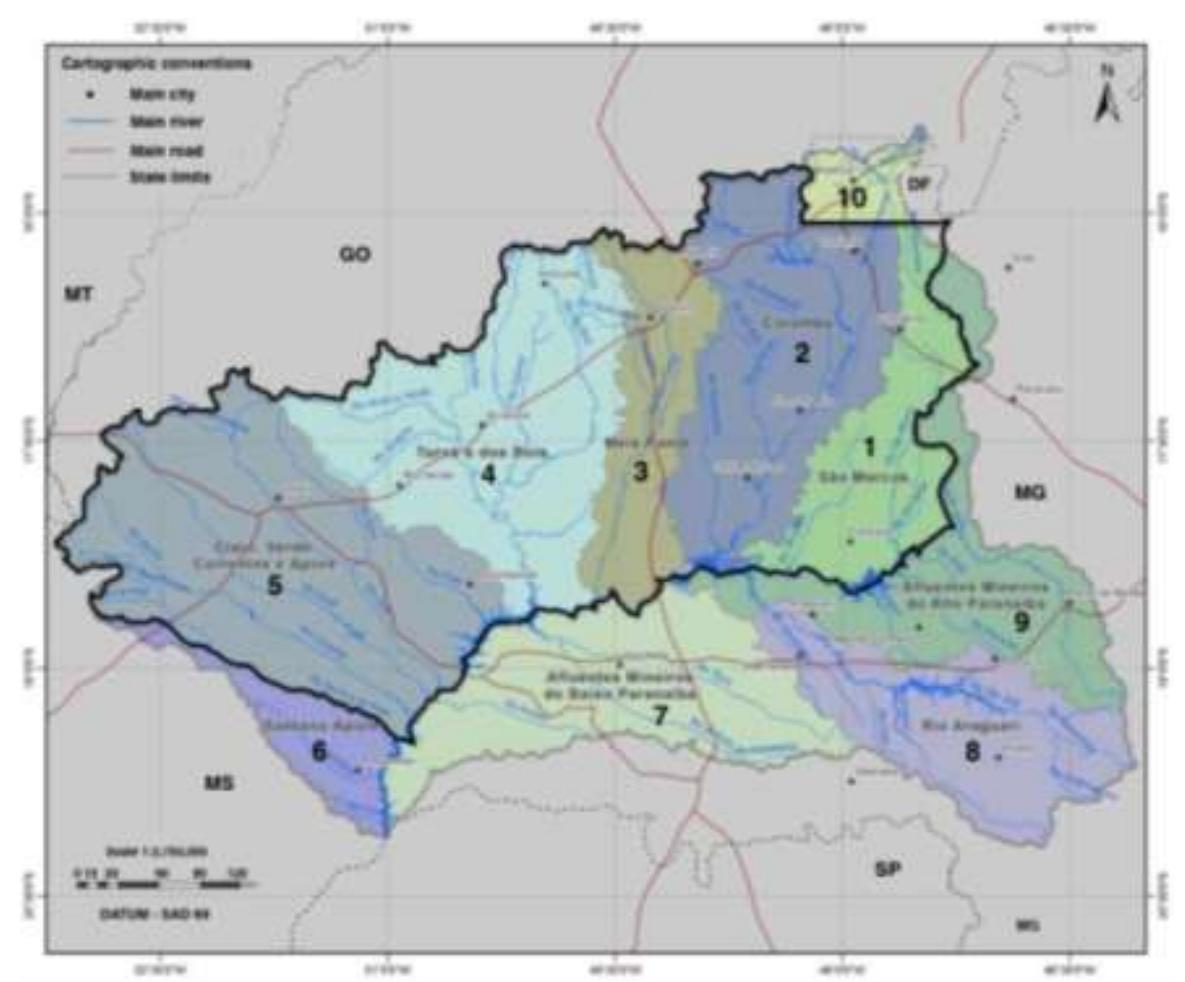

Figure 23. Paranaíba's basin Water Management Units.

Note: Highlighted, the WMU located into the state of Goiás (1 - São Marcos; 2 - Corumbá; 3 Meia Ponte; 4 - Turvo-Bois; 5 - Claro, Verde, Correntes and Aporé).

Source: Adapted from ANA (2015). 
By crossing the data from the ZAE Cana (Figure 19), the land-use in the Paranaíba basin (Figure 22) and the Goiás' WMU location (Figure 23) we can observe that the areas recommended to sugarcane production and expansion are exactly those where sugarcane has already been cultivated in the Goiás State (Figure 24). Additionally, those areas are the same areas indicated by the CANASAT monitoring project (INPE, 2013) (Figure 20).

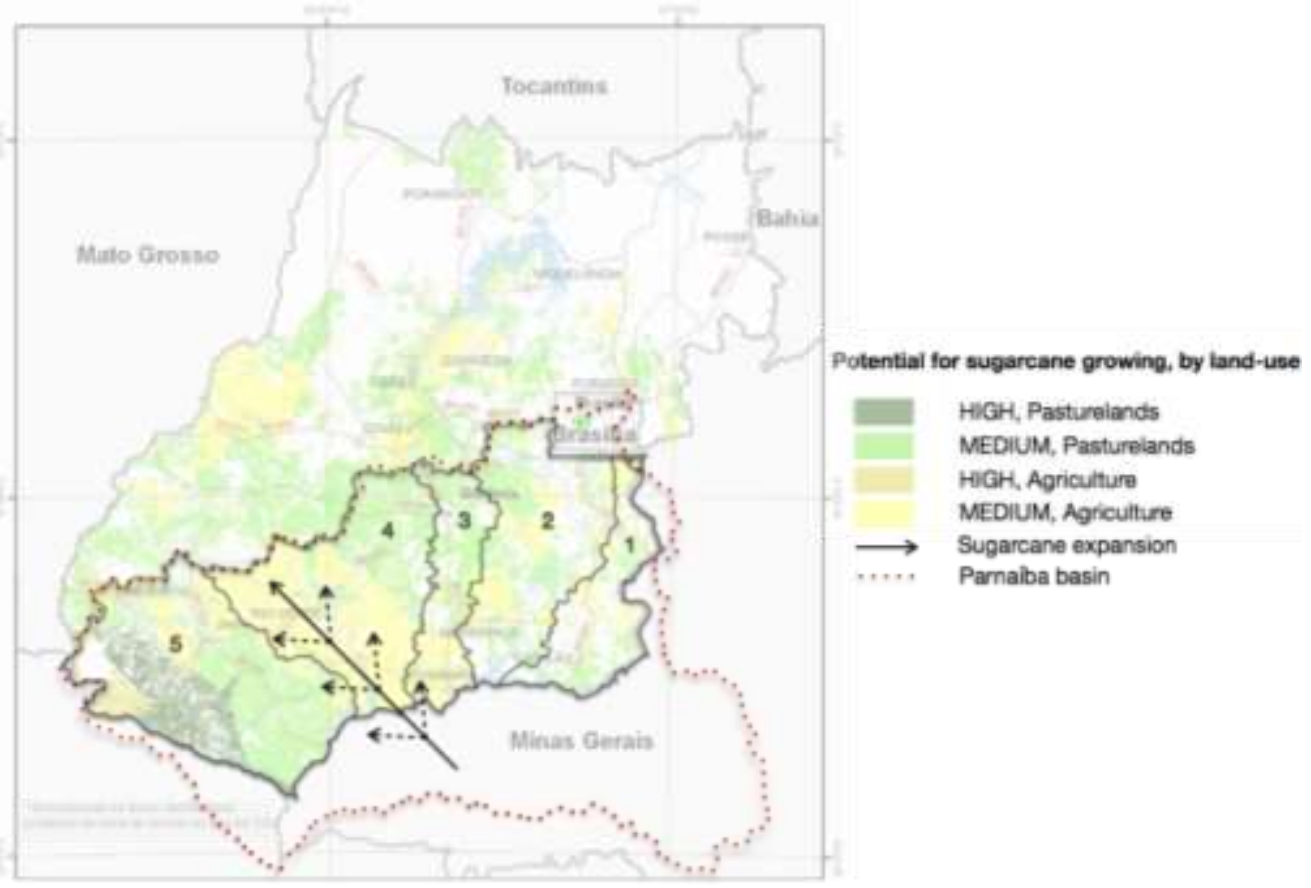

Figure 24. Paranaíba's basin WMU location versus sugarcane agro-ecological zoning. Note: The Paranaiba's River Basin Plan has also pointed out that the region indicated by the arrows has been shown intensification of irrigation practices.

Source: Author's elaboration from MANZATTO et al. (2009) and ANA (2015).

Therefore, besides the water-use analysis for the whole Paranaíba basin, it is important to verify the water availability in each WMU. In this context, it was considered the water availability and demand from WMUs where sugarcane expansion has taken place more intensively, namely, Meia Ponte WMU (3), Turvo-Bois WMU (4), Claro, Verde, Correntes and Aporé WMU (5) and Lower Paranaíba Minas Tributaries WMU (7). Despite the latter WMU being located outside of Goiás' State boundaries (WMU \#7 in Figure 23), this WMU was also considered in the analysis regarding water availability as a sugarcane expansion constraint. According to ANA (2015), the water availability at the mouth of the Paranaíba river is $1,252 \mathrm{~m}^{3} / \mathrm{s}$ for the reference flow $Q_{95 \%}$ and $626 \mathrm{~m}^{3} / \mathrm{s}$ for the flow used for granting of rights to the use of water resources adopted by the state 
of Goiás, i.e., $50 \% Q_{95 \%}$. It should be noted higher water availability in Claro, Verde, Correntes and Aporé WMU and lower water availability in Meia Ponte and São Marcos WMU (Table 14).

Table 14. Surface water availability, water withdrawals and water balance in the Paranaíba basin, by Water Management Unit.

\begin{tabular}{|c|c|c|c|c|c|}
\hline \multirow{3}{*}{ Water Management Units (WMU) } & \multirow{2}{*}{$\begin{array}{l}S W A^{a} \\
Q_{95 \%}\end{array}$} & \multirow{2}{*}{$\begin{array}{c}S W A^{b} \\
50 \% Q_{95 \%}\end{array}$} & \multirow{2}{*}{$\begin{aligned} & W W^{c} \\
+ & W W S^{d}\end{aligned}$} & \multicolumn{2}{|c|}{ Water Balance $e^{f}$} \\
\hline & & & & $\begin{array}{c}W W+W W S \\
Q_{95 \%}\end{array}$ & $\begin{array}{c}W W+W W S \\
50 \% Q_{95 \%}\end{array}$ \\
\hline & $m^{3} / s$ & $m^{3} / s$ & $m^{3} / s$ & $\%$ & $\%$ \\
\hline Paranaíba basin & $1,251.7$ & 625.85 & 364.95 & 29 & 58 \\
\hline São $\operatorname{Marcos}^{e}$ & 75.30 & 37.65 & 30.70 & 41 & 82 \\
\hline Meia Ponte & 62.79 & 31.39 & 33.68 & 54 & 107 \\
\hline Turvo-Bois & 162.19 & 81.09 & 60.22 & 37 & 74 \\
\hline Claro, Verde, Correntes and Aporé & 377.03 & 188.52 & 25.32 & 7 & 13 \\
\hline Lower Paranaíba Minas Tributaries & 104.52 & 52.26 & 30.44 & 29 & 58 \\
\hline
\end{tabular}

Note: ${ }^{a}$ Surface water availability, reference flow $Q_{95 \%}$ : the flow with $95 \%$ probability of occurrence;

${ }^{b}$ Surface water availability, reference flow $50 \%$ Q $Q_{95 \%}$ : the flow used for granting of rights to the use of water resources adopted by the state of Goiás;

${ }^{c} W W$ : Water withdrawals minus water withdrawals for sugarcane irrigation, presented in ANA (2015);

${ }^{d}$ WWS: Water withdrawals for sugarcane destined for ethanol production, calculated by FACHINELLI and PEREIRA (2015).

${ }^{e}$ There is no data on irrigated sugarcane in the São Marcos WMU. Thus, it was applied the total water withdrawal in the WMU, estimated by ANA (2015).

${ }^{f}$ Quantitative impairment indicators (I)

$\begin{array}{cccc}I<50 \% & 50 \%<I<80 \% & 80 \%<I<100 \% & >100 \% \\ \text { (Normal) } & \text { (Alert) } & \text { (Moderately critical) } & \text { (Highly critical) }\end{array}$

Source: Author's elaboration from SEMARH (2012), ANA (2015) and FACHINELLI and PEREIRA (2015).

Again, by crossing the data from the location of current sugarcane production and the forecasted expansion we can verify that sugarcane crops have been occupying mainly Turvo-Bois (4) and Meia Ponte (3) WMU and a smaller section of the Claro, Verde, Correntes and Aporé (5) WMU. Since the Meia Ponte WMU has shown the lowest water availability, it would be important considering this WMU as the lowest limit regarding the water availability for irrigated sugarcane expansion in the region. Additionally, according to the quantitative impairment indicators, the Meia Ponte WMU showed an alert situation in the reference flow $Q_{95}$ and a highly critical condition when considering the flow used for granting rights to water use, i.e., $50 \% Q_{95 \%}$. Similarly, Turvo-Bois and Lower Paranaiba Minas Tributaries WMU were also identified as alert condition when considering the reference flow 50\% $Q_{95 \%}$, as well as the Paranaíba basin as a whole. 
In this context, the water availability in each WMU mentioned above should be further analysed, when considering the water requirements by the Goiás' hybrid IO model in estimating future ethanol demand and supply in the region. The limitation here regards to spatial data distribution in the IO model, since we do not know exactly where the IO table data are geographically located. Then, even indicating the Meia Ponte WMU as the lowest limit regarding water availability in the region we could not perform an analysis on this specific WMU because we cannot indicate the share of this WMU from the Goiás' IO economic and environmental data. In this context, when analysing all the WMU of the Paranaíba basin we can determine the water availability in the region (and its limits), considering the flow used for granting rights to water use, i.e., 50\% $Q_{95 \%}$ (Table 15). Converting the water flow rate (given in $\mathrm{m}^{3} / \mathrm{s}$ ) to an annual basis allows for comparisons between the water available in the basin and the water requirements determined by the Goiás' hybrid IO model, and hence, it helps to determine water-use limits in the region.

Table 15. Surface water availability for granting rights to water use, water withdrawal and annual surface water availability in the Paranaíba basin, by WMU.

\begin{tabular}{|c|c|c|c|c|}
\hline Water Management Units (WMU) & $\begin{array}{c}S W A^{a} \\
50 \% Q_{95 \%}\end{array}$ & $\begin{aligned} & W W^{b} \\
+ & W W S^{c}\end{aligned}$ & $\begin{array}{c}S W A- \\
(W W+W W S)\end{array}$ & $\begin{array}{c}\text { Annual } \\
\text { SWA }\end{array}$ \\
\hline & $m^{3} / s$ & $m^{3} / s$ & $m^{3} / s$ & $h m^{3}$ \\
\hline Paranaíba basin $^{d}$ & 625.85 & 364.95 & 164.37 & 5,183 \\
\hline São $\operatorname{Marcos}^{e}$ & 37.65 & 30.70 & 6.95 & 219 \\
\hline Meia Ponte & 31.39 & 33.68 & $(2.29)$ & (72) \\
\hline Turvo-Bois & 81.09 & 60.22 & 20.87 & 658 \\
\hline Claro, Verde, Correntes and Aporé & 188.52 & 25.32 & 163.20 & 5,146 \\
\hline Lower Paranaíba Minas Tributaries & 52.26 & 30.44 & 21.82 & 688 \\
\hline
\end{tabular}

Note: ${ }^{a}$ Surface water availability, reference flow $50 \% Q_{95 \%}$ : the flow used for granting of rights to the use of water resources adopted by the State of Goiás;

${ }^{b} W W$ : Water withdrawals minus water withdrawals for sugarcane irrigation, presented in ANA (2015);

${ }^{c}$ WWS: Water withdrawals for sugarcane destined for ethanol production, calculated by FACHINELLI and PEREIRA (2015).

${ }^{d}$ The subtraction result was multiplied by $63 \%$ since this is the share of Paranaíba basin in the state of Goiás.

${ }^{e}$ There is no data on irrigated sugarcane in the São Marcos WMU. Thus, it was applied the total water withdrawals in the WMU, estimated by ANA (2015).

It can be observed from the table above that Claro Verde, Correntes and Aporé WMU alone accounts for $30 \%$ of total surface water availability in the section of the Paranaíba basin located into Goiás' territory, before deducting water withdrawals. After subtracting water withdrawals from each WMU, the Claro Verde, Correntes and Aporé WMU has shown $5,146 \mathrm{hm}^{3}$ of water availability (annually), against $5,183 \mathrm{hm}^{3}$ for the whole Paranaíba basin (again, considering only the section of the basin into the Goiás 
State, i.e., 63\%). It can be explained due to both high water availability and low water withdrawals in the mentioned WMU, which corroborates to high livestock production and low agriculture footprint. On the other hand, the remaining WMU which compose the Paranaíba basin indicators have shown lower water availability and higher water withdrawals. In other words, $99 \%$ of the water availability (after discounting the total water withdrawals) in the section of the basin located into the Goiás State comes from the Claro Verde, Correntes and Aporé WMU. These water availability indicators will be used as water-use limits to be considered when analysing the water requirements by the Goiás' hybrid IO model in estimating future ethanol demand and supply in the region.

Despite this issue being discussed further, it is noteworthy mentioning that sugarcane production is pressing the water availability in specific WMU and hence, its expansion should be better addressed focusing on preserving local water resources.

From the energy standpoint, there are 20 hydropower stations in Goiás with 4.8 GW total capacity plus 309 MW from small hydroelectric plants - SHP (ANEEL, 2017), which were omitted from this study (Figure 25). Also, there are 163 hydropower plants in planning stage, totalizing 3.2 GW (ANA, 2015) (Figure 26).

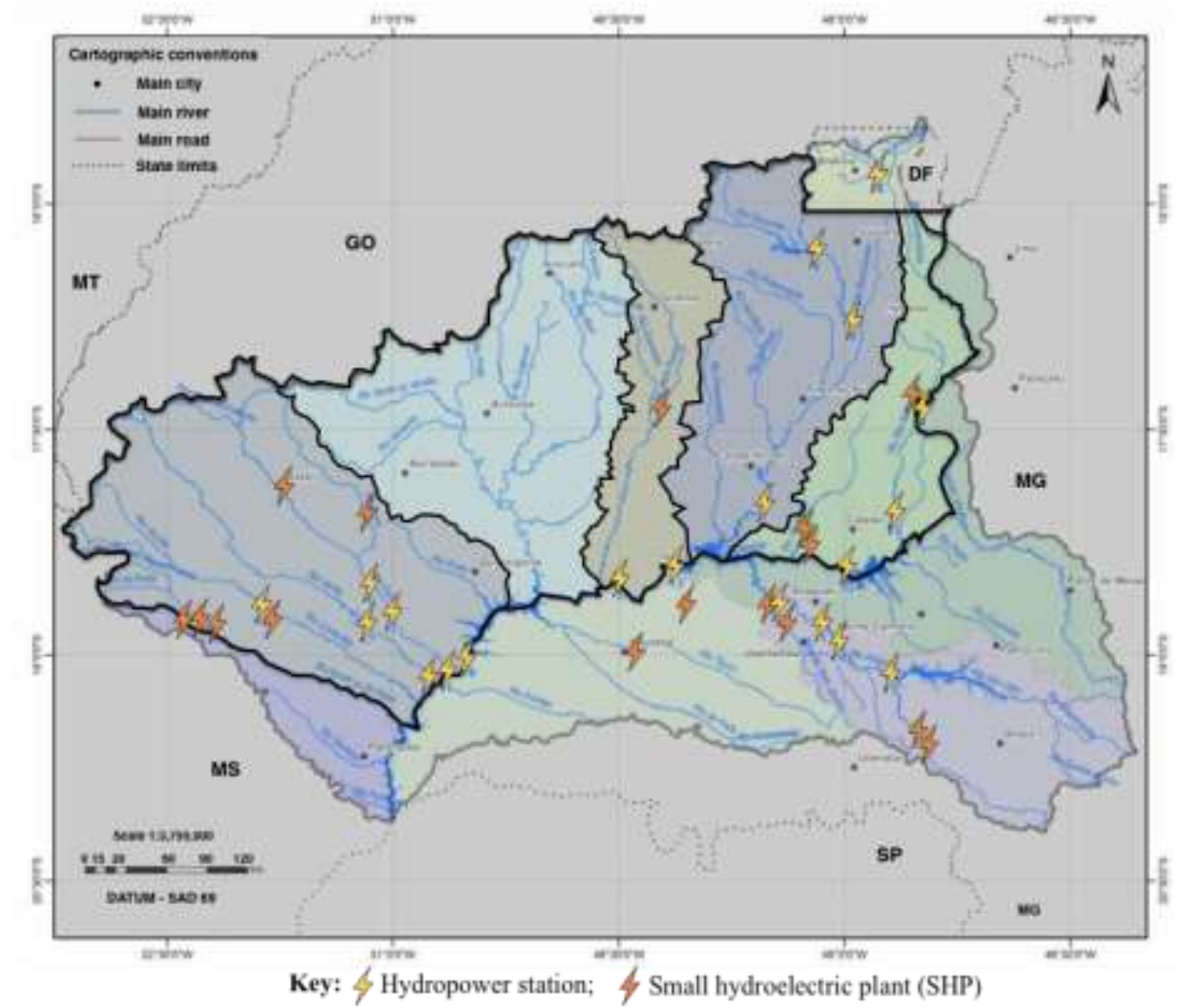

Figure 25. Operating hydropower plants and SHP.

Note: Highlighted, the Paranaíba basin section located into state of Goiás. Source: Adapted from ANA (2015). 


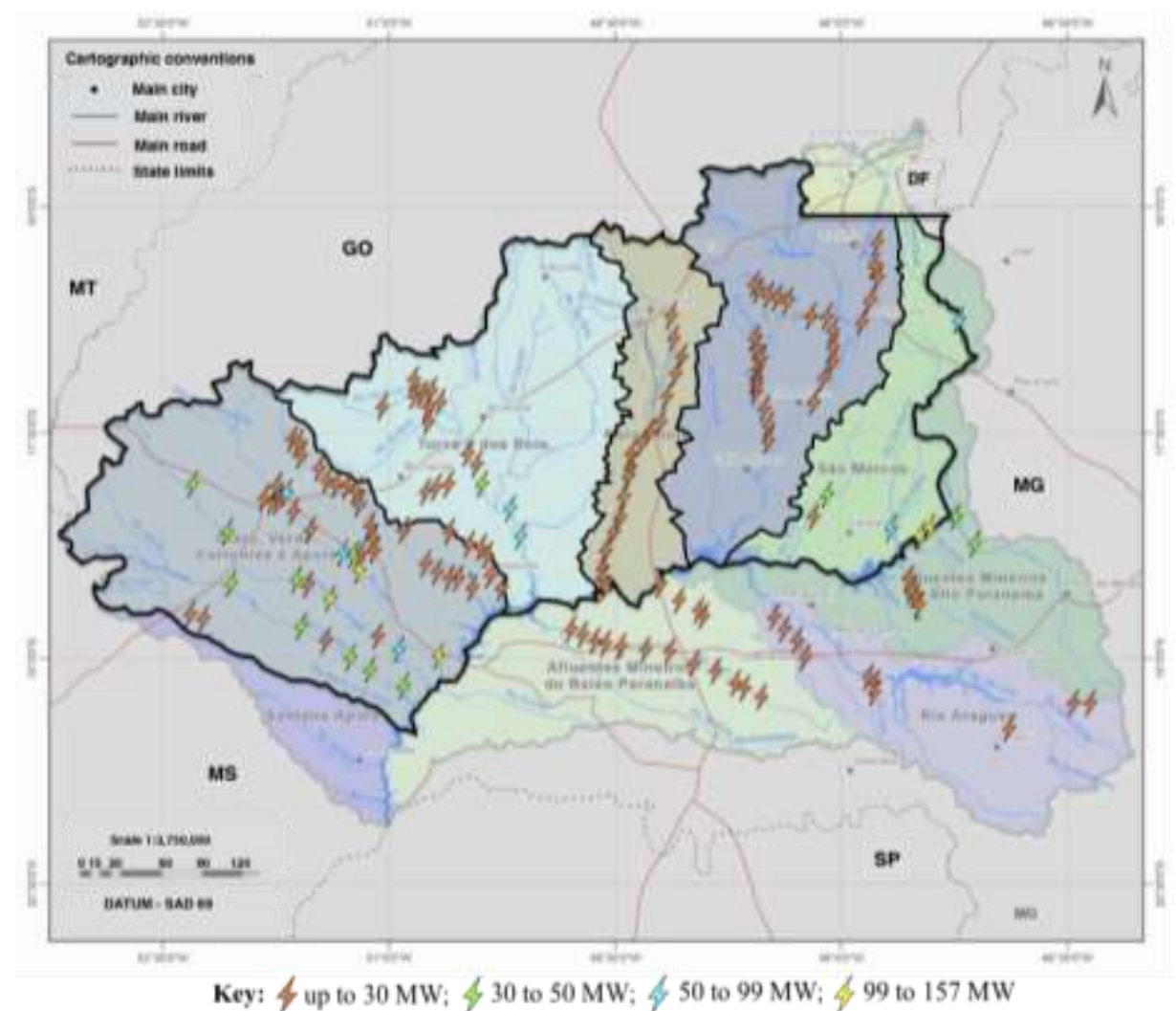

Figure 26. Hydropower plants and SHP in planning stage.

Source: Adapted from ANA (2015).

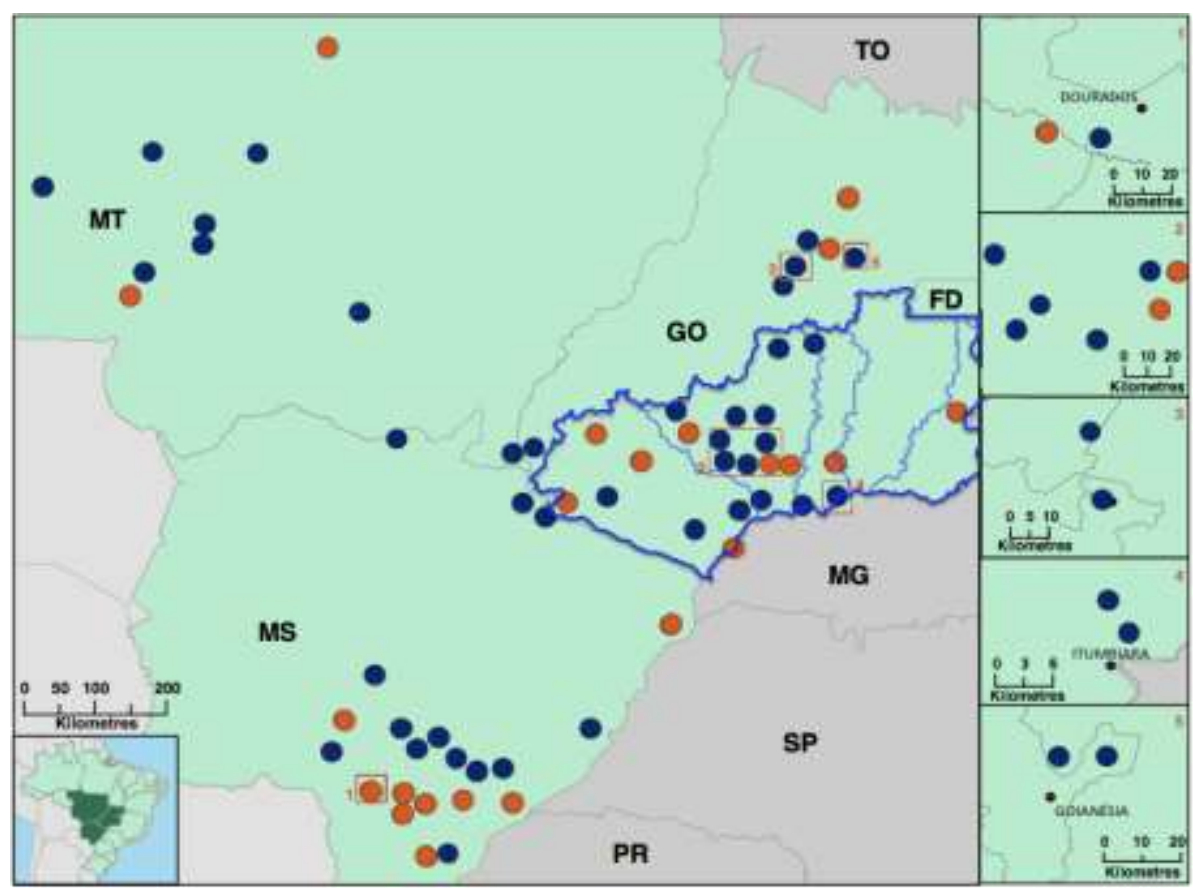

Figure 27. Centre-West ethanol producers' location.

Note: Orange circles: hydrous ethanol plants; Blue circles: Hydrous and anhydrous ethanol plants. Total: 70 plants; GO: 37 (53\%); MS: 23 (33\%) and; MT: 10 (14\%). Highlighted in blue, the Paranaíba's basin WMU located in Goiás State.

Source: Adapted from ANP (2017). 
In Brazil, sugarcane bagasse, i.e. a by-product, is used to co-generate electricity in ethanol mills. As stated by the Ministry of Energy and Mines (MME, 2016), hydropower generation accounted for $81 \%$ of the total electricity supply in 2015 in Goiás, i.e. $28,468 \mathrm{GWh}$, while sugarcane by-products represented $15 \%$. Additionally, Goiás is the nation's second largest ethanol producer with 37 mills (Figure 27), which produced $4.72 \mathrm{hm}^{3}$ of fuel in 2015 (an 11\% increase over 2014) (UNICA, 2017; ANP, 2017).

When excluding LUC GHG emissions from the analysis, Goiás main economic activities contribute little to GHG emissions, as renewable sources are predominant in the power grid. In 2016, the highest emissions have occurred in the Agricultural sector, accounting for $71.97 \mathrm{TgCO}_{2 \mathrm{e}}$, i.e. $83 \%$, followed by the Transport, i.e. $8.39 \mathrm{TgCO}_{2 \mathrm{e}}$, and Industry, i.e. $6.02 \mathrm{TgCO}_{2 \mathrm{e}}$, with little contribution from Services, i.e. $0.7 \mathrm{TgCO}_{2 \mathrm{e}}$ and Power sector (Figure 28) (SEEG, 2017). It is noteworthy observing the role of Agricultural sector in Goiás' GHG total emissions, accounting for about 8-fold higher than Transport sector's emissions.

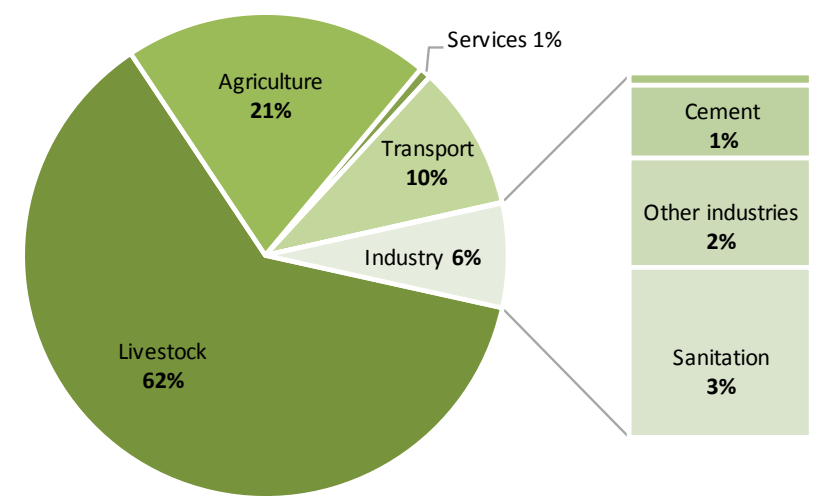

Figure 28. GHG emissions in the state of Goiás, by sector, in 2016.

Note: Emissions from the Power sector and the activity "Metallurgy" were insignificant, i.e. 0.06 $\mathrm{TgCO}_{2 e}$ and $0.2 \mathrm{TgCO}_{2 e}$, respectively. In this graph, Sanitation $\left(2.8 \mathrm{TgCO}_{2 e}\right)$ was included into the Industry sector, according to the Goiás' aggregated IO table.

Source: Author's elaboration from SEEG (2017).

Overall, the state accounted for $3.82 \%$ (i.e. $87.1 \mathrm{TgCO}_{2 \mathrm{e}}$ ) of gross national GHG emissions in 2016, i.e. $2,278 \mathrm{TgCO}_{2 \mathrm{e}}$, being the $11^{\text {th }}$ highest Brazilian emitter state. The leading Brazilian GHG emitter is the state of Pará (280.4 $\left.\mathrm{TgCO}_{2 \mathrm{e}}\right)$, accounting for $12.3 \%$ of gross national emissions, most due to land-use change and deforestation practices (SEEG, 2017). 
However, when considering major categories, such as GHG emissions from Agricultural, Land-use, Energy, Waste and Industrial processes, the share of emissions may differ and most of the GHG emissions from land-use in the state, i.e. $24.45 \mathrm{TgCO}_{2 \mathrm{e}}$, comes from LUC (i.e. 85\%) (Figure 29). Regarding the Agricultural category, i.e. 47.09 $\mathrm{TgCO}_{2 \mathrm{e}}$, the higher emitter activity is Enteric fermentation with $69 \%$ share, i.e. 32.2 $\mathrm{TgCO}_{2 \mathrm{e}}(\mathrm{SEEG}, 2017)$.

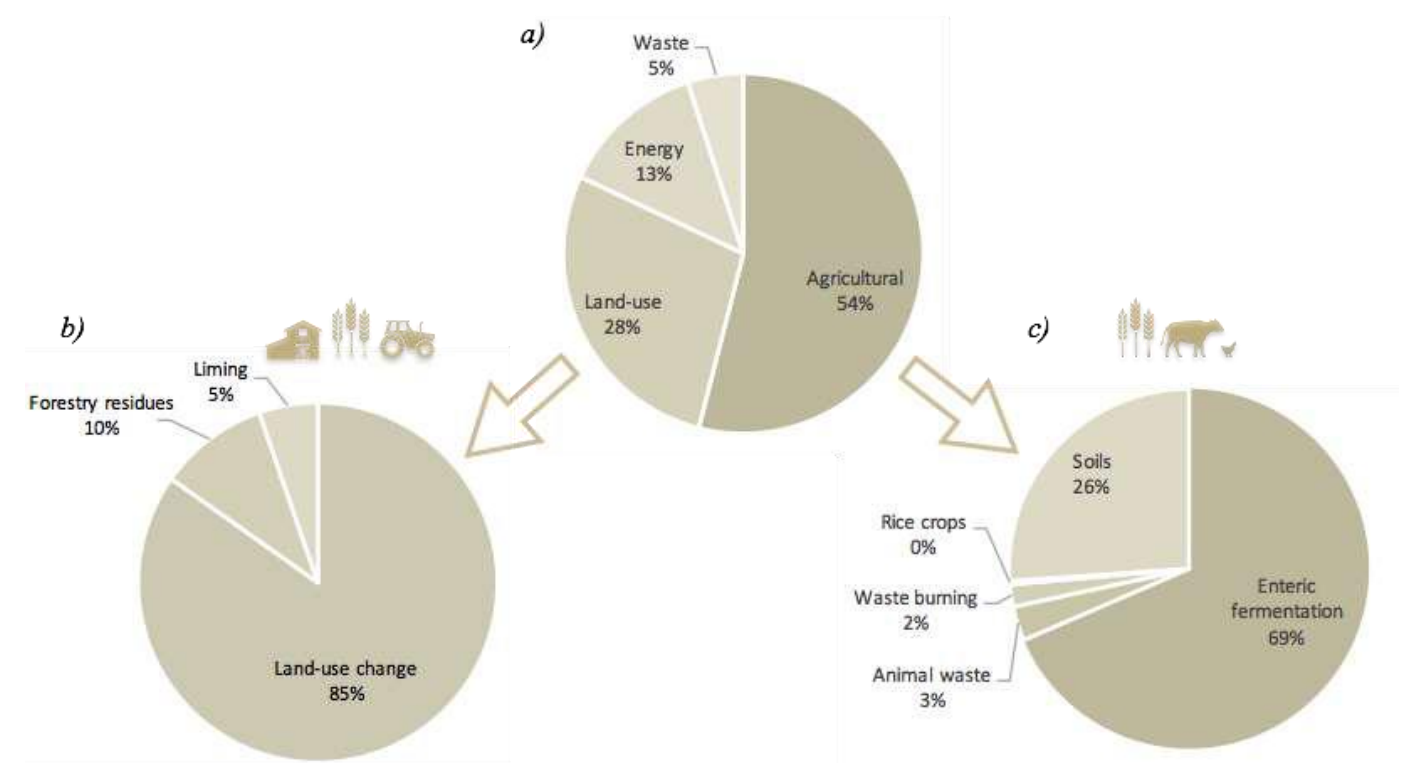

Figure 29. Share of GHG emissions in Goiás State in 2016, by $a$ ) major categories, $b$ ) land-use and $c$ ) agricultural activities.

Source: SEEG (2017).

\subsection{Ethanol policy scenarios}

Scenarios can be useful to explore strategic questions, to review policies and investment decisions, and to create common ground and improved understanding of the interrelations between water, energy and food resources. They present plausible evolutions from the current situation, depending on how major driving forces develop and interact, and they help to assess the implications of specific decisions (FAO, 2014).

Our analysis uses the 2008 IO table for the Goiás economy as a baseline for making comparisons with a set of policy scenarios which will be briefly described next. As stated, this thesis' aim is to analyse both the environmental impacts of sugarcane expansion on Paranaíba basin and its consequences on Goiás' economy. In addition, it will be estimated the environmental constraints on sugarcane expansion in the region. 
As previously mentioned, sugarcane crops have steadily grown in recent times, mainly because of ethanol demand by flex-fuel vehicles, but also because of growing worldwide sugar demand. The Brazilian Energy Research Centre (EPE, 2017) has elaborated three different scenarios for ethanol supply in Brazil to 2030, i.e. expansion by $12.4 \mathrm{hm}^{3}$ in the low supply scenario; $18.2 \mathrm{hm}^{3}$ in the intermediate and $23.5 \mathrm{hm}^{3}$ in the high supply scenario. Overall, the forecasts for each scenario represent, in 2030, $43 \mathrm{hm}^{3}$, $49 \mathrm{hm}^{3}$ and $54 \mathrm{hm}^{3}$ of ethanol, respectively in the low, intermediate and high supply scenarios. Since the current study focuses on the environmental impacts from changes in ethanol production, we have selected the EPE high supply scenario, i.e. $54 \mathrm{hm}^{3}$ of ethanol, as reference when estimating our prospective ethanol scenarios.

As mentioned, Brazil has about $334,000 \mathrm{~m}^{3} /$ day of ethanol installed capacity and Goiás accounts for $14 \%$. This share of overall domestic installed capacity was used as a proxy to determine future ethanol that could be supplied by the state. Brazil produces both anhydrous ethanol (gasoline additive) and hydrous (employed mainly in flex-fuel engines, up to E100). Anhydrous ethanol must have less than $0.4 \%$ water content, while hydrated ethanol has between 4 to $4.9 \%$ water content; therefore, their lower heating values (LHV) differ. According to the Ministry of Energy and Mines (MME, 2017), Brazilian anhydrous ethanol has a LHV $=22.36 \mathrm{GJ} / \mathrm{m}^{3}$, whereas hydrated ethanol's LHV $=21.35 \mathrm{GJ} / \mathrm{m}^{3}$.

Historically, domestic ethanol to gasoline price ratio has varied according to the vagaries of politics. Therefore, we shall consider that, for the period up to 2030, the proportion between anhydrous and hydrated ethanol production in Brazil, in general, and Goiás State will remain the same as the national average observed between 2008 and 2015, namely: 36.7\% anhydrous and 63.3\% hydrated (ANP, 2016). Thus, an average ethanol $\mathrm{LHV}=21.72 \mathrm{GJ} / \mathrm{m}^{3}$ has been employed in the following calculations. Since most governmental scenarios are expressed in energy terms, a weighed LHV value is necessary to derive the projected ethanol volume.

Goiás produced $4.72 \mathrm{hm}^{3}$ of $1 \mathrm{G}$ ethanol in 2015 , i.e. $102.5 \mathrm{PJ}$, of which $2.97 \mathrm{hm}^{3}$ were exported to other states, i.e. $64.48 \mathrm{PJ}$, while consuming $1.75 \mathrm{hm}^{3}$, i.e. $38.01 \mathrm{PJ}$, showing an exporter profile (MME, 2016). The following scenarios were considered to analyse the impacts of different ethanol policies promoting sugarcane expansion towards the Brazilian Cerrado. Additionally, the higher ethanol supply scenario from EPE was applied aiming to determine the worst-case scenario in terms of environmental impacts 
in the region. Since the state of Goiás does not produce any gasoline, we have considered four different scenarios in order to estimate the gradual gasoline substitution for ethanol, i.e. $0 \% ; 25 \% ; 50 \%$ and; $100 \%$ of estimated future gasoline demand in the state.

Scenario 1 - Meeting ethanol demand by 2030

Considering the higher supply scenario of $54 \mathrm{hm}^{3}$ of ethanol (EPE, 2017), Goiás should produce $7.56 \mathrm{hm}^{3}$ of ethanol to meet 2030 demand, assuming the state keeps its $14 \%$ share of Brazil's installed capacity throughout the period. Since Goiás produced 4.72 $\mathrm{hm}^{3}$ of ethanol in 2015, i.e. 102.5 PJ (UNICA, 2017; MME, 2016), sugarcane crops should provide an additional $2.84 \mathrm{hm}^{3}$, i.e. $61.68 \mathrm{PJ}$, to meet the required $7.56 \mathrm{hm}^{3}$ by 2030. This future demand might be met in two different ways:

a) By cutting ethanol exports to other states and;

b) By maintaining current (and future) exports to other states, while adding the future $2.84 \mathrm{hm}^{3}$ of ethanol demand, totalling $7.56 \mathrm{hm}^{3}$ (or $164.2 \mathrm{PJ}$ )

\section{Scenario 2 - Substituting Goiás State's gasoline consumption}

According to the Ministry of Energy and Mines (MME, 2016) and the National Agency of Petroleum, Natural Gas and Biofuels (ANP, 2017a), gasoline accounted for $45 \%$ of oil products demand in Goiás' transport sector in 2015 , equal to $1.47 \mathrm{hm}^{3}$ of fuel, i.e. $47.39 \mathrm{PJ}^{16}$. As stated by EPE (2017), domestic gasoline demand in the period $2015-$ 2030 will increase at a constant annual rate of $0.8 \%$. If Goiás gasoline demand grows at the same rate, this will result in $53.41 \mathrm{PJ}$ in 2030 (or about $1.65 \mathrm{hm}^{3}$ of gasoline).

By converting this gasoline demand, i.e. 53.41 PJ, into an ethanol energy equivalent, the state of Goiás should produce $2.46 \mathrm{hm}^{3}$ of ethanol to replace all projected 2030 gasoline demand in the state ${ }^{17}$. This scenario analyses the impacts of gasoline substitution for ethanol, performed in four different ways:

a) By substituting all Goiás' gasoline demand but not meeting either ethanol exports to other states or future demand for ethanol;

\footnotetext{
${ }^{16}$ Considering the average coefficient of equivalence to gasoline: $1 \mathrm{~m}^{3}$ of gasoline $=32.24 \mathrm{GJ}$ (MME, 2017).

${ }^{17}$ Converting gasoline future demand to an ethanol energy equivalent through the estimated ethanol LHV, i.e., $53.41 / 21.72=2.46 \mathrm{hm}^{3}$.
} 
b) By meeting the exports required from other states and substituting $50 \%$ of gasoline for ethanol, but not meeting ethanol future demands;

c) By maintaining the exports required from other states and meeting ethanol demand projected for 2030 and displacing $25 \%$ of gasoline with ethanol and;

d) By maintaining the exports required from other states, meeting ethanol demand projected for 2030 and replacing all gasoline demand with ethanol.

A summary of the scenarios is shown in Table 16. Of course, additional scenarios can easily be examined using the same methodology. Additionally, estimates were based only on the $1 G$ sugarcane ethanol production due its technological maturity, while $2 G$ ethanol is not commercially competitive in the country due to high production costs and technological constraints. EPE estimates consider only few $2 G$ ethanol plants in Brazil by 2030 without the full implementation of RenovaBio (EPE, 2017; MME, 2017) and the water and land footprint (mainly) from $1 G$ ethanol production are much higher than $2 G$ ethanol, justifying more pessimistic scenarios regarding the use of natural resources by $1 G$ ethanol on determining environmental impacts from sugarcane expansion in the state of Goiás.

Table 16. Ethanol production scenarios considering Goiás' internal demand, exports to other states, meeting 2030 demand and different levels of gasoline substitution for ethanol.

\begin{tabular}{ccrcccrr}
\hline Scenarios & $\begin{array}{c}\text { Current } \\
\text { ethanol } \\
\text { demand } \\
\left(\mathrm{hm}^{3}\right)^{a}\end{array}$ & $\begin{array}{c}\text { Ethanol } \\
\text { exports } \\
\left(\mathrm{hm}^{3}\right)^{a}\end{array}$ & $\begin{array}{c}\text { Meeting } \\
\text { future } \\
\text { demand } \\
\left(\mathrm{hm}^{3}\right)^{b}\end{array}$ & $\begin{array}{c}\text { Gasoline } \\
\text { substitution } \\
\left(\mathrm{hm}^{3}\right)^{c}\end{array}$ & $\begin{array}{c}\text { Total } \\
\text { ethanol } \\
\text { production } \\
\left(\mathrm{hm}^{3}\right)\end{array}$ & $\begin{array}{c}\text { Total } \\
\text { ethanol } \\
\text { production } \\
(\text { PJ) }\end{array}$ & $\begin{array}{c}\text { \%of } \\
\text { current } \\
\text { production }\end{array}$ \\
\hline $1 a$ & 1.75 & 0 & 2.84 & 0 & 4.59 & 99.69 & $97 \%$ \\
$1 b$ & 1.75 & 2.97 & 2.84 & 0 & 7.56 & 164.20 & $+60 \%$ \\
$2 a$ & 1.75 & 0 & 0 & $2.46(100 \%)$ & 4.21 & 91.44 & $89 \%$ \\
$2 b$ & 1.75 & 2.97 & 0 & $1.23(50 \%)$ & 5.95 & 129.22 & $+26 \%$ \\
$2 c$ & 1.75 & 2.97 & 2.84 & $0.62(25 \%)$ & 8.18 & 177.66 & $+73 \%$ \\
$2 d$ & 1.75 & 2.97 & 2.84 & $2.46(100 \%)$ & 10.02 & 217.63 & $+112 \%$ \\
\hline
\end{tabular}

Source: ${ }^{a} M M E$ (2016); Estimated from ${ }^{b} E P E$ (2017) and ${ }^{c} M M E(2017 b)$.

Since the assumptions made for scenarios $1 a$ and $2 a$ does not require any sugarcane expansion regarding current production, i.e. 2015, additional ethanol production was estimated for the remaining policy scenarios (Figure 30). 


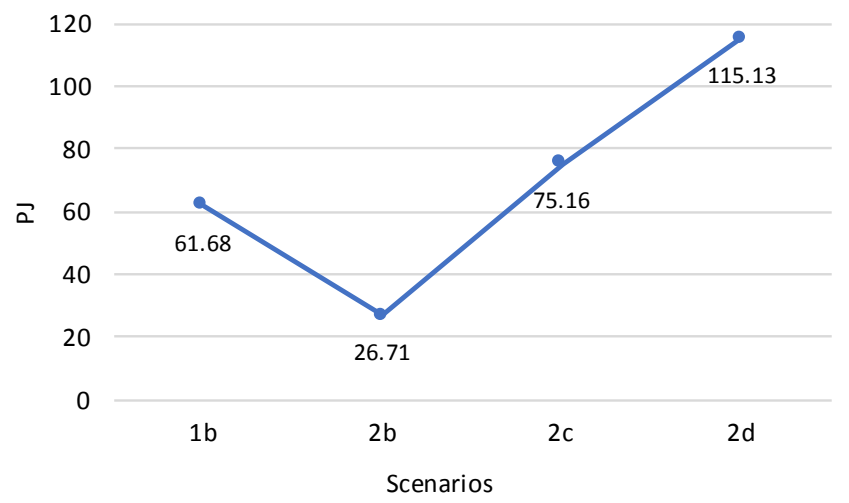

Figure 30. Additional ethanol production required, according to each policy scenario.

Source: Author's elaboration.

Additionally, after analysing both the Goiás' hybrid IO model structure and the region's physical characteristics regarding water and land availability, we can estimate land and water use limits in the region and apply these limits to create other sugarcane expansion scenarios aiming to determine environmental constraints for sugarcane expansion. In this context, we can assume that sugarcane expansion in the state of Goiás must not exceed, in terms of water withdrawals, the water availability of $5,183 \mathrm{hm}^{3}$ (Table 15).

For land-use, even though we determine geographical limits or some amount of land to be defined as a limit for sugarcane expansion in the basin, the existence of 155,000 $\mathrm{km}^{2}$ of pasturelands in the region makes our exercise unnecessary ${ }^{18}$. Pasturelands cover 3 -fold more area than all crops cultivated throughout the state and, since cattle is still mostly raised free range, inefficiently from a land-use standpoint, there is considerable densification potential in those areas. Also, since sugarcane crops have been historically occupying old pasturelands in that region and Brazilian livestock production is known as a low-density profile in terms of cattle heads per $\mathrm{km}^{2}$, we have assumed that would not be major constraints for sugarcane expansion, in terms of area required. Additionally, soybean crops cover about 32,000 $\mathrm{km}^{2}$ throughout the state nowadays (about 3 -fold the sugarcane area) and it should attract more attention regarding their land and water uses in the region, as well as their direct or indirect impacts on native forests.

\footnotetext{
${ }^{18}$ Alternatives to the current extensive livestock production will be further discussed in section 4.3.2, such as pastures rotation system aiming to improve cattle productivity and the optimal use of photosynthesis in growing grasses.
} 
Finally, sugarcane shows higher potential to be cultivated in marginal lands than soybeans, occupying even marginal pasturelands. Authors have confirmed that the expansion of biofuels production in Brazil will occur strongly based on areas currently used by livestock production (NASSAR et al., 2010; SOARES-FILHO and HISSA, 2010). Land-use modelling estimates, for the period 2011-2020, show that sugarcane expansion will occur over areas currently covered by pastures, especially degraded pasturelands (NASSAR, et al., 2011). However, despite the potential for densification in livestock production, part of the cattle raised on old pasturelands replaced by sugarcane crops may be induced to move to other areas and it may cause ILUC impacts. This ILUC issues will be further discussed both in the results (section 4.3.2) and discussions of this paper (section 4.4.2).

Similarly, since replacing gasoline for ethanol helps to reduce GHG emissions, it is not necessary to determine limits for GHG emissions in the state. Indeed, studies show that GHG emission reduction due to one litre of ethanol replacing one litre of gasoline ranges from $19 \%$ to $47 \%$ per kilometre (well-to-wheels analysis) in the case of corn ethanol, from $35 \%$ to $56 \%$ in the case of sugar beet and of $92 \%$ in the case of sugarcane ethanol (LA ROVERE et al., 2011 apud MACEDO, 1998). Additionally, including Goiás' land-use GHG emissions into the emissions from the Agricultural sector brings some uncertainty to the estimates, since GHG emissions in the state have decreased in previous years most due to LUC (Figure 31).

In this context, 2008 Goiás' gross GHG emissions amounted to $100 \mathrm{TgCO}_{2 \mathrm{e}}$ while 2016 Goiás' gross GHG emissions have accounted for about $85 \%$ of that, i.e. $87 \mathrm{TgCO}_{2 \mathrm{e}}$. However, since we are also adding land-use GHG emissions to the emissions from the Agricultural sector in 2008, the GHG estimates provided by the Goiás' hybrid IO model will be much higher than the emissions observed, for example, in 2016. This explains why it is not necessary to determine limits for direct GHG emissions in the IO model, i.e. all policy scenarios will emit more than any year after the baseline year (2008) because of this major reduction of LUC GHG emissions after 2008. Again, despite not included in the modelling exercise, ILUC were estimated for the additional land required by each scenario taking into account that cattle may be induced to move towards Brazilian forests, aiming to identify ILUC GHG emissions from replacing pasturelands by sugarcane crops in Goiás (analysed further, in section 4.3.2). 


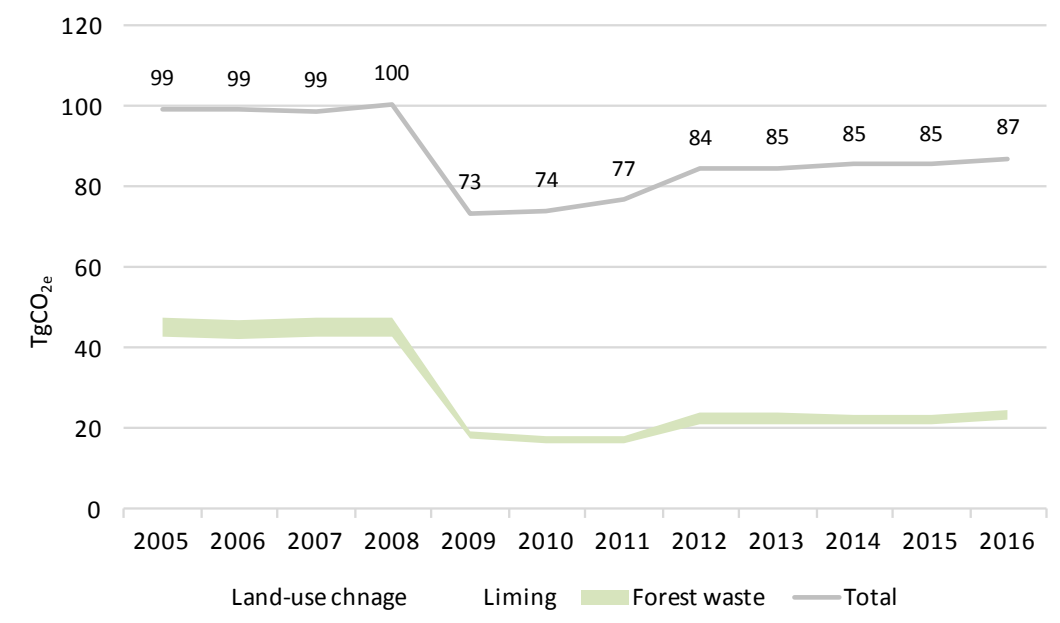

Figure 31. Evolution of GHG emissions in Goiás, highlighting the role of land-use change GHG emissions, 2005-2016.

Source: SEEG (2017).

Similarly, as the energy supply and demand is the main changing variable in the Goiás' hybrid IO model (through changes in ethanol final demand according to each policy scenario), it is not essential to determine limits for energy demand in the state. The ethanol demand will be guided by the policy scenarios described in Table $\mathbf{1 6}$ and limited by resource constraints in the region, especially water resources. The next section presents the results from running the Goiás' economic-ecological hybrid IO model, including the scenario which determines limits for water use in the region of study and what would be the economic impacts from distinct policy choices.

\subsection{Results}

Based on Brazilian government data, soybean crops have occupied 21,800 km², i.e. $44 \%$ of the total agricultural area in Goiás in 2008 (i.e. 49,280 km²), followed by corn, i.e. $9,060 \mathrm{~km}^{2}$, and sugarcane, i.e. $4,160 \mathrm{~km}^{2}$ (Figure 32a). Livestock represented the main activity regarding land use in the region, accounting for $155,230 \mathrm{~km}^{2}$, i.e. $76 \%$ of total agricultural area. Industry $\left(600 \mathrm{~km}^{2}\right)$ and the Power sector $\left(2,800 \mathrm{~km}^{2}\right)$ footprint were far less representative (Figure 32b). Overall, we estimated that the Agricultural sector accounted for $80 \%$ of water use in 2008 , i.e. $3,720 \mathrm{hm}^{3}$, followed by the Power sector, i.e. $700 \mathrm{hm}^{3}$, Industry, i.e. $200 \mathrm{hm}^{3}$, and human supply, i.e. $38 \mathrm{hm}^{3}$ (Figure 32c). 

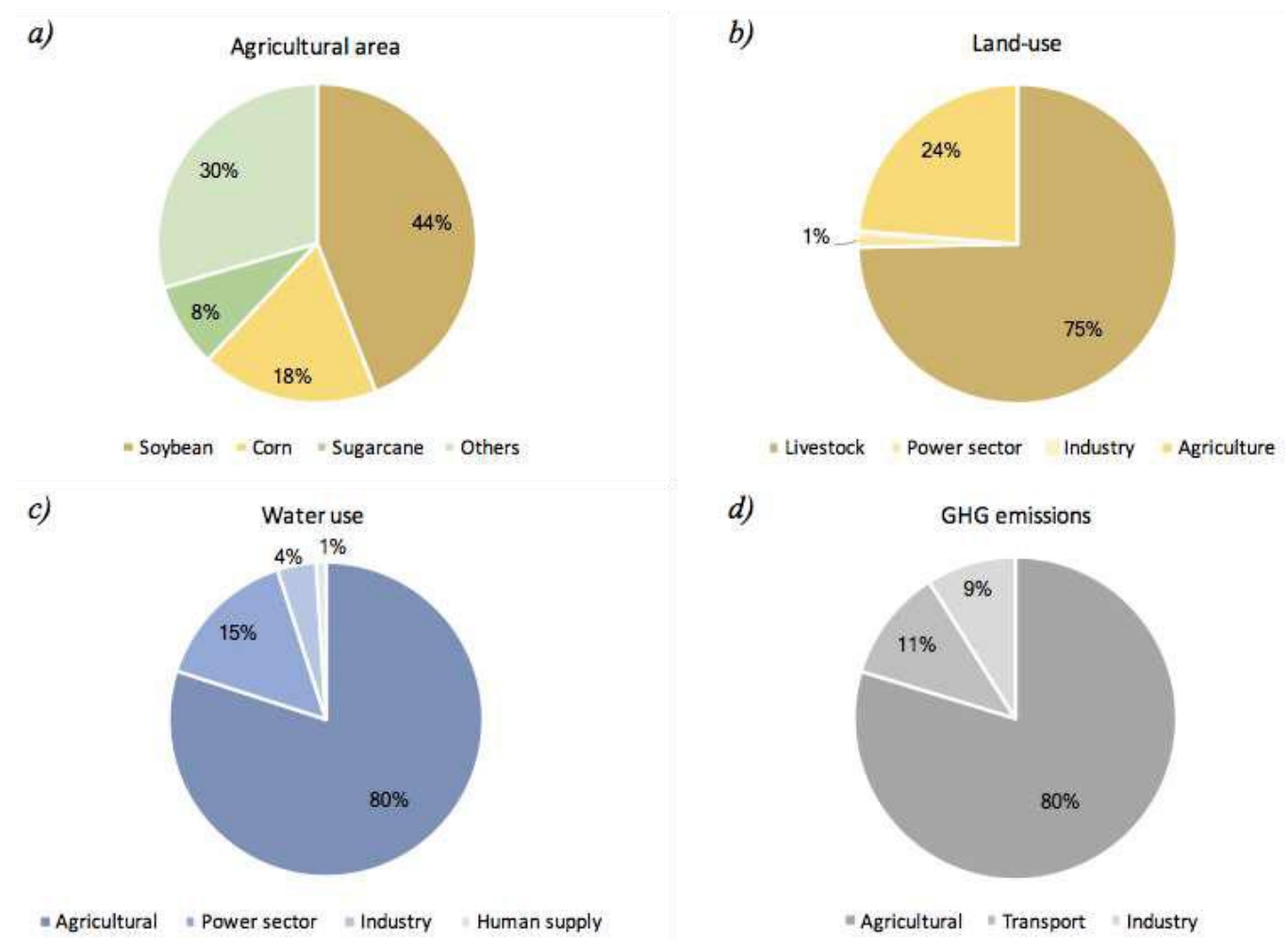

Figure 32. 2008 Goiás' $a$ ) agricultural area, $b$ ) land-use, $c$ ) water use and $d$ ) GHG emissions.

Regarding GHG as mass of $\mathrm{CO}_{2 \mathrm{e}}$, the Agricultural sector has also dominated the emissions in the state for the same period, accounting for $80 \%$, i.e. $41.67 \mathrm{Tg}$, followed by the Transport sector with $11 \%$, i.e. $5.92 \mathrm{Tg}$. Industrial processes have accounted for the remaining 9\%, i.e. $4.69 \mathrm{Tg}$ (Figure 32d). Thermoelectric power plant emissions were insignificant, and they have represented all the emissions from the power sector since hydropower reservoir emissions were not considered for lack of a universal accounting methodology. It is an important fact when considering the $81 \%$ share of hydropower generation in the state. When considering the major GHG emission categories, such as Agricultural, Land-use change, Energy, Industrial processes and Waste, the share of GHG emissions may differ (Figure 33). Land-use change has led GHG emissions in Goiás with 47.73 $\mathrm{TgCO}_{2 \mathrm{e}}$, followed by Agricultural, i.e. $40.23 \mathrm{TgCO}_{2 \mathrm{e}}$, and Energy, i.e. $9.38 \mathrm{TgCO}_{2 \mathrm{e}}$. Waste, i.e. $2.74 \mathrm{TgCO}_{2 \mathrm{e}}$, and Industrial processes, i.e. $0.38 \mathrm{TgCO}_{2 \mathrm{e}}$, were less representative. 


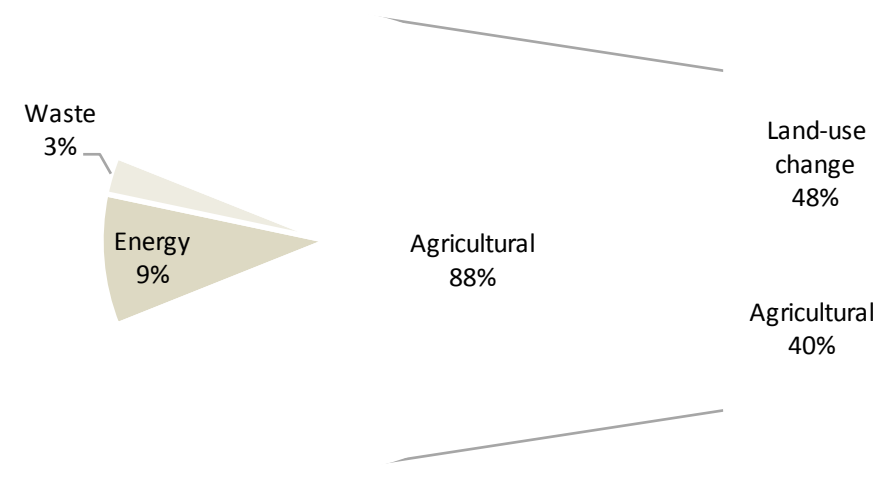

Figure 33. 2008 Goiás' GHG emissions, by major categories.

Note that the Energy category comprises the energy used in industrial processes, all the fuel used in all transport modals and the energy used by the energy sector itself. All emissions from landuse change was allocated into the Agricultural sector, i.e. $41.7 \mathrm{TgCO}_{2 e}$ from land-use change, $1.28 \mathrm{TgCO}_{2 e}$ from liming and, $4.77 \mathrm{TgCO}_{2 e}$ from forestry residues, because of the origin of the emissions.

Source: SEEG(2017).

Therefore, by adding GHG emissions from Land-use, i.e. land-use change, liming and forestry residues, into the Agricultural sector we have: $89.4 \mathrm{TgCO}_{2 \mathrm{e}}$ from Agricultural sector, $5.92 \mathrm{TgCO}_{2 \mathrm{e}}$ from Transport sector and $4.59 \mathrm{TgCO}_{2 \mathrm{e}}$ from Industrial processes (Figure 34).

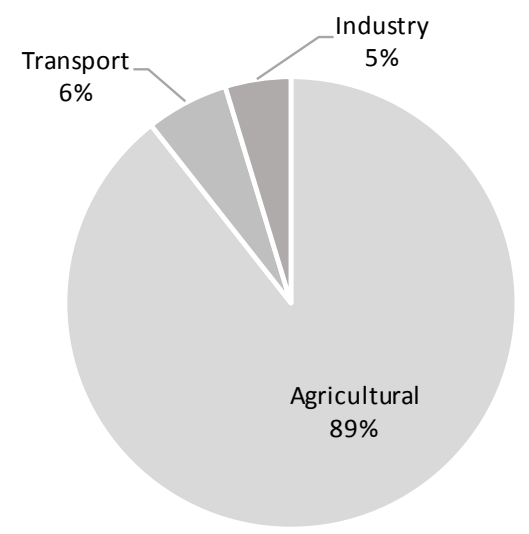

Figure 34. 2008 Goiás' GHG emissions, by sector.

Note that Services and Power sectors were less representative in 2008, i.e. $0.068 \mathrm{TgCO}_{2 e}$ and $0.074 \mathrm{TgCO}_{2 e}$, respectively.

Source: SEEG (2017).

By simulating the Goiás' economic-ecological hybrid IO table, we estimated the use of energy, water and land, as well as GHG emissions, job creation and GDP changing according to changes in future ethanol demand (Table 17), following the scenarios described in section 4.2, (Table 16). 
Table 17. Summary of the estimates for water energy and land uses, as well as GHG emissions, employment and GDP changes for each ethanol prospective scenario.

\begin{tabular}{|c|c|c|c|c|c|c|c|c|c|c|c|c|c|c|}
\hline \multirow[b]{2}{*}{ 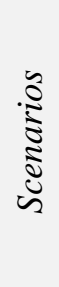 } & \multirow[b]{2}{*}{ 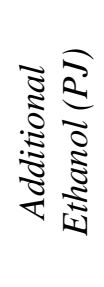 } & \multirow[b]{2}{*}{ 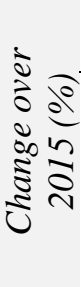 } & \multicolumn{8}{|c|}{ Environmental $^{*}$} & \multicolumn{2}{|c|}{ Social $^{*}$} & \multicolumn{2}{|c|}{ Economic $^{*}$} \\
\hline & & & 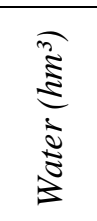 & 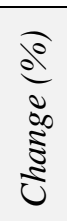 & 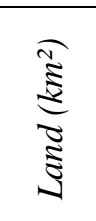 & 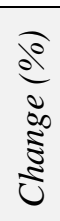 & 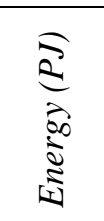 & $\begin{array}{l}\sqrt{0} \\
\frac{0}{0} \\
0 \\
0 \\
0\end{array}$ & 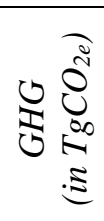 & 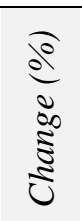 & 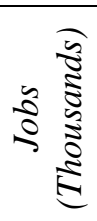 & 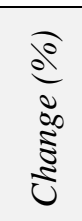 & তิ & 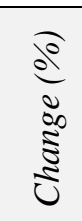 \\
\hline $1 a$ & & - & - & & - & - & - & & & & - & - & - & - \\
\hline $1 b$ & 61.68 & 60 & 54.5 & 1.2 & 2,815 & 1.3 & 80.1 & 14.5 & 1.345 & 1.3 & 23.7 & 0.8 & 177 & 0.87 \\
\hline $2 a$ & - & - & - & - & - & - & - & - & - & - & - & $\begin{array}{ll}- \\
-\end{array}$ & - & - \\
\hline $2 b$ & 26.71 & 26 & 23.6 & 0.5 & 1,220 & 0.6 & 34.72 & 6.8 & 0.583 & 0.57 & 10.3 & 0.35 & 76.5 & 0.38 \\
\hline $2 c$ & 75.16 & 73 & 66.3 & 1.4 & 3,425 & 1.6 & 97.5 & 17 & 1.637 & 1.6 & 28.8 & 0.96 & 214.7 & 1.05 \\
\hline $2 d$ & 115.13 & 112 & 101.7 & 2.1 & 5,250 & 2.5 & 149.5 & 24 & 2.512 & 2.4 & 44.2 & 1.5 & 329.4 & 1.62 \\
\hline
\end{tabular}

To meet the 2030 estimated ethanol demand, Goiás should produce an additional 61.68 PJ of ethanol. According to scenario $1 a$, it could be met by simply cutting ethanol exports to other states, causing no additional environmental impacts to the Paranaíba basin. On the other hand, other states would have to increase their production to meet about $95 \%$ of the 64.48 PJ currently exported by Goiás. Since most of the remaining suitable areas for ethanol expansion are in the Cerrado, this demand would likely be met by Mato Grosso do Sul State. Therefore, the environmental impacts from sugarcane crops expansion would just be transferred from one state to another, located in the same waterstressed region.

Similarly, estimates of scenario 2 a consider substitution of all the 2030 gasoline demand in Goiás, equivalent to 53.41 PJ. In this context, there is no need for additional ethanol production since, again, the exports to other states might be cut back. Just by reducing its current ethanol exports in 83\%, Goiás State could displace all its 2030 gasoline consumption. Since there are no refineries in Goiás, it imports all its gasoline, mainly from nearby states. Also, the gradual gasoline replacement with ethanol might be politically interesting for Goiás' economic and environmental agendas.

Some highlights are presented below based on the four remaining scenarios (Table 17):

- Scenario 1b: $60 \%$ increase over 2015 production, i.e. additional 61.68 PJ, to satisfy both current (102.5 PJ) and future ethanol demand, totalling 164.20 PJ 
About $54.5 \mathrm{hm}^{3}$ of water and $2,815 \mathrm{~km}^{2}$ of land would be necessary. According to BEUCHLE et al. (2015), the required land to meet future ethanol demand accounts for $2.4 \%$ of natural vegetation cover loss in the Cerrado biome, from 2000 to 2010. All energy sources and industrial processes would require an additional $80.1 \mathrm{PJ}$ of energy, i.e. an $14.5 \%$ increase, emitting $1.345 \mathrm{TgCO}_{2 \mathrm{e}}$, i.e. $1.3 \%$ increase. About 23,700 new jobs would be created, i.e. $0.8 \%$ increase over current levels, of which 11,500 in the Agricultural sector, 8,800 in the Biofuels and 2,300 new jobs in Services sector. Regarding GDP changes, estimates show an $0.87 \%$, i.e. 177 million US\$ increase in response to changes in ethanol demand, impacting mostly the Biofuels, i.e. 53\%, Agricultural, i.e. 1.4\%, Transport, i.e. $0.55 \%$, and Chemical products sectors, i.e. $0.33 \%$.

It is noteworthy remembering that scenario $1 b$ may be the most realistic scenario in terms of ethanol policies because it does not propose to replace any gasoline in the state and, it aims to meet future ethanol demand projected to 2030. In this regard, the economic and environmental impacts calculated herein can be seen as estimates closer to the local reality.

- Scenario 2b: $26 \%$ increase over 2015 production, i.e. additional 26.71 PJ, to substitute $50 \%$ of 2030 estimated gasoline consumption but not meeting future internal ethanol demand

This scenario shows the lower additional ethanol requirement and, therefore, lower impacts on state's energy, environmental and socioeconomic systems. It would demand less than $50 \%$ of scenario $1 b$ requirements in terms of water (i.e. $23.6 \mathrm{hm}^{3}$ ), land (i.e. $1,220 \mathrm{~km}^{2}$ ), energy (i.e. $34.72 \mathrm{PJ}$ ), $\mathrm{GHG}$ emissions (i.e. 0.583 $\mathrm{TgCO}_{2 \mathrm{e}}$ ), jobs (i.e. 10,300) and GDP (i.e. 76.5 million US\$). Direct and indirect impacts of changes in final demand would increase the value added mainly in Biofuels (i.e. 23\%), Agricultural (i.e. 0.6\%), Transport (i.e. 0.24\%) and Power sectors (i.e. $0.14 \%)$.

- Scenario 2c: $73 \%$ increase over 2015 production, i.e. additional 75.16 PJ, to meet future ethanol demand and substitute $25 \%$ of 2030 estimated gasoline consumption in Goiás 
The only difference between scenarios $1 b$ and $2 c$ is the $25 \%$ of gasoline substitution for ethanol. Therefore, the difference between estimates of both scenarios would represent the impacts of this level of gasoline substitution in the state, namely, additional $11.8 \mathrm{hm}^{3}$ of water, $610 \mathrm{~km}^{2}$ of land, $17.4 \mathrm{PJ}$ of energy, $0.292 \mathrm{TgCO}_{2 \mathrm{e}}, 5,100$ additional jobs and finally, 37.7 million US\$ of increase in GDP regarding scenario $1 b$. The total requirements for scenario $2 c$ can be verified in Table 17. As one can expect, the Biofuels sector would have its value added increased by 64\%, while Agricultural (i.e. 1.7\%), Transport (i.e. 0.67\%), Chemical products (i.e. 0.4\%) and Power sectors (i.e. 0.39\%) would show lower indirect impacts. Regarding the total 28,800 new jobs, most of them would be created in in the Agricultural sector, i.e. 14,000, followed by Biofuels, i.e. 10,700, and Services sectors, i.e. 2,800 jobs.

Again, scenario $2 c$ constitutes a realistic scenario in terms of ethanol policies because it aims to meet future ethanol demand and replace $25 \%$ of the gasoline projected to be consumed in Goiás in 2030. Even if Goiás' government will not promote any policy targeting displacing gasoline for ethanol, this scenario may help begin understanding the economic and environmental impacts that would happen in the case of a gradual gasoline replacement in the state.

- Scenario 2d: $112 \%$ increase over 2015 production, i.e. additional 115.16 PJ, to meet future ethanol demand and substitute $100 \%$ of 2030 estimated gasoline consumption in Goiás

Regarding this major change in the state's ethanol supply chain, GDP would increase $1.62 \%$, (to 20,720 million US\$) accounting for an additional 329.4 million US\$ due to changes only in final demand for ethanol. To reach the new final demand requirement, it would be necessary an additional $101.7 \mathrm{hm}^{3}$ of water and $5,250 \mathrm{~km}^{2}$ of land, an increase of $2.1 \%$ and $2.5 \%$, respectively. Also, overall energy supply would increase $24 \%$ to 622.15 PJ, while GHG emissions would go up 2.5\%, to about $102.67 \mathrm{TgCO}_{2 \mathrm{e}}$ (Figures 35 and 36). Employment would increase by $1.5 \%$, accounting for 44,200 new jobs, $49 \%$ in the Agricultural sector, due to increased demand for ethanol. Besides the Biofuel sector (i.e. 98\%), the main impacted sectors in terms of value added would be Agricultural (i.e. 2.56\%), Transport (i.e. 1.03\%), Chemical products (i.e. 0.61\%), Power sector (i.e. 0.59\%) 
and Metallurgy (i.e. $0.28 \%$ ). On the other hand, overall, $99 \%$ and $80 \%$ of land and water use change would occur in the Agricultural sector, respectively. The landuse change estimated from future ethanol demands in the scenario $2 d$ would account for $4.6 \%$ of natural vegetation cover loss in the Cerrado (i.e. equivalent to 2-fold the area of Luxembourg), when considered the 2000-2010 period (BEUCHLE et al., 2015).

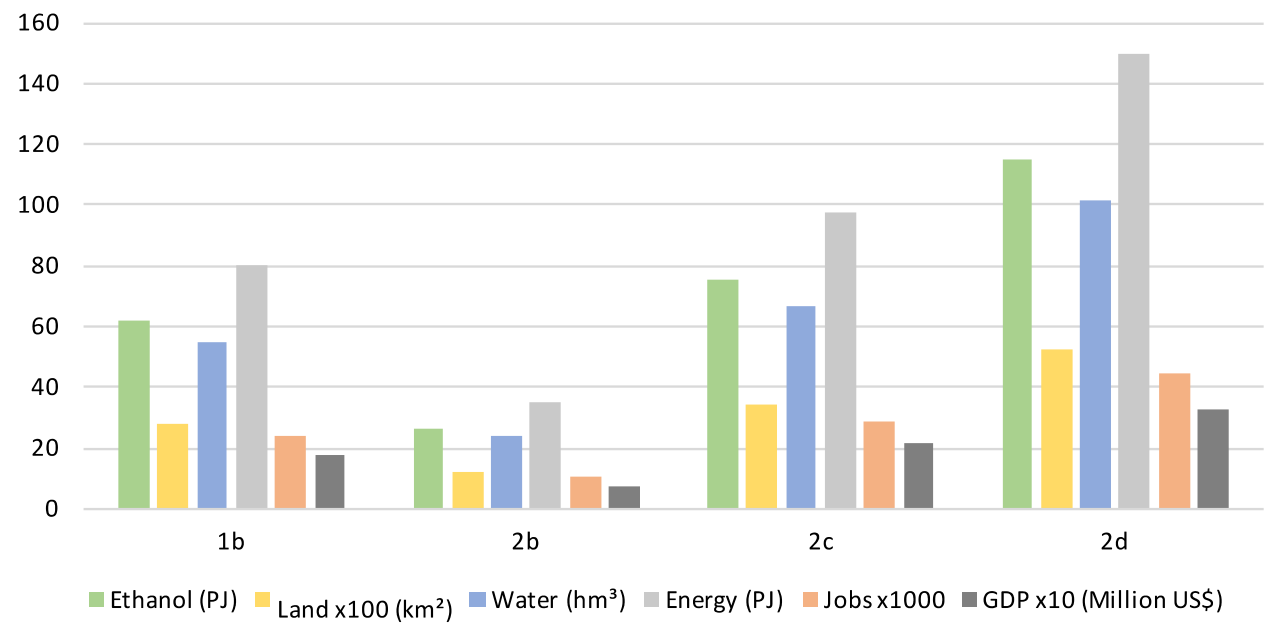

Figure 35. Additional water, energy and land-use requirements, ethanol production, job creation and GDP for all 2030 scenarios.

Source: Author's elaboration.

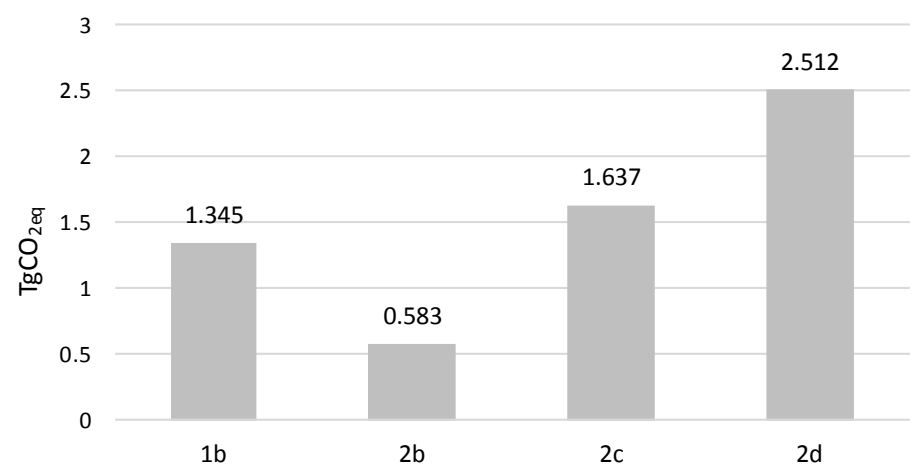

Figure 36. Additional GHG emissions for all 2030 scenarios.

Source: Author's elaboration.

Some general remarks can be made based on the results presented above:

- For every $1 \%$ change in final demand for ethanol, the water demand will change by $0.019 \%$, land-use by $0.023 \%$, GHG emissions by $0.022 \%$, job creation by $0.013 \%$ and finally, GDP will change by $0.014 \%$ (Figure 37). 


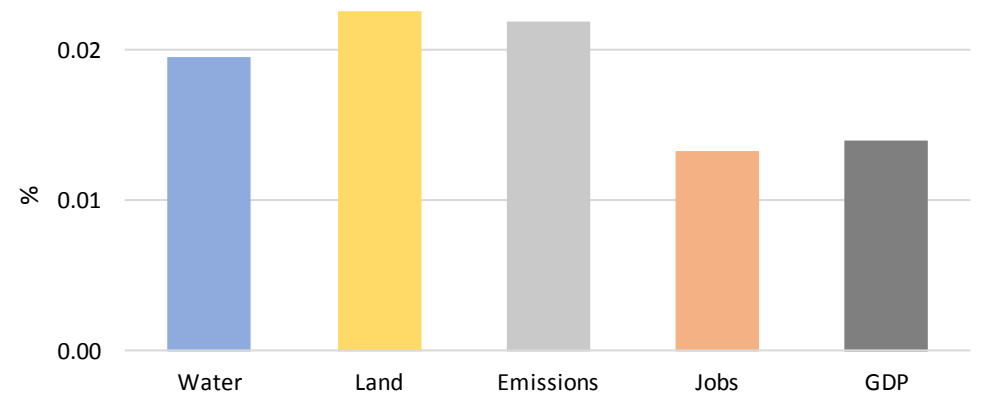

Figure 37. Changes in water and land requirements, GHG emissions, job creation and GDP, from $1 \%$ changes in final demand for ethanol in the state of Goiás.

Source: Author's elaboration.

- The assumptions made in scenarios $1 b$ and $2 c$ seem to be the most realistic when considering policy goals, since these scenarios target meeting both current and future ethanol demand, as well as ethanol exports to other states. However, the potential ethanol supply does not necessarily mean that this production level is feasible or desirable. It will also depend on the impacts on different variables, such as land prices, production costs, externalities costs, required investment in production capacity and infra-structure.

- Respectively, scenarios $1 b, 2 c$ and $2 d$ represent $15 \%, 18 \%$ and $28 \%$ of MAPA's forecasts for the whole country, i.e. an expansion of $19,000 \mathrm{~km}^{2}$ of sugarcane crops in the country by 2026 (MAPA, 2016). Considering only MAPA's projections for the Centre-West region by 2026, i.e. $8,000 \mathrm{~km}^{2}$, scenarios $1 b, 2 c$ and $2 d$ would respectively account for $35 \%, 43 \%$ and $66 \%$ of total area projected for the entire region but produced only in Goiás State (Figure 38).

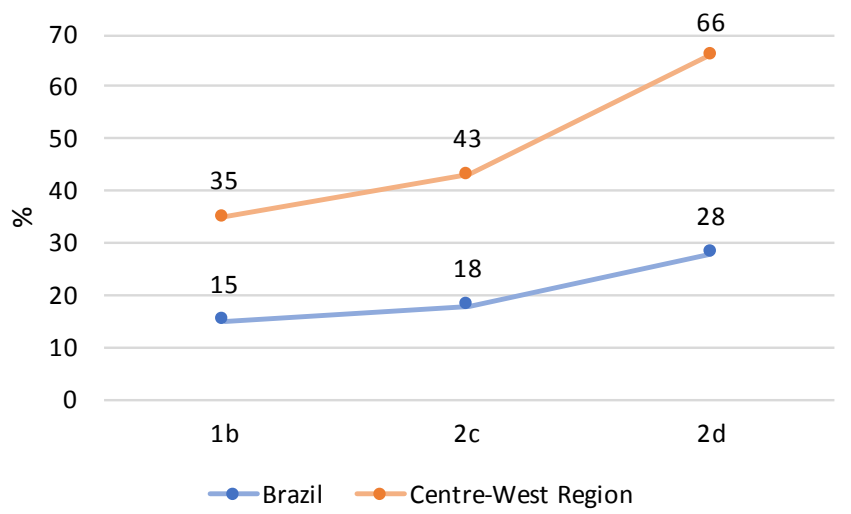

Figure 38. Share of ethanol policy scenarios regarding Brazilian government ethanol expansion forecasts.

Source: Author's elaboration from MAPA (2016). 
- By comparing scenarios $1 b$ e $2 c$, we can observe that replacing $25 \%$ of gasoline for ethanol in the state would account for additional $3 \%$ in land-use terms when considering MAPA's forecast for Brazil and about $8 \%$ when considering only the projections for the Centre-West region, showing potential for a local gradual gasoline substitution for ethanol.

- The land use estimated in scenarios $1 b$ and $2 c$ account for $30 \%$ and $35 \%$ of the 2015 sugarcane crop area in Goiás, and for 2.6\% and 3.2\% in Brazil, respectively (MAPA, 2016) (Figure 39). Since sugarcane crops have been historically replacing old pasture lands, there are still plenty of areas available to their expansion in the state. Additionally, Brazilian livestock production still shows a low-density profile, but great strides are being taken to intensify land use by concentrating more cattle heads per area.

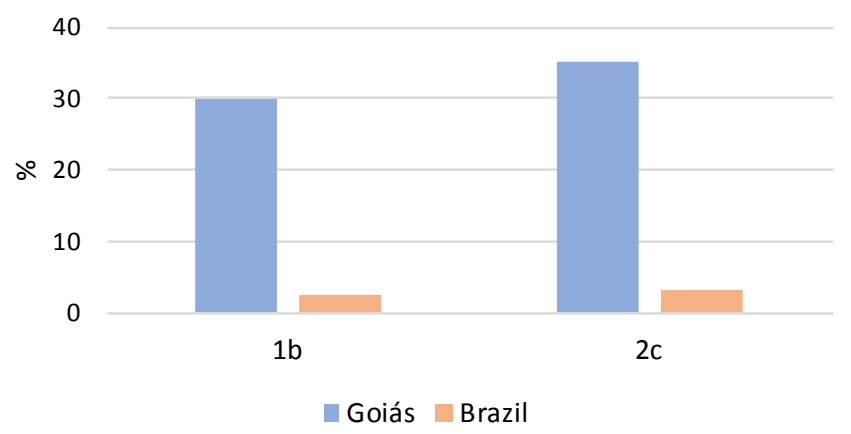

Figure 39. Additional land-use estimates regarding Goiás' sugarcane crop area, in 2015.

Source: Author's elaboration from MAPA (2016).

- Scenarios $2 c$ and $2 d$ would require a total energy demand of $570 \mathrm{PJ}$ and 622 PJ, respectively, an additional 28\% and 40\% regarding 2015 Goiás' internal energy supply (MME, 2016) (Figure 40). Note that changes in ethanol demand would change the overall energy demand in Goiás' economy, which is directly and indirectly used by interindustry sectors to produce the inputs required for meeting that new ethanol demand. 


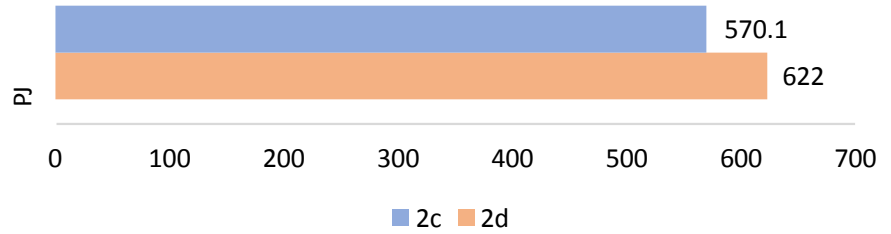

Figure 40. Total energy demand and the share of 2015 Goiás' internal energy supply. Source Author's elaboration from MME (2016).

\subsubsection{Concerns on local water resources}

Despite the Paranaíba basin showing a high overall water availability, the National Water Agency (ANA, 2015) pointed out some conflict areas regarding multiple water uses especially caused by agricultural demands. In this regard, even in the worstcase scenario $(2 d)$, the additional water requirements due to changes in ethanol demand, i.e. $3.2 \mathrm{~m}^{3} / \mathrm{s}$ or $102 \mathrm{hm}^{3}$ in an annual basis; equivalent to $1.5 \%$ of 2010 total water consumption in the basin (ANA, 2015), would cause little impact to its local availability. However, it is fundamental to observe at which basin location the sugarcane expansion would occur, focusing on minimizing conflicts over this resource.

In this regard, we have developed an alternative ethanol production scenario focusing on limiting ethanol expansion according to water use limits in the basin. As previously mentioned, the estimated water availability in the section of the Paranaíba basin located in Goiás was $5,183 \mathrm{hm} 3 /$ year, a water-use volume which must not be exceeded. Keeping this in mind and by manipulating the Goiás' economic-ecological hybrid IO model, we have estimated the limits for ethanol expansion in the basin, namely, an $576 \%$ increase over 2015 production level, i.e. scenario $2 e$. This alternative scenario would make available additional $24.86 \mathrm{hm}^{3}$ of ethanol, i.e. $82 \%$ of total 2015 national production (UNICA, 2017), to be exported to other states, after meeting state's demand, i.e. $1.75 \mathrm{hm}^{3}$, meeting the 2030 demand, i.e. $2.84 \mathrm{hm}^{3}$, and replacing all 2030 estimated gasoline consumption in Goiás, i.e. $2.46 \mathrm{hm}^{3}$.

Thus, scenario $2 e$ would require additional $523 \mathrm{hm}^{3}$ of water to meet that massive ethanol demand, accounting for an increase of $10.1 \%$ on water use. It is noteworthy mentioning that this scenario considers the remaining available surface water according to the water flow used for granting rights to water use in the basin (Table 15), which 
means a half of the reference flow $Q_{95 \%}$ (i.e., a more restrictive measure). Regardless the amount of sugarcane that could be produced by using this volume of water, no policy shall recommend expanding sugarcane production up to the limits of surface water availability. Therefore, this policy scenario consists in an exercise to understand whether this projected ethanol expansion, i.e. 576\% increase, would have enough room to expand towards the Paranaíba basin without heavily impacting water resources and what would be the economic impacts from this measure.

However, since it has been observed a 3 -fold increase on irrigated area in the basin in 15 years, about $400 \%$ increase in the sugarcane planted area from 2000 to 2010 and a more recent $170 \%$ expansion in 5 years (2010-2015), it is not extreme to exercise what could happen to the Paranaíba's basin resources when considering about 500\% sugarcane expansion for the next 15-year period.

Regarding this major change in Goiás' ethanol supply chain, GDP would increase $8.31 \%$, (to 22,085 million US\$) accounting for an additional 1,694 million US\$ due to changes in final demand for ethanol (Figure 41). The Agricultural sector would create about 111,000 new jobs in the scenario $2 e$, an 13.2\% increase, followed by the Biofuels, i.e. 84,800 jobs, Services, i.e. 22,600, Transport i.e. 5,900, and Food, beverages and tobacco sectors, i.e. 1,100. Overall, scenario $2 e$ would create 227,500 new jobs, totalizing 3.19 million jobs in the state, i.e. an $7.13 \%$ of increase. Also, overall energy supply would increase $62 \%$, i.e. $770 \mathrm{PJ}$, to 1,242 PJ, while GHG emissions would go up 11.42\%, i.e. 12.92 $\mathrm{TgCO}_{2 \mathrm{e}}$, to about $113.07 \mathrm{TgCO}_{2 \mathrm{e}}$.

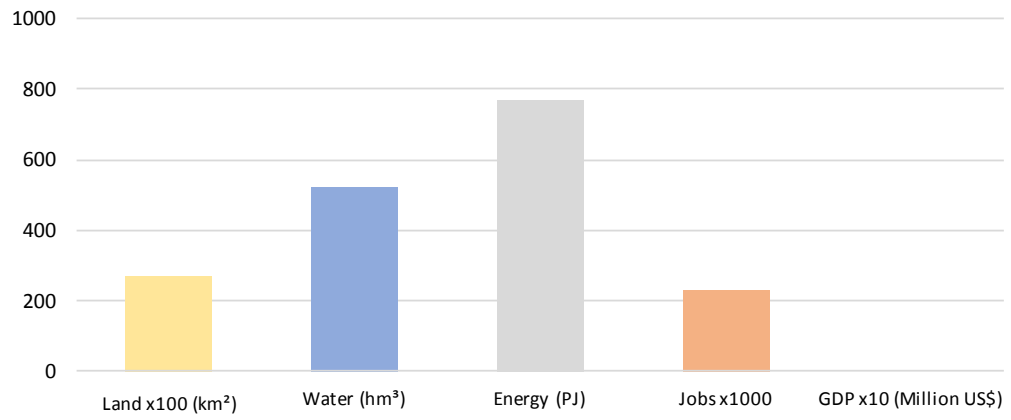

Figure 41. Additional water, energy and land-use requirements, job creation and GDP for scenario $2 e$. Source: Author's elaboration.

To reach this new final demand requirement, it would be necessary an additional $27,022 \mathrm{~km}^{2}$ of land, an increase of $11.53 \%$. It is noteworthy that this land requirement 
represents an area 5,000 $\mathrm{km}^{2}$ bigger than the smallest Brazilian state, Sergipe, which accounts for about $0.3 \%$ of Brazil's territory. Similarly, this $27,000 \mathrm{~km}^{2}$ expansion area accounts for $90 \%$ of Belgium's territory. From the point of view of the area used by agricultural production in Goiás, the land required for this sugarcane expansion would account for only $18 \%$ of total current pasturelands and for $47 \%$ of the total agriculture area currently (i.e. 2016) used in the state (MAPBIOMAS, 2017).

When considering each Water Management Unit - WMU, data from Tables 14 and 15 have shown distinct characteristics regarding water resources use, management and planning. The Meia Ponte, Turvo-Bois and Lower Paranaíba Minas Tributaries WMUs have presented concerns regarding water impairment indicators, i.e., highly critical and alert status, respectively. This can be explained due to high sugarcane production in the Turvo-Bois WMU (i.e. about $15 \%$ of total sugarcane production in the basin), and low surface water availability in Meia Ponte and Lower Paranaíba Minas Tributaries. Also, although Claro, Verde, Correntes and Aporé WMU produces more sugarcane (i.e. $17 \%$ of total) than Meia Ponte WMU (i.e. 5\%) and Lower Paranaíba Minas Tributaries WMU (i.e. 5\%), its water resources were considered as normal condition due to higher water availability and lower withdrawals.

The Turvo-Bois is the WMU which uses more water for irrigation among the analysed WMUs (Figure 42). Also, Turvo-Bois WMU is the second in terms of water used for livestock production, which makes this WMU the highest water demanding regarding the whole Paranaíba basin, i.e. $18.3 \%$ of total water demand in the basin. Since this WMU has the largest number of ethanol mills in the basin and historically have been most receiving sugarcane expansion in the region, besides showing the higher share of water demand in the basin, it is important to take local actions aiming to understand the real impacts of growing sugarcane in that region. 


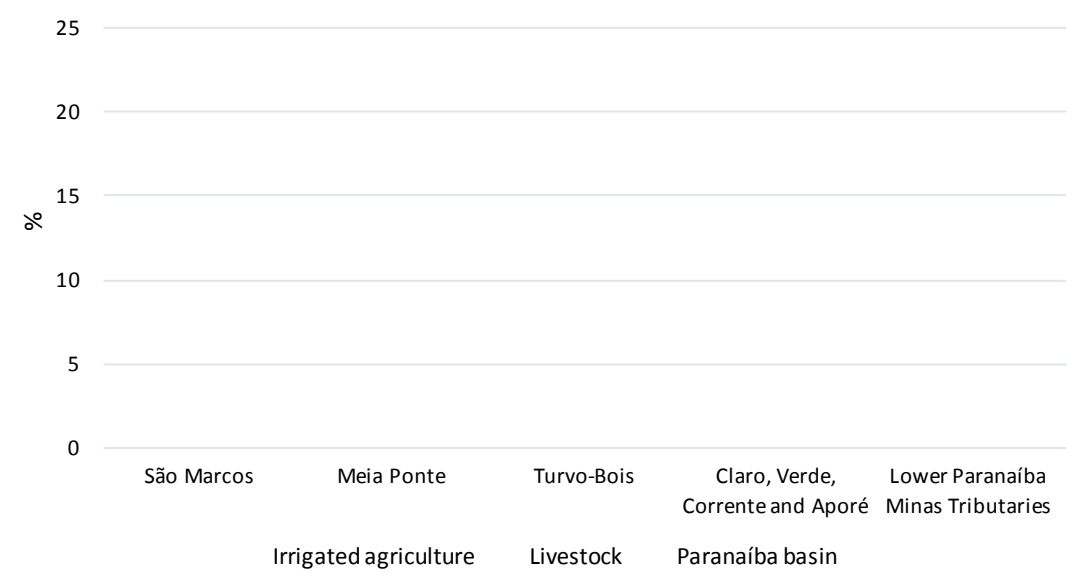

Figure 42. Share of irrigated crops, livestock production and in relation to the whole Paranaiba basin, by WMU.

Source: Author's elaboration from ANA (2015).

\subsubsection{Indirect land-use change impacts}

The replacement of agricultural land for biofuels production may lead to indirect land-use changes, which occur as unintended consequences of land-use decisions elsewhere. The main reason for ILUC analysis is the risk that biofuels production may shift other agricultural activities to land with high natural carbon stocks, resulting in significant GHG emissions from land conversion processes. These effects are also known as leak, i.e. the result of an action occurring in a system that induces indirect effects outside the limits of this system, but which can be attributed to the actions occurring within the system.

According to scenarios previously analysed, each of them shows different additional land requirements according to changes in future demand for ethanol in Goiás. Given pasturelands availability with medium and high potential for growing sugarcane crops in the state, the future local sugarcane expansion could replace old or idle pasturelands. However, the question that arises from this substitution is: What would be the indirect impacts from these changes, in terms of GHG emissions, considering that cattle may be induced to move towards Brazilian forests? Aiming to understand the magnitude of this indirect impact, estimates for ILUC GHG emissions from replacing pasturelands for sugarcane crops are presented below (Table 18).

In fact, if pasturelands replacement for sugarcane crops push the foregone livestock production towards the Amazon, indirect GHG emissions would be much higher than those if the cattle was moved to Cerrado forests (i.e. about $50 \%$ higher). This 
is because the Amazon forest holds a higher carbon density per area (i.e. $120 \mathrm{t} / \mathrm{ha}$ ), when compared to Cerrado forests (i.e. $55 \mathrm{t} / \mathrm{ha}$ ) (YOUNG et al., 2016). On the other hand, the opportunity cost of land in the Cerrado biome is higher than that of the Amazon, causing livestock producers to seek cheaper land for their production; therefore, pushing deforestation to the Amazon. The most realistic scenarios (i.e. $1 b$ and $2 c$ ) would account for additional $56 \%$ and $69 \%$ in GHG emissions to the 2008 GHG emissions baseline, when considering indirect GHG emissions caused by indirect deforestation in Cerrado. If deforestation happens in the Amazon biome, the numbers would be worse, about $220 \%$ and $250 \%$ of additional indirect GHG emissions, respectively. In any of these cases, the possibility of deforestation in native forests, indirectly caused by sugarcane expansion in the state of Goiás would make its expansion prohibitive.

Table 18: Estimates of GHG emissions from expanding Goiás sugarcane crops.

\begin{tabular}{lrrrrrr}
\hline Scenarios & $\begin{array}{r}\text { Area } \\
\left(\mathrm{km}^{2}\right)\end{array}$ & $\begin{array}{r}\text { Area } \\
\text { (ha) }\end{array}$ & Herd & $\begin{array}{r}\text { Forest } \\
\text { area }\end{array}$ & $\begin{array}{r}\text { Emissions Cerrado } \\
\left(\mathrm{TgCO}_{2}\right)\end{array}$ & $\begin{array}{r}\text { Emissions Amazon } \\
\left(\mathrm{TgCO}_{2}\right)\end{array}$ \\
\hline $2 b$ & 1,220 & 122,000 & 122,000 & 122,000 & 24.60 & 53.68 \\
$1 b$ & 2,815 & 281,500 & 281,500 & 281,500 & 56.77 & 123.86 \\
$2 c$ & 3,425 & 342,500 & 342,500 & 342,500 & 69.07 & 150.70 \\
$2 d$ & 5,250 & 525,000 & 525,000 & 525,000 & 105.88 & 231.00 \\
\hline
\end{tabular}

Note: Forest area required $=$ Area (ha) $x$ Herd; assuming 1 cattle head/ha.

Emissions $=$ Forest area $x$ Carbon stock in biome $x \delta M M$.

Carbon stock in Cerrado forests $=55 \mathrm{t} / \mathrm{ha}$

Carbon stock in Amazon forests $=120 \mathrm{t} / \mathrm{ha}$

$\delta M M$ (molecular mass ratio) $=\mathrm{MM} \mathrm{CO}_{2} / M M C$

$M M \mathrm{CO}_{2}=44 u ; M M C=12 u$.

$1 \mathrm{~km}^{2}=100 \mathrm{ha}$

1 ton $=10^{-6} \mathrm{Tg}$.

It is important to highlight that while expansion in Southern Cerrado (i.e. where part of Goiás state is located) has occurred predominantly over pasturelands or croplands with inefficient use, in the Northern frontier region of MATOPIBA ${ }^{19}$ the increase has taken place mostly over native vegetation, despite the availability of suitable lands already cleared and inefficiently used (CARNEIRO FILHO and COSTA, 2016). Overall, there are about $300,000 \mathrm{~km}^{2}$ of Cerrado lands open, with high or medium soil and climate suitability for croplands which are currently under inefficient uses (REIS et al., 2017).

\footnotetext{
${ }^{19}$ Portuguese acronym for the initials of the names of each state that makes up the MATOPIBA region, i.e. Maranhão (MA), Tocantins (TO), Piauí (PI) and Bahia (BA).
} 
Additionally, cattle can be produced in a more intensive way than is currently produced in Brazil. Overall, the low productivity lies in the poor livestock management such as producer inefficiency, food inefficiency, low pregnancy rate, high incidence of invasive plants, soil fertility reduction and erosion. However, there are alternatives to improve productivity and reduce both costs and GHG emissions from livestock production.

In this context, rotation systems use solar energy as a basic input, focusing on pastures' photosynthetic potential. A basic premise of these systems is the division of pastures into plots, while one of them is in use, others remain at rest, favouring photosynthesis and the accumulation of both energy and protein reserves in plant roots. The pasture at its optimum resting point has a more balanced composition, in addition to producing a greater amount of dry matter per area with better fibre content (VILLELA, 2014). Following agroecological concepts, the rotation system is the most efficient and economical technology for cattle production (CASTAGNA et al., 2008). Additionally, according to BARRETO and SILVA (2013), only the division of pastures in plots and the correct cattle rotation may increase productivity from 75 to about $260 \mathrm{~kg} / \mathrm{ha} / \mathrm{year}$.

From the GHG emissions standpoint, since the plough is not used in the rotation system, almost all $\mathrm{CO}_{2}$ is transformed into $\mathrm{H}_{2} \mathrm{CO}_{3}$, minimizing $\mathrm{CO}_{2}$ releasing into the atmosphere. The use of plough buries organic matter and it produces an anaerobic environment; therefore, the decomposition occurs by anaerobic bacteria, releasing methane into the atmosphere. Thus, a well-managed pasture, consumed at the optimum resting point, releases less $\mathrm{CO}_{2}$ and $\mathrm{CH}_{4}$ into the atmosphere than a pasture produced with previous ploughing. As an alternative, YOUNG et al. (2016) have estimated $\mathrm{CH}_{4}$ emissions from cattle's anaerobic digestion, taking into account that a payment for environmental services policy would take place, promoting the intensification of livestock production in Brazil. Their results for the $\mathrm{CH}_{4}$ avoided by the intensification of livestock production indicated a reduction of up to $6.3 \mathrm{GgCH}_{4}$ (i.e. $176.5 \mathrm{GgCO}_{2 \mathrm{e}}{ }^{20}$; when

\footnotetext{
${ }^{20}$ Methane $\left(\mathrm{CH}_{4}\right)$ is estimated to have a GWP of 28 over 100 years, according to the IPCC Fifth Assessment Report (AR5) (IPCC, 2014). $\mathrm{CH}_{4}$ emitted today lasts about a decade on average, which is much less time than $\mathrm{CO}_{2}$. But $\mathrm{CH}_{4}$ also absorbs much more energy than $\mathrm{CO}_{2}$. The net effect of the shorter lifetime and higher energy absorption is reflected in the GWP. The $\mathrm{CH}_{4} \mathrm{GWP}$ also accounts for some indirect effects, such as the fact that $\mathrm{CH}_{4}$ is a precursor to ozone, and ozone is itself a GHG. See more details at: https://www.ipcc.ch/report/ar5/.
} 
considering an intensification scenario of 30\%), making clear that there is a great potential for the intensification of livestock production in the Cerrado and Amazon biomes.

This methane reduction by the means of intensification of livestock production could offset part of indirect $\mathrm{CO}_{2}$ emissions from sugarcane expansion over old pasturelands. Also, if the cattle intensification takes place improving the Brazilian cattle densification average to at least 2 cattle heads/ha, the total indirect $\mathrm{CO}_{2}$ emissions showed in Table 18 could be halved. Again, it is worth mentioning that these indirect GHG emission scenarios from native forests deforestation are based on the assumption that all the area required for sugarcane expansion would be met by local pasturelands and, therefore, $100 \%$ of the cattle produced in the area required by sugarcane crops would move towards native forests. Of course, this is the upper limit of indirect impacts estimated by this paper, in terms of deforestation of native forests and its related GHG emissions.

\subsection{Discussion}

Although the more realistic scenarios for sugarcane expansion in Goiás require up to $35 \%$ increase in crop area growth compared to 2015 level, there is a possibility that they will not impact land use in the region significantly, given the availability of suitable pasturelands for sugarcane crops expansion. This is a very relevant point regarding GHG emissions since sugarcane crops store (much) more biomass than natural grasses. On the other hand, when considering that sugarcane expansion over pasturelands may cause indirect impacts through ILUC in native forests, this sugarcane expansion rises controversial issues, mainly regarding indirect deforestation in already threatened Brazilian biomes, causing massive indirect GHG emissions. In this case, sugarcane crops ILUC impacts would make their local expansion quite questionable.

In Brazil, pastures comprise roughly a quarter of Brazil’s territory, three times the land used in agriculture. On the other hand, Brazil's federal agricultural research agency - EMBRAPA, points that $60 \%$ of pastures in the Cerrado biome are degraded due to faulty management (ANDRADE et al., 2016). Cattle is still mostly raised free range, inefficiently from a land use standpoint; therefore, there is considerable densification potential, freeing up land for food and fuel crops being demanded throughout the world. Also, about $30 \%$ of intensification in livestock production could reduce methane emissions from enteric fermentation by 35\% (YOUNG et al., 2016). 
According to FAO (2009), in order to feed a larger, more urban and richer population, world food production must increase by $70 \%$ till 2050 . On the other hand, UNEP (2014) stated that worldwide, yield increases of cereals and primary crops in general have been slowing down since the 1960s. Yield growth for cereals is expected to drop from an average of $1.96 \%$ per annum for the period $1980-2000$ to $1.01 \%$ in 2000 2050, with even slower growth rates for developed countries.

FISCHER and SHAH (2010) calculated the potentially available good land in current grassland/woodland ecosystems for several food crops and concluded that Brazil had more land available for rain-fed maize, soybean, sugarcane and cassava than any other country in the world. Thus, Brazil's importance in meeting future global food and biofuel demand cannot be overstated. However, most of these crops are cultivated in the Cerrado biome (i.e. $60 \%$ of Brazil's annual crops output), which is an important carbon reservoir, stocking around 32,000 $\mathrm{TgCO}_{2}$ (MCTI, 2016). Unfortunately, the current rate of conversion in the Cerrado is not sustainable (i.e. the highest deforestation rate in the country in the last 15 years; about $43 \%$ higher than the Amazon in the period), releasing a previously unaccounted volume of $\mathrm{CO}_{2}$ (REIS, et al., 2017; NOOJIPADY et al., 2017).

The issue of food crop displacement due to biofuel competition has been raised by the United Nations Environment Programme (UNEP, 2012), concluding that LUC is the main cause of GHG emissions of biofuels in general. LUC is a complex process caused by the interaction of natural and social systems at different temporal and spatial scales. It can induce GHG emissions due to oxidation of soil organic carbon and due to burning or decomposition of above-ground biomass. Unfortunately, we could not estimate the land-use GHG emission from sugarcane production since all the available data for the land-use change GHG emissions do not discriminate their source and, therefore, as explained in previous sections, all the land-use GHG emissions were allocated into the Agricultural sector. However, $70 \%$ of GHG emissions from the Agricultural sector, excluding the emissions from land-use, comes from livestock production in Goiás.

Biofuel crops account for about $4 \%$ of global agricultural production area (UNEP, 2009). Therefore, the magnitude of GHG emissions due to LUC from global biofuel production is small compared to the total LUC-related emissions: agricultural land expansion for food, feed, fibre, cattle ranching, fuel wood and timber (i.e. loggings), and expansion of infrastructure generates the greater part of LUC emissions. 
However, competition with food crops for producing in Brazilian suitable areas must be identified and analysed by further studies, considering variations of both land and agricultural commodities' prices. Indeed, the sugar market, oil prices, land prices, GHG abatement opportunity costs and public subsidies are some key variables to be considered in the analyses. Regarding investments on land, the High-Level Panel of Experts (HLPE, 2013) recommends to governments to ensure that the principles for responsible investment in agriculture will be effectively implemented and monitored, especially in the case of investments for biofuel production. According to RATHMANN et al. (2010), the emergence of agro-energy in large scale has changed the land-use dynamics in the state of Paraná, Brazil, shifting traditional food producing areas to biofuels production and contributing to increase the food prices in the short-run. Also, higher monetary returns to farmers from agro-energy lands can negatively impact local food production (RATHMANN et al., 2010).

Nonetheless, the Brazilian Cerrado has been under increasing anthropic pressure since many years, but land cover and land-use change in the biome have been largely overlooked. Cropland expansion in the biome partially offset recent declines in Amazon deforestation emissions, highlighting the critical need for national scale accounting for successful climate mitigation through $\operatorname{REDD}^{21}$ (NOOJIPADY et al., 2017). Although it is an important agricultural producing state, Goiás must meet $20 \%$ of each rural property as Legal Reserve required by the Brazilian Forest Code and currently, the state has a reserve deficit of 7,500 $\mathrm{km}^{2}$ and another $16,300 \mathrm{~km}^{2}$ of land are projected to be deforested in the coming years (SOARES-FILHO et al., 2013; YOUNG et al., 2016). Thus, besides the need to comply with environmental legislation, understanding recent land-use change patterns (and how it affects the regional water balance) and visualizing a sustainable landuse pathway in the state might become even more strategic in developing local and national policies that ensure sustainable agricultural (and biofuel) development.

The additional water demand from the increasing sugarcane production would not likely impact significantly the region, given the high-water availability in most of the Paranaíba basin, especially in the western section. However, the National Water Agency (ANA, 2015) pointed out some conflict areas regarding multiple water uses especially caused by agricultural demands. Overall, water resources availability in the basin are

\footnotetext{
${ }^{21}$ REED+ stands for countries' efforts to reduce emissions from deforestation and forest degradation, and foster conservation, sustainable management of forests, and enhancement of forest carbon stocks.
} 
considered as unthreatened (FACHINELLI and PEREIRA, 2015; TAYT-SOHN, 2014), but as cropland continues to expand at the expense of Cerrado vegetation, it could affect the rainfall regime that supports both natural vegetation and agricultural production (SPERA et al., 2016; HUNKE et al., 2015). From a broader standpoint, the Cerrado feeds 8 of the 12 hydrographic regions of Brazil and because $70 \%$ of country's electricity comes from hydropower plants, conservation of the biome is also critical for Brazil's energy security (OLIVEIRA, et al., 2015).

Although most of the basin is suitable for growing sugarcane, this crop's expansion would greatly rely on supplementary irrigation when analysed through climate scenarios considering local changes on temperature, evapotranspiration and air humidity (TAYT-SOHN, 2014). Also, it is noteworthy mentioning the relatively low water impacts from irrigated sugarcane in the region due to the so-called salvage irrigation, which corresponds to vinasse application. However, ANA (2017) states that the water used in irrigated sugarcane in Brazil is relatively unknown, raising concerns over the use of this resource.

Thus, both ethanol production limits and environmental constraints must be considered to avoid impacts on water and land resources in Goiás State. Additionally, analyses must consider the water and land availability in each Water Management Unit of the Paranaíba basin since these resources widely vary according to local activities and development.

Goiás' economy would be slightly impacted in terms of economic growth and social welfare in response to changes in final ethanol demand. Still, a positive correlation between GDP growth and the employment level was observed. As expected, the Biofuels sector shows major changes in terms of value added, followed by the Agricultural sector for all scenarios. Despite purposely limited by water constraints in the worst-case scenario (scenario $2 e$ ), sugarcane crops could expand about 5-fold the current level of production in the region, causing significant positive impacts on local GDP, i.e. 8.3\% increase, and employment, i.e. $7.1 \%$ increase, in this hypothetical scenario. However, if biofuel production relies on high mechanization and displacing traditional agriculture, it can lead to employment losses (RAVINDRANATH et al., 2011; LA ROVERE et al., 2011).

In fact, agricultural is one of the sectors with the highest increase in unemployment rates in recent years in Brazil. While the sector's GDP increased from 32.44 million US\$ in 2000 to 47.16 million US in 2015 (i.e. an increase of 45.4\%), labour 
demand decreased from 7.88 million jobs in 2000 to 6.42 million jobs in 2015, a reduction of 1.46 million jobs (i.e. -18.6\%) (IBGE, 2017b). Overall, the occupation/GDP ratio has declined by a factor of $56 \%$, from 0.243 jobs for every US\$ dollar added by the sector to $0.136 \mathrm{jobs} / \mathrm{US} \$$. Therefore, there is a strong trend of reduction in the technical coefficient in terms of labour demand per unit of agricultural output, possibly showing the effects of improved agricultural productivity and increased mechanization in farming activities. This trend requires further analysis addressing the potential socio-economic impacts in promoting biofuels expansion in the country.

Again, without considering land and food price changes from changing traditional food crops to biofuel crops, it is difficult to estimate the socio-economic impacts on lowincome classes regarding the access to food resources. Therefore, increasing local GDP from future sugarcane expansion may positively impact the local socio-economic indicator for income (i.e. employment would be positively impacted only if sugarcane expansion was based on traditional agricultural practices). On the other hand, expanding sugarcane production may also negatively impact socio-economic development and equity, by promoting higher food prices and lower accessibility to food and land. However, by modelling macroeconomic and environmental impacts from biofuels production in Brazil, OBERMAIER et al. (2017) have shown reduced macroeconomic impacts, even when there is high pressure on land resources. Their results show that neither climate change nor the implementation of sustainable measures for land-use as suggested by Brazilian NDCs would cause negative significant impacts on national GDP.

As pointed out by some authors (HRISTU-VARSAKELIS et al., 2010; WHITE et al., 2017; CARVALHO et al., 2015; WANG and CHEN, 2016), our findings may also be useful to theoretical and empirical research on specifying economic and environmental effects of policies with the use of hybrid IO tables. However, note that the deterministic nature of the technical coefficients, i.e. which are constant and reflect the economic structure in the base year, does not capture the fact that livestock and sugarcane production expand towards less and less appropriate areas in terms of soil quality, water availability, land slope, etc. That is, the variation of the first unit of final demand has the same impact of the $n^{\text {th }}$ unit in IO models, underestimating the real impacts. Additionally, some estimates may be biased due to some inter-relationships among sectors being different in 2030, when compared to the baseline year, i.e. 2008. Nevertheless, it is 
important to recognize any initiative focusing on introducing environmental and energy aspects into the conventional national accounts, despite its limitations.

Although the nexus literature identifies policy barriers and options for overcoming them, it is based on a technical-administrative view that is a little distant from the reality of decision-making processes and because ideology, norms and values shape policy-making, the search for policy coherence is not an objective process free of interests (WEITZ et al., 2017). Conflicting objectives may rise from negotiation between varying interests, represented by stakeholders with unequal power and, therefore, nexus analysis must look beyond policy objectives and analyse the principles they are built on (WEITZ et al., 2017). Thus, connecting the nexus to decision-making processes also requires rethinking the boundaries of the nexus analysis, sharing principles which can guide decision-making towards policy coherence and, viewing policy coherence as a continuous process of changing values and perception rather than as an outcome (WEITZ et al., 2017).

\subsubsection{Managing local water resources}

Despite presenting low water demand for agricultural uses and hence, low sugarcane production, the Meia Ponte WMU showed the worst water impairment indicator, i.e. highly critical, when considering the water-flow used for granting rights to water use in the region. Therefore, this WMU must not be the focus of sugarcane expansion in the basin since it has already been suffering real threats regarding surface water availability.

Additionally, since Turvo-Bois and Lower Paranaíba Minas Tributaries have been presented low surface water availability and historically high sugarcane expansion rates, these WMUs must be focus of specific studies regarding water use and availability; irrigated sugarcane crops expansion; available water for irrigating food crops; water requirements for hydroelectric plants; etc., aiming to determine the real conditions of water resources availability in these specific regions and then, maybe further limiting sugarcane expansion through these areas.

As an alternative, the Claro, Verde, Correntes and Aporé WMU presents high potential for growing sugarcane, according to the ZAE Cana, besides having higher surface water availability, high available pasturelands with low-density cattle heads per area, high availability of suitable agriculture areas and relatively low current sugarcane 
production. Thus, sugarcane producers may be encouraged to expand sugarcane crops towards this WMU instead of growing more sugarcane in traditional areas, which may have been harming water resources availability in the region. On the other hand, despite this WMU be most occupied by livestock production, soybean and corn crops are cultivated in its Northwest section and producing more sugarcane in the WMU may lead to some level of competition for water and land resources between sugarcane and food crops. Therefore, biofuel policies shall better understand these distinct characteristics among different WMU before promoting sugarcane expansion on a river basin, region or state.

Another water issue but not addressed by the current study is related to water quality indicators. Sugarcane production requires the use of nitrogenous fertilizers, pesticides and even herbicides, all leading to pollution of soil and down-stream water bodies (RAVINDRANATH et al., 2011). The runoff of nutrients, particularly nitrogen and phosphorus, leads to eutrophication of water bodies affecting aquatic biodiversity. Also, the fertigation of sugarcane crops with vinasse, i.e. a potassium-rich sugarcane byproduct, is widely applied in the Paranaíba basin and this common practice may be an important source of water pollution in the region. As the same as for the water availability in each WMU, further studies should focus on the water quality in these target WMU before promoting sugarcane expansion towards those regions. On the other hand, if properly managed, the fertigation can reduce both fertilizer applications and water withdrawals for sugarcane irrigation.

This work has been focusing on the worst-sugarcane expansion scenario in order to understand the limits to which sugarcane crops could be cultivated in the Paranaíba basin. In this regard, we have applied to our estimates the higher ethanol supply scenarios (i.e. Brazilian official data, from EPE, and our calculations) and the most restrictive data regarding water use, i.e. $50 \%$ of reference flow $Q_{95} \%$. Also, to perform the analyses herein, it has been used both the surface water availability and the water withdrawals, instead of water consumption ${ }^{22}$, i.e., less restrictive. Therefore, when considering the water consumption, i.e. which considers different water rates of return, depending on the

\footnotetext{
22 The water consumption indicator was used to estimate the water-use by economic sectors in the Goiás' hybrid IO table, for representing the volume of water that could not be used for other uses. However, when analysing both the water balance and the water availability in the Paranaiba basin, it was used the water withdrawals indicator, i.e. more restrictive, instead of water consumption indicator. Water consumption indicator considers different rates of return of water, depending on the activity.
} 
activity, the water availability and the impairment indicators of water would be higher (therefore, better) than those presented in this study. Again, we are focusing on the worstcase scenario to limit sugarcane expansion up to that point, which means any point under that limit would cause less impacts than those described herein.

As mentioned above, groundwater availability was not considered for the Paranaíba basin and its WMUs. Therefore, for every WMU identified here as having water constraints, there are additional water from groundwater reserves (Table 19). Again, the sugarcane crops can also pollute groundwater resources through fertigation processes, besides impacting groundwater availability through water withdrawals.

Table 19. Groundwater resources in the Paranaíba basin. Active reserves and water availability, by WMU.

\begin{tabular}{lccc}
\hline \multirow{2}{*}{ Water Management Units $($ WMU) } & \multirow{2}{*}{ Active reserve } & $G A^{a}$ & $\begin{array}{c}\text { Annual } \\
\text { Par }\end{array}$ \\
\cline { 2 - 4 } & $\mathrm{m}^{3} / \mathrm{s}$ & $\mathrm{m}^{3} / \mathrm{s}$ & $\mathrm{hm}^{3}$ \\
\hline Paranaíba basin & 857.43 & 428.87 & 13,525 \\
São Marcos & 80.78 & 40.39 & 1.273 \\
Meia Ponte & 61.59 & 30.79 & 971 \\
Turvo-Bois & 165.34 & 82.67 & 2.607 \\
Claro, Verde, Corrente and Aporé & 439.35 & 219.68 & 6,928 \\
Lower Paranaíba Minas Tributaries & 104.67 & 52.33 & 1,650 \\
\hline
\end{tabular}

Note: ${ }^{a}$ GA: Groundwater Availability. ${ }^{b}$ Data from the Paranaíba basin was multiplied by $63 \%$ since this is the share of Paranaíba basin in the state of Goiás.

Values for the whole Paranaíba basin (100\%): Active reserve (1,361 ms $) ; G A\left(680.75 \mathrm{~m}^{3} / \mathrm{s}\right)$; Annual GA $\left(21,468 \mathrm{hm}^{3}\right)$.

Source: ANA (2015).

Regardless the groundwater availability (and quality) not being considered in our estimates, we can verify similar patterns to the surface water availability in the basin, namely, Meia Ponte WMU showing the lower groundwater availability and Claro, Verde, Correntes and Aporé WMU having the higher groundwater availability throughout the basin.

\subsubsection{Indirect land-use change impacts}

The possibility of expanding future sugarcane crops over old pasturelands rises important concerns related to ILUC impacts. In fact, if sugarcane expansion in Goiás push most of the livestock production towards native florets, the outcome would be quite impactful in terms of deforestation and its associated GHG emissions. However, the use of unproductive lands, better management practices, intensification of livestock production, as well as the implementation of a payment for environmental services policy 
could reduce the need for new producing areas and promote better outcomes in the sector, using the same or lesser amount of land. These measures could free up space for sugarcane production in old pasturelands reducing ILUC impacts from expanding sugarcane in the state. On the other hand, cattle ranchers tend to purposely keep a reduced number of cattle on their lands in order to ensure that the Brazilian Institute for Agrarian Reform - INCRA, does not expropriate their land for agrarian reform purposes; therefore, promoting the intensification of livestock production constitutes a challenging task for the Brazilian government.

Accounting for a significant share of total national production, agricultural activities are mostly expanding over pasturelands and croplands located in the Southern section of the Cerrado biome. Thus, identifying unproductive land in this section of the biome could help to address important gaps on crops expansion in the region, adjusting activities through an agro-ecological zoning that explores better socio-economic and environmental conditions for each producing activity. In this context, if sugarcane crops expand towards the recommended WMU considering water and pasturelands availability (i.e. Claro, Verde, Correntes and Aporé WMU), the foregone livestock production could move to native forests causing unintended indirect impacts from biofuel expansion in the basin. On the other hand, agricultural expansion in the Northern section of the biome, especially in the region of MATOPIBA, has been directly threatening native forests and offsetting most of the avoided emissions in the Amazon biome in recent years, jeopardising Brazilian NDCs targets. Overall, GHG emission reductions in the Amazon are being compensated by emissions in the neighbouring biome due to recent increase in legal, monitoring and control efforts in the Amazon, highlighting the importance of also monitoring and controlling Cerrado's native forests.

This increase in deforestation may be occurring because of the reduced number of areas under protection in Cerrado, which are insufficient for controlling disordered agricultural expansion and to dismantle land-grabbing and speculation. Additionally, the Forest Code defines that only $20 \%$ of a farm must be kept as protected area (i.e. Legal Reserve), but it can also be used as productive land, as long as sustainable production practices are implemented. This percentage of Legal Reserve is considered low, when compared to the $80 \%$ required in the Amazon biome. The lack of knowledge and information gaps contribute to deforestation in the biome, as Cerrado's full potential as a carbon sink and storage is still uncertain. The role of Cerrado's vegetation in water 
balance, both in terms of supporting the recharge of aquifers and the relationships with rainfall formation, is not fully understood and recent changes in precipitation patterns are already affecting agricultural productivity in the biome (SPERA et al., 2016).

Another significant indirect driver for the deforestation in Cerrado is the international demand from agricultural commodities markets. Only for soybeans production, the estimated GHG emissions from deforestation in the biome account for 1,830 $\mathrm{TgCO}_{2}$, which is about $80 \%$ of Brazil's gross GHG emissions in 2016 (SEEG, 2017). Although soy and other mechanized crop production are not the major drivers of deforestation in the Amazon or Cerrado, cropland expansion has larger gross and net carbon emissions per unit area than pasture expansion, based on the need for complete removal of above and below-ground biomass (NOOJIPADY et al., 2017).

Aiming to avoid further deforestation caused by increasing agricultural production in the country, Brazil must prevent further clearing of native forests through the following measures, among others: $i)$ promote and immediately implement the economic mechanisms provided by the Forest Code, which are still missing regulation and implementation; ii) strengthen the enforcement against illegal deforestation, especially in the Cerrado biome; iii) implement in the shortest time possible a payment for environmental services policy and; $i v$ ) regulate ILUC patterns from agricultural activities, in order to reduce indirect impacts on native forests.

Therefore, solutions for agriculture encompass the engagement in environmentally sustainable agricultural production by agents that promote deforestation, by the means of the creation of international certification standards that include a ban on cultivation in newly deforested areas and areas of outstanding conservation interest, as well as compliance with local laws and, in the case of biofuels, by including indirect GHG emissions from their production process (i.e. considering ILUC emissions). As access to special markets or financial rewards usually results from certification schemes, farmers, ranchers and loggers, among others, are joining together to create voluntary records, in which participants undertake to improve their socio-environmental performance.

In order to mitigate the externalities of intensification of livestock and agricultural expansion, the government and the agricultural sector must focus on large-scale environmental conservation and restoration aiming to support the maintenance of the climate stability and environmental services provided by forest ecosystems. 


\subsubsection{Integrated biofuel policy}

The main Brazilian energy policy - PDE (MME, 2017b) was useful in determining future ethanol demand and supply scenarios, as well as was the specific publication from EPE/MME regarding ethanol demand and supply scenarios to 2030 (EPE, 2017). Also, the 2050 energy demand technical report (EPE, 2016) was helpful in understanding the Brazilian long-term targets for energy policies. Even considering macroeconomic and socio-economic data forecasts in the mentioned energy policies, these policies lack on integrating additional aspects included in the current study. For example, even estimating social impacts from future changes in ethanol demand and changes in production practices, the analysed energy policies make their conclusions by using an isolated approach.

Also, even mentioning the GHG emissions reduction from reducing sugarcane burning in the harvesting process, this GHG reduction is not quantitatively linked to the national emissions targets and policies. Neither the PDE nor the ZAE Cana consider GHG emissions from land-use change in any geographic scale. However, that is a major issue even when considering the national efforts on estimating GHG emissions from land-use, since DLUC and ILUC show many methodological inconsistences to date. Also, the National Inventory for GHG Emissions is not currently linked to other land, water or energy policies, being elaborated from estimates from energy use, agricultural and industrial processes. However, the RenovaBio comes to overcome the issues related to GHG emissions, since this biofuel policy aims to determine emission targets to be fulfilled by fuel distributors in the country. On the other hand, it apparently fails in considering ILUC GHG emissions from producing biofuel crops.

The PDE also considers in its forecasts the water required for sugarcane production, however, it is applied a national water-use coefficient (i.e. average) for ethanol production, which includes both the agricultural and industrial production phases. This represent an incipient initiative aiming to include water requirements from sugarcane production in the country, however, in a continental country such as Brazil, it is necessary to evaluate the local water use and the local water availability according to each river basin where sugarcane is cultivated.

Our results show that even considering a specific river basin, the total water use and availability may constitute an inadequate effort on analysing the water available for expanding irrigated sugarcane crops. Land-use, sugarcane production and water 
availability differ from each Water Management Unit into any river basin, showing that water use and availability for sugarcane must be analysed from the WMU standpoint. Also, PDE does not consider the competition for water between different crops and between other consumptive uses such as public supply, livestock production, hydroelectric generation, etc., lacking multiple water uses forecasts and not considering climate change scenarios.

Similarly, the ZAE Cana is a very useful tool in mapping the available land for sugarcane growing in the country, indicating their specific potential and current land-use, but again, it does not consider the PDE's forecasts regarding future ethanol production. Also, the ZAE Cana was elaborated using land-use data before 2008, clearly requiring an urgent update. The last Brazilian Agricultural Census date from 2006 and it also indicates necessity to update many important data regarding agricultural, energy, economic and social aspects in the country. Therefore, despite being useful, the ZAE Cana is not enough to evaluate the potential suitable areas in the country and in the Cerrado biome due to not considering both the updated land-use patterns, the energy policies forecasts (both biofuels, biomass and hydropower generation) and the water availability for each strategic region of sugarcane production.

Also, the Brazilian Forest Code was enacted in 2012 and obviously the ZAE Cana, published in 2009, could not incorporate the Forest Code new requirements on planning the sugarcane expansion in the country. However, when determining suitable lands for sugarcane expansion, the ZAE Cana excluded areas with native vegetation cover, Amazon and Pantanal biomes, environmental protection areas, indigenous lands, forest remnants, dunes and mangroves. Therefore, as the Forest Code imposes use restrictions on these types of land cover, even not updated, the ZAE Cana is still useful to help analyse sugarcane expansion in Brazil. On the other hand, it does not consider the forest liability regarding the forest recovery required by the Forest Code, i.e. $20 \%$ of Legal Reserves in all farms outside the Amazon biome and $80 \%$ in the Amazon.

The Paranaíba River Basin Plan (PRBP) shows a very comprehensive explanation from water use, water availability and water balance based on the total average surface water flow in the basin. It also includes socioeconomic data, land and water use patterns for each WMU of the basin. The Paranaíba basin is a very complex river basin due to covering four different Brazilian states (i.e., a transboundary basin) and its main river, the Paraná river is a national strategic river. Despite this complexity, overall, we can affirm 
that the PRBP constitutes a very well implemented water management structure, especially when comparing to most of the Brazilian states. However, even considering future projections on water use and specific forecasts for land-use, the PRBP does not mention the ZAE Cana regarding potential expansion sugarcane areas in the basin and it also does not consider the PDE's ethanol forecasts for sugarcane growing in Brazil and in the Centre-West region.

In this regard, the projected increase in biomass production will demand more water and land in the region, which is not currently properly addressed through the PRBP, nor the ZAE Cana. As an example, the PRBP shows absolute values for water availability for each WMU but those data are not crossed with data from the PDE and the ZAE Cana to better address the sugarcane expansion towards WMU with higher water availability and higher potential suitable areas for growing sugarcane. That is the case of the Meia Ponte; Turvo-Bois and; Claro, Verde, Correntes e Aporé WMU, where the first shows low water availability, high water demand, low potential for sugarcane production and low sugarcane production; the second shows medium-low water availability, high water demand, high potential for sugarcane production and high sugarcane production; and the last, shows high water availability, low water demand, high potential for sugarcane production and relatively low sugarcane production. Historically, sugarcane production has been mainly occurring in the Turvo-Bois WMU, but we can observe from our analysis that the best WMU for sugarcane expansion would be the Claro, Verde, Correntes and Aporé WMU. However, neither the PDE, nor the ZAE Cana, nor the PRBP cite this pattern and indicate the best region for expanding sugarcane in the basin, after considering land, water and energy analysis through an integrated approach. It clearly shows lack of communication between different Brazilian agencies in charge of managing fundamental production inputs (i.e. not only for sugarcane and ethanol production).

Also, even mentioning sugarcane expansion over the basin, neither the PRBP nor the ZAE Cana show any specific strategy for expanding sugarcane growth in the region. Similarly, those policies do not consider any level of competition for land and water resources in the region of study between different users both in the present and future, such as sugarcane, soybean and corn production, hydropower generation, livestock production, deforestation or the recovering of riparian forests and sensitive areas, etc. Finally, neither the PDE nor the PRBP mention the Forest Code legal requirements in their planning regarding energy forecasts and water management, respectively. The 
assessment of available land hardly considers uses other than crop production, which often play a crucial role to ensure the food security of local populations (HLPE, 2016); therefore, competition for land and water must be assessed and managed at local level. Again, these competing or replacing issues are not taken into account by the PDE nor by Brazilian GHG emission policies.

Taking this lack of policy integration into account, this work aimed to apply an integrated approach focusing on analysing related impacts from sugarcane expansion in the state of Goiás as a preliminary initiative towards the understanding of social, economic and environmental integrated impacts from changing future ethanol demand in the region. In this context, even considering the worst-case scenarios ( $2 d$ and $2 e$ ) our results show that there would probably not be major impacts on water and land resources in the region (i.e. direct impacts), provided that sugarcane expansion occurs over old pasturelands located mainly in the Claro, Verde, Correntes and Aporé WMU (i.e. highwater availability, high pasturelands with low-density cattle heads per area and low current sugarcane production). However, ILUC effects must be taken into account when deciding to push any commodity production, especially in the case of flex-crops, due to their potential to replace traditional agricultural activities and create an indirect need for new agricultural land. In fact, indirect GHG emissions from biofuels production can offset the main objective of an emission reduction policy, justifying the conception of a biofuel policy through an integrated standpoint considering all inputs and outputs related to the biofuels' production process.

Perhaps, the results found herein are not the most important part of this study. Results from model simulations are only numbers which can be managed in any way, following basic assumptions. In a broader context, there is no much hard evidence on the economic and social consequences of the development of biofuels, mainly because these impacts take longer to manifest themselves (HLPE, 2016). But the effective result obtained here is related to the possibility of integrating water, land, energy and GHG emissions to economic and social data through a framework which can model and detect integrated impacts on a region, state or river basin. By applying the economic-ecological hybrid IO model, we can suggest better options to design biofuel policies than those policies performed in a traditional and isolated way, which do not encompass the variety of impacts that can derive from a single change in future final demand for goods and services in the economy. 
Even if one may not consider the hybrid IO model as the best tool for evaluating integrated impacts in designing biofuel policies, we can state that regardless the tool or methodology to be used, the most important change in biofuel policy approach resides on integrating different policies with distinct objectives into a single more embracing and local-specific biofuel policy. Therefore, more coherence between policies related to water, energy, food and GHG emissions are needed at both the basin and nation levels to improve the sustainability of water, energy and food (LAWFORD, et al., 2013). In this context, MAROUN (2014) have applied an integrated approach to assess the biofuels sustainability in Brazil through a case study of ethanol production in the state of São Paulo, and her conclusions were similar to the conclusions found herein, i.e., isolated analyses on biofuels may lead to misleading conclusions, evidencing lack of integration when analysing energy, water and land-use policies and finally, suggesting to design specific biofuel policies in promoting their sustainable development in the country (Figure 43).

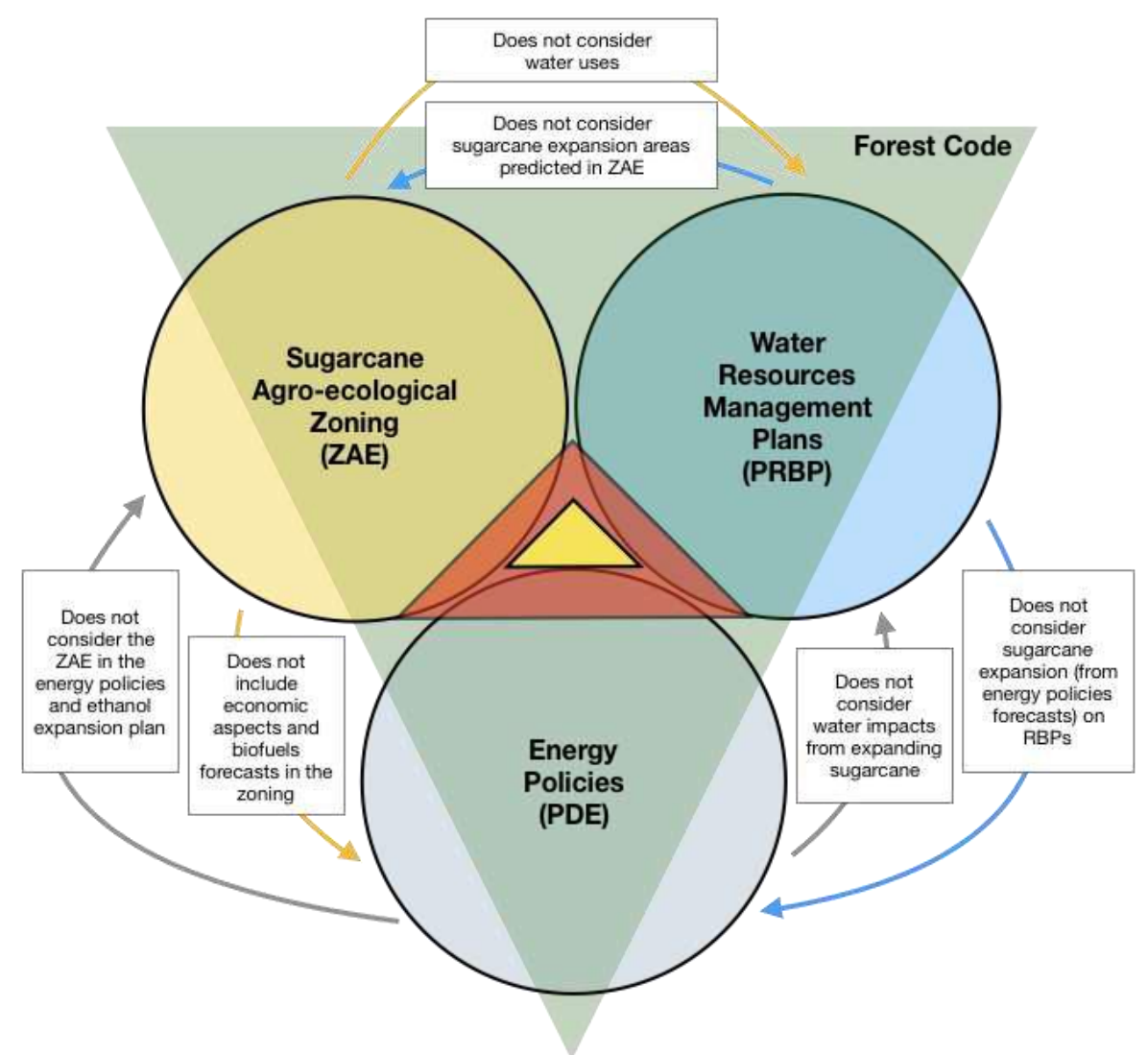

Figure 43. Lack of integration between energy, water and land policies.

Note that the yellow triangle represents the gaps between current isolated policies for water, energy and land use. The red triangle represents the desirable policy integration considering the goals from all the three policies combined, targeting the sustainable ethanol sugarcane expansion. Also, the Forest Code, i.e. the red triangle, must be considered for every policy, isolated or not. 
Finally, as presented in section 2, Brazilian government is expected to implement a national biofuel policy aiming to better address biofuels development in the country for the coming years. Although this is a relevant measure to boost biofuels production and use in the country, which will be based on decarbonisation credits issued by producers and verified by certification process before traded through market mechanisms, this biofuel policy does not mention any policy integration between biofuels, land and water.

Based on GHG emission targets, the RenovaBio constitutes a step forward regarding national initiatives on promoting the development of renewable energies in Brazil and linking the energy sector (through biofuels) to climate commitments. However, at this time, it fails in considering ILUC GHG emissions from biofuel crops, neglecting the fact that biofuels expansion may push other crops (and mainly the cattle) to new land, especially in the Cerrado and the Amazon biomes, emitting a significant amount of GHG due to deforestation. It also fails in treating water and land as fundamental resources on planning the national biofuel production, which raises concerns about this measure. Indeed, despite the Legal Reserve current deficit that must be reforested as required by the Forest Code, Brazil has plenty of land available to expand its agricultural activities but recently, both the water quality and availability have been ignored by government initiatives, causing shortages of supply and socio-economic losses. In this context, even though the RenovaBio arises to boost Brazilian biofuel sector and socio-economic indicators, society will still demand structural changes regarding the way we plan our future; a planning which embraces all externalities related to an energy policy option, whether fossil or renewable.

\subsection{Work limitations}

Because the Brazilian government does not produce a statistical information system that combines conventional national accounts and environmental accounts, part of the data required to carry out the analyses herein were estimated from different sources and based on a set of assumptions. Thus, an uncertainty must be considered for anyone intending to use the results found herein to perform further analysis. However, all the assumptions applied to cover the lack of data availability were performed through scientific fundamentals focusing on justifying and limiting that uncertainty. On the other hand, it is important to recognize the issues and limitations on introducing environmental and energy aspects into the conventional national accounts. 
It should be mentioned that estimates on water use were performed from applying water use coefficients at the bulk production in the country for the base year (Appendix XII). Thus, some units of industrial production in the National Accounts System are incompatible to some water use coefficients, preventing precise estimates in these cases. However, industrial processes were less important in terms of water use in the Goiás economy. Also, there were difficulties in estimating water use by the Power sector, mainly through estimates from reservoirs evaporation (Appendices XVIII, XIV and XV), even though the country's best available data has been employed (ONS, 2004, 2005, 2017).

Regarding livestock production, there are no official data precisely covering the sector's land use in terms of area; the most recent available data is the 2006 Agricultural Census. Most government data are related to the quantity and types of animals and they are poorly related to the area required for raising them. On the other hand, there are several smaller and frequently non-governmental and research initiatives aiming to map the livestock land use in Brazil, to better address this issue in the country (see MAPBIOMAS, 2017). Finally, the agriculture and livestock footprint and production applied to this study are data for the state of Goiás and not for the agricultural production located only in the Paranaíba basin and, therefore, the land-use by these activities were overestimated.

The estimated GHG emissions from the Goiás' hybrid IO model was conducted according to the sectors' emissions published by the Emission Estimating System for GHG (SEEG). However, when our policy scenarios consider substituting gasoline for ethanol, the difference between emissions from replacing gasoline for ethanol were not calculated by the model. Therefore, all GHG emissions for scenarios which consider the gasoline substitution for ethanol (scenarios $2 b, 2 c, 2 d$ and $2 e$ ) were overestimated due to this GHG emissions gap between fuels, not accounted here. Authors have been mentioning that the production and use of ethanol in Brazil have a very positive direct impact on GHG emissions mitigation (SZKLO et al., 2005, COELHO et al., 2006, MACEDO et al., 1998, 2008, GOLDEMBERG, 2008, GOLDEMBERG and GUARDABASSI, 2009, PACCA and MOREIRA, 2009, HIRA and OLIVEIRA, 2009, LA ROVERE et al., 2011; MOREIRA et al., 2014).

Additionally, all GHG emissions for all scenarios may be overestimated due to differences in accounting the land-use GHG emissions for the baseline year, when 
considering subsequent years after 2008 (as explained before, in the section 3.1.5.4). However, the data provider does not mention any inconsistency regarding this major difference between emissions before and after 2008. Despite the high data quality regarding GHG emissions from the Agricultural sector (SEEG, 2017b), emissions from land-use in the Cerrado do not show the same quality. Most of the data regarding landuse change is classified as medium quality, requiring some additional data (i.e. incomplete or restricted data) or needing to improve the method of quantification and the emissions allocation. The liming process is considered as having high-quality data, while forestry residues show medium-quality data due to the same restrictions as land-use data.

Finally, climate change effects (such as temperature increase, rainfall and evaporation changes) on sugarcane crops and other crops, on water availability and future hydropower generation in Goiás were not accounted either by this study, nor the PDE and nor the PRBP, showing lack of understanding of future scenarios for sugarcane and food crops production in the region, besides the additional impacts that can be created from reduced water and land availability for developing local economy. 


\section{Conclusions}

This study presents an economic-ecological hybrid IO framework, used to develop a WEFN analysis applied to Goiás' State economic system. The Goiás' IO table was extended to assess water, energy and land use and GHG emissions. Therefore, environmental and economic aspects were evaluated considering 13 activity sectors and seven prospective ethanol supply scenarios, taking into account direct and indirect effects on the whole economic system from changes in final demand for ethanol.

Overall, the IO framework is useful for developing WEFN analyses, since they can be extended to assess GHG emissions, water, energy and land use, employment levels and GDP as targets to the same policy goal. Therefore, hybrid IO models coupled with WEFN approach are useful in specifying integrated impacts of biofuel policies and they can be applied to other energy commodities, economic sectors and regions in order to provide better solutions towards a greener economy.

The results obtained considering the WEFN approach provide useful insights about the trade-offs involved in biofuels expansion and may be used as a tool for decision makers and planners intending to collectively address economic, social, environmental and energy goals. In this context, our results suggest that decision makers may keep pushing $1 \mathrm{G}$ ethanol expansion in Goiás (i.e. after considering some important environmental concerns and restrictions), since it apparently has no major negative direct impacts on local environment. However, unintended impacts such as the possibility of indirect deforestation and its related GHG emissions must always be taken into account before promoting sugarcane expansion in the Paranaíba basin. Also, as this study did not address the use of agrochemicals and pesticides in sugarcane production, we cannot confirm that biofuels expansion would not significantly impact local environmental quality in terms of contaminants in the soil, water and groundwater.

Because it is a relevant socio-economic and environmental concern, the competition with food crops for producing in Brazilian suitable areas must be identified and analysed by further studies, considering variations of both land and agricultural commodities' prices. Additionally, the Brazilian Cerrado has been under increasing anthropic pressure since many years, but land-use change in the biome have been largely overlooked (also requiring specific policies). Thus, understanding recent land-use change 
patterns and visualizing a sustainable land-use pathway in Goiás might become even more strategic to local and national political agendas.

Considering the share of Goiás in the national ethanol production, expanding $1 \mathrm{G}$ ethanol in the region could contribute to Brazilian NDCs at the UNFCCC, i.e. to achieve $45 \%$ share of renewable energy in the national energy matrix, with $43 \%$ of GHG emissions reduction by 2030. On the other hand, it is important to consider indirect GHG emissions from unintended deforestation that may be caused by sugarcane expansion in the state, which could offset or even surpass the avoided GHG emissions promoted by a higher use of ethanol fuel in the country. Also, it is important to determine and restrict sugarcane expansion to areas with water constraints, especially in the water management units located in the central section of the Paranaíba basin, i.e., Meia Ponte and TurvoBois WMU (FACHINELLI and PEREIRA, 2015; ANA, 2015).

Since there are no refineries in Goiás, as an alternative, the government should encourage ethanol substitution for gasoline in order to reduce its import from nearby states. Policies may promote replacing $25 \%$ of gasoline consumption in the state aiming to increase local and national GDP, since water and land use would be slightly impacted when compared to no gasoline replacement scenarios. However, mechanized cropping in agriculture shows a trend of reduction in terms of labour demand per unit of agricultural output and, therefore, if sugarcane expansion is based on this type of production, socioeconomic indicators could be negatively impacted. In this regard, government should promote better agricultural practices such as agroecological production concepts aiming to develop a more sustainable agricultural sector and include concepts of familiar agricultural in producing food and fuels in the country. Such measures could promote better environmental quality, higher agricultural productivity, increase employment and income in rural populations, as well as contributing to the enforcement of environmental legislations and the compliance with national goals and international agreements.

Brazil suffers from a general lack of integrated federal land and water management, and environmental policy is similarly fragmented (HOCHSTETLER, 2007). Sustainable management of resources imply actions at various scales and, therefore, national management requires resource-use planning policies considering biomass use and its social, environmental and economic impacts through an integrated standpoint. Given the central role of the state in the governance of both the biofuels market and the impacts of their production, Brazilian public agencies, i.e. MAPA, MME, 
EPE, ANP, etc., should develop policies to manage the nexus of energy, water, food and GHG emissions, according to local conditions and by using integrated tools to assist the decision-making process. Discussions on biofuels sustainability shall, therefore, consider contextual factors instead of concentrating on limited sectoral assessments and, in this context, it is noteworthy remembering that Brazilian NDCs heavily depend on land-use strategies which includes biofuels and the agricultural development (OBERMAIER et al., 2017).

This calls for careful ex-ante policies and projects, taking into account all potential direct and indirect effects and, therefore, the big question today is how to integrate those issues in a comprehensive framework. From a broad review of the WEFN projects worldwide, ENDO et al. (2017) have pointed that developing methods to integrate interdisciplinary, multi-sectors, and multi-dimensional research results is essential to analyse and understand interrelationships and trade-offs among these three resources. In this sense, this work presents an approach which may be used to support and overcome some issues identified in the traditional policy-making process, often carried out in isolation by disconnected institutions.

Further improvements to extended IO models applied to the Brazilian ethanol case can include more accurate data and coefficients related to water-use, land-use and jobs creation by economic sectors, as well as including detailed DLUC and ILUC GHG emissions from the agricultural sector. Finally, we strongly suggest analyses considering the use of dynamic IO models, as well as general equilibrium models applied to Brazilian ethanol system.

Therefore, we suggest both the use of WEFN approach and hybrid IO models in analysing biofuels production in Brazil, to face the challenge of providing better solutions towards a greener economy. Also, this integrated analysis might provide good strategies regarding sustainable management of natural resources considering different political interests. Thus, this work may be used as a tool for decision makers and planners intending to collectively address economic, social, environmental and energy goals.

Regarding both the limitations and the main findings of this thesis, we suggest further studies aiming to overcome and better investigate the issues described here.

Since all estimates provided by the Goiás' hybrid IO model were based on original Goiás' IO tables, which were made for the year 2008 from 2000 national data, we strongly 
suggest further analyses considering the updated data from the Brazilian National Accounts System. Recently, IBGE has released a new version of the National Accounts for the year 2010. Additionally, we suggest including analyses on changes for goods and services final demand, other than the biofuels sector.

Overall, our analyses have focused on first-generation sugarcane ethanol production in the state of Goiás (precisely in the Paranaíba basin) but they can be applied to any other Brazilian sugarcane producing state. Results suggest that may occur conflicts between food and fuel crops for water and land resources in the region, in a short- and long-range, depending on the crop's location. However, we could not identify and address these issues properly. Conflicts between food and fuel crops for land resources are consequence of a quasi-open access frontier that exists in Brazil, i.e. since the agricultural land is continuously "produced" by deforestation, land-use conflicts are hidden; therefore, in a zero-deforestation situation, these results are very likely to be quite different. Therefore, further studies are recommended focusing on analysing the local competition between food and fuel crops, including further analyses on soybean biodiesel and second-generation ethanol expansion (from a variety of local available feedstocks).

We also suggest the use of specific tools in modelling the land-use pattern in the region, considering the current land-use and identifying conflicts between food and fuel crops. This initiative would help to estimate both the direct and indirect land-use change impacts from local biofuel production. We strongly suggest performing these analyses based on each water management unit of the Paranaíba basin and others in the CentreWest region. Also, land-price change analyses are encouraged aiming to understand how price-changes could impact the local land availability, food prices and social equity in the region.

Water resources modelling is required for better estimates on water use and availability, despite the data provided by the Paranaíba River Basin Plan. Water modelling tools can be applied on each water management unit aiming to also include future water demand for power generation, to better understand the role of hydropower stations on region's water demand. It is also suggested modelling the water required for irrigating food and fuel crops in the region and the surface and groundwater availability in each water management unit. Additionally, we suggest the simulation of climate change scenarios considering both crop's yield reduction and water availability regarding 
future changes in local environmental aspects and how climate change could impact socio-economic and environmental indicators for the region.

Regarding GHG emissions estimates, we also suggest computing GHG emission reductions from replacing gasoline for ethanol in our case study. Overall, there is need on developing better GHG emission inventories, especially regarding emission from DLUC and ILUC in biofuels production. Again, climate change scenarios are required on estimating their impacts on future sugarcane expansion and local GDP. Additionally, different carbon tax scenarios would help to better understand the role of Goiás' (and Centre-West region) sugarcane ethanol production in a broader context. These scenarios could also be compared to the GHG emission reductions proposed by RenovaBio's targets.

Considering both the lack of a national biofuel policy and the intrinsic complexity of integrated approaches, we strongly suggest the creation of a working group of experts from several strategic fields related to water, energy, land-use, climate change, economy and social issues, aiming to help design integrated biofuel policies through a comprehensive and more participative framework (including this panel of experts which have developed the RenovaBio). In this context, we also suggest updating the data from ZAE Cana considering water-energy-food-emissions-climate nexus analyses aiming to systematically include environmental, social and economic aspects into this relevant report. Similarly, we encourage developing the same policy and technical structure to evaluate the major commodities produced in the country, which also include mineral resources. Additionally, the same nexus approach should be implemented in planning the granting of rights on water resources when developing local, regional and national water resource policies and plans.

Finally, we strongly suggest further studies focusing on governance issues related to the water-energy-food-climate nexus of biofuel production, since none of those technical findings take action in real life without proper communication and the engagement of policy-makers and stakeholders. In short, information alone does not necessarily lead to policy change and administrative processes are not necessarily objective and, therefore, the WEFN approach will arguably have the difficult task of reconciling distinct institutions and interests. Thus, institutional reforms expected from the nexus integration idea can be seen as a key element within a broader nexus governance framework. 


\section{References}

AL-SAIDI, M., ELAGIB, N.A., 2017, "Towards understanding the integrative approach of the water, energy and food nexus", Science of the Total Environment, v. 574, pp. 1131-1139.

ALlOUCHE, J., MIDDLETON, C., GYAWALI, D., 2014, Nexus Nirvana or Nexus Nullity? A Dynamic Approach to Security and Sustainability in the Water - Energy - Food Nexus. STEPS Working Paper, 63, STEPS Centre, Brighton, UK.

ANA (AGÊNCIA NACIONAL DE ÁGUAS), 2002, Manual de Procedimentos para Outorga de uso da Água na Indústria e Mineração. ANA, Brasília.

2012. Conjuntura dos Recursos Hídricos no Brasil: Informe 2012. Brasília. Available at: http://arquivos.ana.gov.br/imprensa/arquivos/Conjuntura2012.pdf. Accessed 16 May 2017.

2015, Plano de recursos hídricos e do enquadramento dos corpos hídricos superficiais da bacia do rio Paranaíba. ANA, Brasília.

,2017, Levantamento da Cana-de-açúcar Irrigada na Região Centro-Sul do Brasil. ANA, Brasília.

ANDRADE, R.G., BOLFE, E.L., VICTORIA, D.C., NOGUEIRA, S.F., 2016, "Recuperação de pastagens no Cerrado", Agroanalysis (February). Available at: http://bibliotecadigital.fgv.br/ojs/index.php/agroanalysis/article/viewFile/63501/61592. Acessed 7 Dec 2017.

ANDREWS-SPEED, P., BLEISCHWITZ, R., et al., 2012, The Global Resource Nexus - The Struggles for Land, Energy, Food, Water, and Minerals. Transatlantic Academy, Washington, D.C. Available at: http://www.boschstiftung.de/content/language1/downloads/TA_2012_report_web_version.pdf. Access 7 Dec 2017.

ANEEL (AGÊNCIA NACIONAL DE ENERGIA ELÉTRICA), 2017. Banco de informações da geração - Usinas e centrais geradoras. ANEEL, Brasília. Available at: http://www2.aneel.gov.br/aplicacoes/capacidadebrasil/energiaassegurada.asp. Access 2 Nov 2017.

ANP (AGÊNCIA NACIONAL DO PETRÓLEO, BIOCOMBUSTÍVEIS E GÁS NATURAL), 2016. National Agency for Petroleum, Natural Gas and Biofuels, Anuário estatístico brasileiro do petróleo, gás natural e biocombustiveis.

, 2017, Ethanol Bulletin $n^{\circ}$ 9/2017. Superintendência de Refino, Processamento de Gás Natural e Produção de Biocombustíveis.

2017a, Vendas, pelas distribuidoras, dos derivados combustíveis de petróleo, Superintendência de pesquisa e desenvolvimento tecnológico. ANP, Brasília. Available at: http://www.anp.gov.br/wwwanp/dados-estatisticos. Access 8 Dec 2017.

2017b, Importações e exportações de petróleo, seus derivados, gás natural e etanol. ANP, Brasília. Available at: http://www.anp.gov.br/wwwanp/dados-estatisticos. Access 26 Feb 2018.

AREZKI, R., DEINIGER K., SELOD, H. 2011, What drives the global land rush? Washington, DC, IMF Working Paper.

BARKER, T., BASHMAKOV, I., et al., 2007, In: B. Metz, O. R. Davidson, P. R. Bosch, R. Dave, L. A. Meyer (Eds), Technical Summary, Climate Change 2007: Mitigation. Contribution of Working Group III to the Fourth Assessment Report of the Intergovernmental Panel on Climate Change, Cambridge University Press, Cambridge and New York, p. 93. 
BARRETO, P., SILVA, D.S., 2013, Como Desenvolver a Economia Rural sem Desmatar a Amazônia? Instituto do Homem e Meio Ambiente da Amazônia. IMAZON. Belém, PA. ISBN 978-85-86212-49-9.

BAZILIAN, M., ROGNER, H., HOWELLS, M., et al, 2011, "Considering the energy, water and food nexus: towards an integrated modelling approach", Energy Policy, v. 39, n. 12, pp. 7896-7906. Available at: http://doi.org/10.1016/j.enpol.2011.09.039. Accessed 9 Oct 2017.

BCB (BANCO CENTRAL DO BRASIL), 2017. Central Bank of Brazil. Rates of Exchange, 2017. Available at: http://www4.bcb.gov.br/pec/taxas/port/ptaxnpesq.asp?id=txcotacao. Access 31 Oct 2017.

BERNDES, G., 2008, Water Demand for Global Bioenergy Production: Trends, Risks and Opportunities, Materialien Wissenschaftlicher Beirat der Bundesregierumg Globale Umveltvaranderungen (WBGU), Berlin, 2008.

BEUCHLE, R., GRECCHI, R.C., SHIMABUKURO, Y.E., SELIGER, R., EVA, H.D., SANO, E., ACHARD, F., 2015, "Land cover changes in the Brazilian Cerrado and Caatinga biomes from 1990 to 2010 based on a systematic remote sensing sampling approach", Applied Geography, v 58, pp. 116-127. Available at: https://doi.org/10.1016/j.apgeog.2015.01.017. Access 15 Nov 2017.

BIGGS, E.M., BRUCE, E., BORUFF, B., et al, 2015, "Sustainable development and the waterenergy-food nexus: a perspective on livelihoods", Environmental Science and Policy, v. 54, (December) pp. 389-397. Available at: http://dx.doi.org/10.1016/j.envsci.2015.08.002. Accessed 9 Oct 2017.

BORZONI, M., 2011, "Multi-scale integrated assessment of soybean biodiesel in Brazil", Ecological Economics, v. 70, n. 11 (Sep.), pp. 2028-2038.

BP (BRITISH PETROLEUM), 2017. BP Statistical Review of World Energy. 66 ${ }^{\text {th }}$ ed., June 2017. Available at: https://www.bp.com/content/dam/bp/en/corporate/pdf/energyeconomics/statistical-review-2017/bp-statistical-review-of-world-energy-2017-full-

report.pdf. Data also available at: https://www.bp.com/en/global/corporate/energyeconomics/statistical-review-of-world-energy/renewable-energy/biofuelsproduction.html. Accessed 9 Oct 2017.

BRASIL, 1997. Lei n. 9.433, de 8 de janeiro de 1997. Institui a Política Nacional de Recursos Hídricos, cria o Sistema Nacional de Gerenciamento de Recursos Hídricos, regulamenta o inciso XIX do art. 21 da Constituição Federal e altera o art. 1o da Lei no 8.001, de 13 de março de 1990, que modificou a Lei no 7.990, de 28 de dezembro de 1989. Diário Oficial da União, Brasília, DF, seção 1, p. 470.

2012. Lei n. 12.651, de 25 de maio de 2012. Dispõe sobre a proteção da vegetação nativa e dá outras providências. Available at: http://www.planalto.gov.br/ccivil_03/_ato20112014/2012/lei/112651.htm. Access 10 Jun 2018.

, 2013. Lei n. 12.787, de 11 de janeiro de 2013. Dispõe sobre a Política Nacional de Irrigação, 2013.

, 2016. Ministério da Ciência, Tecnologia e Inovação (MCTI), Terceira Comunicação Nacional do Brasil à Convenção-Quadro das Nações Unidas sobre Mudança do Clima - Volume III, Coordenação-Geral de Mudanças Globais de Clima, Brasília.

BURNQUIST, H.L., COSTA, C.C., GUILHOTO, J.J.M., 2006, Impacts of changes in regional sugar and ethanol exports upon Brazilian overall economy. In: Input-output and general equilibrium: data, modeling and policy analysis conference, 2 - 4 September, Free University of Brussels, Brussels, Belgium. Available at: http://www.iioa.org/conferences/intermediate-2004/pdf/515.pdf. Access 23 Feb 2018. 
CARNEIRO FILHO, A. \& COSTA, K., 2016, The expansion of soybean production in the Cerrado: paths to sustainable territorial occupation, land use and production. Agroicone Report. Available at: http://www.inputbrasil.org/wp-content/uploads/2016/11/Theexpansion-of-soybean-production-in-the-Cerrado_Agroicone_INPUT.pdf. Access 10 Jun 2018.

CARVAlHO, A.L. de, ANTUNES, C.H., FREIRE, F., HENRIQUES, C.O., 2015, “A hybrid input-output multi-objective model to assess economic-energy-environment trade-offs in Brazil”, Energy, v. 82 (March), pp. 769-785. Available at: http://dx.doi.org/10.1016/j.energy.2015.01.089. Access 7 Dec 2017.

CARVALHO, A.L. de, ANTUNES, C.H., FREIRE, F., HENRIQUES, C.O., 2016, “A multiobjective interactive approach to assess economic-energy-environment trade-offs in Brazil", Renewable Sustainable Energy, v. 54, pp. 1429-1442. Available at: http://dx.doi.org/10.1016/j.rser.2015.10.064. Access 23 Fev 2018.

CARVALHO, A.L. de, ANTUNES, C.H., FREIRE, F., 2016a, "Economic-energy-environment analysis of prospective sugarcane bioethanol production in Brazil", Applied Energy, v. 181, pp. 514-526. Available at: http://dx.doi.org/10.1016/j.apenergy.2016.07.122. Access 23 Fev 2018.

CASTAGnA, A.A., ARONOVICH, M., RODRIGUES, E., 2008, Pastoreio Racional Voisin: Manejo Agroecológico de Pastagens. Programa Rio Rural - Manual Técnico n. 10. Niterói, RJ.

CASTANHEIRA et al., 2014, "Environmental sustainability of biodiesel in Brazil", Energy Policy, v. 65, pp. 680-691.

CAZCARRO, I., DUARTE, R., CHÓLIZ, J.S., 2013, "Multiregional input-output model for the evaluation of Spanish water flows", Environmental Science \& Technology, v. 47, n. 21, pp. 12275-83. Available at: http://doi.org/10.1021/es4019964. Access 7 Dec 2017.

CETESB (COMPANHIA AMBIENTAL DO ESTADO DE SÃO PAULO), 2014, Guia técnico ambiental de curtumes. $2^{\mathrm{a}}$ edição. Grupo de Trabalho Produção Mais Limpa $(\mathrm{P}+\mathrm{L})$ no Setor Coureiro - Calçadista de São Paulo.

CGEE (CENTRO DE GESTÃO DE ESTUDOS ESTRATÉGICOS), 2012, Sustainability of sugarcane bioenergy. Brasília, DF. 336 p. ISBN 978-85-60755-47-9.

CNI (CONFEDERAÇÃO NACIONAL DA INDÚSTRIA), 2013, Uso da água no setor industrial Brasileiro: matriz de coeficientes técnicos. CNI, Brasília.

COELHO, S.T., et al., 2006, "Brazilian sugarcane ethanol: lessons learned", Energy for Sustainable Development, v. 10, n. 2 (June), pp. 26-39.

COMPEÁN, R.G., POLENSKE, K.R., 2011, "Antagonistic bioenergies: technological divergence of the ethanol industry in Brazil", Energy Policy, v. 39, n. 11, pp. 6951-6961. Available at: http://dx.doi.org/10.1016/j.enpol.2010.11.017. Access 23 Feb 2018.

COSTA, C.C., BURNQUIST, H.L., GUILHOTO, J.J.M., 2006, "Impacto de alterações nas exportações de açúcar e álcool nas regiões Centro-Sul e Norte-Nordeste sobre a economia do Brasil”, Revista Economia e Sociologia Rural, v. 44, n. 4, pp. 609-627. Available at: http://dx.doi.org/10.1590/S0103-20032006000400001. Access 23 Feb 2018.

CRUZ JR, J.B., TAN, R.R., CULABA A.B., BALLACILLO, J., 2009, “A dynamic input-output model for nascent bioenergy supply chains”, Applied Energy, v. 86, pp. S86-S94. Available at: http://dx.doi.org/10.1016/j.apenergy.2009.04.007. Access 23 Feb 2018.

CSR (CENTRO DE CENSORIAMENTO REMOTO), 2018, Unidade animal por hectare, em 2013. Servidor de Mapas, 2018 (Maps Server). Centro de Sensoriamento Remoto da Universidade Federal de Minas Gerais - CSR/UFMG. Available at: http://maps.csr.ufmg.br. Access: 10 Jun 2018. 
CUNHA, M. P., SCARAMUCCI, J.A., 2006, The construction of an updated economic database for energy studies: an application to the Brazilian sugarcane agroindustry. In: International conference on regional and urban modelling, 1-3, June, Brussels, Belgium. Available at: http://ecomod.net/sites/default/files/document-conference/ecomod2006rum/1400.pdf. Access 23 Feb 2018.

CUNHA, M. P., SCARAMUCCI, J.A., 2006a, Bioethanol as basis for regional development in Brazil: an input-output model with mixed technologies. In: Intermediate international input-output meeting, 26 - 28 July, Sendai, Japan. Available at: http://www-sre.wuwien.ac.at/ersa/ersaconfs/ersa06/papers/242.pdf. Access 23 Feb 2018.

DE FRAITURE, C., GIORDANO, M., LIAO, Y., 2008, "Biofuels and implications for agricultural water use: blue impacts of green energy", Water Policy, v. 10, n. 1, pp. 67 81. Available at: http://dx.doi.org/10.2166/wp.2008.054. Accessed 9 Oct 2017.

DHILLON, R.S., VON WUEHLISCH, G., 2013, "Mitigation of global warming through renewable biomass", Biomass \& Bioenergy, v. 48, pp. 75-89.

DNPM (DEPARTAMENTO NACIONAL DE PRODUÇÃO MINERAL), 2009, Desempenho do setor mineral, Goiás: Ano base: 2008, Exercício: 2009. Ministério de Minas e Energia (MME), Brasília.

DOE (UNITED STATES DEPARTMENT OF ENERGY), 2012, Climate and Energy-WaterLand System Interactions. In: Technical Report to the U.S. Department of Energy in Support of the National Climate Assessment, Pacific Northwest National Laboratory, Washington.

DUMORTIER, J., HAYES, D.J., CARRIQUIRY M., et al., 2011, "Sensitivity of Carbon Emission Estimates from Indirect Land-Use Change", App Econ Persp and Policy, v. 33, n. 3, pp. 428-448. Available at: http://dx.doi.org/10.1093/aepp/ppr015. Accessed 19 Feb 2018.

ELY, R.N, 2015. Advanced Input-Output Techniques for Assessing Direct and Indirect Economic Impacts of Sugarcane Conversion Technologies. Ph.D. dissertation, Programa de Planejamento Energético, Universidade Federal do Rio de Janeiro, 2015.

EMBRAPA (EMPRESA BRASILEIRA DE PESQUISA AGROPECUÁRIA), 2013, Comunicado técnico 102: Consumo de água na produção animal. EMBRAPA, São Carlos.

2016. Desempenho da vinicultura brasileira. Available at: https://www.embrapa.br/buscade-noticias/-/noticia/9952204/artigo-desempenho-da-vitivinicultura-brasileira-em-2015.

Access 2 Nov 2017.

ENDO, A., BURNETT, K., ORENCIO, P.M., KUMAZAWA, T., WADA, C.A., ISHII, A., TSURITA, I., TANIGUCHI, M., 2015, "Methods of the Water-Energy-Food Nexus", Water, v. 7, n. 10, pp. 5806-5830. Available at: http://dx.doi.org/10.3390/w7105806. Access 24 Oct 2017.

ENDO, A., TSURITA, I., BURNETT, K., ORENCIO, P.M., 2017, "A review of the current state of research on the water, energy, and food nexus", Journal of Hydrology: Regional Studies, v. 11 (June) pp. 20-30. Available at: http://dx.doi.org/10.1016/j.ejrh.2015.11.010. Access 24 Oct 2017.

EPE (EMPRESA DE PESQUISA ENERGÉTICA), 2015, Análise da Conjuntura dos Biocombustíveis - Ano 2014. EPE-DPG-SDB-Bios-NT-01-2015. Rio de Janeiro, EPE/MME.

2016, Demanda de energia 2050. Série - Estudos da demanda de energia. Nota técnica DEA 13/15. EPE/MME, Rio de Janeiro, pp. 257. 
,2017. Energy Research Centre, Cenários de oferta de etanol e demanda do Ciclo Otto: Versão estendida 2030. Rio de Janeiro, Ministério de Minas e Energia EPE/MME.

2017b. RenovaBio: Biocombustiveis 2030, Nota Técnica: Papel dos biocombustiveis na matriz. Rio de Janeiro, EPE/MME.

FACHINELLI, N.P., PEREIRA JR., A.O., 2015, "Impacts of sugarcane ethanol production in the Paranaiba basin water resources", Biomass and Bioenergy, v. 83, pp. 8-16.

FAO (FOOD AND AGRICULTURE ORGANIZATION OF THE UNITED NATIONS), 2008. Bioenergy and Food Security Project - BEFS. Available at: http://www.fao.org/energy/befs/en/. Accessed 16 May 2017.

,2008b. The State of Food and Agriculture. Biofuels: prospects, risks and opportunities. Rome, FAO.

, 2009, How to Feed the World in 2050. High-level expert forum, Rome. Available at: http://www.fao.org/fileadmin/templates/wsfs/docs/expert paper/How to Feed the Wo rld in 2050.pdf. Accessed 28 Nov 2017.

2012, World Agriculture Towards 2030/2050: The 2012 Revision, ESA Working Paper No. 12-03 - FAO. Written by: Alexandratos, N. \& Bruinsma, J.. Rome, FAO.

2013. Biofuels and the sustainability challenge: A global assessment of sustainability issues, trends and policies for biofuels and related feedstocks. Rome, FAO.

2013a, An Innovative Accounting Framework for the Food-Energy-Water Nexus Application of the MUSIASEM approach to three case studies. Environment and Natural Resources Working Paper No.56 - FAO. Written by: Mario Giampietro, Richard J. Aspinall, Sandra G.F. Bukkens, Juan Cadillo Benalcazar, François Diaz-Maurin, Alessandro Flammini, Tiziano Gomiero, Zora Kovacic, Cristina Madrid, Jesús RamosMartín, Tarik Serrano-Tovar. Rome, FAO, pp. 81.

,2014, The water-energy-food nexus a new approach in support of food security and sustainable agriculture. Food and Agriculture Organization of the United Nations, Rome. Available at: http://www.fao.org/3/a-bl496e.pdf. Access 24 Oct 2014.

2017. Statistics Division (FAOSTAT), online data base. Available at: http://www.fao.org/faostat/en/\#home. Access 31 Oct 2017.

FARGIONE, J. HILL, J., TILMAN, D., POLASKY, S., HAWTHORNE, P., 2008, “Land clearing and biofuel carbon", Science, v. 319, pp. 1235-1238.

FARGIONE, J.E, PLEVIN, R.J., HILL, J.D., 2010, “The Ecological Impact of Biofuels”, Annual Review of Ecology, Evolution and Systematics, v. 41, pp. 351-77. Available at: http://dx.doi.org/10.1146/annurev-ecolsys-102209-144720. Accessed 18 Oct 2017.

FENG, M., LIU, P., LI, Z., ZHANG, J., LIU, D., XIONG, L., 2016, "Modeling the nexus across water supply, power generation and environment systems using the system dynamics approach: Hehuang Region, China", Journal of Hydrology, v. 543, part B, (December), pp. 344-359. Available at: http://dx.doi.org/10.1016/j.jhydrol.2016.10.011. Accessed 7 Dec 2017.

FIGUEIREDO, N.R.M., JÚNIOR, I.T.A., PEROBELLI, F. S., 2008, Construção da matriz de insumo-produto híbrida para o estado de Pernambuco e avaliação da intensidade energética e de emissões de CO2 setorial. In: Proceedings of the Fórum Banco do Nordeste do Brasil de desenvolvimento - XIV Encontro regional de economia, 16 - 17 July, Banco do Nordeste do Brasil, Fortaleza, Brazil. Available at: http://edi.bnb.gov.br/content/aplicacao/eventos/forumbnb2009/docs/construcao.pdf. Access 23 Fev 2018.

FILHO, J.H.C., FILHO, J.B.S.F., 2009, Os impactos econômicos da expansão da produção de etanol sob a ótica da matriz de contabilidade social brasileira. In: Proceedings of the 
XLVII Congresso da Sociedade Brasileira de Economia, Administração e Sociologia Rural, $26-30$ July, Porto Alegre, Brazil. Available at: http://www.sober.org.br/palestra/13/816.pdf. Access 23 Fev 2018.

FINGERMAN, K.R., BERNDES, G., ORR, S., RICHTER, B.D., VUGTEVEEN, P., 2011, "Impact assessment at the bioenergy-water nexus", Biofuels, Bioproducts and Biorefing, v. 5, n. 4, pp. 375-386. Available at: http://dx.doi.org/10.1002/bbb.294. Accessed 9 Oct 2017.

FISCHER, G., SHAH, M., 2010, Farmland Investments and Food Security. Report prepared under World Bank IIASA contract - Lessons for the large-scale acquisition of land from a global analysis of agricultural land use.

FUNARBE (FUNDAÇÃO DE APOIO À UNIVERSIDADE FEDERAL DE VIÇOSA), 2011, Desenvolvimento de Matriz de Coeficientes Técnicos para Recursos Hídricos no Brasil. FUNARBE, Brasília.

GALDOS, M. et al., 2013, "Trends in global warming and human health impacts related to Brazilian sugarcane ethanol production considering black carbon emissions", Applied Energy, v. 104 (Apr.), pp. 576-582.

GARCEZ, C.A.G., VIANNA, J.N.S., 2009, "Brazilian Biodiesel Policy: Social and environmental considerations of sustainability", Energy, v. 34, n. 5 (May), pp. 645- 654.

GARCIA, D.J., YOU, F., 2016, “The water-energy-food nexus and process systems engineering: A new focus", Computers and Chemical Engineering, v. 91, n. 4, pp. 49-67. Available at: http://dx.doi.org/10.1016/j.compchemeng.2016.03.003. Accessed 7 Dec 2017.

GASPARATOS, A., STROMBERG, P., 2012, Socioeconomic and environmental impacts of biofuels; evidence from developing nations. Cambridge, USA, Cambridge University Press.

GAY, P.W., PROOPS, J.L.R, 1993, "Carbon-dioxide production by the UK economy: an input output assessment", Appl. Energy, v. 44, pp. 113-130. Available at: https://doi.org/10.1016/0306-2619(93)90057-V. Access 23 Feb 2018.

GELLER, H., 1985, "Ethanol fuel from sugar cane in Brazil", Annual Reviews of Energy, v. 10 (November), pp. 135-164.

GERBENS-LEENES, W., HOEKSTRA, A.Y., VAN DER MEER, T.H., 2009, "The water footprint of bioenergy", Proceedings of the National Academy of Sciences, v. 106, n. 25, pp. 10219-10223.

GERBENS-LEENES, W., HOEKSTRA, A.Y., 2012, “The water footprint of sweeteners and bioethanol”, Environment International, v. 40, pp. $202-211$.

GOIÁS, 2010. Governo do Estado de Goiás, Balanço Energético do Estado de Goiás - BEGO 2009: Série 1994 - 2008. Secretaria de Estado de Infraestrutura, Goiânia.

GOLDEMBERG, J. et al., 2004. "Ethanol learning curve - the Brazilian experience", Biomass and Bioenergy, v. 26, pp. 301-304.

GOLDEMBERG, J., 2008, “The Brazilian biofuels industry”, Biotechnology for Biofuels, v. 1, n. 1, pp. 1-7. Available at: http://dx.doi.org/10.1186/1754-6834-1-6. Accessed 9 Oct 2017.

GOLDEMBERG, J., GUARDABASSI, P., 2009, “Are biofuels a feasible option?”, Energy Policy, v. 37, n. 1 (November), pp.10-14.

GOLDEMBERG, J. and MOREIRA, J. R. 1999. "The alcohol program”, Energy Policy, v. 27, n. 4 (April), pp. 229-245.

GUILHOTO, J.J.M., 2004, Análise de Insumo-Produto: teoria e fundamentos. Departamento de Economia FEA/USP. Available at: 
http://www.erudito.fea.usp.br/PortalFEA/Repositorio/835/Documentos/Guilhoto\%20Ins umo\%20Produto.pdf. Access 25 Oct 217.

, 2010, Matrizes interregionais de Insumo-Produto, Brasil 2008: Ano base, 2000. NEREUS, Universidade de São Paulo. Available at: http://www.usp.br/nereus/?dados=matrizes-interregionais-de-insumo-produto-brasil2008. Access 25 Oct 2017.

GUILHOTO, J.J.M., AZZONI, C.R., ICHIHARA, S.M., KADOTA, D.K., HADDAD, E.A., 2010, Matriz de Insumo-Produto do Nordeste e estados: Metodologia e resultados, Fortaleza: Banco do Nordeste do Brasil.

GUILHOTO, J.J.M., SESSO FILHO, U., 2005, "Estimação da matriz Insumo-Produto a partir de dados preliminares das contas nacionais", Economia Aplicada, v. 9, n. 2, pp. 277-299.

2010, "Estimação da matriz Insumo-Produto utilizando dados preliminares das contas Nacionais: Aplicação e análise de indicadores econômicos para o Brasil em 2005", Economia \& Tecnologia, ano 6, 23, pp. 53-62.

HALL, J., et al., 2009, "Brazilian biofuels and social exclusion: established and concentrated ethanol versus emerging and dispersed biodiesel", Journal of Cleaner Production, v. 17 (November), pp. S77-S85.

HAVLÍK, P., SCHNEIDER, U.A., SCHMID, E., BÖTTCHER, H., et al., 2011, "Global land-use implications of first and second generation biofuel targets", Energy Policy, v. 39, n. 10, pp. 5690- 5702. Available at: http://dx.doi.org/10.1016/j.enpol.2010.03.030. Accessed 19 Feb 2018.

HEAPS, C., 2008, An Introduction to LEAP. Stockholm Environment Institute, Stockholm, Sweden.

HELLEGERS, P., et al, 2008, "Interactions between water, energy, food and environment: Evolving perspectives and policy issues", Water Policy, v. 10, pp. 1-10.

HERENDEEN, R.A., 1978, "Input-output techniques and energy cost of commodities", Energy Policy, v. 6, pp. 162-165.

HERMANN, S., et al., 2012, "Climate, land, energy and water (CLEW) interlinkages in Burkina Faso: An analysis of agricultural intensification and bioenergy production". Natural Resources Forum v. 36, n. 4 (November), pp. 245-262.

HERNANDES, T., BUFON, V., SEABRA, J., 2013, "Water footprint of biofuels in Brazil: assessing regional differences", Biofuels, Bioproducts and Biorefining. Available at: http://dx.doi.org/10.1002/bbb.1454. Accessed 16 Oct 2017.

HERRERA, S., 2014. "Análise da governança global da sustentabilidade dos biocombustíveis e proposta para o etanol brasileiro", D.Sc., Programa de Planejamento Energético, Universidade Federal do Rio de Janeiro, 2014.

HERRERA, S., PEREIRA JUNIOR, A.O., LA ROVERE, E.L., 2013. "Biofuels in a broader context of sustainability: The energy-land-water nexus and Brazilian ethanol". $8^{\text {th }}$ Conference on Sustainable Development of Energy, Water and Environment Systems, 1 - 14, Dubrovnik, Croatia, 22 - 27 September 2013.

HERTEL, T.W., GOLUB, A.A., JONES, A.D., et al., 2010, "Effects of US Maize Ethanol on Global Land Use and Greenhouse Gas Emissions: Estimating Market-mediated Responses", BioScience, v. 60, n. 3, pp 223-231. Available at: http://dx.doi.org/10.1525/bio.2010.60.3.8. Acessed 19 Feb 2018.

HILGEMBERG, E.M., GUILHOTO, J.J.M, 2006, "Uso de combustíveis e emissões de $\mathrm{CO}_{2}$ no Brasil: Um modelo inter-regional de insumo-produto", Nova Economia (UFMG. Impresso), v. 16, n. 1, p. 49-99. 
HIRA, A., OLIVEIRA, L.G., 2009, "No substitute for oil? How Brazil developed its ethanol industry", Energy Policy, v. 37, n. 6 (June), pp. 2450-2456.

HLPE (HIGH-LEVEL PANEL OF EXPERTS), 2013. Biofuels and food security. A report by the High-Level Panel of Experts on Food Security and Nutrition of the Committee on World Food Security. Rome, FAO.

HOCHSTETLER, K., KECK, M.E., 2007, Greening Brazil: Environmental activism in state and society. Duke University Press, Durham, USA.

HOFF, H, 2011, Understanding the NEXUS, Background Paper for the Bonn 2011 Conference: The Water, Energy and Food Security Nexus, Stockholm: Stockholm Environment Institute, 2011. Available at: http://www.water-energyfood.org/en/whats_the_nexus/background.html. Accessed 16 May 2017.

HOLLAND, R.A., SCOTT, K.A., FLORKE, M., et al., 2015, "Global impacts of energy demand on the freshwater resources of nations", Proceeding of the National Academy of Sciences, v. 112, n. 48, pp. 6707-6716. Available at: http://dx.doi.org/10.1073/pnas.1507701112. Accessed 18 Oct 2017.

HOWELLS, M., HERMANN, S., WELSCH, M., et al., 2013, "Integrated analysis of climate change, land-use, energy and water strategies", Nature Climate Change, v. 3, n. 7, pp. 621-626. Available at: http://doi.org/10.1038/nclimate1789. Accessed 9 Oct 2017.

HRISTU-VARSAKELIS, D., KARAGIANNI, S., PEMPETZOGLOU, M., SFETSOS, A., 2010, "Optimizing production with energy and GHG emission constraints in Greece: An inputoutput analysis”, Energy Policy, v. 38, pp. 1566-1577.

HUNKE, P., MUELLER, E.N., SCHRÖDER, B., ZEILHOFER, P., 2015, "The Brazilian Cerrado: assessment of water and soil degradation in catchments under intensive agricultural use", Ecohydrology, v. 8, pp. 1154-1180. Available at: http://dx.doi.org/10.1002/eco.1573. Access 27 Feb 2018.

HUSSEY, K., PITTOCK, J., 2012, "The Energy-Water Nexus: Managing the Links between Energy and Water for a Sustainable Future", Ecology and Society, v. 17, n. 1, art. 31. Available at: http://dx.doi.org/10.5751/ES-04641-170131. Access 7 Dec 2017.

IAEA (INTERNATIONAL ATOMIC ENERGY AGENCY), 2009. Seeking Sustainable Climate, Land, Energy and Water (CLEW) Strategies. International Atomic Energy Agency. Available http://www.iaea.org/About/Policy/GC/GC53/GC53InfDocuments/English/gc53inf-3att6_en.pdf. Accessed: 11 Oct 2017.

IBGE (INSTITUTO BRASILEIRO DE GEOGRAFIA E ESTATÍSTICA), 2008, Matriz de Insumo-Produto Brasil 2000/2005 - Contas Nacionais n. 23, Diretoria de Pesquisas, Coordenação de Contas Nacionais, Instituto Brasileiro de Geografia e Estatística.

,2009, Produção agrícola municipal 2008, Culturas temporárias e permanentes, vol. 35. IBGE, Brasília.

,2009a, Produção da pecuária municipal 2008, vol. 36. IBGE, Brasília.

, 2009b, Pesquisa industrial Brasil 2008, 27 (1). IBGE, Brasília.

,2010, Contas Regionais do Brasil: 2004 - 2008. Contas Nacionais $n$. 32. Divulga os resultados do Sistema de Contas Nacionais relativos às tabelas de recursos e usos, contas econômicas integradas, contas regionais do Brasil, produto interno bruto dos municípios e matriz de insumo-produto. Ministério do Planejamento, Orçamento e gestão. Rio de janeiro. Available at: https://www.ibge.gov.br/estatisticasnovoportal/economicas/contas-nacionais/9054-contas-regionais-dobrasil.html?edicao $=17236 \& \mathrm{t}=$ downloads. Access 6 Nov 2017 . 
2011, Sistema de Contas Nacionais Brasil 2005-2009, Contas Nacionais n. 34, Rio de Janeiro, Diretoria de Pesquisas - Coordenação de Contas Nacionais.

,2012, Municipal Agricultural Production and Population Census, Rio de Janeiro, IBGE.

2016, Matriz de insumo-produto: Brasil: 2010. Contas Nacionais n. 51. Rio de Janeiro, IBGE, pp. 59. ISBN: 9788524043901. Available at: https://biblioteca.ibge.gov.br/visualizacao/livros/liv98180.pdf. Access 25 Oct 2017.

2017. Levantamento sistemático da produção agrícola. Pesquisa Mensal de Previsão e Acompanhamento das Safras Agrícolas no Ano Civil, Rio de Janeiro, v. 30, n. 1, pp. 181.

2017a, Censo agropecuário 2006, 2017. IBGE, Brasília. Available at: http://www.sidra.ibge.gov.br/bda/pesquisas/ca/. Access 31 Oct 2017.

, 2017b, Sistema de Contas Nacionais Brasil 2015, Contas Nacionais n. 56, Rio de Janeiro, Diretoria de Pesquisas - Coordenação de Contas Nacionais. ISSN 1415-9813.

ICIMOD (INTERNATIONAL CENTRE FOR INTEGRATED MOUNTAIN DEVELOPMENT), 2012. Contribution of Himalayan ecosystems to water, energy, and food security in South Asia: A nexus approach. Kathmandu, Nepal: International Centre for Integrated Mountain Development.

IEA (INTERNATIONAL ENERGY AGENCY), 2007. World Energy Outlook 2006. Paris, OECD/IEA.

2010. Status of $2^{\text {nd }}$ generation biofuels demonstration facilities in June 2010.

, 2012. Water for energy: is energy becoming a thirstier resource? World Energy Outlook 2012. Paris, OECD/IEA.

2016. Key world energy statistics. Data also available at: http://www.iea.org/statistics/statisticssearch/. Accessed 9 Oct 2017.

2017. Available at: https://www.iea.org/stats/WebGraphs/WORLD4.pdf. Statistics on the web: http://www.iea.org/statistics/. Accessed 9 Oct 2017.

IIASA (INTERNATIONAL INSTITUTE FOR APPLIED SYSTEMS ANALYSIS), FAO, 2012. Global Agro-ecological Zones - Model Documentation (GAEZ v.3.0). International Institute of Applied Systems Analysis \& Food and Agricultural Organization, Luxemburg, Austria \& Rome, Italy.

IISD (INTERNATIONAL INSTITUTE FOR SUSTAINABLE DEVELOPMENT), 2013, The Water-Energy-Food Security Nexus: Towards a practical planning and decisionsupport framework for landscape investment and risk management. IISD Report. Written by Bizikova, L., Roy, D., Swanson, D., Venema, H.D., McCandless, M.. Canada, International Institute for Sustainable Development, Manitoba, Canada.

IMB (INSTITUTO MAURO BORGES DE ESTATÍSTICAS E ESTUDOS SOCIOECONÔMICOS), 2014, Atlas do Estado de Goiás. Goiás, Secretaria de Estado de Gestão e Planejamento, Governo do Estado de Goiás, Goiás.

IMORI, D., GUILHOTO, J.J.M., 2010, "Estrutura produtiva brasileira e emissão de $\mathrm{CO}_{2}$ ”. In: Veiga, J. E. (ed.), Economia Socioambiental, São Paulo: Editora Senac. pp. 205-233. ISBN: 9788573599206.

IMORI, D., GUILHOTO, J.J.M., DAVID, L.S., GUTIERRE, L.M., WAISMAN, C., "Regional Development and Greenhouse Gases Emission: The Case of the Amazon Region". 58 Annual North American Meetings of the Regional Science Association International. Miami, USA - November 9th - 12th, 2011.

IPCC (INTERGOVERNMENTAL PANEL ON CLIMATE CHANGE), 1990, Climate Change: The IPCC Scientific Assessment. Intergovernmental Panel on Climate Change. 
2014, IPCC $5^{\text {th }}$ Assessment Report Climate Change 2014, Chapter 11: Agriculture, Forestry and Other Land Use (AFOLU). Working Group III: Mitigation of Climate Change. Intergovernmental Panel on Climate Change.

IPT (INSTITUTO DE PESQUISAS TECNOLÓGICAS DO ESTADO DE SÃO PAULO), 2013, Catálogo de madeiras brasileiras para a construção civil. São Paulo, IPT. ISBN 978-8509-00175-9

IRENA (INTERNATIONAL RENEWABLE ENERGY AGENCY), 2016. Boosting Biofuels: Sustainable Paths to Greater Energy Security. Available at: http://www.irena.org/DocumentDownloads/Publications/IRENA_Boosting_Biofuels_2 016.pdf. Accessed 9 Oct 2017.

ISARD, W., 1951, "Inter-regional and Regional Input-Output Analysis: A Model of a SpaceEconomy", Review of Economics and Statistics, n. 33, pp. 319-328.

ISARD, W., CHOGUILL, C., KISSIN, J., et al, 1972, Ecologic-economic analysis for regional development: some initial explorations with particular reference to recreational resource use and environmental planning. New York, The Free Press.

KARKACIER, H.O., GOKTOLGA, Z. G., 2005, "Input-output analysis of energy use in agriculture", Energy Conversion Management, v. 46, pp. 1513-1521.

KARP, A., RICHTER, G.M., 2011, "Meeting the challenge of food and energy security", Journal of Experimental Botany, pp. 1-9.

KHAN, S., HANJRA, M.A., 2009, "Footprints of water and energy inputs in food production", Food Policy, v. 34, pp. 130-140.

KOHLHEPP, G., 2010, "Análise da situação da produção de etanol e biodiesel no Brasil", Estudos Avançados, v. 24, n. 68, pp. 223 - 253.

LA ROVERE, E.L., PEREIRA, A.S., SIMÕES, A.F., 2011, "Biofuels and Sustainable Energy Development in Brazil", World Development, v. 39, n. 6, pp. 1026-1036. Available at: http://dx.doi:10.1016/j.worlddev.2010.01.004. Accessed 9 Oct 2017.

LAPOLA, D.M., et al., 2010, "Indirect land-use changes can overcome carbon savings from biofuels in Brazil", Proceedings of the National Academy of Sciences, v. 107, n. 8, pp. 3388-3393. Available at: http://dx.doi.org/10.1073/pnas.0907318107. Accessed 9 Oct 2017.

LAPOLA, D.M., MARTINELLI, L.A., PERES, C.A., et al., 2014, "Pervasive transition of the Brazilian land-use system", Nature Climate Change, v. 4, pp. 27 - 35. Available at: http://dx.doi.org/10.1038/nclimate2056. Accessed 16 Oct 2017.

LAWFORD, R., BOGARDI, J., MARX, S., JAIN, S., WOSTL, C.P., KNÜPPE, K., RINGLER, C., LANSIGAN, F., MEZA, F., 2013, "Basin perspectives on the Water-Energy-Food Security Nexus", Current Opinion in Environmental Sustainability, v. 5, n. 6 (December), pp. 607-616. Available at: http://dx.doi.org/10.1016/j.cosust.2013.11.005. Accessed 7 Dec 2017.

LECK, H., CONWAY, D., BRADSHAW, M., REES, J., 2015, "Tracing the Water-Energy-Food Nexus: description, theory and practice", Geography Compass, v. 9, n. 8, pp. 445-60.

LEHTONEN, M., 2009, "Social sustainability of the Brazilian bioethanol: Power relations in a centre-periphery perspective", Biomass and Bioenergy, v. 35, n. 6 (June), pp. 2425-2434.

LEONTIEF, W., 1936, "Quantitative Input-Output Relations in the Economic System of the United States", Review of Economics and Statistics, v. 18, pp. 105-125. 1941, The Structure of American Economy 1919-1939. New York: Oxford University Press.

1970. In: LEONTIEF, W. (Ed.), Input-output economics, $2^{\text {nd }}$ ed., New York. 
LEONTIEF, W., Ford, D., 1971, “Input-Output Techniques”. In: Bródy, A. P. Carter (Eds.), Proceedings of the Fifth International Conference on Input-Output Techniques, Geneva, 1971.

LI, X., FENG, K., SIU, Y., HUBACEK, K., 2012, "Energy-water nexus of wind power in China: the balancing act between $\mathrm{CO}^{2}$ emissions and water consumption", Energy Policy, v. 45, pp. $440-448$.

LYND, L., WOODS, J., 2001, "Perspective: a new hope for Africa", Nature, v. 474, pp 20-21.

MACEDO, I.C., 2005, Sugarcane's energy - twelve studies on Brazilian sugarcane agribusiness and its sustainability. ( $2^{\text {nd }}$ ed 2007 )São Paulo, UNICA, Berlendis \& Vertecchia.

MACEDO, I.C., LEAL, M.R.L.V., DA SILVA, J.E.A.R., 2004. Assessment of Greenhouse Gas Emissions in the Production and Use of Fuel Ethanol in Brazil. Secretariat of the Environment of the State of São Paulo, Brazil Available at: https://www.wilsoncenter.org/sites/default/files/brazil.unicamp.macedo.greenhousegas. pdf. Accessed 18 Oct 2017.

MACEDO, I.C., SEABRA, J.E.A, SILVA, J.E.A.R., 2008, "Greenhouse gases emissions in the production and use of ethanol from sugarcane in Brazil: The 2005/2006 averages and a prediction for 2020", Biomass and Bioenergy, v. 32, pp. 582-595.

MANKIW, N.G., 2010, Macroeconomics. $7^{\text {th }}$ edition, Worth Publishers, Harvard University, USA, pp. 598.

MANZATTO, C.V., ASSAD, E.D., BACCA, J.F.M., ZARONI, M.J., PEREIRA, S.E.M., 2009. Zoneamento agroecológico da cana-de-açúcar. $1^{\text {a }}$ ed., Rio de Janeiro, Embrapa Solos.

MAPA (MINISTÉRIO DA AGRICULTURA, PECUÁRIA E ABASTECIMENTO), 2016, Brasil projeções do agronegócio 2015/2016 a 2025/2026. MAPA, Brasília. Available at: http://www.agricultura.gov.br/assuntos/politica-agricola/todas-publicacoes-de-politicaagricola/projecoes-do-agronegocio/proj_agronegocio2016.pdf/view. Access 07 Nov 2017.

MAPBIOMAS, 2017, Projeto de Mapeamento Anual da Cobertura e Uso do Solo do Brasil, coleção 2 - Annual land-use and coverage mapping in Brazil, 2017. Available at: http://mapbiomas.org/map\#coverage. Access 31 Oct 2017.

MAROUN, C., 2014. "Sustainability of the ethanol expansion in Brazil from a water-energy-land perspective", D.Sc., Programa de Planejamento Energético, Universidade Federal do Rio de Janeiro, 2014.

MARTA, A.D., NATALI, F., MANCINI, M., FERRISE, R., BINDI, M., ORLANDINI, S., 2011, "Energy and water use related to the cultivation of energy crops: a case study in the Tuscany region", Ecology and Society, (online), v. 16, n. 2, art. 2. Available at: http://www.ecologyandsociety.org/vol16/iss2/art2/. Accessed 20 Oct 2017.

MARTINELLI, L. A. \& FILOSO, S., 2008, "Expansion of sugarcane ethanol production in Brazil: Environmental and social challenges", Ecology Applied, v. 18, pp. 885-898.

MATA, T., et al., 2013, "Sustainability analysis of biofuels through the supply chain using indicators", Sustainable Energy Technologies and Assessments, v. 3, (September), pp. 53-60.

MCT (MINISTÉRIO DA CIÊNCIA E TECNOLOGIA), 2010, Segundo inventário brasileiro de emissões antrópicas de gases de efeito estufa. Relatórios de referência: Emissões de gases de efeito estufa nos processos industriais - produtos minerais, Parte I-Produção de Cimento. MCT, Brasília.

,2010a. Segundo inventário brasileiro de emissões antrópicas de gases de efeito estufa. Relatórios de referência: Emissões de gases de efeito estufa nos processos industriais - 
produtos minerais, Parte II - Produção de Cal, Outros Usos do Calcário e Dolomita Produção e Uso de Barrilha. MCT, Brasília.

,2010b, Segundo inventário brasileiro de emissões antrópicas de gases de efeito estufa. Relatórios de referência: Emissões de gases de efeito estufa nos processos industriais Indústria química. MCT, Brasília.

2010c, Segundo inventário brasileiro de emissões antrópicas de gases de efeito estufa. Relatórios de referência: Emissões de gases de efeito estufa nos processos industriais Produção de metais, Alumínio. MCT, Brasília.

,2010d, Segundo inventário brasileiro de emissões antrópicas de gases de efeito estufa. Relatórios de referência: Emissões de gases de efeito estufa nos processos industriais Produção de metais, Ferro e Aço. MCT, Brasília.

2010e, Segundo inventário brasileiro de emissões antrópicas de gases de efeito estufa. Relatórios de referência: Emissões de gases de efeito estufa por queima de combustiveis: Abordagem bottom-up. MCT, Brasília.

MCTI (MINISTÉRIO DA CIÊNCIA, TECNOLOGIA E INOVAÇÃO), 2014, Estimativas anuais de emissões de gases de efeito estufa no Brasil. $2^{\mathrm{a}}$ edição, MCTI, Brasília.

2016, Terceira Comunicação Nacional do Brasil à Convenção-Quadro das Nações Unidas sobre Mudança do Clima - Volume III. Coordenação-Geral de Mudanças Globais de Clima, Brasília.

MEKONNEN, M.M., HOEKSTRA, A.Y., 2011, "The green, blue and grey water footprint of crops and derived crop products", Hydrology and Earth Systems Sciences, v. 15, pp. 1577-1600. Available at: http://dx.doi.org/10.5194/hess-15-1577-2011. Access 7 Dec 2017.

MIARA, A., VÖRÖSMARTY, C.J., STEWART, R., WOLLHEIM, W., ROSENZWEIG, B., 2013, "Riverine ecosystem services and the thermoelectric sector: Strategic issues facing the Northeastern United States", Environ Research Letters, v. 8 n. 2 pp. 11. Available at: http://dx.doi.org/10.1088/1748-9326/8/2/025017. Access 7 Dec 2017.

MILLER, R.E., BLAIR, P.D., 2009, Input-Output Analysis: Foundations and Extensions. $2^{\text {nd }}$ ed., Cambridge, Cambridge University Press.

MMA (MINISTRY OF ENVIRONEMNT). Federal Deforestation Prevention and Control Plan, Deforestation Prevention and Control, Ministério do Meio Ambiente, Brasíla. Available at: http://combateaodesmatamento.mma.gov.br.

MME (MINISTÉRIO DAS MINAS E ENERGIA), 2016. Balanços energéticos estaduais 2000, 2012, 2015 - Matrizes energéticas, matrizes de emissões e indicadores, Departamento de informações e estudos energéticos.

2017. Ministry of Energy and Mines, Brazilian Energy Balance 2017 Year 2016. Rio de Janeiro, Empresa de Pesquisa Energética EPE/MME.

, 2017b. Plano decenal de expansão da energia 2026. Ministério de Minas e Energia. Empresa de Pesquisa Energética. Brasília: MME/EPE.

2017c. Boletim Mensal dos Combustíveis Renováveis. Ed. 109, Junho, 2017. Available at: http://www.mme.gov.br/web/guest/secretarias/petroleo-gas-natural-e-combustiveisrenovaveis/publicacoes/boletim-mensal-de-biocombustiveis. Acessed 23 Feb 2018.

MORAES, M.A.F.D., COSTA, C.C., GUILHOTO, J.J.M., SOUZA, L.G.A., OLIVEIRA, F.C.R., "Externalidades sociais dos combustíveis". In: Sousa, E.L.L., Macedo, I.C. (Eds.), Etanol e Bioeletricidade: A Cana-de-açúcar no Futuro da Matriz Energética, São Paulo, ÚNICA, pp. 48-75, 2010. 
MOREIRA, J., PACCA, S., PARENTE, V., 2014. "The future of oil and bioethanol in Brazil", Energy Policy, v. 65, pp. 7-15.

MUSHTAQ, S., et al, 2009, "Energy and water trade-offs in enhancing food security: A selective international assessment", Energy Policy, v. 37, pp. 3635-3644.

NARDON, L. and ATEN, K. 2008. "Beyond a better mousetrap: A cultural analysis of the adoption of ethanol in Brazil", Journal of World Business, v. 43, n. 3, pp. 261- 273.

NASSAR et al., 2010, Modelagem do Uso da Terra no Brasil. Sponsored to Estudo de Baixo Carbono by World Bank. 94p.

NASSAR et al., 2011, Simulating Land Use and Agriculture Expansion in Brazil: Food, Energy, Agro-industrial and Environmental Impacts. Programme BIOEN. Project 2008/561560. ICONE: Instituto de Estudos do Comércio e Negociações Internacionais. February.

NEPSTAD, D. et al., 2009, "The end of deforestation in the Brazilian Amazon", Science, v. 61, n. 326, pp. 1350-1351.

NOGUEIRA, L., 2011, “Does biodiesel make sense?”, Energy, v. 36, n. 6 (June), pp. 3659-3666.

NOGUEIRA, L., CAPAZ, R., 2013, "Biofuels in Brazil: Evolution, achievements and perspectives on food security", Global Food Security, v. 2, n. 2 (July), pp. 117- 125.

NOOJIPADY, P., MORTON, D., MACEDO, M., VICTORIA, D., HUANG, C., GIBBS, H. BOLFE, E., 2017, "Forest carbon emissions from cropland expansion in the Brazilian Cerrado biome", Environmental Research Letters, v. 12, n. 2, pp. 1-11. Available at: http://dx.doi.org/10.1088/1748-9326/aa5986. Access 11 Jun 2018.

OBERMAIER, M., WILLS, W., KING, C. W., MOREIRA, M. M., RODRIGUEZ, R. del G., KIMURA, W., HARFUCH, L., BACHION, L. C., "Consequências da expansão de biocombustíveis no Brasil sobre uso da terra, água e a economia até 2030 sob mudanças climáticas". XVII Congresso Brasileiro de Energia, Rio de Janeiro, Rio de Janeiro, Brasil, 21-22 November, 2017.

OECD/IEA, 2010. Sustainable production of second-generation biofuels, potential and perspectives in major economies and developing countries. Anselm Eisentraut, Paris. Available

at: http://www.iea.org/publications/freepublications/publication/second_generation_biofuel s.pdf. Accessed 13 Oct 2017.

OLIVEIRA, J. A., 2002. "The policymaking process for creating competitive assets for the use of biomass energy: the Brazilian alcohol program", Renewable and Sustainable Energy Reviews, v. 6, n. 1-2, pp. 129-140.

OLIVEIRA, P.T.S., NEARING, M.A., WENDLAND, E., 2015, "Orders of magnitude increase in soil erosion associated with land use change from native to cultivated vegetation in a Brazilian Savannah environment", Earth Surface Processes and Landforms, v. 40, n. 11 (September), pp. 1524-1532. Available at: http://dx.doi.org/10.1002/esp.3738. Access 7 Dec 2017.

ONS (OPERADOR NACIONAL DO SISTEMA ELÉTRICO), 2004, Evaporação Líquida nas usinas Hidrelétricas. Diretoria de Planejamento e Programação da Operação, Rio de Janeiro.

2005, Estimativa das Vazões para Atividades de Uso Consuntivo da Água em Bacias do Sistema Interligado Nacional. Diretoria de Planejamento e Programação da Operação, Rio de Janeiro.

,2017. Histórico da operação - Volume útil dos principais reservatórios. ONS, Brasília. Available at: http://www.ons.org.br/historico/percentual_volume_util.aspx. Access 1 Nov 2017. 
PACCA, S., MOREIRA, J.R., 2009, "Historical carbon budget of the Brazilian ethanol program", Energy Policy, v. 37, n. 11 (November), pp. 863-4873.

PALERMO, G., 2011, Emissões de gases de efeito estufa e medidas mitigatórias da pecuária: potencialidades da intensificação e do confinamento do gado bovino de corte brasileiro. M.Sc Dissertation, Energy Planning Program, Federal University of Rio de Janeiro, COPPE/UFRJ.

PATE, R., HIGHTOWER, M., CAMERON, C., EINFELD, W., 2007, Overview of Energy-Water Interdependencies and the emerging energy demands on Water Resources. Report SAND 2007-1349C. Los Alamos, NM: Sandia National Laboratories, 2007.

PEREIRA, A.O., SOARES, J.B., DE OLIVEIRA, R.G., DE QUEIROZ, R.P., "Energy in Brazil: toward sustainable development?", Energy Policy, v. 36, n. 1, pp. 73-83. Available at: http://dx.doi.org/10.1016/j.enpol.2007.08.022. Accessed 9 Oct 2017.

POUSA, G. P. A. G., et al., 2007, "History and policy of biodiesel in Brazil", Energy Policy, v. 35, n. 11 (November), pp. 5393-5398.

PRITCHARD, B., RAMMOHAN, A., SEKHER, M., PARASURAMN, S., CHOITHANI, C., 2013, Feeding India: Livelihoods, Entitlements and Capabilities. Routledge, London.

RATHMANN, R., SZKLO, A., SCHAEFFER, R., 2010, "Land use competition for production of food and liquid biofuels: An analysis of the arguments in the current debate", Renewable Energy, v. 35, n. 1 (January), pp. 14-22.

,2011. "Targets and Results of the Brazilian Biodiesel Incentive Program - Has it Reached the Promised Land?" In: ICAE 2011 - International Conference on Applied Energy, Perugia, Italy. May.

RAVINDRANATH, N.H., SITA, L.C., RITUMBRA, M., BALACHANDRA, P., 2011, "Biofuel production and implications for land use, food production and environment in India", Energy Policy, v. 39, pp. 5737-5745.

REIS T., RUSSO, G., RIBEIRO, V., MOUTINHO, P., GUIMARÃES, A., STABILE, M., ALENCAR, A., CRISOSTOMO, A.C., SILVA, D., SHIMBO, J., 2017. Climate challenges and opportunities in the Brazilian Cerrado, Policy Brief. 23th Conference on Climate, Bonn, Germany, November. Available at: http://ipam.org.br/bibliotecas/climate-challenges-and-opportunities-in-the-braziliancerrado/.

RFA (RENEWABLE FUELS ASSOCIATION), 2008. Changing the Climate: Ethanol Industry Outlook.

RINGLER, C., BHADURI, A., LAWFORD, R., 2013, "The nexus across water, energy, land and food (WELF): potential for improved resource use efficiency?", Current Opinion in Environmental Sustainability, v. 5, n. 6, pp. 617-624. Available at: http://dx.doi.org/10.1016/j.cosust.2013.11.002. Accessed 7 Dec 2017.

RULLI, M.C., BELLOMI, D., CAZZOLI, A., DE CAROLIS, G., D’ODORICO, P., 2016, “The water-land-food nexus of first-generation biofuels", Scientific Reports 6, article number 22521. Available at: http://dx.doi.org/10.1038/srep22521. Access 27 Feb 2018.

SCARAMUCCI, J.A., CUNHA, M. P., "Aspectos socioeconômicos do uso energético da biomassa de cana-de-açúcar”, In: Cortez, L., Lora, E., Gómez, E., (Eds), Biomassa para Energia, Unicamp Press, Brazil, 2008.

SCHAEFFER, R., MAROUN, C., RATHMANN, R., 2011. "Brazilian Biofuels Programs from the WEL Nexus Perspective". Background paper for the 2011/2012 European Report on Development. Confronting Scarcity: Managing Water, Energy and Land for Inclusive and Sustainable Growth, Overseas Development Institute (ODI), European Centre for 
Development Policy Management (ECDPM), German Development Institute/Deutsches Institut für Entwicklungspolitik (GDI/DIE). European Union, 2012.

SEEG (SISTEMA DE ESTIMATIVAS DE EMISSÕES DE GASES DE EFEITO ESTUFA), 2016. Estimativas anuais das emissões de GEE. Nota Metodológica SEEG 4.0, Setor Agropecuário.

, 2016a. Estimativas anuais das emissões de GEE. Nota Metodológica SEEG 4.0, Setor de Energia.

2016b. Estimativas anuais das emissões de GEE. Nota Metodológica SEEG 4.0, Processos Industriais e Uso de Produtos.

2017. Estimativas anuais das emissões de GEE no Brasil. Available at: http://seeg.eco.br/en/. Access 31 Oct 2017.

2017b. Estimativas anuais das emissões de GEE. Nota Metodológica SEEG 5.0, Setor Mudanças de Uso do Solo e Florestas.

SEI (STOCKHOLM ENVIRONMENT INSTITUTE), 2014, Cross-sectoral integration in the Sustainable Development Goals: a nexus approach. SEI discussion brief. Written by Weitz, N., Huber-Lee, A., Nilsson, M., Davis, M., Hoff, H., adapted from Approaching Interaction in the SDGs - A Nexus Approach, Background Paper \#4 for the Independent Research Forum on a Post-2015 Sustainable Development Agenda.

, 2015, WEAP - Water Evaluation and Planning System - User Guide. Stockholm Environment Institute, Somerville, MA, USA. Available at: http://www.weap21.org/downloads/WEAP User Guide.pdf. Access 24 Oct 2017.

SEMARH (SECRETARIA DO MEIO AMBIENTE E DOS RECURSOS HÍDRICOS), 2012, Manual Técnico de Outorga. SEMARH, Goiás.

SEPLAN (SECRETARIA DE PLANEJAMENTO E DESENVOLVIMENTO DO ESTADO DE GOIÁS), 2009, Perfil Competitivo das Regiões de Planejamento do Estado de Goiás. SEPLAN, Goiânia. ,2010, Ranking dos Municípios Goianos: 2009. SEPLAN, Goiânia.

SHAPOURI, H., DUFFIELD, J., WANG, M., 2002, The energy balance of corn Ethanol: an update. In: Agricultural Economic Report No. 814, US Department of Agriculture, Economic Research Service, Office of the Chief Economist, Office of Energy Policy and New Uses, Washington, D.C..

SHAPOURI, H., GALlAGHER P., NEFSTEAD, W., BUTLER, R., NOE, S., 2008, Energy Balance for the Corn-Ethanol Industry. In: AER No. 846, Office of Energy Policy and New Uses, U.S. Department of Agriculture, Washington, D.C..

SHEEHAN, J.J., 2009, "Biofuels and the conundrum of sustainability", Current Opinion Biotechnology, v. 20, pp. 318-324.

SIRENE (SISTEMA DE REGISTRO NACIONAL DE EMISSÕES), 2017. Ministério da Ciência, Tecnologia, Inovação e Comunicação (MCTIC), Emissões de gases do efeito estufa por setor, subsetor e unidade da federação. MCTI, Brasília. Available at: http://sirene.mcti.gov.br. Access 31 Oct 2017.

SOARES-FILHO, B.S., HISSA, L., 2010, Emissões Associadas à Mudanças do Uso do Solo. Estudo de Baixo Carbono para o Brasil. Banco Mundial. 61p.

SOARES- FILHO, B.S., et al., 2009, Cenários para a pecuária de corte Amazônica. Belo Horizonte - MG: ed. IGC/UFMG.

SOARES-FILHO, B. S., 2013, Impacto da revisão do Código Florestal: como viabilizar o grande desafio adiante? Report. Secretaria de Assuntos Estratégicos, Brasília, 2013. Available at: 
https://www.socioambiental.org/sites/blog.socioambiental.org/files/nsa/arquivos/artigocodigo-florestal_britaldo_soares_sae_2013pdf.pdf. Access 10 Jun 2018.

2015, Modelagem de utilização de Cotas de Reserva Ambiental (CRA). Research Report. Centro de Sensoriamento Remoto - CSR/UFMG, Belo Horizonte, Brasil.

SPAROVEK, G. et al., 2010, "Brazilian agriculture and environmental legislation: Status and future challenges", Environmental Science Technology, v. 4, pp. 6046-6053.

SPERA, S.A., GALFORD, G.L., COE, M.T., MACEDO, M.N., MUSTARD, J.F., 2016, "Landuse change affects water recycling in Brazil's last agricultural frontier", Global Change Biology, v. 22, pp. 3405-3413. Available at: https://doi.org/10.1111/gcb.13298. Accessed 28 Nov 2017.

STILLWELL, A.S., KING, C.W., WEBBER, M.E., DUNCAN, I.J., HARDBERGER, A., 2011, "The energy-water nexus in Texas", Ecology and Society, v. 16, n. 1, art. 2. Available at: http://www.ecologyandsociety.org/vol16/iss1/art2/. Access 7 Dec 2017.

SZKLO, A., SCHAEFFER, R., DELGADO, F., 2007, "Can one say ethanol is a real threat to gasoline?", Energy Policy, v. 35, pp. 5411-5421.

SZKLO, A.S., et al., 2005, "Brazilian energy policies side-effects on $\mathrm{CO}_{2}$ emissions reduction", Energy Policy, v. 33, n. 3 (February), pp. 349-364.

TAHERIPOUR, F., HERTEL, T.W., TYNER, W.E., 2011, "Implications of biofuels mandates for the global livestock industry: a computable general equilibrium analysis", Agricultural Econ, v. 42, pp 325-342. Available at: http://dx.doi.org/10.1111/j.15740862.2010.00517.x. Accessed 19 Feb 2018.

TAKAHASHI, F. and ORTEGA, E., 2010, “Assessing the sustainability of Brazilian oleaginous crops - possible raw material to produce biodiesel”, Energy Policy, v. 38, n. 5 (May), pp. 2446-2454.

TAN, R.R., AVISO, K.B., BARILEA, I.U., CULABA, A.B., CRUZ JR, J.B., 2012, “A fuzzy multi-regional input-output optimization model for biomass production and trade under resource and footprint constraints", Applied Energy, v. 90, n. 1, pp. 154-160. Available at: http://dx.doi.org/10.1016/j.apenergy.2011.01.032. Access 23 Feb 2018.

TAYT-SOHN, F.C.O., 2014, Avaliação dos impactos das mudanças climáticas na aptidão para o cultivo da cana-de-açúcar na região da bacia hidrográfica do Paranaíba. M.Sc. Dissertation, Energy Planning Program, Federal University of Rio de Janeiro, Brazil.

TERCIOTE, R., 2006, Impactos econômicos da implementação das novas usinas de cana- deaçúcar. In: Proceedings of the 6th Encontro de Energia no Meio Rural, 2006, Campinas, Brazil.

Available

at: http://www.proceedings.scielo.br/scielo.php?script=sci_arttext\&pid=MSC00000000220 06000200004\&lng=en\&nrm=iso. Access 23 Feb 2018.

TILMAN, D., SOCOLOW, R., FOLEY, J.A., et al., 2009, "Beneficial biofuels: the food, energy, and environment trilemma", Science, v. 325, pp. 270-1.

TIMILSINA, G.R., BEGHIN, J.C., VAN DER MENSBRUGGHE, D., MEVEL, S., 2012 "The impacts of biofuels targets on land-use change and food supply: A global CGE assessment", Agr Econ, v. 43, n. 3, pp. 315-332. Available at: http://dx.doi.org/10.1111/j.1574-0862.2012.00585.x. Accessed 19 Feb 2018.

UNCTAD (UNITED NATIONS CONFERENCE ON TRADE AND DEVELOPMENT), 2016. Second generation biofuel markets: state of play, trade and developing country perspectives. Geneva, Switzerland, $61 \mathrm{pp}$.

UNEP (UNITED NATIONS ENVIRONMENT PROGRAMME), 2009, Towards sustainable production and use of resources: Assessing biofuels. International Panel for Sustainable Resource Management. UNEP DTI/1213/PA. ISBN: 978-92-807-3052-4. 
, 2012, "Land". In: UNEP, Environment for the future we want, Global Environment Outlook 5, Chapter 3.

,2014, Assessing Global Land Use: Balancing Consumption with Sustainable Supply. A Report of the Working Group on Land and Soils of the International Resource Panel.

UNICA (UNIÃO DA INDÚSTRIA DE CANA-DE-AÇÚCAR), 2017. Statistics of Sugarcane Industry Union, UNICAData. Available at: http://www.unicadata.com.br/. Accessed 16 May 2017.

USNIC (UNITED STATES NATIONAL INTELLIGENCE COUNCIL), 2012, Global Trends 2030: Alternative Worlds. US NIC, Washington DC, USA, pp. 137.

VAN VLIET, M.T H., YEARSLEY, J.R., LUDWIG, F., VOEGELE, S., LETTENMEIER, D.P., KABAT, P., 2012, "Vulnerability of US and European electricity supply to climate change", Nature Climate Change, v. 2 pp. 676-681. Available at: http://dx.doi.org/10.1038/nclimate1546. Access 7 Dec 2017.

VICTOR, P. A., 1972, Pollution: economics and environment. London, George Allen \& Unwin.

VILLELA, A.A., 2014, Expansão da palma na Amazônia oriental para fins energéticos. D.Sc. Dissertation, Energy Planning Program, Federal University of Rio de Janeiro, Brazil.

WALTER, A., et al., 2011, "Sustainability assessment of bio-ethanol production in Brazil considering land use change, GHG emissions and socio-economic aspects", Energy Policy, v. 39, pp. 5703-5716.

WANG, S., CHEN, B., 2016, "Energy-water nexus of urban agglomeration based on multiregional input-output tables and ecological network analysis: A case study of the Beijing-Tianjin-Hebei region", Applied Energy, v. 178 (September), pp. 773-783. Available at: https://doi.org/10.1016/j.apenergy.2016.06.112. Access 7 Dec 2017.

WARNER, E., ZHANG, Y., INMAN, D., HEATH, G., 2014, "Challenges in the estimation of greenhouse gas emissions from biofuel-induced global land-use change", Biofuels, Bioproducts and Biorefinering, v. 8, n. 1, pp. 114-125. Available at: http://dx.doi.org/10.1002/bbb.1434

WAUGHRAY, D. (Ed.), 2011, Water security-The water-food-energy-climate nexus. Washington, D.C., Island Press.

WATANABE, M.D.B., CHAGAS, M.F., CAVALETT, O., et al., 2016, "Hybrid Input-Output Life Cycle Assessment of First- and Second-Generation Ethanol Production Technologies in Brazil", Journal of Industrial Ecology, v. 20, n. 4, pp. 764-774. Available at: http://dx.doi.org/10.1111/jiec.12325. Access 23 Feb 2018.

WEF (WORLD ECONOMIC FORUM), 2011, Global risks 2011. $6^{\text {th }}$ ed, Cologne/Geneva, World Economic Forum.

WEITZ, N., STRAMBO, C., KEMP-BENEDICT, E., NILSSON, M., 2017, "Closing the governance gaps in the water-energy-food nexus: Insights from integrative governance", Global Environmental Change, v. 45 (July), pp. 165-173. Available at: http://dx.doi.org/10.1016/j.gloenvcha.2017.06.006. Access 7 Dec 2017.

WELSCH et al., 2014, "Adding value with CLEWS - Modelling the energy system and its interdependencies for Mauritius", Applied Energy, v. 113, (January), pp. 1434-1445. Available at: https://doi.org/10.1016/j.apenergy.2013.08.083. Access 24 Oct 2017.

WHITE, D.J., HUBACEK, K., FENG, K., SUN, L., MENG, B., 2017, “The Water-Energy-Food Nexus in East Asia: A tele-connected value chain analysis using inter-regional inputoutput analysis", Applied Energy, In Press (2017). 
WICHELNS, D., 2017, "The water-energy-food nexus: Is the increasing attention warranted, from either a research or policy perspective?", Environmental Scientific Policy, v. 69, pp.113-23.

WILKINSON, J., 2015, The Brazilian Sugar Alcohol Sector in the current national and international conjuncture. $1^{\text {st }}$ ed Rio de Janeiro, Actionaid, $20 \mathrm{pp}$.

WILLIAMS, T., 2012, Large-scale land acquisitions in West Africa: the ignored water dimension, International Water Management Institute. Available at: http://wle.cgiar.org/blogs/2012/11/08/large-scale-land-acquisitions-in-west-africa-theignored-water-dimensions/. Accessed 13 Oct 2017.

YANG, J., XU, M., ZHANG, X., HU, Q., SOMMERFELD, M., CHEN, Y., 2011, "Life-cycle analysis on biodiesel production from microalgae: Water footprint and nutrients balance", Bioresource Technology, v. 102, n. 1, pp. 159-165. Available at: https://doi.org/10.1016/j.biortech.2010.07.017. Access 16 Oct 2017.

YANG, Y.J., GOODRICH, J.A., 2014, "Toward quantitative analysis of water-energy-urbanclimate nexus for urban adaptation planning", Current Opinion in Chemical Engineering, v. 5, (August) pp. 22-28. Available at: http://doi.org/10.1016/j.coche.2014.03.006. Accessed 9 Oct 2017.

YOUNG, C.E.F. (coord.), 2016, Estudos e produção de subsídios técnicos para a construção de uma Política Nacional de Pagamento por Serviços Ambientais. Relatório Final. Instituto de Economia, UFRJ, Rio de Janeiro. Rio de Janeiro, p. 93.

ZHANG, Y., ZHENG, H.M., YANG, Z.F., LI, Y.X., LIU, G.Y., SU, M.R., Yin, X., 2016, “Urban energy flow processes in the Beijing-Tianjin-Hebei (Jing-Jin-Ji) urban agglomeration: combining multi-regional input-output tables with ecological network analysis", Journal of Cleaner Production, v. 114 (February), pp. 243-256. Available at: https://doi.org/10.1016/j.jclepro.2015.06.093. Access 7 Dec 2017. 


\section{Appendix I: Goiás' Original Input-Output table}

Goiás’ original inter-regional IO table (GUILHOTO, 2010)

\begin{tabular}{|c|c|c|c|c|c|c|c|c|c|c|c|c|c|c|c|c|c|c|c|c|c|c|c|c|c|c|c|}
\hline & & \multicolumn{26}{|c|}{ Goiás State } \\
\hline & & (l) & (2) & (3) & (4) & (5) & (6) & (7) & (8) & (9) & (10) & (11) & (12) & (13) & (14) & (15) & (16) & (17) & (18) & (19) & (20) & (21) & (22) & (23) & (24) & (25) & (26) \\
\hline \multirow{26}{*}{ 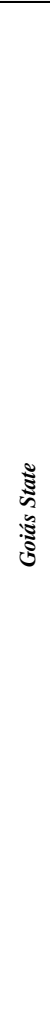 } & Agriculture and forestry (I) & 361 & 286 & 1 & 2,486 & 13 & 41 & 411 & 10 & 4 & 2 & 1 & 0 & 0 & 0 & 2 & 0 & 1 & 1 & 0 & 9 & 0 & 0 & 28 & 6 & 1 & 3 \\
\hline & Livestock and fishing (2) & 43 & 285 & 0 & 2,754 & 3 & 1 & 9 & 3 & 0 & 0 & 0 & 0 & 0 & 0 & 1 & 0 & 0 & 0 & 0 & 7 & 0 & 0 & 15 & 3 & 1 & 3 \\
\hline & Mining (3) & 10 & 43 & 70 & 5 & 0 & 1 & 0 & 102 & 0 & 32 & 19 & 1 & 0 & 0 & 0 & 0 & 59 & 1 & 0 & 1 & 0 & 0 & 0 & 0 & 0 & 1 \\
\hline & Food, beverages and tobacco (4) & 90 & 475 & 0 & 2,768 & 30 & 3 & 24 & 82 & 0 & 0 & 0 & 0 & 0 & 0 & 1 & 1 & 2 & 22 & 3 & 63 & 1 & 1 & 421 & 45 & 20 & 50 \\
\hline & Textile, clothes and shoes (5) & 0 & 0 & 0 & 0 & 124 & 2 & 0 & 1 & 2 & 0 & 1 & 2 & 0 & 3 & 1 & 1 & 1 & 6 & 8 & 19 & 3 & 0 & 2 & 0 & 5 & 2 \\
\hline & Wood, paper and printing (6) & 0 & 0 & 1 & 8 & 8 & 133 & 0 & 14 & 12 & 7 & 6 & 3 & 1 & 2 & 20 & 1 & 2 & 11 & 3 & 62 & 25 & 2 & 1 & 6 & 15 & 12 \\
\hline & Oil refining, coke and ethanol (7) & 13 & 5 & 2 & 7 & 1 & 3 & 45 & 53 & 1 & 2 & 1 & 1 & 1 & 1 & 0 & 20 & 5 & 114 & 35 & 14 & 5 & 8 & 1 & 4 & 9 & 69 \\
\hline & Chemical and pharmaceutical products ( 8 ) & 751 & 67 & 12 & 30 & 13 & 34 & 7 & 476 & 25 & 24 & 43 & 10 & 1 & 5 & 7 & 32 & 32 & 1 & 2 & 23 & 2 & 1 & 4 & 11 & 115 & 23 \\
\hline & Plastic and rubber goods (9) & 6 & 0 & 1 & 22 & 7 & 18 & 1 & 14 & 27 & 1 & 31 & 16 & 1 & 39 & 21 & 1 & 29 & 16 & 17 & 88 & 0 & 2 & 2 & 0 & 30 & 1 \\
\hline & Cement and other non-metallic mineral products $(10)$ & 1 & 1 & 2 & 2 & 1 & 1 & 0 & 15 & 0 & 59 & 18 & 1 & 0 & 14 & 13 & 0 & 353 & 2 & 0 & 9 & 0 & 0 & 0 & 1 & 20 & 3 \\
\hline & Metallurgy (11) & 18 & 2 & 3 & 16 & 5 & 11 & 7 & 28 & 8 & 7 & 180 & 70 & 7 & 65 & 17 & 1 & 83 & 9 & 0 & 9 & 0 & 0 & 1 & 1 & 9 & 24 \\
\hline & Machinery and equipment (12) & 0 & 0 & 1 & 1 & 2 & 4 & 4 & 3 & 2 & 2 & 15 & 24 & 0 & 8 & 1 & 0 & 4 & 0 & 0 & 2 & 0 & 0 & 0 & 2 & 0 & 1 \\
\hline & Electrical and electronic materials (13) & 0 & 0 & 0 & 0 & 0 & 1 & 0 & 1 & 0 & 0 & 1 & 1 & 9 & 1 & 0 & 0 & 1 & 0 & 0 & 1 & 0 & 0 & 0 & 0 & 0 & 0 \\
\hline & Transport materials (14) & 0 & 0 & 1 & 0 & 0 & 0 & 0 & 1 & 0 & 0 & 2 & 6 & 0 & 128 & 0 & 0 & 2 & 2 & 3 & 6 & 0 & 0 & 0 & 0 & 0 & 0 \\
\hline & Miscellaneous industries (15) & 0 & 0 & 0 & 0 & 2 & 0 & 0 & 0 & 0 & 0 & 2 & 0 & 0 & 0 & 11 & 0 & 3 & 0 & 4 & 15 & 23 & 1 & 0 & 24 & 0 & 1 \\
\hline & Power, gas, sewage and public cleaning (16) & 50 & 28 & 60 & 331 & 31 & 33 & 23 & 129 & 19 & 68 & 111 & 13 & 1 & 39 & 9 & 1,019 & 14 & 218 & 75 & 217 & 29 & 7 & 34 & 136 & 79 & 123 \\
\hline & Construction (17) & 0 & 0 & 0 & 11 & 1 & 1 & 1 & 4 & 2 & 3 & 1 & 1 & 0 & 25 & 0 & 1 & 158 & 11 & 1 & 58 & 26 & 150 & 1 & 219 & 50 & 189 \\
\hline & Commerce (18) & 453 & 248 & 85 & 1,549 & 161 & 44 & 31 & 307 & 43 & 80 & 104 & 45 & 6 & 244 & 43 & 52 & 430 & 341 & 233 & 265 & 43 & 14 & 237 & 78 & 122 & 102 \\
\hline & Transport, storage and mail (19) & 218 & 51 & 135 & 836 & 33 & 31 & 43 & 143 & 21 & 39 & 121 & 25 & 3 & 84 & 11 & 60 & 74 & 423 & 421 & 190 & 32 & 7 & 16 & 30 & 48 & 43 \\
\hline & Private services (20) & 34 & 23 & 58 & 446 & 26 & 37 & 42 & 221 & 19 & 26 & 60 & 23 & 5 & 119 & 7 & 188 & 111 & 606 & 263 & 1,604 & 515 & 72 & 34 & 251 & 409 & 722 \\
\hline & Financial and insurance (2I) & 53 & 17 & 25 & 250 & 20 & 20 & 17 & 112 & 15 & 16 & 62 & 30 & 2 & 56 & 7 & 30 & 38 & 139 & 78 & 107 & 391 & 18 & 8 & 6 & 7 & 300 \\
\hline & Real estate services (22) & 5 & 1 & 10 & 78 & 10 & 6 & 7 & 23 & 3 & 5 & 10 & 4 & 0 & 3 & 2 & 10 & 12 & 219 & 35 & 147 & 19 & 16 & 19 & 35 & 28 & 111 \\
\hline & Accommodation and food services (23) & 1 & 0 & 6 & 12 & 0 & 1 & 4 & 3 & 1 & 4 & 3 & 0 & 0 & 5 & 1 & 1 & 11 & 19 & 26 & 52 & 16 & 3 & 4 & 19 & 69 & 83 \\
\hline & Public and private education (24) & 0 & 0 & 0 & 4 & 0 & 0 & 0 & 1 & 0 & 0 & 0 & 0 & 0 & 0 & 0 & 1 & 1 & 9 & 2 & 7 & 5 & 1 & 1 & 6 & 6 & 9 \\
\hline & Public and private healthcare (25) & 2 & 1 & 1 & 11 & 1 & 1 & 1 & 3 & 0 & 1 & 1 & 0 & 0 & 1 & 0 & 1 & 2 & 14 & 3 & 10 & 1 & 1 & 2 & 2 & 2 & 7 \\
\hline & Public administration and social security (26) & 7 & 2 & 5 & 39 & 2 & 3 & 2 & 11 & 1 & 3 & 5 & 1 & 0 & 5 & 1 & 26 & 5 & 29 & 14 & 25 & 11 & 2 & 2 & 8 & 13 & 14 \\
\hline
\end{tabular}




\begin{tabular}{|c|c|c|c|c|c|c|c|c|c|c|c|c|c|c|c|c|c|c|c|c|c|c|c|c|c|c|c|}
\hline & & \multicolumn{26}{|c|}{ Rest of Brazil } \\
\hline & & (I) & (2) & (3) & (4) & (5) & (6) & (7) & (8) & (9) & $(10)$ & (11) & $(12)$ & (13) & (14) & (15) & (16) & (17) & (18) & (19) & (20) & (21) & (22) & (23) & (24) & (25) & (26) \\
\hline \multirow{26}{*}{ 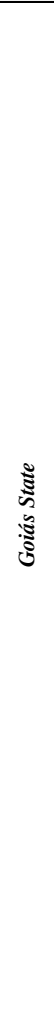 } & Agriculture and forestry (I) & 229 & 167 & 1 & 2,325 & 117 & 60 & 112 & 15 & 8 & 3 & 2 & 0 & 0 & 0 & 2 & 0 & 1 & 0 & 0 & 15 & 0 & 0 & 43 & 4 & 2 & 8 \\
\hline & Livestock and fishing (2) & 20 & 134 & 0 & 1,518 & 17 & 2 & 2 & 6 & 1 & 0 & 0 & 0 & 0 & 0 & 2 & 0 & 0 & 0 & 0 & 17 & 0 & 0 & 31 & 4 & 3 & 10 \\
\hline & Mining (3) & 8 & 49 & 47 & 4 & 1 & 6 & 1 & 254 & 0 & 94 & 199 & 8 & 2 & 6 & 1 & 0 & 98 & 0 & 0 & 1 & 0 & 0 & 0 & 0 & 0 & 1 \\
\hline & Food, beverages and tobacco (4) & 42 & 344 & 2 & 4,559 & 124 & 4 & 92 & 306 & 0 & 0 & 1 & 0 & 0 & 1 & 5 & 3 & 1 & 27 & 3 & 137 & 1 & 2 & 665 & 69 & 52 & 179 \\
\hline & Textile, clothes and shoes (5) & 2 & 1 & 4 & 3 & 98 & 2 & 0 & 2 & 2 & 1 & 1 & 2 & 1 & 5 & 2 & 0 & 1 & 5 & 6 & 17 & 3 & 0 & 2 & 0 & 4 & 4 \\
\hline & Wood, paper and printing (6) & 1 & 0 & 10 & 25 & 6 & 61 & 0 & 20 & 4 & 10 & 6 & 4 & 5 & 6 & 21 & 2 & 17 & 20 & 4 & 82 & 22 & 4 & 1 & 7 & 12 & 20 \\
\hline & Oil refining, coke and ethanol (7) & 11 & 6 & 4 & 6 & 3 & 6 & 270 & 166 & 3 & 4 & 6 & 3 & 8 & 3 & 0 & 8 & 3 & 163 & 36 & 10 & 7 & 14 & 0 & 3 & 12 & 98 \\
\hline & Chemical and pharmaceutical products (8) & 280 & 77 & 40 & 30 & 17 & 38 & 9 & 363 & 37 & 33 & 117 & 26 & 13 & 15 & 6 & 20 & 61 & 0 & 2 & 25 & 1 & 1 & 4 & 9 & 128 & 39 \\
\hline & Plastic and rubber goods (9) & 10 & 1 & 7 & 43 & 5 & 9 & 2 & 22 & 5 & 1 & 26 & 13 & 10 & 93 & 12 & 3 & 42 & 18 & 17 & 40 & 0 & 1 & 2 & 0 & 16 & 1 \\
\hline & Cement and other non-metallic mineral products (10) & 2 & 2 & 17 & 5 & 1 & 1 & 1 & 24 & 0 & 42 & 38 & 5 & 7 & 22 & 7 & 0 & 261 & 1 & 0 & 3 & 0 & 0 & 0 & 0 & 11 & 3 \\
\hline & Metallurgy (II) & 16 & 3 & 80 & 36 & 4 & 11 & 7 & 31 & 4 & 7 & 321 & 87 & 57 & 163 & 11 & 1 & 74 & 5 & 0 & 5 & 0 & 0 & 1 & 1 & 6 & 32 \\
\hline & Machinery and equipment (12) & 0 & 0 & 30 & 9 & 3 & 3 & 3 & 9 & 1 & 5 & 27 & 9 & 2 & 22 & 1 & 1 & 11 & 0 & 0 & 3 & 0 & 1 & 0 & 2 & 0 & 1 \\
\hline & Electrical and electronic materials (13) & 0 & 0 & 1 & 1 & 0 & 0 & 0 & 2 & 0 & 0 & 1 & 1 & 4 & 3 & 0 & 1 & 1 & 0 & 1 & 2 & 0 & 0 & 0 & 0 & 0 & 0 \\
\hline & Transport materials (14) & 1 & 1 & 2 & 1 & 0 & 0 & 0 & 3 & 0 & 1 & 3 & 9 & 1 & 89 & 0 & 0 & 2 & 10 & 15 & 8 & 0 & 0 & 0 & 0 & 0 & 1 \\
\hline & Miscellaneous industries (15) & 0 & 0 & 0 & 1 & 2 & 0 & 0 & 0 & 0 & 0 & 5 & 0 & 0 & 0 & 1 & 0 & 5 & 0 & 2 & 11 & 16 & 0 & 0 & 17 & 1 & 2 \\
\hline & Power, gas, sewage and public cleaning (16) & 6 & 5 & 33 & 37 & 18 & 23 & 9 & 59 & 11 & 31 & 93 & 14 & 15 & 32 & 6 & 143 & 3 & 67 & 28 & 101 & 17 & 2 & 14 & 30 & 29 & 99 \\
\hline & Construction (17) & 0 & 0 & 12 & 1 & 0 & 0 & 1 & 1 & 1 & 1 & 1 & 0 & 1 & 7 & 0 & 0 & 8 & 2 & 0 & 15 & 9 & 27 & 0 & 23 & 7 & 70 \\
\hline & Commerce (18) & 25 & 20 & 14 & 72 & 25 & 16 & 7 & 48 & 12 & 16 & 34 & 22 & 28 & 89 & 9 & 5 & 37 & 5 & 28 & 45 & 10 & 2 & 27 & 5 & 15 & 18 \\
\hline & Transport, storage and mail (19) & 9 & 3 & 30 & 26 & 5 & 9 & 7 & 18 & 4 & 7 & 33 & 8 & 9 & 27 & 1 & 4 & 4 & 16 & 30 & 17 & 4 & 0 & 1 & 2 & 6 & 6 \\
\hline & Private services (20) & 2 & 1 & 26 & 15 & 2 & 5 & 3 & 25 & 4 & 3 & 14 & 9 & 14 & 25 & 1 & 12 & 7 & 43 & 20 & 77 & 89 & 5 & 3 & 14 & 24 & 89 \\
\hline & Financial and insurance (21) & 2 & 1 & 6 & 7 & 1 & 1 & 1 & 12 & 1 & 1 & 11 & 5 & 5 & 11 & 1 & 2 & 2 & 9 & 6 & 6 & 0 & 1 & 1 & 0 & 0 & 46 \\
\hline & Real estate services (22) & 1 & 0 & 34 & 7 & 1 & 3 & 2 & 5 & 1 & 1 & 4 & 2 & 2 & 3 & 0 & 2 & 2 & 32 & 7 & 28 & 7 & 2 & 3 & 5 & 5 & 35 \\
\hline & Accommodation and food services (23) & 0 & 0 & 4 & 1 & 0 & 0 & 1 & 1 & 0 & 1 & 1 & 0 & 0 & 2 & 0 & 0 & 1 & 2 & 3 & 7 & 3 & 0 & 0 & 4 & 9 & 12 \\
\hline & Public and private education (24) & 0 & 0 & 1 & 0 & 0 & 0 & 0 & 0 & 0 & 0 & 0 & 0 & 0 & 0 & 0 & 0 & 0 & 1 & 0 & 1 & 1 & 0 & 0 & 0 & 0 & 2 \\
\hline & Public and private healthcare (25) & 0 & 0 & 2 & 1 & 0 & 0 & 0 & 1 & 0 & 0 & 0 & 0 & 0 & 1 & 0 & 0 & 0 & 2 & 1 & 2 & 0 & 0 & 0 & 0 & 0 & 2 \\
\hline & Public administration and social security (26) & 1 & 0 & 2 & 5 & 1 & 1 & 0 & 2 & 0 & 1 & 3 & 1 & 1 & 2 & 0 & 3 & 0 & 3 & 2 & 6 & 3 & 0 & 1 & 1 & 2 & 4 \\
\hline
\end{tabular}

Continue 


\begin{tabular}{|c|c|c|c|c|c|c|c|c|c|c|c|c|c|c|c|c|}
\hline & & \multirow[t]{2}{*}{$\begin{array}{c}\text { Total } \\
\text { Intermediate } \\
\text { Consumption }\end{array}$} & $\begin{array}{l}\begin{array}{c}\text { Goods } \\
\text { and } \\
\text { services } \\
\text { exports }\end{array} \\
\end{array}$ & $\begin{array}{c}\text { Consumption of } \\
\text { public } \\
\text { administration }\end{array}$ & $\begin{array}{l}\text { Consumption of } \\
\text { financial } \\
\text { institutions } \\
\end{array}$ & $\begin{array}{l}\text { Households } \\
\text { consumption }\end{array}$ & $\begin{array}{c}\text { Gross fixed } \\
\text { capitial } \\
\text { formation } \\
\end{array}$ & $\begin{array}{c}\text { Stock } \\
\text { change }\end{array}$ & $\begin{array}{l}\text { Goods } \\
\text { and } \\
\text { services } \\
\text { exports } \\
\end{array}$ & $\begin{array}{c}\text { Consumption of } \\
\text { public } \\
\text { administration }\end{array}$ & $\begin{array}{c}\text { Consumption of } \\
\text { financial } \\
\text { institutions }\end{array}$ & $\begin{array}{l}\text { Households } \\
\text { consumption }\end{array}$ & $\begin{array}{c}\text { Gross fixed } \\
\text { capitial } \\
\text { formation } \\
\end{array}$ & $\begin{array}{l}\text { Stock } \\
\text { change }\end{array}$ & \multirow[t]{2}{*}{$\begin{array}{c}\text { Final } \\
\text { Demand }\end{array}$} & \multirow[t]{2}{*}{$\begin{array}{c}\text { Total } \\
\text { Output }\end{array}$} \\
\hline & & & \multicolumn{6}{|c|}{ Goiás State } & \multicolumn{6}{|c|}{ Rest of Brazil } & & \\
\hline \multirow{26}{*}{ 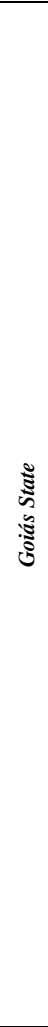 } & Agriculture and forestry (l) & 6,783 & 1,644 & 0 & 0 & 834 & 137 & 557 & 0 & 0 & 0 & 742 & 36 & 0 & 3,950 & 10,732 \\
\hline & Livestock and fishing (2) & 4,895 & 239 & 0 & 0 & 393 & 380 & 80 & 0 & 0 & 0 & 598 & 141 & 0 & 1,831 & 6,726 \\
\hline & Mining (3) & 1,127 & 701 & 0 & 0 & 12 & 1 & 211 & 0 & 0 & 0 & 17 & 0 & 0 & 942 & 2,069 \\
\hline & Food, beverages and tobacco (4) & 10,723 & 2,835 & 0 & 0 & 3,913 & 2 & 312 & 0 & 0 & 0 & 8,655 & 1 & 0 & 15,718 & 26,441 \\
\hline & Textile, clothes and shoes (5) & 354 & 190 & 0 & 0 & 762 & 1 & 13 & 0 & 0 & 0 & 527 & 0 & 0 & 1,493 & 1,847 \\
\hline & Wood, paper and printing (6) & 726 & 3 & 0 & 0 & 77 & 6 & 4 & 0 & 0 & 0 & 146 & 4 & 0 & 240 & 966 \\
\hline & Oil refining, coke and ethanol (7) & 1,276 & 2 & 0 & 0 & 1,120 & 3 & 36 & 0 & 0 & 0 & 686 & 1 & 0 & 1,848 & 3,124 \\
\hline & Chemical and pharmaceutical products (8) & 3,137 & 118 & 165 & 0 & 865 & 3 & -29 & 0 & 0 & 0 & 912 & 2 & 0 & 2,035 & 5,173 \\
\hline & Plastic and rubber goods $(9)$ & 791 & 7 & 0 & 0 & 22 & 1 & 5 & 0 & 0 & 0 & 28 & 1 & 0 & 64 & 855 \\
\hline & Cement and other non-metallic mineral products (10) & 972 & 6 & 0 & 0 & 22 & 1 & 79 & 0 & 0 & 0 & 13 & 1 & 0 & 121 & 1,093 \\
\hline & Metallurgy (11) & 1,545 & 520 & 0 & 0 & 57 & 200 & 481 & 0 & 0 & 0 & 35 & 140 & 0 & 1,433 & 2,978 \\
\hline & Machinery and equipment (12) & 223 & 3 & 0 & 0 & 11 & 141 & 117 & 0 & 0 & 0 & 13 & 368 & 0 & 652 & 875 \\
\hline & Electrical and electronic materials (13) & 39 & 2 & 0 & 0 & 2 & 4 & 13 & 0 & 0 & 0 & 7 & 17 & 0 & 45 & 83 \\
\hline & Transport materials (14) & 304 & 47 & 0 & 0 & 1,242 & 665 & 142 & 0 & 0 & 0 & 420 & 285 & 0 & 2,801 & 3,105 \\
\hline & Miscellaneous industries (15) & 154 & 3 & 0 & 0 & 202 & 56 & 6 & 0 & 0 & 0 & 180 & 60 & 0 & 507 & 661 \\
\hline & Power, gas, sewage and public cleaning (16) & 3,820 & 0 & 0 & 0 & 1,672 & 1 & 0 & 0 & 0 & 0 & 397 & 0 & 0 & 2,070 & 5,891 \\
\hline & Construction (17) & 1,101 & 49 & 0 & 0 & 16 & 5,764 & 0 & 0 & 0 & 0 & 2 & 1,016 & 0 & 6,847 & 7,948 \\
\hline & Commerce (18) & 5,991 & 983 & 0 & 0 & 5,106 & 1,199 & -1 & 0 & 0 & 0 & 432 & 144 & 0 & 7,863 & 13,854 \\
\hline & Transport, storage and mail (19) & 3,428 & 223 & 0 & 0 & 1,838 & 124 & 0 & 0 & 0 & 0 & 156 & 9 & 0 & 2,351 & 5,779 \\
\hline & Private services (20) & 6,453 & 67 & 0 & 726 & 4,191 & 82 & 0 & 0 & 0 & 0 & 212 & 12 & 0 & 5,289 & 11,743 \\
\hline & Financial and insurance (2I) & 1,961 & 37 & 41 & 0 & 2,258 & 1 & 0 & 0 & 0 & 0 & 112 & 0 & 0 & 2,448 & 4,409 \\
\hline & Real estate services (22) & 1,016 & 47 & 0 & 0 & 4,296 & 107 & 0 & 0 & 0 & 0 & 429 & 27 & 0 & 4,906 & 5,922 \\
\hline & Accommodation and food services (23) & 393 & 299 & 0 & 0 & 1,856 & 2 & 0 & 0 & 0 & 0 & 151 & 0 & 0 & 2,307 & 2,700 \\
\hline & Public and private education (24) & 65 & 2 & 3,550 & 0 & 609 & 4 & 0 & 0 & 0 & 0 & 28 & 1 & 0 & 4,194 & 4,260 \\
\hline & Public and private healthcare (25) & 84 & 8 & 2,836 & 59 & 734 & 11 & -0 & 0 & 0 & 0 & 38 & 2 & 0 & 3,687 & 3,771 \\
\hline & Public administration and social security (26) & 284 & 8 & 7,556 & 1 & 124 & 8 & 1 & 0 & 0 & 0 & 30 & 1 & 0 & 7,729 & 8,012 \\
\hline
\end{tabular}

Continue 


\begin{tabular}{|c|c|c|c|c|c|c|c|c|c|c|c|c|c|c|c|c|c|c|c|c|c|c|c|c|c|c|c|}
\hline & & \multicolumn{26}{|c|}{ Goiás State } \\
\hline & & (l) & (2) & (3) & (4) & (5) & (6) & (7) & (8) & (9) & (10) & $(11)$ & (12) & (13) & (14) & (15) & (16) & (17) & (18) & (19) & (20) & (21) & (22) & (23) & (24) & (25) & (26) \\
\hline \multirow{26}{*}{ 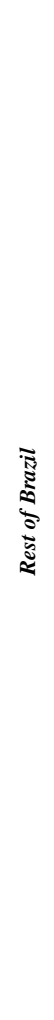 } & Agriculture and forestry (I) & 505 & 90 & 0 & 2,249 & 8 & 29 & 240 & 29 & 2 & 2 & 2 & 0 & 0 & 0 & 2 & 0 & 1 & 0 & 0 & 2 & 0 & 0 & 10 & 2 & 0 & 1 \\
\hline & Livestock and fishing (2) & 28 & 51 & 0 & 1,687 & 1 & 1 & 5 & 1 & 0 & 0 & 0 & 0 & 0 & 0 & 0 & 0 & 0 & 0 & 0 & 1 & 0 & 0 & 3 & 0 & 0 & c \\
\hline & Mining (3) & 2 & 5 & 19 & 5 & 0 & 0 & 790 & 17 & 0 & 14 & 127 & 4 & 0 & 0 & 0 & 215 & 6 & 0 & 0 & 0 & 0 & 0 & 1 & 0 & 0 & c \\
\hline & Food, beverages and tobacco (4) & 60 & 546 & 2 & 1,747 & 3 & 0 & 20 & 22 & 0 & 0 & 0 & 0 & 0 & 0 & 0 & 5 & 1 & 4 & 1 & 12 & 0 & 0 & 155 & 11 & 4 & 8 \\
\hline & Textile, clothes and shoes (5) & 19 & 11 & 45 & 8 & 421 & 3 & 3 & 9 & 7 & 7 & 0 & 0 & 0 & 1 & 11 & 1 & 6 & 19 & 11 & 35 & 1 & 0 & 7 & 0 & 7 & 1 \\
\hline & Wood, paper and printing (6) & 32 & 1 & 16 & 160 & 3 & 42 & 3 & 78 & 3 & 24 & 13 & 2 & 0 & 8 & 64 & 7 & 183 & 73 & 11 & 262 & 52 & 13 & 2 & 31 & 20 & 28 \\
\hline & Oil refining, coke and ethanol (7) & 407 & 128 & 132 & 217 & 9 & 6 & 231 & 263 & 18 & 44 & 31 & 10 & 1 & 13 & 5 & 84 & 95 & 111 & 732 & 31 & 4 & 4 & 3 & 6 & 4 & 26 \\
\hline & Chemical and pharmaceutical products (8) & 1,571 & 166 & 60 & 192 & 39 & 24 & 13 & 435 & 202 & 25 & 78 & 7 & 1 & 22 & 34 & 17 & 166 & 0 & 3 & 17 & 0 & 1 & 5 & 11 & 49 & 17 \\
\hline & Plastic and rubber goods (9) & 56 & 4 & 57 & 298 & 5 & 3 & 14 & 51 & 7 & 2 & 15 & 3 & 0 & 170 & 3 & 12 & 130 & 52 & 63 & 24 & 0 & 4 & 2 & 0 & 7 & c \\
\hline & Cement and other non-metallic mineral products $(10)$ & 9 & 0 & 3 & 46 & 0 & 0 & 3 & 21 & 0 & 50 & 2 & 0 & 0 & 12 & 1 & 0 & 639 & 2 & 0 & 1 & 0 & 0 & 0 & 0 & 6 & c \\
\hline & Metallurgy (11) & 70 & 10 & 68 & 268 & 1 & 4 & 20 & 30 & 11 & 18 & 564 & 160 & 2 & 303 & 36 & 12 & 400 & 11 & 1 & 16 & 0 & 0 & 1 & 1 & 6 & 3 \\
\hline & Machinery and equipment (12) & 1 & 0 & 56 & 107 & 4 & 4 & 18 & 33 & 4 & 12 & 20 & 3 & 0 & 43 & 2 & 4 & 54 & 1 & 2 & 17 & 0 & 3 & 2 & 6 & 1 & 2 \\
\hline & Electrical and electronic materials (13) & 2 & 1 & 19 & 41 & 1 & 1 & 5 & 17 & 3 & 5 & 3 & 32 & 6 & 108 & 7 & 97 & 83 & 22 & 31 & 128 & 3 & 2 & 0 & 2 & 13 & 6 \\
\hline & Transport materials (14) & 15 & 1 & 7 & 16 & 0 & 0 & 1 & 3 & 2 & 2 & 4 & 14 & 0 & 612 & 1 & 8 & 12 & 149 & 187 & 61 & 0 & 4 & 0 & 0 & 0 & 6 \\
\hline & Miscellaneous industries (15) & 0 & 2 & 0 & 7 & 6 & 2 & 0 & 0 & 0 & 0 & 10 & 0 & 0 & 0 & 1 & 0 & 17 & 0 & 4 & 13 & 2 & 1 & 0 & 58 & 1 & 1 \\
\hline & Power, gas, sewage and public cleaning (16) & 10 & 5 & 12 & 65 & 0 & 0 & 3 & 5 & 0 & 0 & 1 & 0 & 0 & 0 & 0 & 0 & 0 & 0 & 0 & 0 & 0 & 0 & 0 & 0 & 0 & c \\
\hline & Construction (17) & 0 & 0 & 0 & 2 & 0 & 0 & 0 & 0 & 0 & 0 & 0 & 0 & 0 & 0 & 0 & 0 & 0 & 0 & 0 & 0 & 0 & 0 & 0 & 0 & 0 & c \\
\hline & Commerce (18) & 107 & 58 & 20 & 366 & 4 & 1 & 4 & 37 & 1 & 2 & 2 & 1 & 0 & 14 & 1 & 13 & 61 & 10 & 17 & 13 & 3 & 1 & 4 & 3 & 5 & 3 \\
\hline & Transport, storage and mail (19) & 102 & 24 & 64 & 390 & 11 & 7 & 15 & 65 & 5 & 10 & 26 & 6 & 1 & 34 & 2 & 28 & 33 & 201 & 88 & 47 & 11 & 3 & 7 & 10 & 9 & 10 \\
\hline & Private services (20) & 11 & 8 & 23 & 181 & 5 & 5 & 10 & 86 & 2 & 8 & 12 & 3 & 1 & 45 & 1 & 81 & 44 & 245 & 117 & 322 & 69 & 31 & 10 & 76 & 137 & 166 \\
\hline & Financial and insurance (2I) & 56 & 19 & 26 & 267 & 17 & 12 & 18 & 116 & 9 & 15 & 47 & 18 & 1 & 56 & 4 & 32 & 41 & 147 & 83 & 103 & 240 & 19 & 8 & 4 & 4 & 320 \\
\hline & Real estate services (22) & 1 & 0 & 3 & 21 & 0 & 0 & 1 & 2 & 0 & 0 & 0 & 0 & 0 & 0 & 0 & 3 & 3 & 9 & 0 & 0 & 0 & 0 & 0 & 0 & 0 & c \\
\hline & Accommodation and food services (23) & 0 & 0 & 1 & 3 & 0 & 0 & 0 & 1 & 0 & 0 & 0 & 0 & 0 & 1 & 0 & 0 & 2 & 4 & 0 & 0 & 0 & 0 & 0 & 0 & 11 & c \\
\hline & Public and private education (24) & 0 & 0 & 0 & 1 & 0 & 0 & 0 & 0 & 0 & 0 & 0 & 0 & 0 & 0 & 0 & 0 & 0 & 1 & 0 & 0 & 4 & 0 & 0 & 5 & 5 & 5 \\
\hline & Public and private healthcare (25) & 1 & 0 & 0 & 3 & 0 & 0 & 0 & 0 & 0 & 0 & 0 & 0 & 0 & 0 & 0 & 0 & 0 & 1 & 0 & 0 & 0 & 0 & 0 & 0 & 0 & c \\
\hline & Public administration and social security (26) & 3 & 1 & 2 & 16 & 0 & 0 & 1 & 5 & 0 & 0 & 1 & 0 & 0 & 2 & 0 & 3 & 2 & 12 & 4 & 18 & 4 & 1 & 0 & 3 & 5 & 6 \\
\hline
\end{tabular}

Continue 


\begin{tabular}{|c|c|c|c|c|c|c|c|c|c|c|c|c|c|c|c|c|c|c|c|c|c|c|c|c|c|c|c|}
\hline & & \multicolumn{26}{|c|}{ Rest of Brazil } \\
\hline & & (l) & (2) & (3) & (4) & (5) & (6) & (7) & (8) & (9) & (10) & (11) & (12) & (13) & (14) & (15) & (16) & (17) & (18) & (19) & (20) & (21) & (22) & (23) & (24) & (25) & (26) \\
\hline \multirow{26}{*}{ 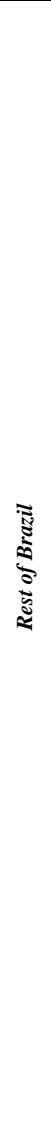 } & Agriculture and forestry (l) & 9,117 & 5,659 & 32 & 58,544 & 2,465 & 6,796 & 8,155 & 1,392 & 401 & 151 & 147 & 5 & 5 & 33 & 182 & 3 & 51 & 31 & 4 & 494 & 3 & 1 & 1,643 & 289 & 76 & 192 \\
\hline & Livestock and fishing (2) & 740 & 5,054 & 1 & 51,372 & 337 & 173 & 171 & 89 & 27 & 3 & 4 & 0 & 0 & 1 & 69 & 0 & 0 & 0 & 0 & 366 & 0 & 0 & 780 & 85 & 54 & 155 \\
\hline & Mining (3) & 119 & 703 & 5,797 & 102 & 19 & 75 & 74,014 & 3,769 & 3 & 1,749 & 12,093 & 459 & 38 & 85 & 33 & 6,818 & 1,689 & 15 & 9 & 30 & 2 & 2 & 34 & 8 & 22 & 32 \\
\hline & $\begin{array}{l}\text { Food, beverages and tobacco } \\
\text { (4) }\end{array}$ & 1,572 & 15,438 & 47 & 49,400 & 1,923 & 230 & 1,092 & 2,400 & 30 & 14 & 34 & 12 & 34 & 25 & 94 & 189 & 81 & 833 & 151 & 3,310 & 45 & 35 & 25,153 & 1,647 & 1,072 & 2,659 \\
\hline & Textile, clothes and shoes (5) & 212 & 163 & 351 & 464 & 24,511 & 403 & 38 & 297 & 590 & 283 & 57 & 291 & 55 & 180 & 719 & 41 & 198 & 835 & 774 & 2,575 & 200 & 9 & 398 & 11 & 789 & 172 \\
\hline & Wood, paper and printing $(6)$ & 350 & 11 & 437 & 2,515 & 680 & 17,590 & 64 & 2,742 & 1,018 & 1,257 & 900 & 860 & 1,018 & 741 & 4,963 & 243 & 5,125 & 2,855 & 556 & 16,538 & 4,413 & 582 & 146 & 1,205 & 1,758 & 1,954 \\
\hline & $\begin{array}{l}\text { Oil refining, coke and ethanol } \\
\text { (7) }\end{array}$ & 4,525 & 2,046 & 3,208 & 2,692 & 816 & 1,050 & 24,028 & 11,391 & 1,325 & 1,983 & 2,637 & 1,320 & 2,499 & 1,900 & 319 & 3,287 & 2,773 & 7,402 & 31,373 & 2,169 & 530 & 415 & 156 & 540 & 665 & 4,224 \\
\hline & $\begin{array}{l}\text { Chemical and pharmaceutical } \\
\text { products }(8)\end{array}$ & 24,783 & 3,536 & 1,900 & 2,672 & 4,460 & 4,777 & 1,519 & 42,999 & 15,484 & 1,968 & 7,610 & 2,120 & 3,097 & 2,034 & 2,429 & 1,520 & 5,428 & 24 & 164 & 1,942 & 137 & 50 & 412 & 871 & 6,557 & 1,926 \\
\hline & Plastic and rubber goods (9) & 650 & 71 & 618 & 3,796 & 780 & 1,800 & 248 & 2,508 & 2,345 & 124 & 2,456 & 2,317 & 1,716 & 10,920 & 1,437 & 437 & 4,360 & 2,310 & 3,265 & 5,405 & 55 & 204 & 176 & 11 & 2,471 & 37 \\
\hline & $\begin{array}{l}\text { Cement and other non-metallic } \\
\text { mineral products }(10)\end{array}$ & 110 & 21 & 1,032 & 570 & 89 & 82 & 45 & 1,076 & 17 & 4,375 & 1,432 & 396 & 607 & 1,495 & 877 & 14 & 27,193 & 145 & 1 & 478 & 1 & 2 & 1 & 32 & 1,328 & 139 \\
\hline & Metallurgy (II) & 937 & 182 & 4,695 & 3,423 & 318 & 1,346 & 854 & 2,477 & 1,290 & 1,090 & 43,821 & 25,699 & 10,670 & 26,494 & 3,135 & 410 & 13,296 & 654 & 61 & 1,095 & 7 & 5 & 82 & 61 & 630 & 1,304 \\
\hline & Machinery and equipment (12) & 14 & 2 & 2,763 & 1,307 & 464 & 695 & 643 & 1,347 & 373 & 595 & 2,329 & 3,459 & 578 & 3,197 & 182 & 145 & 1,616 & 40 & 111 & 934 & 4 & 121 & 71 & 457 & 87 & 118 \\
\hline & $\begin{array}{l}\text { Electrical and electronic } \\
\text { materials (13) }\end{array}$ & 23 & 17 & 1,256 & 507 & 105 & 183 & 423 & 549 & 253 & 263 & 250 & 3,888 & 18,027 & 4,785 & 437 & 3,097 & 2,305 & 751 & 1,274 & 5,957 & 192 & 93 & 5 & 77 & 634 & 326 \\
\hline & Transport materials (14) & 168 & 26 & 182 & 196 & 24 & 48 & 54 & 142 & 145 & 94 & 356 & 2,049 & 652 & 49,182 & 43 & 247 & 368 & 5,145 & 7,781 & 3,441 & 11 & 163 & 5 & 17 & 28 & 321 \\
\hline & Miscellaneous industries (15) & 3 & 32 & 5 & 93 & 269 & 135 & 1 & 23 & 59 & 22 & 919 & 40 & 30 & 26 & 729 & 1 & 552 & 8 & 326 & 1,340 & 1,402 & 76 & 2 & 2,441 & 61 & 99 \\
\hline & $\begin{array}{l}\text { Power, gass, sevage and public } \\
\text { cleaning }(16)\end{array}$ & 633 & 504 & 3,160 & 4,766 & 2,315 & 2,731 & 1,047 & 6,142 & 1,319 & 2,786 & 8,299 & 1,406 & 1,766 & 3,006 & 549 & 32,234 & 392 & 7,371 & 3,027 & 10,058 & 1,642 & 242 & 1,501 & 4,395 & 3,346 & 5,965 \\
\hline & Construction (17) & 1 & 0 & 2,385 & 162 & 51 & 74 & 117 & 186 & 154 & 136 & 84 & 69 & 214 & 925 & 21 & 23 & 4,355 & 389 & 37 & 2,658 & 1,478 & 5,544 & 28 & 6,953 & 1,642 & 9,267 \\
\hline & Commerce (18) & 6,018 & 4,715 & 3,390 & 23,042 & 7,769 & 4,267 & 1,709 & 12,153 & 2,961 & 3,386 & 6,834 & 5,407 & 7,235 & 15,107 & 2,632 & 2,042 & 13,548 & 11,950 & 10,226 & 13,469 & 2,610 & 555 & 10,787 & 2,728 & 5,773 & 5,169 \\
\hline & $\begin{array}{l}\text { Transport, storage and mail } \\
\text { (19) }\end{array}$ & 3,441 & 1,157 & 13,462 & 15,064 & 2,499 & 3,454 & 2,801 & 7,117 & 1,765 & 2,206 & 10,046 & 3,687 & 4,104 & 6,976 & 811 & 2,787 & 2,981 & 21,235 & 20,848 & 11,053 & 2,511 & 358 & 1,055 & 1,537 & 2,592 & 2,613 \\
\hline & Private services (20) & 478 & 478 & 13,038 & 7,825 & 1,874 & 3,640 & 3,078 & 8,854 & 1,446 & 1,479 & 4,594 & 3,203 & 6,629 & 9,328 & 466 & 8,535 & 4,308 & 28,959 & 15,568 & 91,261 & 33,489 & 3,841 & 1,981 & 13,286 & 22,463 & 43,707 \\
\hline & Financial and insurance (2I) & 1,177 & 553 & 3,396 & 6,568 & 2,132 & 2,776 & 546 & 9,463 & 1,622 & 1,330 & 7,532 & 5,369 & 4,146 & 7,458 & 635 & 1,943 & 2,195 & 9,735 & 6,584 & 9,966 & 36,237 & 1,341 & 710 & 541 & 697 & 30,525 \\
\hline & Real estate services (22) & 73 & 21 & 4,275 & 1,221 & 414 & 493 & 437 & 846 & 217 & 212 & 586 & 413 & 325 & 374 & 149 & 391 & 400 & 7,795 & 1,455 & 6,921 & 1,076 & 599 & 859 & 1,396 & 1,249 & 5,513 \\
\hline & $\begin{array}{l}\text { Accommodation and food } \\
\text { services (23) }\end{array}$ & 7 & 6 & 682 & 203 & 9 & 133 & 225 & 125 & 66 & 184 & 239 & 7 & 89 & 311 & 42 & 29 & 362 & 784 & 1,060 & 2,402 & 909 & 108 & 190 & 1,106 & 3,156 & 4,065 \\
\hline & $\begin{array}{l}\text { Public and private education } \\
\text { (24) }\end{array}$ & 3 & 2 & 182 & 63 & 19 & 25 & 23 & 57 & 10 & 10 & 26 & 18 & 20 & 28 & 6 & 28 & 22 & 344 & 73 & 324 & 531 & 29 & 35 & 330 & 379 & 716 \\
\hline & $\begin{array}{l}\text { Public and private healthcare } \\
\text { (25) }\end{array}$ & 29 & 21 & 265 & 166 & 56 & 46 & 32 & 99 & 25 & 26 & 62 & 46 & 49 & 84 & 20 & 31 & 79 & 506 & 121 & 456 & 72 & 37 & 95 & 92 & 96 & 344 \\
\hline & $\begin{array}{l}\text { Public administration and } \\
\text { social security (26) }\end{array}$ & 102 & 46 & 658 & 668 & 157 & 290 & 145 & 508 & 98 & 138 & 436 & 129 & 237 & 443 & 42 & 908 & 209 & 1,399 & 766 & 2,097 & 861 & 134 & 111 & 423 & 714 & 967 \\
\hline
\end{tabular}




\begin{tabular}{|c|c|c|c|c|c|c|c|c|c|c|c|c|c|c|c|c|}
\hline & & \multirow[t]{2}{*}{$\begin{array}{c}\text { Total } \\
\text { Intermediate } \\
\text { Consumption }\end{array}$} & $\begin{array}{c}\begin{array}{c}\text { Goods } \\
\text { and } \\
\text { services } \\
\text { exports }\end{array} \\
\end{array}$ & $\begin{array}{c}\text { Consumption of } \\
\text { public } \\
\text { administration }\end{array}$ & $\begin{array}{c}\text { Consumption of } \\
\text { financial } \\
\text { institutions }\end{array}$ & $\begin{array}{l}\text { Households } \\
\text { consumption }\end{array}$ & $\begin{array}{c}\text { Gross fixed } \\
\text { capital } \\
\text { formation }\end{array}$ & $\begin{array}{l}\text { Stock } \\
\text { change }\end{array}$ & $\begin{array}{l}\text { Goods } \\
\text { and } \\
\text { services } \\
\text { exports }\end{array}$ & $\begin{array}{c}\text { Consumption of } \\
\text { public } \\
\text { administration }\end{array}$ & $\begin{array}{c}\text { Consumption of } \\
\text { financial } \\
\text { institutions }\end{array}$ & $\begin{array}{c}\text { Households } \\
\text { consumption }\end{array}$ & $\begin{array}{c}\text { Gross fixed } \\
\text { capitial } \\
\text { formation }\end{array}$ & $\begin{array}{l}\text { Stock } \\
\text { change }\end{array}$ & \multirow[t]{2}{*}{$\begin{array}{c}\text { Final } \\
\text { Demand }\end{array}$} & \multirow[t]{2}{*}{$\begin{array}{c}\text { Total } \\
\text { Output }\end{array}$} \\
\hline & & & \multicolumn{6}{|c|}{ Goiás State } & \multicolumn{6}{|c|}{ Rest of Brazil } & & \\
\hline \multirow{26}{*}{ 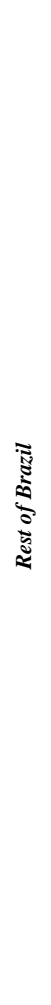 } & Agriculture and forestry (l) & 99,047 & 0 & 0 & 0 & 192 & 38 & 0 & 24,477 & 0 & 0 & 35,309 & 3,550 & 6,579 & 70,146 & 169,193 \\
\hline & Livestock and fishing (2) & 61,259 & 0 & 0 & 0 & 79 & 150 & 0 & 3,985 & 0 & 0 & 17,802 & 8,436 & 1,363 & 31,815 & 93,074 \\
\hline & Mining (3) & 108,922 & 0 & 0 & 0 & 31 & 0 & 0 & 54,501 & 0 & 0 & 1,165 & 27 & -571 & 55,153 & 164,075 \\
\hline & Food, beverages and tobacco (4) & 110,121 & 0 & 0 & 0 & 1,213 & 2 & 0 & 52,567 & 2 & 0 & 162,645 & 155 & 2,759 & 219,342 & 329,462 \\
\hline & Textile, clothes and shoes (5) & 35,246 & 0 & 0 & 0 & 848 & 1 & 0 & 8,790 & 0 & 0 & 57,377 & 64 & 3,083 & 70,163 & 105,410 \\
\hline & Wood, paper and printing (6) & 71,654 & 0 & 0 & 0 & 445 & 14 & 0 & 14,841 & 2 & 0 & 18,108 & 781 & 702 & 34,892 & 106,546 \\
\hline & Oil refining, coke and ethanol (7) & 117,882 & 0 & 0 & 0 & 370 & 2 & 0 & 18,107 & 0 & 0 & 37,383 & 151 & 468 & 56,482 & 174,363 \\
\hline & Chemical and pharmaceutical products (8) & 143,576 & 0 & 0 & 0 & 352 & 5 & 0 & 16,257 & 6,039 & 0 & 40,223 & 322 & 1,194 & 64,392 & 207,968 \\
\hline & Plastic and rubber goods (9) & 51,501 & 0 & 0 & 0 & 92 & 3 & 0 & 4,376 & 0 & 0 & 3,431 & 187 & 859 & 8,949 & 60,450 \\
\hline & Cement and other non-metallic mineral products (10) & 42,356 & 0 & 0 & 0 & 30 & 2 & 0 & 3,198 & 0 & 0 & 1,284 & 110 & 2,277 & 6,900 & 49,256 \\
\hline & Metallurgy (11) & 146,048 & 0 & 0 & 0 & 33 & 123 & 0 & 39,608 & 0 & 0 & 3,146 & 15,422 & 9,399 & 67,731 & 213,780 \\
\hline & Machinery and equipment (12) & 22,054 & 0 & 0 & 0 & 334 & 1,288 & 0 & 15,456 & 0 & 0 & 11,903 & 56,984 & 4,832 & 90,797 & 112,850 \\
\hline & Electrical and electronic materials (13) & 46,321 & 0 & 0 & 0 & 460 & 819 & 0 & 12,290 & 0 & 0 & 14,582 & 41,262 & 2,637 & 72,050 & 118,371 \\
\hline & Transport materials (14) & 71,994 & 0 & 0 & 0 & 445 & 722 & 0 & 42,332 & 0 & 0 & 47,596 & 52,927 & 9,531 & 153,553 & 225,547 \\
\hline & Miscellaneous industries (15) & 8,824 & 0 & 0 & 0 & 466 & 127 & 0 & 2,116 & 0 & 0 & 23,776 & 7,777 & 802 & 35,064 & 43,887 \\
\hline & Power, gas, sewage and public cleaning (16) & 110,705 & 0 & 0 & 0 & 0 & 0 & 0 & 89 & 0 & 0 & 48,360 & 31 & 26 & 48,505 & 159,209 \\
\hline & Construction (17) & 36,958 & 0 & 0 & 0 & 0 & 0 & 0 & 1,451 & 0 & 0 & 484 & 196,131 & 0 & 198,066 & 235,024 \\
\hline & Commerce (18) & 186,232 & 0 & 0 & 0 & 179 & 20 & 0 & 35,952 & 0 & 0 & 170,482 & 49,846 & -2 & 256,477 & 442,709 \\
\hline & Transport, storage and mail (19) & 149,369 & 0 & 0 & 0 & 566 & 59 & 0 & 12,961 & 0 & 0 & 85,916 & 7,469 & 2 & 106,973 & 256,342 \\
\hline & Private services (20) & 335,510 & 0 & 0 & 0 & 1,317 & 12 & 0 & 25,666 & 0 & 31,636 & 170,719 & 4,250 & 0 & 233,601 & 569,110 \\
\hline & Financial and insurance (2I) & 156,856 & 0 & 0 & 0 & 2,408 & 0 & 0 & 2,271 & 1,670 & 0 & 110,056 & 39 & 0 & 116,444 & 273,300 \\
\hline & Real estate services (22) & 37,753 & 0 & 0 & 0 & 649 & 0 & 0 & 2,091 & 0 & 0 & 175,746 & 4,796 & 1 & 183,283 & 221,036 \\
\hline & Accommodation and food services (23) & 16,524 & 0 & 0 & 0 & 96 & 0 & 0 & 11,235 & 0 & 0 & 73,694 & 66 & 1 & 85,091 & 101,615 \\
\hline & Public and private education (24) & 3,327 & 0 & 0 & 0 & 627 & 0 & 0 & 148 & 125,705 & 3 & 41,843 & 183 & 0 & 168,509 & 171,836 \\
\hline & Public and private healthcare (25) & 2,959 & 0 & 0 & 0 & 1,173 & 0 & 0 & 335 & 91,771 & 2,521 & 70,308 & 472 & -0 & 166,580 & 169,540 \\
\hline & Public administration and social security (26) & 12,775 & 0 & 0 & 0 & 65 & 2 & 0 & 1,155 & 372,768 & 40 & 6,236 & 378 & 1 & 380,645 & 393,421 \\
\hline
\end{tabular}

Continue 


\begin{tabular}{|c|c|c|c|c|c|c|c|c|c|c|c|c|c|c|c|c|c|c|c|c|c|c|c|c|c|c|}
\hline & \multicolumn{26}{|c|}{ Goiás State } \\
\hline & (1) & (2) & (3) & (4) & (5) & (6) & (7) & (8) & (9) & (10) & $(11)$ & (12) & (13) & (14) & (15) & (16) & (17) & (18) & (19) & (20) & (2I) & (22) & (23) & (24) & (25) & (26) \\
\hline National production & 5,186 & 2,669 & 1,114 & 20,031 & 1,034 & 576 & $\begin{array}{ll}2,098 \\
\end{array}$ & 3,088 & 485 & 625 & 1,757 & 540 & 54 & 2,293 & 353 & 2,065 & 3,416 & 3,289 & 2,582 & 4,133 & 1,542 & 394 & 1,053 & 1,123 & 1,356 & 2,500 \\
\hline Imports & 757 & 122 & 147 & 627 & 71 & 46 & 214 & 618 & 106 & 70 & 199 & 50 & 9 & 278 & 31 & 142 & 214 & 169 & 200 & 206 & 42 & 14 & 28 & 39 & 101 & 98 \\
\hline Taxes on Imports & 31 & 6 & 6 & 25 & 16 & 3 & 2 & 15 & 8 & 3 & 9 & 4 & 1 & 14 & 3 & 4 & 25 & 6 & 8 & 16 & 1 & 0 & 3 & 2 & 7 & 5 \\
\hline $\begin{array}{l}\text { Taxes on goods and services } \\
\text { (ICMS)+ Imports }\end{array}$ & 130 & 126 & 44 & 565 & 29 & 21 & 15 & 113 & 9 & 35 & 44 & 16 & 3 & 76 & 14 & 173 & 133 & 103 & 92 & 298 & 60 & 6 & 112 & 60 & 82 & 182 \\
\hline $\begin{array}{l}\text { Zeros (ICMS on Imports, } \\
\text { included above) }\end{array}$ & 22 & 6 & 4 & 12 & 2 & 1 & 1 & 12 & 1 & 3 & 4 & 1 & 0 & 6 & 1 & 9 & 20 & 6 & 12 & 21 & 2 & 1 & 4 & 3 & 9 & 9 \\
\hline $\begin{array}{l}\text { Taxes on industrial products } \\
(I P I)+\text { Imports }\end{array}$ & 3 & 10 & 4 & 33 & 2 & 2 & 1 & 8 & 1 & 3 & 4 & 3 & 1 & 9 & 2 & 3 & 18 & 1 & 3 & 13 & 2 & 0 & 31 & 6 & 4 & 2 \\
\hline $\begin{array}{l}\text { Zeros (IPI on imports, included } \\
\text { above) }\end{array}$ & 1 & 1 & 1 & 1 & 0 & 0 & 0 & 1 & 0 & 0 & 0 & 0 & 0 & 1 & 0 & 1 & 22 & 3 & 1 & 5 & 0 & 0 & 3 & 0 & 1 & 3 \\
\hline $\begin{array}{l}\text { Other Net Indirect Taxes (NIT) + } \\
\text { Imports }\end{array}$ & 201 & 82 & 49 & 704 & 40 & 21 & 94 & 100 & 17 & 15 & 51 & 18 & 1 & 74 & 9 & 57 & 58 & 74 & 78 & 59 & 25 & 7 & 12 & 24 & 20 & 31 \\
\hline $\begin{array}{l}\text { Zeros (other NIT on Imports, } \\
\text { included above) }\end{array}$ & 25 & 4 & 6 & 19 & 3 & 2 & 13 & 17 & 3 & 1 & 7 & 2 & 0 & 8 & 1 & 3 & 3 & 3 & 4 & 2 & 0 & 0 & 0 & 1 & 1 & 1 \\
\hline Intermediate Consumption & 6,356 & 3,027 & 1,375 & 22,018 & 1,196 & 672 & 2,438 & 3,971 & 630 & 754 & 2,075 & 633 & 69 & 2,758 & 413 & 2,458 & 3,907 & 3,654 & 2,980 & 4,754 & 1,675 & 423 & 1,247 & 1,259 & 1,581 & 2,831 \\
\hline Remuneration & 1,172 & 1,581 & 318 & 2,947 & 317 & 117 & 259 & 533 & 128 & 169 & 344 & 121 & 8 & 278 & 89 & 809 & 1,374 & 4,089 & 919 & 4,050 & 1,140 & 197 & 456 & 2,853 & 1,751 & 4,471 \\
\hline Wages & 998 & 1,341 & 249 & 2,234 & 263 & 91 & 204 & 395 & 99 & 135 & 265 & 93 & 6 & 202 & 74 & 652 & 1,093 & 3,163 & 742 & 3,458 & 891 & 163 & 390 & 2,407 & 1,458 & 3,213 \\
\hline Effective Social Contributions & 174 & 239 & 69 & 713 & 54 & 26 & 55 & 138 & 30 & 35 & 79 & 28 & 2 & 76 & 15 & 157 & 282 & 926 & 177 & 592 & 249 & 34 & 66 & 351 & 214 & 550 \\
\hline Official Pension plan / FGTS & 174 & 239 & 66 & 690 & 53 & 25 & 52 & 127 & 29 & 33 & 76 & 28 & 2 & 72 & 15 & 143 & 276 & 916 & 176 & 581 & 228 & 34 & 66 & 346 & 210 & 548 \\
\hline Private Pension & 0 & 0 & 3 & 23 & 1 & 1 & 3 & 11 & 1 & 1 & 3 & 1 & 0 & 3 & 0 & 14 & 6 & 10 & 0 & 12 & 21 & 0 & 0 & 6 & 4 & 2 \\
\hline Imputed Social Contributions & 0 & 0 & 0 & 0 & 0 & 0 & 0 & 0 & 0 & 0 & 0 & 0 & 0 & 0 & 0 & 0 & 0 & 0 & 0 & 0 & 0 & 0 & 0 & 95 & 79 & 708 \\
\hline $\begin{array}{l}\text { Gross operational surplus and } \\
\text { gross mixed revenue }\end{array}$ & 3,142 & 2,078 & 356 & 1,252 & 315 & 167 & 406 & 622 & 87 & 158 & 534 & 112 & 6 & 47 & 153 & 2,583 & 2,632 & 5,906 & 1,835 & 2,800 & 1,561 & 5,296 & 985 & 139 & 430 & 710 \\
\hline Gross mixed revenue & 1,995 & 1,812 & 17 & 138 & 195 & 15 & 0 & 3 & 3 & 9 & 41 & 4 & 0 & 0 & 39 & 0 & 890 & 1,775 & 652 & 914 & 17 & 69 & 401 & 33 & 208 & 0 \\
\hline Gross operational surplus (GOS) & 1,147 & 266 & 339 & 1,114 & 121 & 152 & 406 & 620 & 84 & 149 & 493 & 109 & 5 & 47 & 114 & 2,583 & 1,742 & 4,132 & 1,182 & 1,885 & 1,545 & 5,227 & 584 & 106 & 222 & 710 \\
\hline Value-added cost factors & 4,314 & 3,659 & 674 & 4,198 & 633 & 284 & 665 & 1,155 & 216 & 327 & 878 & 233 & 14 & 325 & 242 & 3,392 & 4,007 & 9,996 & 2,753 & 6,850 & 2,701 & 5,492 & 1,441 & 2,993 & 2,181 & 5,181 \\
\hline Other taxes on production & 63 & 40 & 20 & 230 & 19 & 10 & 21 & 46 & 9 & 12 & 28 & 9 & 1 & 27 & 5 & 51 & 43 & 204 & 52 & 145 & 34 & 7 & 12 & 8 & 10 & 1 \\
\hline Other production subsidies & -1 & 0 & 0 & -5 & -0 & 0 & 0 & 0 & 0 & 0 & -2 & -1 & -0 & -5 & 0 & -10 & -8 & 0 & -7 & -6 & 0 & 0 & 0 & 0 & 0 & 0 \\
\hline Gross value-added (GDP) & 4,376 & 3,699 & 694 & 4,423 & 651 & 294 & 686 & 1,201 & 225 & 339 & 903 & 242 & 15 & 347 & 247 & 3,433 & 4,041 & 10,200 & 2,799 & 6,988 & 2,735 & 5,499 & 1,453 & 3,000 & 2,191 & 5,182 \\
\hline Value of production & 10,732 & 6,726 & 2,069 & 26,441 & 1,847 & 966 & 3,124 & 5,173 & 855 & 1,093 & 2,978 & 875 & 83 & 3,105 & 661 & 5,891 & 7,948 & 13,854 & 5,779 & 11,743 & 4,409 & 5,922 & 2,700 & 4,260 & 3,771 & 8,012 \\
\hline Employed people & 556,087 & 283,616 & 15,046 & 127,220 & 86,855 & 9,972 & 16,763 & 18,150 & 6,686 & 17,787 & 18,402 & 8,017 & 518 & 4,955 & 22,631 & 15,137 & 196,301 & 456,074 & 111,623 & 561,432 & 16,321 & 20,131 & 93,847 & 135,845 & 67,184 & 96,126 \\
\hline
\end{tabular}

Continue 


\begin{tabular}{|c|c|c|c|c|c|c|c|c|c|c|c|c|c|c|c|c|c|c|c|c|c|c|c|c|c|c|}
\hline & & & & & & & & & & & & & & of Brazil & & & & & & & & & & & & \\
\hline & (l) & (2) & (3) & (4) & (5) & (6) & (7) & (8) & (9) & (10) & (11) & $\begin{array}{ll}(12) \\
\end{array}$ & (13) & (14) & (15) & (16) & (17) & (18) & (19) & (20) & (21) & (22) & (23) & (24) & (25) & (26) \\
\hline 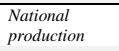 & 55,952 & 41,283 & 67,627 & 246,138 & 55,008 & 53,576 & 122,042 & 120,146 & 33,144 & 26,124 & 114,727 & 62,900 & 64,027 & 145,763 & 21,113 & 65,014 & 94,531 & 111,950 & 105,824 & 197,423 & 88,612 & 14,608 & 47,217 & 40,741 & 58,683 & 123,293 \\
\hline Imports & 9,736 & 2,763 & 7,489 & 9,452 & 6,290 & 5,450 & 30,570 & 28,984 & 7,670 & 3,721 & 20,951 & 9,739 & 16,336 & 24,064 & 2,368 & 6,067 & 8,357 & 7,926 & 11,919 & 13,683 & 3,366 & 706 & 1,736 & 2,193 & 5,953 & 6,437 \\
\hline $\begin{array}{l}\text { Taxes on } \\
\text { Imports }\end{array}$ & 190 & 58 & 220 & 253 & 823 & 236 & 60 & 884 & 527 & 97 & 644 & 568 & 849 & 1,375 & 166 & 118 & 483 & 144 & 227 & 433 & 32 & 14 & 97 & 58 & 163 & 59 \\
\hline $\begin{array}{l}\text { Taxes on } \\
\text { goods and } \\
\text { services } \\
\text { (ICSS)+ } \\
\text { Imports }\end{array}$ & 1,593 & 2,282 & 2,306 & 7,709 & 1,846 & 2,212 & 912 & 4,333 & 694 & 1,511 & 3,595 & 2,391 & 3,194 & 4,977 & 869 & 6,312 & 3,953 & 3,717 & 4,142 & 12,400 & 2,846 & 234 & 4,647 & 2,341 & 3,402 & 6,026 \\
\hline 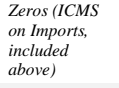 & 235 & 102 & 124 & 142 & 96 & 106 & 94 & 449 & 72 & 100 & 301 & 171 & 370 & 378 & 46 & 296 & 519 & 203 & 476 & 810 & 96 & 24 & 147 & 126 & 347 & 293 \\
\hline $\begin{array}{l}\text { Taxes on } \\
\text { industrial } \\
\text { products } \\
\text { (IPI) } \\
\text { Imports }\end{array}$ & 33 & 172 & 280 & 645 & 121 & 306 & 68 & 438 & 84 & 149 & 406 & 591 & 1,319 & 982 & 168 & 143 & 583 & 34 & 137 & 733 & 147 & 23 & 1,660 & 236 & 218 & 90 \\
\hline $\begin{array}{l}\begin{array}{l}\text { Zeros (IPI on on } \\
\text { imports, } \\
\text { included } \\
\text { abover) }\end{array} \\
\text { ate }\end{array}$ & 5 & 7 & 40 & 16 & 9 & 19 & 8 & 51 & 11 & 12 & 42 & 50 & 188 & 89 & 15 & 42 & 497 & 79 & 20 & 155 & 11 & 5 & 89 & 13 & 23 & 24 \\
\hline $\begin{array}{l}\text { ther ret } \\
\text { Indirect } \\
\text { Taxes (NIT) }\end{array}$ & 1,970 & 1,111 & 3,021 & 9,034 & 2,249 & 2,639 & 7,049 & 4,717 & 1,355 & 1,029 & 5,202 & 2,632 & 2,636 & 5.996 & 830 & 3,041 & 3,431 & 5,295 & 6,992 & 9,712 & 5,443 & 614 & 1,623 & 1,677 & 2,407 & 6,456 \\
\hline $\begin{array}{l}\text { Zeros (other } \\
\text { NIIT on } \\
\text { Imports } \\
\text { included } \\
\text { above) }\end{array}$ & 193 & 45 & 165 & 188 & 130 & 139 & 924 & 620 & 162 & 78 & 548 & 210 & 327 & 521 & 48 & 135 & 161 & 186 & 390 & 338 & 103 & 16 & 33 & 48 & 126 & 172 \\
\hline Remuneration & 26,975 & 20,417 & 16,004 & 34,247 & 21,724 & 19,407 & 7,250 & 23,073 & 10,913 & 9,385 & 26,680 & 20,855 & 17,015 & 30,490 & 7,260 & 18,206 & 44,520 & 138,669 & 59,892 & 178,063 & 69,538 & 7,631 & 18,447 & 118,091 & 76,223 & 216,208 \\
\hline Wages & 22,971 & 17,326 & 11,329 & 25,939 & 17,754 & 15,461 & 5,286 & 17,007 & 8,386 & 7,437 & 20,300 & 15,932 & 12,807 & 22,903 & 6,036 & 14,669 & 35,399 & 107,269 & 48,382 & 149,496 & 54,351 & 6,320 & 15,782 & 99,710 & 63,896 & 155,361 \\
\hline $\begin{array}{l}\text { Sffective } \\
\text { Social } \\
\text { Contributions }\end{array}$ & 4,004 & 3,092 & 4,675 & 8,308 & 3,970 & 3,946 & 1,964 & 6,066 & 2,526 & 1,947 & 6,380 & 4,923 & 4,208 & 7,587 & 1,224 & 3,537 & 9,120 & 31,400 & 11,510 & 28.567 & 15,187 & 1,311 & 2,665 & 14,806 & 9,675 & 26,587 \\
\hline $\begin{array}{l}\text { Official } \\
\text { Pension plan } \\
\text { IFGTS }\end{array}$ & 4,004 & 3,092 & 4,123 & 8,037 & 3,919 & 3,858 & 1,754 & 5,596 & 2,456 & 1,863 & 6,065 & 4,783 & 4,027 & 7,295 & 1,201 & 3,226 & 8,933 & 31,051 & 11,492 & 28,006 & 13,883 & 1,303 & 2,665 & 14,450 & 9,342 & 26,514 \\
\hline 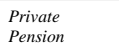 & 0 & 0 & 552 & 271 & 51 & 88 & 210 & 470 & 70 & 85 & 315 & 139 & 181 & 293 & 23 & 311 & 187 & 349 & 19 & 560 & 1,304 & 8 & 0 & 355 & 333 & 73 \\
\hline $\begin{array}{l}\text { Imputed } \\
\text { Social }\end{array}$ & 0 & 0 & 0 & 0 & 0 & 0 & 0 & 0 & 0 & 0 & 0 & 0 & 0 & 0 & 0 & 0 & 0 & 0 & 0 & 0 & 0 & 0 & 0 & 3,575 & 2,652 & 34,260 \\
\hline $\begin{array}{l}\text { Gross } \\
\text { operational } \\
\text { surplus and } \\
\text { gross mixed }\end{array}$ & 71,334 & 24,277 & 65,832 & 18,841 & 16,122 & 21,365 & 4,436 & 22,483 & 5,171 & 6,506 & 38,866 & 11,695 & 11,182 & 8,971 & 10,670 & 58,141 & 76,965 & 167,989 & 64,307 & 148,481 & 101,012 & 196,908 & 25,464 & 5,811 & 21,271 & 34,317 \\
\hline $\begin{array}{l}\text { Gross mixed } \\
\text { revenue }\end{array}$ & 45,292 & 21,167 & 207 & 1,947 & 7,951 & 2,285 & 0 & 85 & 183 & 335 & 1,909 & 331 & 621 & 113 & 2,725 & 0 & 26,034 & 50,477 & 22,860 & 44,395 & 1,080 & 2,562 & 10,355 & 2,153 & 11,008 & 0 \\
\hline $\begin{array}{l}\text { Gross } \\
\text { operational } \\
\text { surplus } \\
\text { (GOS) }\end{array}$ & 26,042 & 3,110 & 65,625 & 16,894 & 8,170 & 19,080 & 4,436 & 22,397 & 4,988 & 6,171 & 36,957 & 11,363 & 10,562 & 8,858 & 7,945 & 58,141 & 50,931 & 117,511 & 41,448 & 104,087 & 99,931 & 194,346 & 15,109 & 3,658 & 10,263 & 34,317 \\
\hline $\begin{array}{l}\text { Value-added } \\
\text { costfactors }\end{array}$ & 98,309 & 44,694 & 81,836 & 53,089 & 37,845 & 40,772 & 11,686 & 45,556 & 16,083 & 15,891 & 65,546 & 32,550 & 28,197 & 39,461 & 17,930 & 76,347 & 121,484 & 306,657 & 124,200 & 326,544 & 170,550 & 204,540 & 43,911 & 123,901 & 97,494 & 250,525 \\
\hline $\begin{array}{l}\begin{array}{l}\text { ther raxes } \\
\text { on production }\end{array}\end{array}$ & 991 & 556 & 968 & 2,855 & 1,057 & 1,089 & 949 & 1,791 & 650 & 545 & 1,918 & 1,200 & 1,122 & 2,106 & 335 & 1,379 & 1,276 & 6,518 & 2,305 & 7,224 & 2,094 & 252 & 454 & 501 & 723 & 45 \\
\hline $\begin{array}{l}\text { Other } \\
\text { production } \\
\text { subsidies }\end{array}$ & -13 & 0 & 0 & -58 & -65 & 0 & 0 & 0 & 0 & 0 & -100 & -152 & -194 & -165 & 0 & -284 & -251 & 0 & -290 & -346 & 0 & 0 & 0 & 0 & 0 & 0 \\
\hline $\begin{array}{l}\text { Employed } \\
\text { people }\end{array}$ & $11,243,518$ & $5,035,728$ & 279,509 & $2,235,927$ & $3,488,040$ & $1,078,086$ & 152,010 & 484,127 & 414,769 & 613,457 & $1,061,023$ & 614,619 & 537,426 & 582,831 & 920,014 & 394,624 & $6,710,378$ & $15,069,321$ & $4,176,534$ & $19,651,977$ & 931,342 & 636,595 & 3,609,867 & $5,189,185$ & $3,203,648$ & $4,955,328$ \\
\hline
\end{tabular}




\begin{tabular}{|c|c|c|c|c|c|c|c|c|c|c|c|c|c|c|c|}
\hline & \multirow[t]{2}{*}{$\begin{array}{c}\text { Total } \\
\text { Intermediate } \\
\text { Consumption }\end{array}$} & $\begin{array}{c}\text { Goods } \\
\text { and } \\
\text { services } \\
\text { exports }\end{array}$ & $\begin{array}{l}\text { Consumption } \\
\text { of public } \\
\text { administration }\end{array}$ & $\begin{array}{l}\text { Consumption } \\
\text { of financial } \\
\text { institutuions }\end{array}$ & $\begin{array}{l}\text { Households } \\
\text { consumption }\end{array}$ & $\begin{array}{l}\text { Gross } \\
\text { fixed capital } \\
\text { formation }\end{array}$ & $\begin{array}{l}\text { Stock } \\
\text { change }\end{array}$ & $\begin{array}{l}\text { Goods and } \\
\text { Services } \\
\text { exports }\end{array}$ & $\begin{array}{c}\text { Consumption } \\
\text { of public } \\
\text { administration }\end{array}$ & $\begin{array}{l}\text { Consumption } \\
\text { of financial } \\
\text { institutions }\end{array}$ & $\begin{array}{l}\text { Households } \\
\text { consumption }\end{array}$ & $\begin{array}{c}\text { Gross } \\
\text { fixed capital } \\
\text { formation }\end{array}$ & $\begin{array}{l}\text { Stock } \\
\text { change }\end{array}$ & \multirow[t]{2}{*}{$\begin{array}{c}\text { Final } \\
\text { Demand }\end{array}$} & \multirow[t]{2}{*}{ Total Output } \\
\hline & & \multicolumn{6}{|c|}{ Goiás State } & \multicolumn{6}{|c|}{ Rest of Brazil } & & \\
\hline National production & $2,243,419$ & 8,043 & 14,148 & 787 & 44,706 & 12,289 & 2,025 & 406,252 & 597,957 & 34,200 & $1,444,538$ & 454,086 & 45,941 & $3,064,972$ & $5,308,391$ \\
\hline Imports & 258,522 & 0 & 0 & 0 & 2,544 & 1,434 & 0 & 0 & 0 & 0 & 84,275 & 61,759 & 0 & 150,012 & 408,534 \\
\hline Taxes on Imports & 9,001 & 0 & 0 & 0 & 112 & 81 & 0 & 0 & 0 & 0 & 3,676 & 4,203 & 0 & 8,073 & 17,074 \\
\hline $\begin{array}{l}\text { Taxes on goods and services } \\
\text { (ICMS) + Imports }\end{array}$ & 92,986 & 0 & 0 & 0 & 2,788 & 477 & 0 & 0 & 0 & 0 & 91,034 & 17,588 & 0 & 111,887 & 204,873 \\
\hline $\begin{array}{l}\text { Zeros (ICMS on Imports, } \\
\text { included above) }\end{array}$ & 6,296 & 0 & 0 & 0 & 145 & 51 & 0 & 0 & 0 & 0 & 4,758 & 2,668 & 0 & 7,623 & 13,918 \\
\hline $\begin{array}{l}\text { Taxes on industrial products } \\
(I P I)+\text { Imports }\end{array}$ & 9,938 & 0 & 0 & 0 & 333 & 160 & 0 & 0 & 0 & 0 & 10,689 & 5,381 & 0 & 16,564 & 26,502 \\
\hline $\begin{array}{l}\text { Zeros (IPI on imports, } \\
\text { included above) }\end{array}$ & 1,566 & 0 & 0 & 0 & 162 & 74 & 0 & 0 & 0 & 0 & 5,311 & 3,290 & 0 & 8,837 & 10,402 \\
\hline $\begin{array}{l}\text { Other Net Indirect Taxes } \\
(\text { NIT })+\text { Imports }\end{array}$ & 100,081 & 0 & 0 & 0 & 1,700 & 382 & 0 & 0 & 0 & 0 & 53,329 & 14,416 & 0 & 69,827 & 169,908 \\
\hline $\begin{array}{l}\text { Zeros (other NIT on Imports, } \\
\text { included above) }\end{array}$ & 6,134 & 0 & 0 & 0 & 52 & 22 & 0 & 0 & 0 & 0 & 1,700 & 1,168 & 0 & 2,943 & 9,077 \\
\hline Intermediate Consumption & $2,727,942$ & 8,043 & 14,148 & 787 & 52,544 & 14,971 & 2,025 & 406,252 & 597,957 & 34,200 & $1,699,309$ & 564,560 & 45,941 & $3,440,737$ & $6,168,679$ \\
\hline Remuneration & $1,267,673$ & 0 & 0 & 0 & 0 & 0 & 0 & 0 & 0 & 0 & 0 & 0 & 0 & 0 & $1,267,673$ \\
\hline Wages & $1,001,788$ & 0 & 0 & 0 & 0 & 0 & 0 & 0 & 0 & 0 & 0 & 0 & 0 & 0 & $1,001,788$ \\
\hline Effective Social Contributions & 224,516 & 0 & 0 & 0 & 0 & 0 & 0 & 0 & 0 & 0 & 0 & 0 & 0 & 0 & 224,516 \\
\hline Official Pension plan / FGTS & 218,143 & 0 & 0 & 0 & 0 & 0 & 0 & 0 & 0 & 0 & 0 & 0 & 0 & 0 & 218,143 \\
\hline Private Pension & 6,373 & 0 & 0 & 0 & 0 & 0 & 0 & 0 & 0 & 0 & 0 & 0 & 0 & 0 & 6,373 \\
\hline Imputed Social Contributions & 41,369 & 0 & 0 & 0 & 0 & 0 & 0 & 0 & 0 & 0 & 0 & 0 & 0 & 0 & 41,369 \\
\hline $\begin{array}{l}\text { Gross operational surplus and } \\
\text { gross mixed revenue }\end{array}$ & $1,272,729$ & 0 & 0 & 0 & 0 & 0 & 0 & 0 & 0 & 0 & 0 & 0 & 0 & 0 & $1,272,729$ \\
\hline Gross mixed revenue & 265,305 & 0 & 0 & 0 & 0 & 0 & 0 & 0 & 0 & 0 & 0 & 0 & 0 & 0 & 265,305 \\
\hline $\begin{array}{l}\text { Gross operational surplus } \\
\text { (GOS) }\end{array}$ & $1,007,424$ & 0 & 0 & 0 & 0 & 0 & 0 & 0 & 0 & 0 & 0 & 0 & 0 & 0 & $1,007,424$ \\
\hline Value-added cost factors & $2,540,402$ & 0 & 0 & 0 & 0 & 0 & 0 & 0 & 0 & 0 & 0 & 0 & 0 & 0 & $2,540,402$ \\
\hline Other taxes on production & 42,010 & 0 & 0 & 0 & 0 & 0 & 0 & 0 & 0 & 0 & 0 & 0 & 0 & 0 & 42,010 \\
\hline Other production subsidies & $-1,963$ & 0 & 0 & 0 & 0 & 0 & 0 & 0 & 0 & 0 & 0 & 0 & 0 & 0 & $-1,963$ \\
\hline Gross value-added (GDP) & $2,580,449$ & 0 & 0 & 0 & 0 & 0 & 0 & 0 & 0 & 0 & 0 & 0 & 0 & 0 & $2,580,449$ \\
\hline Value of production & $5,308,391$ & 0 & 0 & 0 & 0 & 0 & 0 & 0 & 0 & 0 & 0 & 0 & 0 & 0 & $5,308,391$ \\
\hline Employed people & $96,232,609$ & 0 & 0 & 0 & 0 & 0 & 0 & 0 & 0 & 0 & 0 & 0 & 0 & 0 & $96,232,609$ \\
\hline
\end{tabular}

[Back to page 53] 


\section{Appendix II: Aggregated Input-Output table for the state of Goiás and the rest of Brazil}

Input-Output table for the state of Goiás and the rest of Brazil ( $X=Z+Y$ matrix). Aggregated from Goiás' inter-regional IO table (GUILHOTO, 2010), based both on the National and Regional Accounts and by applying the methodology described in (GUILHOTO and SESSO FILHO, 2005, 2010; GUILHOTO et al., 2010).

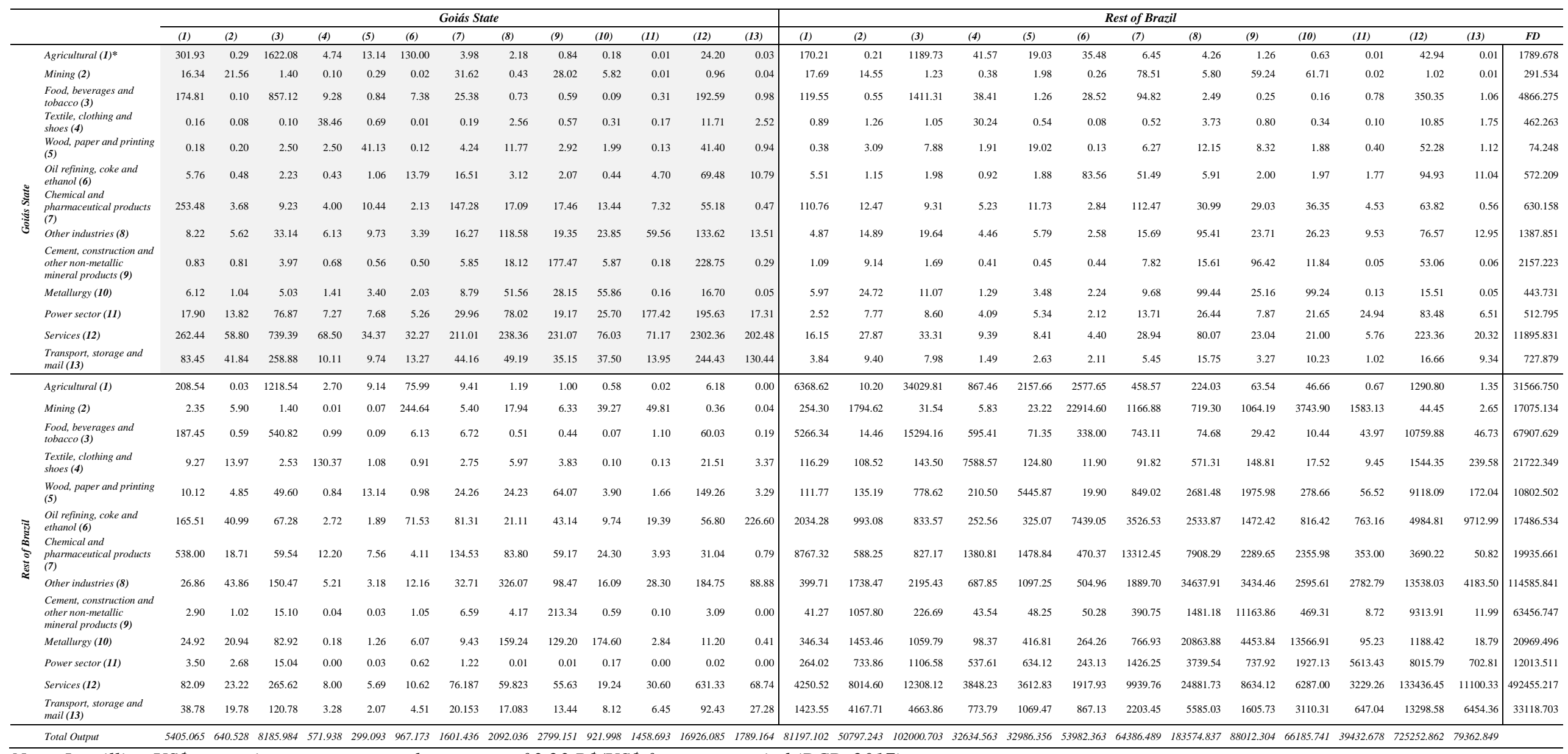

Note: In million US\$; assuming an average exchange rate of $3.23 \mathrm{R} \$ /$ US $\$$ for a year period (BCB, 2017).

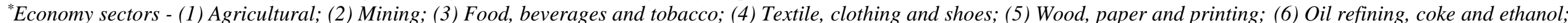

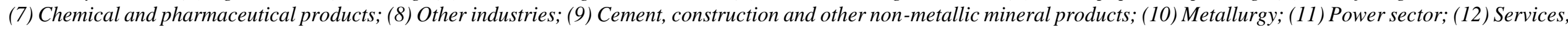
(13) Transport, storage and mail.

FD: Final Demand. 


\section{Appendix III: Goiás and rest of Brazil technical coefficients}

A matrix, where: $A=Z x^{-1} ; A=\left[a_{i j}\right]$.

\begin{tabular}{|c|c|c|c|c|c|c|c|c|c|c|c|c|c|c|c|c|c|c|c|c|c|c|c|c|c|c|c|}
\hline & & \multicolumn{13}{|c|}{ Goiás State } & \multicolumn{13}{|c|}{ Rest of Brazil } \\
\hline & & (I) & (2) & (3) & (4) & (5) & (6) & (7) & (8) & (9) & (10) & (11) & (12) & (13) & (I) & (2) & (3) & (4) & (5) & & (7) & (8) & (9) & (10) & (11) & (12) & (13) \\
\hline \multirow{13}{*}{ 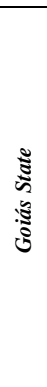 } & Agricultural (1)* & 0.0559 & 0.0005 & 0.1982 & 0.0083 & 0.0439 & 0.1344 & 0.0025 & 0.0010 & 0.0003 & 0.0002 & 0.0000 & 0.0014 & 0.0000 & 0.0021 & 0.0000 & 0.0117 & 0.0013 & 0.0006 & 0.0007 & 0.0001 & 0.0000 & 0.0000 & 0.0000 & 0.0000 & 0.0001 & 0.0000 \\
\hline & Mining (2) & 0.0030 & 0.0337 & 0.0002 & 0.0002 & 0.0010 & 0.0000 & 0.0197 & 0.0002 & 0.0100 & 0.0063 & 0.0000 & 0.0001 & 0.0000 & 0.0002 & 0.0003 & 0.0000 & 0.0000 & 0.0001 & 0.0000 & 0.0012 & 0.0000 & 0.0007 & 0.0009 & 0.0000 & 0.0000 & 0.0000 \\
\hline & Food, beverages and tobacco (3) & 0.0323 & 0.0002 & 0.1047 & 0.0162 & 0.0028 & 0.0076 & 0.0159 & 0.0003 & 0.0002 & 0.0001 & 0.0002 & 0.0114 & 0.0005 & 0.0015 & 0.0000 & 0.0138 & 0.0012 & 0.0000 & 0.0005 & 0.0015 & 0.0000 & 0.0000 & 0.0000 & 0.0000 & 0.0005 & 0.0000 \\
\hline & Textile, clothing and shoes (4) & 0.0000 & 0.0001 & 0.0000 & 0.0672 & 0.0023 & 0.0000 & 0.0001 & 0.0012 & 0.0002 & 0.0003 & 0.0001 & 0.0007 & 0.0014 & 0.0000 & 0.0000 & 0.0000 & 0.0009 & 0.0000 & 0.0000 & 0.0000 & 0.0000 & 0.0000 & 0.0000 & 0.0000 & 0.0000 & 0.0000 \\
\hline & Wood, paper and printing (5) & 0.0000 & 0.0003 & 0.0003 & 0.0044 & 0.1375 & 0.0001 & 0.0026 & 0.0056 & 0.0010 & 0.0022 & 0.0001 & 0.0024 & 0.0005 & 0.0000 & 0.0001 & 0.0001 & 0.0001 & 0.0006 & 0.0000 & 0.0001 & 0.0001 & 0.0001 & 0.0000 & 0.0000 & 0.0001 & 0.0000 \\
\hline & Oil refining, coke and ethanol (6) & 0.0011 & 0.0008 & 0.0003 & 0.0008 & 0.0035 & 0.0143 & 0.0103 & 0.0013 & 0.0007 & 0.0005 & 0.0034 & 0.0041 & 0.0060 & 0.0001 & 0.0000 & 0.0000 & 0.0000 & 0.0001 & 0.0015 & 0.0008 & 0.0000 & 0.0000 & 0.0000 & 0.0000 & 0.0001 & 0.0001 \\
\hline & Chemical and pharmaceutical products (7) & 0.0469 & 0.0057 & 0.0011 & 0.0070 & 0.0349 & 0.0022 & 0.0920 & 0.0079 & 0.0062 & 0.0146 & 0.0054 & 0.0033 & 0.0003 & 0.0014 & 0.0002 & 0.0001 & 0.0002 & 0.0004 & 0.0001 & 0.0017 & 0.0002 & 0.0003 & 0.0005 & 0.0001 & 0.0001 & 0.0000 \\
\hline & Other industries $(8)$ & 0.0013 & 0.0073 & 0.0034 & 0.0099 & 0.0308 & 0.0031 & 0.0089 & 0.0527 & 0.0065 & 0.0240 & 0.0349 & 0.0071 & 0.0069 & 0.0001 & 0.0003 & 0.0002 & 0.0001 & 0.0002 & 0.0000 & 0.0002 & 0.0005 & 0.0003 & 0.0004 & 0.0002 & 0.0001 & 0.0002 \\
\hline & Cement, construction and other non-metallic mineral products (9) & 0.0002 & 0.0013 & 0.0005 & 0.0012 & 0.0019 & 0.0005 & 0.0037 & 0.0087 & 0.0634 & 0.0064 & 0.0001 & 0.0135 & 0.0002 & 0.0000 & 0.0002 & 0.0000 & 0.0000 & 0.0000 & 0.0000 & 0.0001 & 0.0001 & 0.0011 & 0.0002 & 0.0000 & 0.0001 & 0.0000 \\
\hline & Metallurgy (10) & 0.0011 & 0.0016 & 0.0006 & 0.0025 & 0.0114 & 0.0021 & 0.0055 & 0.0246 & 0.0101 & 0.0606 & 0.0001 & 0.0010 & 0.0000 & 0.0001 & 0.0005 & 0.0001 & 0.0000 & 0.0001 & 0.0000 & 0.0002 & 0.0005 & 0.0003 & 0.0015 & 0.0000 & 0.0000 & 0.0000 \\
\hline & Power sector (11) & 0.0035 & 0.0230 & 0.0100 & 0.0136 & 0.0274 & 0.0058 & 0.0200 & 0.0338 & 0.0073 & 0.0297 & 0.1384 & 0.0123 & 0.0103 & 0.0000 & 0.0002 & 0.0001 & 0.0001 & 0.0002 & 0.0000 & 0.0002 & 0.0001 & 0.0001 & 0.0003 & 0.0007 & 0.0001 & 0.0001 \\
\hline & Services (12) & 0.0486 & 0.0918 & 0.0903 & 0.1198 & 0.1149 & 0.0334 & 0.1318 & 0.1117 & 0.0825 & 0.0825 & 0.0520 & 0.1360 & 0.1132 & 0.0002 & 0.0005 & 0.0003 & 0.0003 & 0.0003 & 0.0001 & 0.0004 & 0.0004 & 0.0003 & 0.0003 & 0.0002 & 0.0003 & 0.0003 \\
\hline & Transport, storage and mail (13) & 0.0154 & 0.0653 & 0.0316 & 0.0177 & 0.0326 & 0.0137 & 0.0276 & 0.0231 & 0.0126 & 0.0407 & 0.0102 & 0.0144 & 0.0729 & 0.0000 & 0.0002 & 0.0001 & 0.0000 & 0.0001 & 0.0000 & 0.0001 & 0.0001 & 0.0000 & 0.0002 & 0.0000 & 0.0000 & 0.0001 \\
\hline \multirow{13}{*}{ 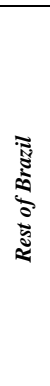 } & Agricultural (I) & 0.0386 & 0.0001 & 0.1489 & 0.0047 & 0.0306 & 0.0786 & 0.0059 & 0.0006 & 0.0004 & 0.0006 & 0.0000 & 0.0004 & 0.0000 & 0.0784 & 0.0002 & 0.3336 & 0.0266 & 0.0654 & 0.0477 & 0.0071 & 0.0012 & 0.0007 & 0.0007 & 0.0000 & 0.0018 & 0.0000 \\
\hline & Mining (2) & 0.0004 & 0.0092 & 0.0002 & 0.0000 & 0.0002 & 0.2529 & 0.0034 & 0.0070 & 0.0023 & 0.0426 & 0.0364 & 0.0000 & 0.0000 & 0.0031 & 0.0353 & 0.0003 & 0.0002 & 0.0007 & 0.4245 & 0.0181 & 0.0033 & 0.0121 & 0.0566 & 0.0428 & 0.0001 & 0.0000 \\
\hline & Food, beverages and tobacco (3) & 0.0347 & 0.0009 & 0.0661 & 0.0017 & 0.0003 & 0.0063 & 0.0042 & 0.0002 & 0.0002 & 0.0001 & 0.0008 & 0.0035 & 0.0001 & 0.0649 & 0.0003 & 0.1499 & 0.0182 & 0.0022 & 0.0063 & 0.0115 & 0.0004 & 0.0003 & 0.0002 & 0.0012 & 0.0148 & 0.0006 \\
\hline & Textile, clothing and shoes (4) & 0.0017 & 0.0218 & 0.0003 & 0.2279 & 0.0036 & 0.0009 & 0.0017 & 0.0028 & 0.0014 & 0.0001 & 0.0001 & 0.0013 & 0.0019 & 0.0014 & 0.0021 & 0.0014 & 0.2325 & 0.0038 & 0.0002 & 0.0014 & 0.0031 & 0.0017 & 0.0003 & 0.0003 & 0.0021 & 0.0030 \\
\hline & Wood, paper and printing (5) & 0.0019 & 0.0076 & 0.0061 & 0.0015 & 0.0439 & 0.0010 & 0.0151 & 0.0115 & 0.0229 & 0.0042 & 0.0012 & 0.0088 & 0.0018 & 0.0014 & 0.0027 & 0.0076 & 0.0065 & 0.1651 & 0.0004 & 0.0132 & 0.0146 & 0.0225 & 0.0042 & 0.0015 & 0.0126 & 0.0022 \\
\hline & Oil refining, coke and ethanol (6) & 0.0306 & 0.0640 & 0.0082 & 0.0048 & 0.0063 & 0.0740 & 0.0508 & 0.0095 & 0.0154 & 0.0106 & 0.0142 & 0.0034 & 0.1267 & 0.0251 & 0.0195 & 0.0082 & 0.0077 & 0.0099 & 0.1378 & 0.0548 & 0.0135 & 0.0167 & 0.0123 & 0.0206 & 0.0069 & 0.1224 \\
\hline & Chemical and pharmaceutical products (7) & 0.0995 & 0.0292 & 0.0073 & 0.0213 & 0.0253 & 0.0043 & 0.0840 & 0.0399 & 0.0211 & 0.0264 & 0.0029 & 0.0018 & 0.0004 & 0.1080 & 0.0116 & 0.0081 & 0.0423 & 0.0448 & 0.0087 & 0.2068 & 0.0430 & 0.0260 & 0.0356 & 0.0095 & 0.0051 & 0.0006 \\
\hline & Other industries (8) & 0.0049 & 0.0682 & 0.0183 & 0.0091 & 0.0106 & 0.0125 & 0.0204 & 0.1550 & 0.0352 & 0.0174 & 0.0207 & 0.0109 & 0.0497 & 0.0047 & 0.0333 & 0.0208 & 0.0200 & 0.0320 & 0.0091 & 0.0279 & 0.1865 & 0.0385 & 0.0373 & 0.0652 & 0.0179 & 0.0521 \\
\hline & Cement, construction and other non-metallic mineral products $(9)$ & 0.0005 & 0.0016 & 0.0018 & 0.0001 & 0.0001 & 0.0011 & 0.0041 & 0.0020 & 0.0762 & 0.0006 & 0.0001 & 0.0002 & 0.0000 & 0.0005 & 0.0208 & 0.0022 & 0.0013 & 0.0015 & 0.0009 & 0.0061 & 0.0081 & 0.1268 & 0.0071 & 0.0002 & 0.0128 & 0.0002 \\
\hline & Metallurgy (10) & 0.0046 & 0.0327 & 0.0101 & 0.0003 & 0.0042 & 0.0063 & 0.0059 & 0.0760 & 0.0462 & 0.1894 & 0.0021 & 0.0007 & 0.0002 & 0.0043 & 0.0286 & 0.0104 & 0.0030 & 0.0126 & 0.0049 & 0.0119 & 0.1136 & 0.0506 & 0.2050 & 0.0026 & 0.0016 & 0.0002 \\
\hline & Power sector (II) & 0.0007 & 0.0045 & 0.0020 & 0.0000 & 0.0001 & 0.0007 & 0.0008 & 0.0000 & 0.0000 & 0.0002 & 0.0000 & 0.0000 & 0.0000 & 0.0035 & 0.0154 & 0.0116 & 0.0176 & 0.0205 & 0.0048 & 0.0236 & 0.0196 & 0.0089 & 0.0311 & 0.1620 & 0.0118 & 0.0094 \\
\hline & Services (12) & 0.0152 & 0.0362 & 0.0324 & 0.0140 & 0.0190 & 0.0110 & 0.0476 & 0.0276 & 0.0199 & 0.0209 & 0.0224 & 0.0373 & 0.0384 & 0.0523 & 0.1578 & 0.1207 & 0.1179 & 0.1095 & 0.0355 & 0.1544 & 0.1344 & 0.0981 & 0.0950 & 0.0874 & 0.1840 & 0.1399 \\
\hline & Transport, storage and mail (13) & 0.0072 & 0.0309 & 0.0148 & 0.0057 & 0.0069 & 0.0047 & 0.0126 & 0.0080 & 0.0048 & 0.0088 & 0.0047 & 0.0055 & 0.0152 & 0.0175 & 0.0820 & 0.0457 & 0.0237 & 0.0324 & 0.0161 & 0.0342 & 0.0302 & 0.0182 & 0.0470 & 0.0175 & 0.0183 & 0.0813 \\
\hline
\end{tabular}




\section{Appendix IV: Goiás and rest of Brazil $(I-A)$ matrix}

\begin{tabular}{|c|c|c|c|c|c|c|c|c|c|c|c|c|c|c|c|c|c|c|c|c|c|c|c|c|c|c|c|}
\hline & & \multicolumn{13}{|c|}{ Goiás State } & \multicolumn{13}{|c|}{ Rest of Brazil } \\
\hline & & (I) & (2) & (3) & (4) & (5) & (6) & (7) & (8) & (9) & (10) & (11) & (12) & (13) & (I) & (2) & (3) & (4) & (5) & (6) & (7) & (8) & (9) & (10) & (II) & (12) & (13) \\
\hline & Agricultural (I)* & 0.9441 & $\begin{array}{l}(0.0005) \\
\end{array}$ & $\begin{array}{ll}(0.1982) \\
\end{array}$ & $\begin{array}{lll}(0.0083) \\
\end{array}$ & $\begin{array}{l}(0.0439) \\
\end{array}$ & $\begin{array}{l}(0.1344) \\
\end{array}$ & $(0.0025)$ & $(0.0010)$ & $(0.0003)$ & $(0.0002)$ & $(0.0000)$ & $(0.0014)$ & $(0.0000)$ & $(0.0021)$ & $(0.0000)$ & $(0.0117)$ & $(0.0013)$ & $(0.0006)$ & $(0.0007)$ & $(0.0001)$ & $(0.0000)$ & $(0.0000)$ & $(0.0000)$ & $(0.0000)$ & $\begin{array}{l}(0.0001) \\
\end{array}$ & $(0.0000)$ \\
\hline & Mining (2) & $(0.0030)$ & 0.9663 & $(0.0002)$ & $(0.0002)$ & $(0.0010)$ & $(0.0000)$ & $(0.0197)$ & $(0.0002)$ & $(0.0100)$ & $(0.0063)$ & $(0.0000)$ & $(0.0001)$ & $(0.0000)$ & $(0.0002)$ & $(0.0003)$ & $(0.0000)$ & $(0.0000)$ & $(0.0001)$ & $(0.0000)$ & $(0.0012)$ & $(0.0000)$ & $(0.0007)$ & $(0.0009)$ & $(0.0000)$ & $(0.0000)$ & $(0.0000)$ \\
\hline & d tobacco (3) & $(0.0323)$ & $(0.0002)$ & 0.8953 & $(0.0162)$ & $(0.0028)$ & $(0.0076)$ & $(0.0159)$ & $(0.0003)$ & $(0.0002)$ & $(0.0001)$ & $(0.0002)$ & $(0.0114)$ & $(0.0005)$ & $(0.0015)$ & $(0.0000)$ & $(0.0138)$ & $(0.0012)$ & $(0.0000)$ & $(0.0005)$ & $(0.0015)$ & $(0.0000)$ & $(0.0000)$ & $(0.0000)$ & $(0.0000)$ & $(0.0005)$ & $(0.0000)$ \\
\hline & Textile, clothing and shoes (4) & $(0.0000)$ & $(0.0001)$ & $(0.0000)$ & 0.9328 & $(0.0023)$ & $(0.0000)$ & $(0.0001)$ & $(0.0012)$ & $(0.0002)$ & $(0.0003)$ & $(0.0001)$ & $(0.0007)$ & $(0.0014)$ & $(0.0000)$ & $(0.0000)$ & $(0.0000)$ & $(0.0009)$ & $(0.0000)$ & $(0.0000)$ & $(0.0000)$ & $(0.0000)$ & $(0.0000)$ & $(0.0000)$ & $(0.0000)$ & $(0.0000)$ & $(0.0000)$ \\
\hline & Wood, paper and printing (5) & $(0.0000)$ & $(0.0003)$ & $(0.0003)$ & $(0.0044)$ & 0.8625 & $(0.0001)$ & $(0.0026)$ & $(0.0056)$ & $(0.0010)$ & $(0.0022)$ & $(0.0001)$ & $(0.0024)$ & $(0.0005)$ & $(0.0000)$ & $(0.0001)$ & $(0.0001)$ & $(0.0001)$ & $(0.0006)$ & $(0.0000)$ & $(0.0001)$ & $(0.0001)$ & $(0.0001)$ & $(0.0000)$ & $(0.0000)$ & $(0.0001)$ & $(0.0000)$ \\
\hline & Oil refining, coke and ethanol (6) & $(0.0011)$ & $(0.0008)$ & $(0.0003)$ & $(0.0008)$ & $(0.0035)$ & 0.9857 & $(0.0103)$ & $(0.0013)$ & $(0.0007)$ & $(0.0005)$ & $(0.0034)$ & $(0.0041)$ & $(0.0060)$ & $(0.0001)$ & $(0.0000)$ & $(0.0000)$ & $(0.0000)$ & $(0.0001)$ & $(0.0015)$ & $(0.0008)$ & $(0.0000)$ & $(0.0000)$ & $(0.0000)$ & $(0.0000)$ & $(0.0001)$ & $(0.0001)$ \\
\hline & $\begin{array}{l}\text { Chemical and pharmaceutical } \\
\text { products } 7)\end{array}$ & $(0.0469)$ & $(0.0057)$ & $(0.0011)$ & $(0.0070)$ & $(0.0349)$ & $(0.0022)$ & 0.9080 & $(0.0079)$ & $(0.0062)$ & $(0.0146)$ & $(0.0054)$ & $(0.0033)$ & $(0.0003)$ & $(0.0014)$ & $(0.0002)$ & $(0.0001)$ & $(0.0002)$ & $(0.0004)$ & $(0.0001)$ & $(0.0017)$ & $(0.0002)$ & $(0.0003)$ & $(0.0005)$ & $(0.0001)$ & $(0.0001)$ & $(0.0000)$ \\
\hline & $\begin{array}{l}\text { Other industries }(8) \\
\text { Cement, construction and other non- } \\
\text { metallic mineral products (9) }\end{array}$ & $\begin{array}{l}(0.0013) \\
(0.0002)\end{array}$ & $\begin{array}{l}(0.0073) \\
(0.0013)\end{array}$ & $\begin{array}{l}(0.0034) \\
(0.0005)\end{array}$ & $\begin{array}{l}(0.0099) \\
(0.0012)\end{array}$ & $\begin{array}{l}(0.0308) \\
(0.0019)\end{array}$ & $\begin{array}{l}(0.0031) \\
(0.0005)\end{array}$ & $\begin{array}{l}(0.0089) \\
(0.0037)\end{array}$ & $\begin{array}{r}0.9473 \\
(0.0087)\end{array}$ & $\begin{array}{r}(0.0065) \\
0.9366\end{array}$ & $\begin{array}{l}(0.0240) \\
(0.0064)\end{array}$ & $\begin{array}{l}(0.0349) \\
(0.0001)\end{array}$ & $\begin{array}{l}(0.0071) \\
(0.0135)\end{array}$ & $\begin{array}{l}(0.0069) \\
(0.0002)\end{array}$ & $\begin{array}{l}(0.0001) \\
(0.0000)\end{array}$ & $\begin{array}{l}(0.0003) \\
(0.0002)\end{array}$ & $\begin{array}{l}(0.0002) \\
(0.0000)\end{array}$ & $\begin{array}{l}(0.0001) \\
(0.0000)\end{array}$ & $\begin{array}{l}(0.0002) \\
(0.0000)\end{array}$ & $\begin{array}{l}(0.0000) \\
(0.0000)\end{array}$ & $\begin{array}{l}(0.0002) \\
(0.0001)\end{array}$ & $\begin{array}{l}(0.0005) \\
(0.0001)\end{array}$ & $\begin{array}{l}(0.0003) \\
(0.0011)\end{array}$ & $\begin{array}{l}(0.0004) \\
(0.0002)\end{array}$ & $\begin{array}{l}(0.0002) \\
(0.0000)\end{array}$ & $\begin{array}{l}(0.0001) \\
(0.0001)\end{array}$ & $\begin{array}{l}(0.0002) \\
(0.0000)\end{array}$ \\
\hline & Metallurgy (10) & $(0.0011)$ & $(0.0016)$ & $(0.0006)$ & $(0.0025)$ & $(0.0114)$ & $(0.0021)$ & $(0.0055)$ & $(0.0246)$ & $(0.0101)$ & 0.9394 & $(0.0001)$ & $(0.0010)$ & $(0.0000)$ & $\mid(0.0001)$ & $(0.0005)$ & $(0.0001)$ & $(0.0000)$ & $(0.0001)$ & $(0.0000)$ & $(0.0002)$ & $(0.0005)$ & $(0.0003)$ & $(0.0015)$ & $(0.0000)$ & $(0.0000)$ & $(0.0000)$ \\
\hline & Power sector (11) & $(0.0035)$ & $(0.0230)$ & $(0.0100)$ & $(0.0136)$ & $(0.0274)$ & $(0.0058)$ & $(0.0200)$ & $(0.0338)$ & $(0.0073)$ & $(0.0297)$ & 0.8616 & $(0.0123)$ & $(0.0103)$ & $(0.0000)$ & $(0.0002)$ & $(0.0001)$ & $(0.0001)$ & $(0.0002)$ & $(0.0000)$ & $(0.0002)$ & $(0.0001)$ & $(0.0001)$ & $(0.0003)$ & $(0.0007)$ & $(0.0001)$ & $(0.0001)$ \\
\hline & Services (12) & $(0.0486)$ & $(0.0918)$ & $(0.0903)$ & $(0.1198)$ & $(0.1149)$ & $(0.0334)$ & $(0.1318)$ & $(0.1117)$ & $(0.0825)$ & $(0.0825)$ & $(0.0520)$ & 0.8640 & $(0.1132)$ & (0.0002) & $(0.0005)$ & $(0.0003)$ & $(0.0003)$ & $(0.0003)$ & $(0.0001)$ & $(0.0004)$ & $(0.0004)$ & $(0.0003)$ & $(0.0003)$ & $(0.0002)$ & $(0.0003)$ & $(0.0003)$ \\
\hline & $d$ mail (13) & $(0.0154)$ & $(0.0653)$ & $(0.0316)$ & $(0.0177)$ & $(0.0326)$ & $(0.0137)$ & $(0.0276)$ & $(0.0231)$ & $(0.0126)$ & $(0.0407)$ & $(0.0102)$ & $(0.0144)$ & 0.9271 & $\mid(0.0000)$ & $(0.0002)$ & $(0.0001)$ & $(0.0000)$ & $(0.0001)$ & $(0.0000)$ & $(0.0001)$ & $(0.0001)$ & $(0.0000)$ & $(0.0002)$ & $(0.0000)$ & $(0.0000)$ & $(0.0001)$ \\
\hline \multirow{12}{*}{ 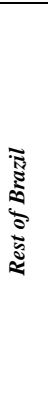 } & Agricult & $\begin{array}{l}(0.0386) \\
\end{array}$ & $\begin{array}{l}(0.0001) \\
\end{array}$ & $\begin{array}{l}(0.1489) \\
\end{array}$ & $(0.0047)$ & $\begin{array}{l}(0.0306) \\
\end{array}$ & $(0.0786)$ & $\begin{array}{l}(0.0059) \\
\end{array}$ & $(0.0006)$ & $\begin{array}{l}(0.0004) \\
\end{array}$ & $\begin{array}{l}(0.0006) \\
\end{array}$ & $(0.0000)$ & $\begin{array}{l}(0.0004) \\
\end{array}$ & $(0.0000)$ & 0.9216 & $\begin{array}{l}(0.0002) \\
\end{array}$ & $(0.3336)$ & $(0.0266)$ & $(0.0654)$ & $\begin{array}{l}(0.0477) \\
\end{array}$ & $\begin{array}{l}(0.0071) \\
\end{array}$ & $(0.0012)$ & $\begin{array}{l}(0.0007) \\
\end{array}$ & $\begin{array}{l}(0.0007) \\
\end{array}$ & $(0.0000)$ & $\begin{array}{l}(0.0018) \\
\end{array}$ & $(0.0000)$ \\
\hline & Mining (2) & $(0.0004)$ & $(0.0092)$ & $(0.0002)$ & $(0.0000)$ & $(0.0002)$ & $(0.2529)$ & $(0.0034)$ & $(0.0070)$ & $(0.0023)$ & $(0.0426)$ & $(0.0364)$ & $(0.0000)$ & $(0.0000)$ & $\mid(0.0031)$ & 0.9647 & $(0.0003)$ & $(0.0002)$ & $(0.0007)$ & $(0.4245)$ & $(0.0181)$ & $(0.0033)$ & $(0.0121)$ & $(0.0566)$ & $(0.0428)$ & $(0.0001)$ & $(0.0000)$ \\
\hline & Food, bever & $(0.0347)$ & $(0.0009)$ & $(0.0661)$ & $(0.0017)$ & $(0.0003)$ & $(0.0063)$ & $(0.0042)$ & $(0.0002)$ & $(0.0002)$ & $(0.0001)$ & $(0.0008)$ & $(0.0035)$ & $(0.0001)$ & $\mid(0.0649)$ & $(0.0003)$ & 0.8501 & $(0.0182)$ & $(0.0022)$ & $(0.0063)$ & $(0.0115)$ & $(0.0004)$ & $(0.0003)$ & $(0.0002)$ & $(0.0012)$ & $(0.0148)$ & $(0.0006)$ \\
\hline & Textile, clothing and shoes (4) & $(0.0017)$ & $(0.0218)$ & $(0.0003)$ & $(0.2279)$ & $(0.0036)$ & $(0.0009)$ & $(0.0017)$ & $(0.0028)$ & $(0.0014)$ & $(0.0001)$ & $(0.0001)$ & $(0.0013)$ & $(0.0019)$ & $(0.0014)$ & $(0.0021)$ & $(0.0014)$ & 0.7675 & $(0.0038)$ & $(0.0002)$ & $(0.0014)$ & $(0.0031)$ & $(0.0017)$ & $(0.0003)$ & $(0.0003)$ & $(0.0021)$ & $(0.0030)$ \\
\hline & Wood, paper and printing (5) & $(0.0019)$ & $(0.0076)$ & $(0.0061)$ & $(0.0015)$ & $(0.0439)$ & $(0.0010)$ & $(0.0151)$ & $(0.0115)$ & $(0.0229)$ & $(0.0042)$ & $(0.0012)$ & $(0.0088)$ & $(0.0018)$ & $(0.0014)$ & $(0.0027)$ & $(0.0076)$ & $(0.0065)$ & 0.8349 & $(0.0004)$ & $(0.0132)$ & $(0.0146)$ & $(0.0225)$ & $(0.0042)$ & $(0.0015)$ & $(0.0126)$ & (0.0022) \\
\hline & Oil refining, coke and ethanol ( & $(0.0306)$ & $(0.0640)$ & $(0.0082)$ & $(0.0048)$ & $(0.0063)$ & $(0.0740)$ & $(0.0508)$ & $(0.0095)$ & $(0.0154)$ & $(0.0106)$ & $(0.0142)$ & $(0.0034)$ & $(0.1267)$ & $(0.0251)$ & $(0.0195)$ & $(0.0082)$ & $(0.0077)$ & $(0.0099)$ & 0.8622 & $(0.0548)$ & $(0.0135)$ & $(0.0167)$ & $(0.0123)$ & $(0.0206)$ & 0.0069) & $(0.1224)$ \\
\hline & $\begin{array}{l}\text { Chemical and pharmaceutical } \\
\text { products (7) }\end{array}$ & $(0.0995)$ & $(0.0292)$ & $(0.0073)$ & $(0.0213)$ & $(0.0253)$ & $(0.0043)$ & $(0.0840)$ & .0399) & $(0.0211)$ & $(0.0264)$ & $(0.0029)$ & $(0.0018)$ & $(0.0004)$ & $(0.1080)$ & $(0.0116)$ & $(0.0081)$ & $(0.0423)$ & $(0.0448)$ & $(0.0087)$ & 0.7932 & $(0.0430)$ & $(0.0260)$ & $(0.0356)$ & $(0.0095)$ & $(0.0051)$ & $(0.0006)$ \\
\hline & $\begin{array}{l}\text { Other industries }(8) \\
\text { Cement, construction and other non- } \\
\text { metallic mineral products }(9)\end{array}$ & $\begin{array}{l}(0.0049) \\
(0.0005)\end{array}$ & $\begin{array}{l}(0.0682) \\
(0.0016)\end{array}$ & $\begin{array}{l}(0.0183) \\
(0.0018)\end{array}$ & $\begin{array}{l}(0.0091) \\
(0.0001)\end{array}$ & $\begin{array}{l}(0.0106) \\
(0.0001)\end{array}$ & $\begin{array}{l}(0.0125) \\
(0.0011)\end{array}$ & $\begin{array}{l}(0.0204) \\
(0.0041)\end{array}$ & $\begin{array}{l}(0.1550) \\
(0.0020)\end{array}$ & $\begin{array}{l}(0.0352) \\
(0.0762)\end{array}$ & $\begin{array}{l}(0.0174) \\
(0.0006)\end{array}$ & $\begin{array}{l}(0.0207) \\
(0.0001)\end{array}$ & $\begin{array}{l}(0.0109) \\
(0.0002)\end{array}$ & $\left.\begin{array}{l}(0.0497) \\
(0.0000)\end{array}\right]$ & $\mid \begin{array}{l}(0.0047) \\
(0.0005)\end{array}$ & $\begin{array}{l}(0.0333) \\
(0.0208)\end{array}$ & $\begin{array}{l}(0.0208) \\
(0.0022)\end{array}$ & $\begin{array}{l}(0.0200) \\
(0.0013)\end{array}$ & $\begin{array}{l}(0.0320) \\
(0.0015)\end{array}$ & $\begin{array}{l}(0.0091) \\
(0.0009)\end{array}$ & $\begin{array}{l}(0.0279) \\
(0.0061)\end{array}$ & $\begin{array}{r}0.8135 \\
(0.0081)\end{array}$ & $\begin{array}{r}(0.0385) \\
0.8732\end{array}$ & $\begin{array}{l}(0.0373) \\
(0.0071)\end{array}$ & $\begin{array}{l}(0.0652) \\
(0.0002)\end{array}$ & $\begin{array}{l}(0.0179) \\
(0.0128)\end{array}$ & $\begin{array}{l}(0.0521) \\
(0.0002)\end{array}$ \\
\hline & Metallurgy (10 & $(0.0046)$ & $(0.0327)$ & $(0.0101)$ & $(0.0003)$ & $(0.0042)$ & $(0.0063)$ & $(0.0059)$ & $(0.0760)$ & $(0.0462)$ & $(0.1894)$ & $(0.0021)$ & $(0.0007)$ & $(0.0002)$ & $(0.0043)$ & $(0.0286)$ & $(0.0104)$ & $(0.0030)$ & $(0.0126)$ & $(0.0049)$ & $(0.0119)$ & & $(0.0506)$ & 0.7950 & 26) & 16) & .0002) \\
\hline & 1) & $(0.0007)$ & $(0.0045)$ & $(0.0020)$ & $(0.0000)$ & $(0.0001)$ & $(0.0007)$ & $(0.0008)$ & $(0.0000)$ & $(0.0000)$ & $(0.0002)$ & $(0.0000)$ & $(0.0000)$ & $(0.0000)$ & \begin{tabular}{|l|}
$(0.0035)$ \\
\end{tabular} & $(0.0154)$ & $(0.0116)$ & $(0.0176)$ & $(0.0205)$ & $(0.0048)$ & $(0.0236)$ & 6) & $(0.0089)$ & $(0.0311)$ & 0.8380 & $0.0118)$ & 94) \\
\hline & Services (12) & $(0.0152)$ & $(0.0362)$ & $(0.0324)$ & $(0.0140)$ & $(0.0190)$ & $(0.0110)$ & $(0.0476)$ & $(0.0276)$ & $(0.0199)$ & $(0.0209)$ & $(0.0224)$ & $(0.0373)$ & $(0.0384)$ & $(0.0523)$ & $(0.1578)$ & $(0.1207)$ & $(0.1179)$ & $(0.1095)$ & $(0.0355)$ & $(0.1544)$ & $(0.1344)$ & $(0.0981)$ & $(0.0950)$ & $(0.0874)$ & 0.8160 & $(0.1399)$ \\
\hline & orage and mail (13) & $(0.0072)$ & $(0.0309)$ & $(0.0148)$ & $(0.0057)$ & $(0.0069)$ & $(0.0047)$ & $(0.0126)$ & $(0.0080)$ & $(0.0048)$ & $(0.0088)$ & $(0.0047)$ & $(0.0055)$ & $(0.0152)$ & $(0.0175)$ & $(0.0820)$ & $(0.0457)$ & $(0.0237)$ & $(0.0324)$ & $(0.0161)$ & $(0.0342)$ & $0.0302)$ & $(0.0182)$ & $(0.0470)$ & $(0.0175)$ & (0.0183) & 0.9187 \\
\hline
\end{tabular}

[Back to page 53] 


\section{Appendix V: Goiás and rest of Brazil Leontief inverse matrix}

\begin{tabular}{|c|c|c|c|c|c|c|c|c|c|c|c|c|c|c|c|c|c|c|c|c|c|c|c|c|c|c|c|}
\hline & & \multicolumn{13}{|c|}{ Goiás State } & \multicolumn{13}{|c|}{ Rest of Brazil } \\
\hline & & (I) & (2) & (3) & (4) & (5) & (6) & (7) & (8) & (9) & (10) & (11) & (12) & (13) & (I) & (2) & (3) & (4) & (5) & (6) & (7) & (8) & (9) & (10) & (II) & (12) & (13) \\
\hline \multirow{12}{*}{ 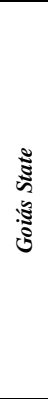 } & Agricultural (I)* & 1.06963 & 0.00189 & 0.23991 & 0.01591 & 0.05776 & 0.14874 & 0.01050 & 0.00304 & 0.00147 & 0.00158 & 0.00136 & 0.00612 & \begin{tabular}{l|l|}
0.00229 \\
\end{tabular} & 0.00458 & 0.00029 & 0.020590 & 0.00308 & 0.00147 & 0.00184 & 0.00146 & 0.00041 & 0.00031 & 0.00031 & 0.00025 & 0.00072 & 0.00044 \\
\hline & Mining (2) & 0.00479 & 1.03524 & 0.00153 & 0.00065 & 0.00268 & 0.00099 & 0.02296 & 0.00108 & 0.01158 & 0.00784 & 0.00028 & 0.00042 & 0.00017 & 0.00055 & 0.00044 & 0.000390 & 0.00020 & 0.00029 & 0.00030 & 0.00176 & 0.00038 & 0.00101 & 0.00141 & 0.00010 & 0.00006 & 0.00 \\
\hline & Food, beverages and tobacco (3) & 0.04206 & 0.00250 & 1.13029 & 0.02324 & 0.00958 & 0.01582 & 0.02312 & 0.00312 & 0.00216 & 0.00243 & 0.00172 & 0.01547 & 0.00304 & 0.00387 & 0.00039 & 0.020770 & 0.00287 & 0.00086 & 0.00141 & 0.00293 & 0.00054 & 0.00038 & 0.00044 & 0.00033 & 116 & \\
\hline & Textile, clothing a & 0.00016 & 0.00041 & 0.00023 & 1.07262 & 0.00317 & 0.00012 & 0.00039 & 0.00160 & 0.00038 & 0.00062 & 0.00030 & 0.00093 & 0.00177 & 0.00003 & 0.00005 & 0.00004 & 0.00131 & 0.00004 & 0.00003 & 0.00003 & 0.00005 & 0.00003 & 0.00003 & 0.00002 & 003 & 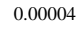 \\
\hline & Wood, paper and printing (5) & 0.00054 & 0.00094 & 0.00100 & 0.00612 & 1.16057 & 0.00046 & 0.00414 & 0.00756 & 0.00181 & 0.00338 & 0.00070 & 0.00347 & 0.00119 & 0.00007 & 0.00013 & 0.00020 & 0.00016 & 0.00086 & 0.00009 & 0.00023 & 0.00018 & 0.00020 & 0.00012 & 0.00006 & 0014 & 40 \\
\hline & Oil refining, coke and ethanol (6) & 0.00252 & 0.00225 & 0.00189 & 0.00203 & 0.00619 & 1.01542 & 0.01304 & 0.00277 & 0.00167 & 0.00190 & 0.00471 & 0.00520 & 0.00763 & 0.00036 & 0.00019 & 0.00034 & 0.00023 & 0.00028 & 0.00198 & 0.00131 & 0.00026 & 0.00019 & 0.00024 & 0.00020 & 0.00023 & 0.00048 \\
\hline & $\begin{array}{l}\text { Chemical and pharmaceutical products (7) } \\
\text { Other industries }(8)\end{array}$ & $\begin{array}{l}0.05624 \\
0.00344\end{array}$ & $\begin{array}{l}0.00776 \\
0.01106\end{array}$ & $\begin{array}{l}0.01519 \\
0.00687\end{array}$ & $\begin{array}{l}0.01053 \\
0.01401\end{array}$ & $\begin{array}{l}0.04954 \\
0.04232\end{array}$ & $\begin{array}{l}0.01097 \\
0.00496\end{array}$ & $\begin{array}{l}1.10373 \\
0.01403\end{array}$ & $\begin{array}{l}0.01146 \\
1.06014\end{array}$ & $\begin{array}{l}0.00857 \\
0.00942\end{array}$ & $\begin{array}{l}0.01877 \\
0.03048\end{array}$ & $\begin{array}{l}0.00777 \\
0.04385\end{array}$ & $\begin{array}{l}0.00509 \\
0.01005\end{array}$ & $\begin{array}{l}0.00137 \\
0.00982\end{array}$ & $\begin{array}{l}0.00232 \\
0.00027\end{array}$ & $\begin{array}{l}0.00049 \\
0.00051\end{array}$ & $\begin{array}{l}0.00219 \\
0.00062\end{array}$ & $\begin{array}{l}0.00075 \\
0.00038\end{array}$ & $\begin{array}{l}0.00099 \\
0.00043\end{array}$ & $\begin{array}{l}0.00059 \\
0.00039\end{array}$ & $\begin{array}{l}0.00275 \\
0.00058\end{array}$ & $\begin{array}{l}0.00066 \\
0.00093\end{array}$ & $\begin{array}{l}0.00071 \\
0.00054\end{array}$ & $\begin{array}{l}0.00109 \\
0.00079\end{array}$ & $\begin{array}{l}0.00034 \\
0.00046\end{array}$ & $\begin{array}{l}0.00027 \\
0.00022\end{array}$ & $\begin{array}{l}0.00018 \\
0.00034\end{array}$ \\
\hline & $\begin{array}{l}\text { Cement, construction and other non-metallic } \\
\text { mineral products }(\mathbf{9})\end{array}$ & 0.00166 & 0.00344 & 0.00289 & 0.00396 & 0.00574 & 0.00162 & 0.00730 & 0.01236 & 1.06969 & 0.00948 & 0.00180 & 0.01702 & 0.00245 & 0.00011 & 0.00031 & 0.00019 & 0.00011 & 0.00011 & 0.00020 & 0.00030 & 0.00026 & 0.00143 & 0.00037 & .000007 & 0.00015 & .00 \\
\hline & Metallurgy (10) & 0.00197 & 0.00255 & 0.00165 & 0.00367 & 0.01590 & 0.00302 & 0.00739 & 0.02870 & 0.01215 & 1.0 & 0.00157 & 0.0 & 65 & 0.00022 & 0.00072 & 0.00038 & 0.00018 & 0.00031 & 0.00047 & 0.00041 & 0.00111 & 0.00061 & 0.00220 & 0. & 0 & t \\
\hline & & 0.00805 & 0.03131 & 0.01763 & 0.02112 & 0.04410 & 0.00943 & 0.03083 & 0.04598 & 0.01239 & 0.04142 & 1.16402 & 0.01808 & 0.01575 & 0.00034 & 0.00043 & 0.00080 & 0.00047 & 0.00050 & 0.00038 & 0.00073 & 0.00056 & 0.00039 & 0.00088 & 0.00114 & 029 & 027 \\
\hline & Services & 0.07828 & 0.12593 & 0.14305 & 0.16198 & 0.18393 & 0.05572 & 0.18542 & 0.15188 & 0.11115 & 0.12080 & 0.08005 & 1.16789 & 0.14578 & 0.00174 & 0.00134 & 0.004930 & 0.00164 & 0.00126 & 0.00130 & 0.00228 & 0.00152 & 0.00121 & 0.00163 & 0.00073 & 085 & 0.00081 \\
\hline & Transport, storage and mail (13) & 0.02287 & 0.07617 & 0.04594 & 0.02547 & 0.04909 & 0.01982 & 0.03981 & 0.03166 & 0.01843 & 0.05147 & 0.01569 & 0.01999 & 1.08182 & 0.00048 & 0.00040 & $0.00145 \quad 0$ & 0.00038 & 0.00034 & 0.00040 & 0.00061 & 0.00037 & 0.00030 & 0.00059 & 0.00016 & 0.00015 & 0.00026 \\
\hline \multirow{13}{*}{ 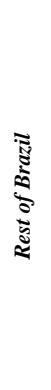 } & & 02 & 0.01244 & 0.24189 & 0.02894 & 0.05582 & 0.11354 & 0.02706 & 0.00973 & 0.00831 & 0.00791 & 0.00464 & 0.00919 & 0.01360 & 1.12411 & 0.00683 & $0.45126 \quad 0$ & 0.05629 & 0.09500 & 0.07067 & 0.02806 & 0.01065 & 0.00881 & 0.00776 & 0.00587 & 0.01398 & 0.01298 \\
\hline & Mining (2) & 3596 & 0.06623 & 0.02989 & 0.01628 & 0.02507 & 0.32467 & 0.05648 & 0.04070 & 0.02860 & 0.08691 & 0.06064 & 0.00952 & 0.08063 & 0.03196 & 1.06290 & 0.02880 & 0.01890 & 0.02305 & 0.52993 & 0.07331 & 0.03819 & 0.03880 & 0.09842 & 0.07434 & 0.01052 & 0.07547 \\
\hline & Food, bevera & 813 & 0.00779 & 0.12106 & 0.01755 & 0.01228 & 0.02816 & 0.01613 & 0.00646 & 0.00451 & 0.00522 & 0.00382 & 0.00879 & 0.00584 & 0.09149 & 0.00645 & 1.21987 & 0.03852 & 0.01618 & 0.01883 & 0.02623 & 0.00820 & 0.00591 & 0.00635 & 0.00617 & & 762 \\
\hline & $T e_{i}$ & 0.00418 & 0.03158 & 0.00337 & 0.31999 & 0.00858 & 0.00401 & 0.00529 & 0.00687 & 0.00394 & 0.00244 & 0.00134 & 0.00293 & 0.00469 & 0.00343 & 0.00464 & 0.004891 & 1.30500 & 0.00760 & 0.00328 & 0.00439 & 0.00676 & 0.00406 & 0.00236 & 0187 & 66 & 578 \\
\hline & Wood, $p a$ & 0.01047 & 0.01771 & 0.01750 & 0.01106 & 0.06925 & 0.00869 & 0.02962 & 0.02642 & 0.03788 & 0.01425 & 0.00607 & 0.01551 & 0.00844 & 0.00841 & 0.01044 & 0.01949 & 0.01712 & 1.20488 & 0.00808 & 0.02760 & 0.02962 & 0.03696 & 0.01366 & 0.00801 & 0.02083 & 0.00897 \\
\hline & & & 0.10899 & 0.05228 & 0.02677 & 0.03754 & 0.12138 & 0.09574 & 0.03926 & 0.03 & 0.04328 & 0.03 & 0.01404 & 0.17213 & 0.05310 & & & & & & & & & & & & \\
\hline & & 6 & 0.05772 & 0.08510 & .05982 & 0.07068 & 0.05419 & 0.13479 & 0.08195 & 0.04730 & 006113 & 0.01416 & 0.01054 & 0.01426 & 0.15992 & 0.02696 & 0.08624 & & 0.09006 & & & 0.08441 & 0.05204 & 24 & 0.02595 & 44 & 01402 \\
\hline & ther ind & 0.02891 & 0.11587 & 0.05312 & 0.03825 & 0.04609 & 0.04848 & 0.05785 & 0.22949 & 0.07061 & 0.06306 & 0.04827 & 0.02594 & 0.08366 & 0.02494 & 0.06471 & 0.05618 & 0.05118 & 0.06714 & 0.05200 & 0.06786 & 1.25958 & 0.07329 & 0.08263 & 0.10941 & 0.03571 & 0.08547 \\
\hline & $\begin{array}{l}\text { untion and other } \\
\text { s(9) }\end{array}$ & 0.00533 & 0.00811 & 0.00762 & 0.00414 & 0.00452 & 0.01276 & 0.01152 & 0.01072 & 0.09740 & 0.00907 & 0.00365 & 0.00360 & 0.00513 & 0.00533 & 0.03051 & 0.00961 & 0.00750 & 0.00758 & 0.01809 & 0.01635 & 0.01895 & 1.15112 & 0.01742 & 0.00625 & 0.01941 & 0.00677 \\
\hline & Metallurgy (10 & 0.01852 & 0.06669 & 0.03166 & 0.01304 & 0.02647 & 0.03303 & 0.02823 & 0.14680 & 0.08585 & 0.27278 & 0.01797 & 0.00887 & 0.01888 & 0.01571 & 0.05137 & 0.03123 & 0.01678 & 0.03316 & 0.03708 & 0.03522 & 0.18593 & 0.08772 & 1.27732 & 0.02399 & 0.01054 & 90 \\
\hline & & & & 0.01432 & & & & 0.01 & & & & & & & & & & & & & & & & & & & \\
\hline & Services (12) & 956 & 0.13471 & 0.14327 & 11252 & 0.09829 & 0.13707 & 0.15063 & 0.14369 & 0.09589 & 0.125 & 07027 & 0.07 & 0.11198 & 0.14182 & 25846 & 0.27056 & 0.24584 & 0.22519 & 39 & 25 & 000 & 19 & 46 & 13 & 25631 & 23791 \\
\hline & $t$ t, storage and mail (13) & 226 & & 4685 & (180 & 81 & 1122 & 03966 & & 6 & & 1837 & 1365 & $0.03 \pi$ & & & & & & 0.08084 & & & 0.042 & 0.08721 & 0.04060 & & \\
\hline
\end{tabular}

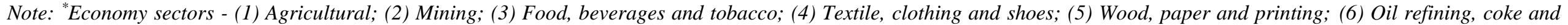

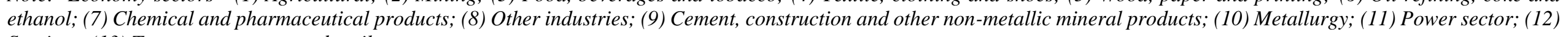
Services; (13) Transport, storage and mail.

The Leontief model's solution can be represented by $X=(I-A)^{-1} . Y$ 


\section{Appendix VI: Goiás economic-ecological hybrid Input-Output matrix}

\begin{tabular}{|c|c|c|c|c|c|c|c|c|c|c|c|c|c|c|c|}
\hline & & \multicolumn{13}{|c|}{ Goiás State } & \multirow{2}{*}{$\begin{array}{c}\text { Emissions } \\
\left(\mathrm{TgCO}_{2 e}\right)\end{array}$} \\
\hline & & (1) & $(2)$ & (3) & (4) & (5) & (6) & (7) & (8) & (9) & (10) & (11) & (12) & (13) & \\
\hline \multirow{19}{*}{ 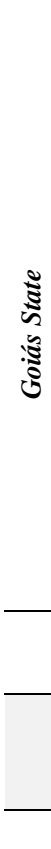 } & Agricultural $(1) *$ & 301.93 & 0.29 & 1622.08 & 4.74 & 13.14 & 130.00 & 3.98 & 2.18 & 0.84 & 0.18 & 0.01 & 24.20 & 0.03 & 89.402 \\
\hline & Mining (2) & 16.34 & 21.56 & 1.40 & 0.10 & 0.29 & 0.02 & 31.62 & 0.43 & 28.02 & 5.82 & 0.01 & 0.96 & 0.04 & 0.189 \\
\hline & Food, beverages and tobacco (3) & 174.81 & 0.10 & 857.12 & 9.28 & 0.84 & 7.38 & 25.38 & 0.73 & 0.59 & 0.09 & 0.31 & 192.59 & 0.98 & 0.591 \\
\hline & Textile, clothing and shoes (4) & 0.16 & 0.08 & 0.10 & 38.46 & 0.69 & 0.01 & 0.19 & 2.56 & 0.57 & 0.31 & 0.17 & 11.71 & 2.52 & 0.0005 \\
\hline & Wood, paper and printing (5) & 0.18 & 0.20 & 2.50 & 2.50 & 41.13 & 0.12 & 4.24 & 11.77 & 2.92 & 1.99 & 0.13 & 41.40 & 0.94 & 0.026 \\
\hline & Oil refining, coke and ethanol (6) & 5.76 & 0.48 & 2.23 & 0.43 & 1.06 & 13.79 & 16.51 & 3.12 & 2.07 & 0.44 & 4.70 & 69.48 & 10.79 & 0.154 \\
\hline & $\begin{array}{l}\text { Chemical and pharmaceutical products } \\
\text { (7) }\end{array}$ & 253.48 & 3.68 & 9.23 & 4.00 & 10.44 & 2.13 & 147.28 & 17.09 & 17.46 & 13.44 & 7.32 & 55.18 & 0.47 & 0.067 \\
\hline & Other industries $(8)$ & 8.22 & 5.62 & 33.14 & 6.13 & 9.73 & 3.39 & 16.27 & 118.58 & 19.35 & 23.85 & 59.56 & 133.62 & 13.51 & 2.458 \\
\hline & $\begin{array}{l}\text { Cement, construction and other non- } \\
\text { metallic mineral products }(\boldsymbol{9})\end{array}$ & 0.83 & 0.81 & 3.97 & 0.68 & 0.56 & 0.50 & 5.85 & 18.12 & 177.47 & 5.87 & 0.18 & 228.75 & 0.29 & 0.439 \\
\hline & Metallurgy (10) & 6.12 & 1.04 & 5.03 & 1.41 & 3.40 & 2.03 & 8.79 & 51.56 & 28.15 & 55.86 & 0.16 & 16.70 & 0.05 & 0.765 \\
\hline & Power sector (11) & 17.90 & 13.82 & 76.87 & 7.27 & 7.68 & 5.26 & 29.96 & 78.02 & 19.17 & 25.70 & 177.42 & 195.63 & 17.31 & 0.074 \\
\hline & Services (12) & 262.44 & 58.80 & 739.39 & 68.50 & 34.37 & 32.27 & 211.01 & 238.36 & 231.07 & 76.03 & 71.17 & 2302.36 & 202.48 & 0.068 \\
\hline & Transport, storage and mail (13) & 83.45 & 41.84 & 258.88 & 10.11 & 9.74 & 13.27 & 44.16 & 49.19 & 35.15 & 37.50 & 13.95 & 244.43 & 130.44 & 5.924 \\
\hline & Value added & 2500.03 & 214.93 & 1369.37 & 201.52 & 90.97 & 212.43 & 371.92 & 545.52 & 1356.23 & 279.63 & 850.27 & 11531.79 & 866.45 & \\
\hline & Jobs (Thousands) & 839.70 & 15.05 & 1276.22 & 86.86 & 9.97 & 16.76 & 18.15 & 45.83 & 214.09 & 18.40 & 12.11 & 1446.96 & 111.62 & \\
\hline & Land-use $\left(\mathrm{km}^{2}\right)$ & 204517.41 & 30.12 & 6.90 & - & 3.65 & 0.09 & 3.69 & 1.57 & 4.23 & 7.12 & 2755.16 & 0.62 & - & \\
\hline & Water $\left(h m^{3}\right)$ & 3721.594 & 64.093 & 22.491 & 2.012 & 13.165 & 1.673 & 21.027 & 0.175 & 1.358 & 74.501 & 699.264 & 38.474 & & \\
\hline & Energy $(P J)$ & 13.523 & 7.034 & 30.857 & 0.126 & 0.754 & 149.552 & 2.386 & 2.973 & 15.240 & 0.126 & 99.018 & 7.536 & 143.482 & \\
\hline & Total Output & 5405.065 & 640.528 & 8185.984 & 571.938 & 299.093 & 967.173 & 1601.436 & 2092.036 & 2799.151 & 921.998 & 1458.963 & 16926.085 & 1789.164 & \\
\hline
\end{tabular}

Note: Economic variables in million US\$; assuming an average exchange rate of 3.23 R\$/US\$ for a year period (BCB, 2017. Environmental variables in physical units.

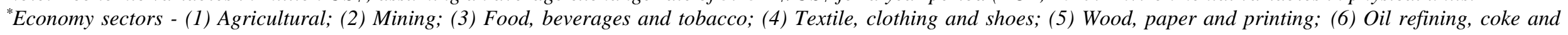
ethanol; (7) Chemical and pharmaceutical products; (8) Other industries; (9) Cement, construction and other non-metallic mineral products; (10) Metallurgy; (11) Power sector; (12) Services; (13) Transport, storage and mail 


\section{Appendix VII: Useful volume of hydropower reservoirs}

Useful volume: Monthly average.

\begin{tabular}{|c|c|c|c|c|c|c|c|c|c|c|c|c|}
\hline Useful volume (\%) & Jan & Feb & Mar & Apr & May & Jun & Jul & Aug & Sep & Oct & Nov & Dec \\
\hline Emborcação & 0.49 & 0.57 & 0.64 & 0.67 & 0.66 & 0.64 & 0.61 & 0.55 & 0.49 & 0.42 & 0.38 & 0.41 \\
\hline Itumbiara & 0.49 & 0.57 & 0.68 & 0.74 & 0.76 & 0.73 & 0.67 & 0.56 & 0.45 & 0.36 & 0.34 & 0.39 \\
\hline Nova Ponte & 0.54 & 0.59 & 0.65 & 0.68 & 0.68 & 0.67 & 0.64 & 0.60 & 0.55 & 0.51 & 0.48 & 0.50 \\
\hline São Simão & 0.60 & 0.77 & 0.87 & 0.85 & 0.82 & 0.78 & 0.73 & 0.63 & 0.55 & 0.44 & 0.44 & 0.48 \\
\hline Average of four power stations & 0.53 & 0.62 & 0.71 & 0.73 & 0.73 & 0.71 & 0.66 & 0.59 & 0.51 & 0.43 & 0.41 & 0.45 \\
\hline
\end{tabular}

Note: The ONS has made available data only for Emborcação, Itumbiara, Nova Ponte and São Simão reservoirs. Due to the lack of data, the monthly average of useful volume for the other reservoirs in the region of study was estimated from the average found to these four reservoirs.

Source: ONS (2017). 


\section{Appendix VIII: Useful monthly volume}

Real monthly average*. Historical series $(2000-2015)$.

\begin{tabular}{|c|c|c|c|c|c|c|c|c|c|c|c|c|}
\hline Hydropower reservoir & Jan & Feb & Mar & Apr & May & Jun & Jul & Aug & Sep & Oct & Nov & Dec \\
\hline UHE Batalha & 1148.9 & 1272.5 & 1391.0 & 1422.9 & 1417.6 & 1383.3 & 1325.0 & 1220.8 & 1118.3 & 1012.2 & 987.0 & 1031.6 \\
\hline UHE Nova Ponte & 8007.3 & 8531.1 & 9163.7 & 9440.3 & 9478.4 & 9368.0 & 9091.7 & 8629.9 & 8142.6 & 7666.2 & 7375.7 & 7611.9 \\
\hline UHE Corumbá I & 1017.8 & 1112.0 & 1202.4 & 1226.6 & 1222.6 & 1196.4 & 1152.1 & 1072.6 & 994.5 & 913.6 & 894.4 & 928.4 \\
\hline UHE Barra dos Coqueiros & 325.4 & 329.8 & 334.0 & 335.1 & 334.9 & 333.7 & 331.7 & 328.0 & 324.3 & 320.6 & 319.7 & 321.3 \\
\hline UHE Salto & 826.1 & 826.1 & 826.1 & 826.1 & 826.1 & 826.1 & 826.1 & 826.1 & 826.1 & 826.1 & 826.1 & 826.1 \\
\hline UHE Emborcação & 11089.6 & 12059.9 & 12972.0 & 13406.0 & 13324.0 & 13060.8 & 12609.4 & 11867.6 & 11026.8 & 10162.9 & 9680.0 & 10019.3 \\
\hline UHE Cachoeira Dourada & 460.0 & 460.0 & 460.0 & 460.0 & 460.0 & 460.0 & 460.0 & 460.0 & 460.0 & 460.0 & 460.0 & 460.0 \\
\hline Queimado & 340.8 & 383.1 & 423.6 & 434.5 & 432.7 & 420.9 & 401.0 & 365.4 & 330.4 & 294.1 & 285.5 & 300.7 \\
\hline Corumbá IV & 3346.9 & 3417.4 & 3485.1 & 3503.3 & 3500.3 & 3480.7 & 3447.4 & 3387.9 & 3329.4 & 3268.8 & 3254.5 & 3279.9 \\
\hline Corumbá III & 848.9 & 872.9 & 896.0 & 902.2 & 901.2 & 894.5 & 883.2 & 862.9 & 842.9 & 822.3 & 817.4 & 826.0 \\
\hline Serra do Facão & 3585.3 & 3900.6 & 4202.9 & 4284.2 & 4270.7 & 4183.1 & 4034.6 & 3768.8 & 3507.4 & 3236.6 & 3172.3 & 3286.1 \\
\hline Itumbiara & 10722.2 & 11697.8 & 13085.5 & 13823.4 & 13983.9 & 13637.2 & 12862.1 & 11568.9 & 10174.3 & 9041.0 & 8854.2 & 9386.9 \\
\hline Salto Verdinho & 264.5 & 264.5 & 264.5 & 264.5 & 264.5 & 264.5 & 264.5 & 264.5 & 264.5 & 264.5 & 264.5 & 264.5 \\
\hline $\mathrm{Cacu}$ & 215.6 & 218.8 & 221.8 & 222.6 & 222.5 & 221.6 & 220.1 & 217.5 & 214.8 & 212.1 & 211.5 & 212.6 \\
\hline Espora & 144.4 & 157.0 & 169.1 & 172.4 & 171.8 & 168.3 & 162.4 & 151.7 & 141.3 & 130.4 & 127.9 & 132.4 \\
\hline Castelo Branco II & 878.5 & 878.6 & 878.7 & 878.7 & 878.7 & 878.7 & 878.7 & 878.6 & 878.5 & 878.4 & 878.4 & 878.4 \\
\hline Castelo Branco I & 235.1 & 236.3 & 237.4 & 237.7 & 237.7 & 237.3 & 236.8 & 235.8 & 234.8 & 233.8 & 233.6 & 234.0 \\
\hline Miranda & 1051.6 & 1065.0 & 1077.8 & 1081.3 & 1080.7 & 1077.0 & 1070.7 & 1059.4 & 1048.4 & 1036.9 & 1034.2 & 1039.0 \\
\hline São Simão & 10339.5 & 11241.3 & 11843.1 & 11705.3 & 11562.0 & 11323.7 & 11052.6 & 10480.4 & 10037.0 & 9421.2 & 9451.0 & 9675.2 \\
\hline
\end{tabular}

Note: Useful volume, monthly average (UVMA), from Appendix VII; Real useful volume (RUV), from Table 7; Minimum volume (MINV), from Table 7.

"Useful monthly volume, Real monthly average = UVMA $x$ RUV - MINV

Source: Author's calculation from the variables made available from ONS (2017). 


\section{Appendix IX: Polynomials for reservoirs calculation}

\begin{tabular}{|c|c|c|c|c|c|c|c|c|c|c|}
\hline Hydropower reservoir & $a_{Q V P}$ & $b_{Q V P}$ & $c_{Q V P}$ & $d_{Q V P}$ & $e_{Q V P}$ & $a_{Q A P}$ & $b_{Q A P}$ & $c_{Q A P}$ & $d_{Q A P}$ & $e_{Q A P}$ \\
\hline UHE Batalha & $7.75 \mathrm{E}+02$ & $2.64 \mathrm{E}-02$ & $-1.06 \mathrm{E}-05$ & $1.99 \mathrm{E}-09$ & $0.00 \mathrm{E}+00$ & $-4.58 \mathrm{E}+03$ & $5.89 \mathrm{E}+00$ & $-4.65 \mathrm{E}-09$ & $-6.03 \mathrm{E}-13$ & $0.00 \mathrm{E}+00$ \\
\hline UHE Nova Ponte & $7.52 \mathrm{E}+02$ & $1.23 \mathrm{E}-02$ & $-1.26 \mathrm{E}-06$ & $7.85 \mathrm{E}-11$ & $-1.98 \mathrm{E}-15$ & $-3.23 \mathrm{E}+05$ & $9.30 \mathrm{E}+02$ & $-3.85 \mathrm{E}-01$ & $-8.80 \mathrm{E}-04$ & $6.76 \mathrm{E}-07$ \\
\hline UHE Corumbá I & $5.46 \mathrm{E}+02$ & $6.47 \mathrm{E}-02$ & $-3.24 \mathrm{E}-05$ & 7.39E-09 & $0.00 \mathrm{E}+00$ & $-3.89 \mathrm{E}+04$ & $2.13 \mathrm{E}+02$ & $-3.90 \mathrm{E}-01$ & 2.39E-04 & $0.00 \mathrm{E}+00$ \\
\hline UHE Barra dos Co & $4.18 \mathrm{E}+02$ & $1.73 \mathrm{E}-01$ & $-4.19 \mathrm{E}-04$ & $5.91 \mathrm{E}-07$ & $-3.20 \mathrm{E}-10$ & $1.27 \mathrm{E}+06$ & $-1.13 E+04$ & $3.79 \mathrm{E}+01$ & $-5.64 \mathrm{E}-02$ & $3.15 \mathrm{E}-05$ \\
\hline UHE Salto & $4.47 \mathrm{E}+02$ & $0.00 \mathrm{E}+00$ & $0.00 \mathrm{E}+00$ & $0.00 \mathrm{E}+00$ & $0.00 \mathrm{E}+00$ & $6.02 \mathrm{E}+01$ & $0.00 \mathrm{E}+00$ & $0.00 \mathrm{E}+00$ & $0.00 \mathrm{E}+00$ & $0.00 \mathrm{E}+00$ \\
\hline UHE Emborcação & $5.68 \mathrm{E}+02$ & $1.45 \mathrm{E}-02$ & $-1.20 \mathrm{E}-06$ & $5.83 \mathrm{E}-11$ & $-1.12 \mathrm{E}-15$ & $-1.82 \mathrm{E}+04$ & $5.66 \mathrm{E}+01$ & $4.52 \mathrm{E}-02$ & $-2.91 \mathrm{E}-04$ & $2.39 \mathrm{E}-07$ \\
\hline UHE Cachoeira Dourada & $4.34 \mathrm{E}+02$ & $0.00 \mathrm{E}+00$ & $0.00 \mathrm{E}+00$ & $0.00 \mathrm{E}+00$ & $0.00 \mathrm{E}+00$ & $6.90 \mathrm{E}+01$ & $0.00 \mathrm{E}+00$ & $0.00 \mathrm{E}+00$ & $0.00 \mathrm{E}+00$ & $0.00 \mathrm{E}+00$ \\
\hline Queimado & $8.02 \mathrm{E}+02$ & $1.14 \mathrm{E}-01$ & $-1.98 \mathrm{E}-04$ & $1.44 \mathrm{E}-07$ & $-2.49 \mathrm{E}-17$ & $-7.22 \mathrm{E}+06$ & $2.65 \mathrm{E}+04$ & $-3.25 \mathrm{E}+01$ & $1.33 \mathrm{E}-02$ & $0.00 \mathrm{E}+00$ \\
\hline Corumbá IV & $7.89 \mathrm{E}+02$ & $3.97 \mathrm{E}-02$ & $-1.50 \mathrm{E}-05$ & 3.07E-09 & $-2.37 \mathrm{E}-13$ & $-2.44 \mathrm{E}+05$ & $9.31 \mathrm{E}+02$ & $-1.19 \mathrm{E}+00$ & $5.06 \mathrm{E}-04$ & $0.00 \mathrm{E}+00$ \\
\hline Corumbá III & $7.50 \mathrm{E}+02$ & 2.03E-02 & 4.57E-05 & $-7.84 \mathrm{E}-08$ & $3.52 \mathrm{E}-11$ & $4.18 \mathrm{E}+04$ & $-1.12 \mathrm{E}+02$ & $7.50 \mathrm{E}-02$ & $0.00 \mathrm{E}+00$ & $0.00 \mathrm{E}+00$ \\
\hline Serra do Facão & $6.83 \mathrm{E}+02$ & 4.87E-02 & $-1.59 \mathrm{E}-05$ & 2.67E-09 & $-1.71 \mathrm{E}-13$ & $-8.18 \mathrm{E}+05$ & $3.33 \mathrm{E}+03$ & $-4.53 \mathrm{E}+00$ & $2.05 \mathrm{E}-03$ & $0.00 \mathrm{E}+00$ \\
\hline Itumbiara & $4.71 \mathrm{E}+02$ & $7.28 \mathrm{E}-03$ & $-5.61 \mathrm{E}-07$ & $2.60 \mathrm{E}-11$ & $-4.85 \mathrm{E}-16$ & $-8.75 E+05$ & $5.33 \mathrm{E}+03$ & $-1.09 \mathrm{E}+01$ & 7.38E-03 & $0.00 \mathrm{E}+00$ \\
\hline Salto Verdinho & $3.71 \mathrm{E}+02$ & $0.00 \mathrm{E}+00$ & $0.00 \mathrm{E}+00$ & $0.00 \mathrm{E}+00$ & $0.00 \mathrm{E}+00$ & $3.66 \mathrm{E}+01$ & $0.00 \mathrm{E}+00$ & $0.00 \mathrm{E}+00$ & $0.00 \mathrm{E}+00$ & $0.00 \mathrm{E}+00$ \\
\hline $\mathrm{Cacu}$ & $4.53 \mathrm{E}+02$ & $2.00 \mathrm{E}-01$ & $-7.76 \mathrm{E}-04$ & $2.17 \mathrm{E}-06$ & $-2.59 \mathrm{E}-09$ & $4.50 \mathrm{E}+05$ & $-3.90 \mathrm{E}+03$ & $1.27 \mathrm{E}+01$ & $-1.84 \mathrm{E}-02$ & $1.00 \mathrm{E}-05$ \\
\hline Espora & $5.59 \mathrm{E}+02$ & 4.00E-01 & $-2.78 \mathrm{E}-03$ & $9.26 \mathrm{E}-06$ & $-1.15 \mathrm{E}-08$ & $-1.08 \mathrm{E}+04$ & $6.50 \mathrm{E}+01$ & $-9.14 \mathrm{E}-02$ & $-4.83 \mathrm{E}-05$ & $1.18 \mathrm{E}-07$ \\
\hline Castelo Branco II & $5.27 \mathrm{E}+02$ & $1.10 \mathrm{E}-01$ & $-1.89 \mathrm{E}-04$ & $1.93 \mathrm{E}-07$ & $-7.45 \mathrm{E}-11$ & $1.07 \mathrm{E}+06$ & $-7.79 \mathrm{E}+03$ & $2.12 \mathrm{E}+01$ & $-2.58 \mathrm{E}-02$ & 1.17E-05 \\
\hline Castelo Branco I & $5.94 \mathrm{E}+02$ & $3.52 \mathrm{E}-01$ & $-2.16 \mathrm{E}-03$ & 7.36E-06 & $-9.60 \mathrm{E}-09$ & $-3.58 \mathrm{E}+06$ & $2.35 \mathrm{E}+04$ & $-5.79 \mathrm{E}+01$ & $6.34 \mathrm{E}-02$ & $-2.60 \mathrm{E}-05$ \\
\hline Miranda & $6.85 \mathrm{E}+02$ & $-4.02 \mathrm{E}-03$ & $-7.94 \mathrm{E}-07$ & 2.79E-08 & $-1.42 \mathrm{E}-11$ & $6.34 \mathrm{E}+04$ & $-9.56 \mathrm{E}+01$ & $-6.59 \mathrm{E}-02$ & $2.46 \mathrm{E}-05$ & $1.14 \mathrm{E}-07$ \\
\hline São Simão & $3.58 \mathrm{E}+02$ & $8.62 \mathrm{E}-03$ & $-8.84 \mathrm{E}-07$ & $5.29 \mathrm{E}-11$ & $-1.24 \mathrm{E}-15$ & $-1.85 \mathrm{E}+05$ & $1.54 \mathrm{E}+03$ & $-4.30 \mathrm{E}+00$ & $4.02 \mathrm{E}-03$ & $0.00 \mathrm{E}+00$ \\
\hline
\end{tabular}

Source: ONS (2017). 


\section{Appendix X: Relative quota}

Quota-Volume polynomial $\left(\right.$ in $\left.\mathrm{hm}^{3}\right):$ Quota $=a_{Q V P}+b_{Q V P} . V o l+c_{Q V P} . V_{o l}{ }^{2}+d_{Q V P} . V_{o l}{ }^{3}+e_{Q V P} . V o l^{4}$

\begin{tabular}{|c|c|c|c|c|c|c|c|c|c|c|c|c|}
\hline Hydropower reservoir & Jan & Feb & Mar & Apr & May & Jun & Jul & Aug & Sep & Oct & Nov & Dec \\
\hline UHE Batalha & 794.36 & 795.52 & 796.55 & 796.82 & 796.77 & 796.49 & 795.99 & 795.05 & 794.06 & 792.94 & 792.66 & 793.15 \\
\hline UHE Nova Ponte & 802.10 & 803.74 & 805.64 & 806.45 & 806.56 & 806.24 & 805.43 & 804.04 & 802.53 & 801.00 & 800.03 & 800.82 \\
\hline UHE Corumbá I & 586.01 & 587.99 & 589.75 & 590.20 & 590.13 & 589.64 & 588.78 & 587.18 & 585.50 & 583.63 & 583.16 & 583.98 \\
\hline UHE Barra dos Coqueiros & 447.05 & 447.24 & 447.42 & 447.46 & 447.46 & 447.40 & 447.32 & 447.16 & 447.00 & 446.84 & 446.80 & 446.87 \\
\hline UHE Salto & 446.50 & 446.50 & 446.50 & 446.50 & 446.50 & 446.50 & 446.50 & 446.50 & 446.50 & 446.50 & 446.50 & 446.50 \\
\hline UHE Emborcação & 643.54 & 646.57 & 649.29 & 650.54 & 650.31 & 649.55 & 648.22 & 645.98 & 643.34 & 640.49 & 638.81 & 639.99 \\
\hline UHE Cachoeira Dourada & 434.12 & 434.12 & 434.12 & 434.12 & 434.12 & 434.12 & 434.12 & 434.12 & 434.12 & 434.12 & 434.12 & 434.12 \\
\hline Queimado & 823.47 & 824.64 & 825.66 & 825.92 & 825.88 & 825.60 & 825.10 & 824.17 & 823.15 & 821.95 & 821.64 & 822.18 \\
\hline Corumbá IV & 839.99 & 840.50 & 840.99 & 841.12 & 841.10 & 840.96 & 840.72 & 840.29 & 839.86 & 839.42 & 839.31 & 839.50 \\
\hline Corumbá III & 770.16 & 770.51 & 770.85 & 770.94 & 770.92 & 770.82 & 770.66 & 770.37 & 770.08 & 769.78 & 769.71 & 769.83 \\
\hline Serra do Facão & 747.31 & 749.16 & 750.88 & 751.33 & 751.26 & 750.77 & 749.93 & 748.40 & 746.85 & 745.18 & 744.76 & 745.49 \\
\hline Itumbiara & 510.35 & 512.08 & 514.38 & 515.54 & 515.78 & 515.25 & 514.02 & 511.85 & 509.34 & 507.09 & 506.70 & 507.80 \\
\hline Salto Verdinho & 370.50 & 370.50 & 370.50 & 370.50 & 370.50 & 370.50 & 370.50 & 370.50 & 370.50 & 370.50 & 370.50 & 370.50 \\
\hline Cacu & 476.20 & 476.40 & 476.59 & 476.64 & 476.63 & 476.58 & 476.48 & 476.32 & 476.15 & 475.98 & 475.93 & 476.01 \\
\hline Espora & 581.63 & 582.05 & 582.41 & 582.50 & 582.49 & 582.39 & 582.21 & 581.88 & 581.52 & 581.09 & 580.97 & 581.17 \\
\hline Castelo Branco II & 564.99 & 565.00 & 565.00 & 565.00 & 565.00 & 565.00 & 565.00 & 564.99 & 564.99 & 564.99 & 564.99 & 564.99 \\
\hline Castelo Branco I & 623.75 & 623.82 & 623.88 & 623.90 & 623.90 & 623.88 & 623.85 & 623.79 & 623.73 & 623.67 & 623.66 & 623.68 \\
\hline Miranda & 694.62 & 694.90 & 695.16 & 695.23 & 695.21 & 695.14 & 695.01 & 694.78 & 694.55 & 694.32 & 694.26 & 694.36 \\
\hline São Simão & 397.21 & 398.82 & 399.85 & 399.62 & 399.37 & 398.96 & 398.48 & 397.46 & 396.66 & 395.51 & 395.56 & 395.98 \\
\hline
\end{tabular}

Source: Author's calculation, from ONS (2017) polynomials data. 


\section{Appendix XI: Average monthly area}

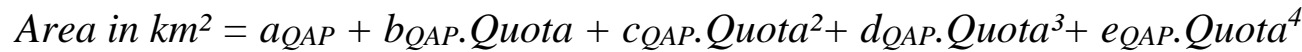

\begin{tabular}{|c|c|c|c|c|c|c|c|c|c|c|c|c|c|}
\hline Hydropower reservoir & Jan & Feb & Mar & Apr & May & Jun & Jul & Aug & Sep & Oct & Nov & Dec & $\begin{array}{c}\text { Annual } \\
\text { average }\end{array}$ \\
\hline UHE Batalha & 104.89 & 111.75 & 117.81 & 119.37 & 119.11 & 117.42 & 114.49 & 108.96 & 103.10 & 96.51 & 94.86 & 97.75 & 108.83 \\
\hline UHE Nova Ponte & 308.25 & 323.00 & 340.84 & 348.67 & 349.75 & 346.63 & 338.81 & 325.79 & 312.07 & 298.63 & 290.41 & 297.10 & 323.33 \\
\hline UHE Corumbá I & 45.52 & 49.18 & 52.65 & 53.58 & 53.43 & 52.42 & 50.72 & 47.66 & 44.61 & 41.40 & 40.63 & 41.99 & 47.82 \\
\hline UHE Barra dos Coqueiros & 26.34 & 26.59 & 26.83 & 26.89 & 26.88 & 26.81 & 26.69 & 26.48 & 26.27 & 26.06 & 26.00 & 26.10 & 26.49 \\
\hline UHE Salto & 60.24 & 60.24 & 60.24 & 60.24 & 60.24 & 60.24 & 60.24 & 60.24 & 60.24 & 60.24 & 60.24 & 60.24 & 60.24 \\
\hline UHE Emborcação & 316.69 & 340.97 & 363.99 & 375.00 & 372.92 & 366.24 & 354.81 & 336.14 & 315.13 & 293.63 & 281.59 & 290.05 & 333.93 \\
\hline UHE Cachoeira Dourada & 69.00 & 69.00 & 69.00 & 69.00 & 69.00 & 69.00 & 69.00 & 69.00 & 69.00 & 69.00 & 69.00 & 69.00 & 69.00 \\
\hline Queimado & 35.43 & 39.55 & 43.88 & 45.13 & 44.92 & 43.59 & 41.42 & 37.79 & 34.47 & 31.31 & 30.61 & 31.87 & 38.33 \\
\hline Corumbá IV & 153.67 & 156.67 & 159.58 & 160.37 & 160.24 & 159.39 & 157.95 & 155.41 & 152.94 & 150.41 & 149.82 & 150.87 & 155.61 \\
\hline Corumbá III & 65.58 & 66.83 & 68.05 & 68.38 & 68.33 & 67.97 & 67.37 & 66.31 & 65.27 & 64.21 & 63.96 & 64.40 & 66.39 \\
\hline Serra do Facão & 160.63 & 170.74 & 180.69 & 183.40 & 182.96 & 180.04 & 175.12 & 166.49 & 158.16 & 149.58 & 147.53 & 151.16 & 167.21 \\
\hline Itumbiara & 534.31 & 573.97 & 631.44 & 662.56 & 669.37 & 654.67 & 622.09 & 568.70 & 512.20 & 466.48 & 458.91 & 480.46 & 569.60 \\
\hline Salto Verdinho & 36.55 & 36.55 & 36.55 & 36.55 & 36.55 & 36.55 & 36.55 & 36.55 & 36.55 & 36.55 & 36.55 & 36.55 & 36.55 \\
\hline $\mathrm{Cacu}$ & 15.51 & 15.67 & 15.83 & 15.87 & 15.87 & 15.82 & 15.74 & 15.61 & 15.47 & 15.33 & 15.30 & 15.35 & 15.61 \\
\hline Espora & 25.66 & 26.69 & 27.60 & 27.84 & 27.80 & 27.55 & 27.10 & 26.28 & 25.39 & 24.35 & 24.08 & 24.55 & 26.24 \\
\hline Castelo Branco II & 54.48 & 54.49 & 54.49 & 54.49 & 54.49 & 54.49 & 54.49 & 54.48 & 54.48 & 54.48 & 54.48 & 54.48 & 54.48 \\
\hline Castelo Branco I & 30.84 & 30.90 & 30.96 & 30.98 & 30.98 & 30.96 & 30.93 & 30.88 & 30.82 & 30.77 & 30.76 & 30.78 & 30.88 \\
\hline Miranda & 47.84 & 48.28 & 48.75 & 48.88 & 48.86 & 48.72 & 48.48 & 48.09 & 47.74 & 47.40 & 47.33 & 47.46 & 48.15 \\
\hline São Simão & 560.16 & 602.86 & 631.76 & 625.13 & 618.24 & 606.81 & 593.86 & 566.77 & 546.03 & 517.61 & 518.97 & 529.28 & 576.46 \\
\hline
\end{tabular}

Source: Author's calculation, from ONS (2017) polynomials data. 


\section{Appendix XII: Water-use coefficients, total production and total water-use by sector}

Water-use coefficients, total production and total water-use by sector in the state of Goiás, in 2008.

\begin{tabular}{|c|c|c|c|c|c|c|c|c|c|c|c|c|c|}
\hline \multirow{3}{*}{ Unit } & \multirow{3}{*}{ Economy sectors } & \multicolumn{9}{|c|}{ Water-use coefficients ${ }^{*}$} & \multirow{3}{*}{$\begin{array}{l}\text { Production } \\
\text { (2008) }\end{array}$} & \multirow{2}{*}{\multicolumn{2}{|c|}{$\begin{array}{c}\text { Total } \\
\text { water-use }\left(\mathrm{hm}^{3}\right)\end{array}$}} \\
\hline & & \multicolumn{3}{|c|}{ Withdrawal $\left(m^{3}\right)$} & \multicolumn{3}{|c|}{ Consumption $\left(m^{3}\right)$} & \multicolumn{3}{|c|}{ Effluent $\left(m^{3}\right)$} & & & \\
\hline & & Min & $\operatorname{Max}$ & Average & Min & $\operatorname{Max}$ & Average & Min & $\operatorname{Max}$ & Average & & Brazil & Goiás \\
\hline & Agricultural & & & & & & & & & & & - & $3,721.59$ \\
\hline t produced & Sugarcane ${ }^{1 ; 2 ; 3}$ & & & 168 & & & 75 & & & & $33,112,209$ & & $2,494.84$ \\
\hline t produced & Soybeans $\mathrm{s}^{1 ; 2 ; 3}$ & & & 954 & & & 7 & & & & $6,604,805$ & & 46.23 \\
\hline t produced & $\operatorname{Corn}^{4 ; 5}$ & & & 478 & & & 81 & & & & $5,101,543$ & & 413.22 \\
\hline tproduced & Beans $\mathrm{s}^{4 ; 5}$ & & & & & & 89.5 & & & & 220,449 & & 19.73 \\
\hline t produced & Other culture $4: 5$ & & & & & & 117 & & & & $3,596,904$ & & 420.84 \\
\hline head/day & Bovine $^{6}$ & & & & & & 0.04229 & & & & $20,466,360$ & & 315.92 \\
\hline head/day & Swine $^{6}$ & & & & & & 0.01142 & & & & $1,592,760$ & & 6.64 \\
\hline \multirow[t]{3}{*}{ head/day } & Poultry ${ }^{6}$ & & & & & & 0.00024 & & & & $47,651,370$ & & 4.17 \\
\hline & Industry & & & & & & & & & & & - & 200.49 \\
\hline & Mining $^{7}$ & & & & & & & & & & & $1,125.77$ & 64.09 \\
\hline t produced & Coal extraction & & & 6.25 & & & 1.25 & & & 5 & & 9.04 & 0.00 \\
\hline t produced & Iron ore extraction & & & 1.05 & 0.18 & 1 & 0.59 & & & 0.87 & 55,631 & 241.36 & 0.03 \\
\hline tproduced & Aluminium ore extraction & & & 3.42 & & & 2.91 & & & 0.51 & & 112.25 & 0.00 \\
\hline t produced & Tin ore extraction & & & 6.25 & & & 1.25 & & & 5 & & 0.02 & 0.00 \\
\hline t produced & Manganese ore extraction & & & 6.25 & & & 1.25 & & & 5 & 1,200 & 4.59 & 0.00 \\
\hline t produced & Precious metals ores extraction & 0.14 & 1.78 & 0.96 & 0.05 & 1.67 & 0.86 & 0.14 & 0.37 & 0.255 & 12.3 & 1.26 & 0.00 \\
\hline t produced & Radioactive ores extraction & & & 6.25 & & & 1.25 & & & 5 & & 0.00 & 0.00 \\
\hline t produced & Non-ferrous metal ores extraction & & & 1.86 & & & 1.58 & & & 0.28 & 43,526 & 2.37 & 0.07 \\
\hline t produced & Stone, sand and clay extractions & 0.04 & 7.64 & 3.84 & 0.03 & 7.42 & 3.725 & 0.01 & 0.22 & 0.115 & $6,953,183$ & 681.96 & 25.90 \\
\hline t produced & $\begin{array}{l}\text { Extraction of minerals for the manufacture of fertilizers and other } \\
\text { chemical products }\end{array}$ & 16.4 & 47.5 & 31.95 & 6.6 & 13.8 & 10.2 & 2.6 & 36.8 & 19.7 & $3,542,870$ & 63.87 & 36.14 \\
\hline t produced & Sea salt extraction and refining & & & 6.25 & & & 1.25 & & & 5 & & 5.56 & 0.00 \\
\hline t produced & Gemstones extractions (precious and semi-precious stones) & & & 6.25 & & & 1.25 & & & 5 & 10.23 & 0.00 & 0.00 \\
\hline \multirow[t]{2}{*}{ t produced } & Extraction of non-metallic minerals not previously specified & & & 6.25 & & & 1.25 & & & 5 & $1,561,801$ & 3.50 & 1.95 \\
\hline & Food, beverages and tobacco & & & & & & & & & & & 858.45 & 22.49 \\
\hline tof live animal & Slaughter of cattle except swine & & & 2 & & & 0.25 & & & 1.75 & $7,136,568$ & 1.78 & 0.05 \\
\hline tof live animal & Slaughter of swine, poultry and other small animals & 4 & 12 & 8 & 0.5 & 1.5 & 1 & 3.5 & 10.5 & 7 & $12,395,702$ & 12.40 & 0.32 \\
\hline t produced & Manufacture of meat products & & & 12 & & & 1.5 & & & 10.5 & $1,828,366$ & 2.74 & 0.07 \\
\hline t produced & Preservation of fish and manufacture of fish products & & & 12.5 & & & 2.5 & & & 10 & 327,759 & 0.82 & 0.02 \\
\hline toffeedstock & Manufacture of canned fruit and vegetables & & & 18.75 & & & 3.75 & & & 15 & $2,174,600$ & 8.15 & 0.21 \\
\hline toffeedstock & Manufacture of vegetable oils and fats & 0.2 & 14 & 7.1 & & & & 0.2 & 14 & 7.1 & $31,815,133$ & 0.00 & 0.00 \\
\hline
\end{tabular}




\begin{tabular}{|c|c|c|c|c|c|c|c|c|c|c|c|c|c|}
\hline$m^{3}$ of milk & Dairy products & 1.1 & 2 & 1.55 & & & & 1.6 & 2.2 & 1.9 & $10,072,008$ & 0.00 & 0.00 \\
\hline t produced & Grinding, manufacture of starch products and animal feed & 1.7 & 3 & 2.35 & 0.3 & 1.2 & 0.75 & 1.4 & 1.8 & 1.6 & $34,136,289$ & 25.60 & 0.67 \\
\hline tof sugar & Manufacture and refining of sugar & & & 17 & & & 17 & & & & $45,169,130$ & 767.88 & 20.12 \\
\hline t produced & Manufacture of other food products & & & 4.72 & & & 0.95 & & & 3.78 & $9,292,352$ & 8.83 & 0.23 \\
\hline$m^{3}$ produced & Manufacture of spirits and other distilled beverages & & & 1.24 & & & 0.47 & & & 0.77 & $1,506,552$ & 0.71 & 0.02 \\
\hline tof grape & Manufacture of wine $e^{8}$ & & & 2.5 & & & 0.5 & & & 2 & 283,190 & 0.14 & 0.00 \\
\hline$m^{3}$ produced & Manufacture of malt, beer and draft beer & 4 & 5.4 & 4.7 & 0.8 & 1.2 & 1 & 3.2 & 4.3 & 3.75 & $10,848,516$ & 10.85 & 0.28 \\
\hline$m^{3}$ produced & Manufacture of non-alcoholic beverages & 1.4 & 3 & 2.2 & & & 0.9 & 0.5 & 2.1 & 1.3 & $14,114,237$ & 12.70 & 0.33 \\
\hline \multirow[t]{2}{*}{ toffeedstock } & Manufacture of tobacco products & & & 31.25 & & & 6.25 & & & 25 & 935,666 & 5.85 & 0.15 \\
\hline & Textile, clothes and shoes & & & & & & & & & & & 76.78 & 2.01 \\
\hline t produced & Manufacture and spinning of textile fibres & 115 & 118 & 116.5 & 22 & 23 & 22.5 & 93 & 96 & 94.5 & 982,190 & 22.10 & 0.58 \\
\hline tproduced & Weaving, except knitted & 42 & 48 & 45 & 7 & 8 & 7.5 & 35 & 40 & 37.5 & $1,377,733$ & 10.33 & 0.27 \\
\hline t produced & Manufacture of knitted fabrics & & & 36 & & & 6 & & & 30 & 274,473 & 1.65 & 0.04 \\
\hline t produced & Textile yarn, fabric and textile finishing & 19 & 104 & 61.5 & 3.5 & 20 & 11.75 & 15 & 83 & 49 & - & 0.00 & 0.00 \\
\hline Thousand pieces & Manufacture of other textile products, except apparel & 2.1 & 8.2 & 5.15 & 1.8 & 6.9 & 4.35 & 0.3 & 1.3 & 0.8 & $1,251,334$ & 5.44 & 0.14 \\
\hline Thousand pieces & Manufacture of wearing apparel and accessories & & & 11.9 & & & 2.2 & & & 9.8 & $1,269,363$ & 2.79 & 0.07 \\
\hline Thousand pieces & Manufacture of knitted and crocheted articles & & & 3.32 & & & 0.64 & & & 2.68 & 6,849 & 0.00 & 0.00 \\
\hline Skin processed & Tanning and other leather preparations ${ }^{9}$ & 0.47 & 1 & 0.735 & & & 0.735 & 0.47 & 1 & 0.735 & $45,908,697$ & 33.74 & 0.88 \\
\hline Pair of shoes & Manufacture of shoes & & & 0.0021 & & & 0.0004 & & & 0.0017 & $778,164,312$ & 0.31 & 0.01 \\
\hline \multirow[t]{2}{*}{ Pair of shoes } & Manufacture of parts for footwear, of any material & & & 0.0038 & & & 0.0008 & & & 0.003 & $514,221,340$ & 0.41 & 0.01 \\
\hline & Wood, paper and printing & & & & & & & & & & & 502.47 & 13.16 \\
\hline $\begin{array}{l}\text { Thousand } m^{3} \text { of } \\
\text { wood }\end{array}$ & $\begin{array}{l}\text { Manufacture of products of wood, cork and plaited materials, } \\
\text { other than furniture }{ }^{10}\end{array}$ & & & 3.2 & & & 0.84 & & & 2.36 & 26,270 & 0.02 & 0.00 \\
\hline Air dried $t$ & Manufacture of pulp and paper pulp & 25.9 & 46.8 & 36.35 & 3.2 & 5.8 & 4.5 & 22.7 & 41 & 31.85 & $9,645,659$ & 43.41 & 1.14 \\
\hline tof paper & Manufacture of paper and paperboard & 10 & 46.3 & 28.15 & 1.8 & 8.4 & 5.1 & 8.2 & 37.9 & 23.05 & $80,179,983$ & 408.92 & 10.71 \\
\hline tof paper & $\begin{array}{l}\text { Manufacture of paper packaging, cardboard, corrugated } \\
\text { paperboard and paperboard }\end{array}$ & & & 0.46 & & & 0.33 & & & 0.13 & $4,867,168$ & 1.61 & 0.04 \\
\hline tof paper & $\begin{array}{l}\text { Manufacture of other products from paper, paperboard, cardboard } \\
\text { and corrugated paperboard }\end{array}$ & 13 & 27 & 20 & 4 & 9 & 6.5 & 9 & 18 & 13.5 & $7,464,755$ & 48.52 & 1.27 \\
\hline \multirow[t]{2}{*}{ tof finished } & Printing and reproduction of recordings & 0.17 & 9 & 4.585 & 0.03 & 1.8 & 0.915 & 0.14 & 7.2 & 3.67 & 2,602 & 0.00 & 0.00 \\
\hline & Oil refining, coke and alcohol ${ }^{l ; 11}$ & & & & & & & & & & & 436.12 & 1.67 \\
\hline tof coke & Manufacture of coke & & & 12.4 & & & 2.5 & & & 9.9 & 649.60 & 0.42 & 0.00 \\
\hline Barrels of oil & Manufacture of petroleum products & & & 0.188 & & & 0.038 & & & 0.15 & & 0.00 & 0.00 \\
\hline \multirow[t]{2}{*}{$m^{3} / G J$} & Manufacture of biofuels (ethanol) & & & & & & 45 & & & & 37,139 & 435.70 & 1.67 \\
\hline & Chemical and pharmaceutical products & & & & & & & & & & & 802.55 & 21.03 \\
\hline t produced & Manufacture of inorganic products & 3 & 16 & 9.5 & 2 & 4 & 3 & 2 & 12 & 7 & $32,562,593$ & 97.69 & 2.56 \\
\hline t produced & Manufacture of organic products & 2 & 70 & 36 & 1 & 40 & 20.5 & 1 & 30 & 15.5 & $32,500,860$ & 666.27 & 17.46 \\
\hline t produced & Manufacture of resins and elastomers & 2 & 15 & 8.5 & 1 & 4 & 2.5 & 1 & 11 & 6 & $3,808,384$ & 9.52 & 0.25 \\
\hline t produced & Manufacture of artificial and synthetic fibres & & & 1.25 & & & 0.25 & & & 1 & 368,064 & 0.09 & 0.00 \\
\hline t produced & Manufacture of pesticides and disinfectants & & & 10.3 & & & 3.3 & & & 7 & 778,477 & 2.57 & 0.07 \\
\hline t produced & $\begin{array}{l}\text { Manufacture of soap, detergents, cleaning products, cosmetics, } \\
\text { perfumery and personal care products }\end{array}$ & 1.2 & 1.7 & 1.45 & 0.6 & 0.8 & 0.7 & 0.6 & 0.9 & 0.75 & $6,073,451$ & 4.25 & 0.11 \\
\hline t produced & $\begin{array}{l}\text { Manufacture of paints, varnishes, enamels, lacquers and related } \\
\text { products }\end{array}$ & & & 1 & & & 0.7 & & & 0.3 & $1,468,857$ & 1.03 & 0.03 \\
\hline t produced & Manufacture of other chemical products and preparations & 0.5 & 60 & 30.25 & 0 & 10 & 5 & 0.5 & 50 & 25.25 & $3,587,391$ & 17.94 & 0.47 \\
\hline
\end{tabular}




\begin{tabular}{|c|c|c|c|c|c|c|c|c|c|c|c|c|c|}
\hline \multirow[t]{2}{*}{ t produced } & Manufacture of pharmaceutical and chemical products & & & 312.5 & & & 62.5 & & & 250 & 51,086 & 3.19 & 0.08 \\
\hline & Other industries & & & & & & & & & & & 6.67 & 0.17 \\
\hline tproduced & Manufacture of rubber products & & & 16.2 & & & 3.2 & & & 13 & $1,888,193$ & 6.04 & 0.16 \\
\hline \multirow[t]{2}{*}{ tproduced } & Manufacture of plastic materials & & & 0.23 & & & 0.05 & & & 0.18 & $12,603,992$ & 0.63 & 0.02 \\
\hline & Cement, construction and other non-metallic minerals & & & & & & & & & & & 41.21 & 1.36 \\
\hline t produced & Manufacture of glass and glass products & 0.3 & 10 & 5.15 & & & 0.1 & 0.2 & 9.9 & 5.05 & 768,911 & 0.08 & 0.00 \\
\hline t produced & Manufacture of cement & 0.08 & 0.4 & 0.24 & 0.08 & 0.4 & 0.24 & & & & $52,279,324$ & 12.55 & 0.41 \\
\hline$m^{3}$ of concrete & $\begin{array}{l}\text { Manufacture of articles of concrete, cement, asbestos cement, } \\
\text { plaster and similar materials }\end{array}$ & & & 0.25 & & & 0.25 & & & & $27,847,966$ & 6.96 & 0.23 \\
\hline Piece & Manufacture of ceramic products & & & 0.0471 & & & 0.01 & & & 0.00371 & $706,566,254$ & 7.07 & 0.23 \\
\hline \multirow[t]{2}{*}{ tproduced } & $\begin{array}{l}\text { Stone working and other non-metallic mineral products } \\
\text { manufacturing }\end{array}$ & 0.41 & 7.27 & 3.84 & 0.08 & 1.45 & 0.765 & 0.33 & 5.82 & 3.075 & $19,036,665$ & 14.56 & 0.48 \\
\hline & Metallurgy & & & & & & & & & & & $2,862.33$ & 74.50 \\
\hline t produced & Manufacture of pig iron and iron-alloys & & & 1.25 & & & 0.25 & & & 1 & $11,059,906$ & 2.76 & 0.00 \\
\hline tof crude steel & Steel industry & & & 33.6 & & & 8.7 & & & 24.9 & $118,248,271$ & $1,028.76$ & 26.95 \\
\hline t produced & Manufacture of steel tubes & 1.25 & 52.5 & 26.875 & 0.25 & 10.5 & 5.375 & 1 & 42 & 21.5 & $2,981,729$ & 16.03 & 0.00 \\
\hline t produced & Metallurgy of non-ferrous metals & 1.24 & 3.5 & 2.37 & 0.25 & 0.7 & 0.475 & 0.99 & 2.8 & 1.895 & $11,460,190$ & 5.44 & 0.14 \\
\hline t produced & Foundry & & & 5 & & & 1 & & & 4 & $1,329,157$ & 1.33 & 0.03 \\
\hline t produced & Manufacture of metal products, except machinery and equipment & & & 2.65 & & & 1.24 & & & 1.41 & $11,998,958$ & 14.88 & 0.39 \\
\hline Unit produced & Manufacture of computers, electronics and optical products & & & 0.0985 & & & 0.0197 & & & 0.0788 & $7,977,494,924$ & $1,57.16$ & 4.12 \\
\hline Unit produced & Manufacture of machinery and equipment & 2.2 & 9.7 & 5.95 & 0.4 & 1.9 & 1.15 & 1.8 & 7.8 & 4.8 & $690,725,562$ & 794.33 & 20.81 \\
\hline Unit produced & Manufacture of cars, vans and commercial vehicles & 2.6 & 5 & 3.8 & 0.47 & 0.9 & 0.685 & 2.13 & 4.1 & 3.115 & $5,364,948$ & 3.67 & 0.10 \\
\hline Unit produced & Manufacture of trucks and buses & & & 9 & & & 1.6 & & & 7.4 & 866,138 & 1.39 & 0.04 \\
\hline \multirow[t]{2}{*}{ t produced } & Manufacture of parts and accessories for motor vehicles & & & 1.39 & & & 0.53 & & & 0.87 & $1,578,448,061$ & 836.58 & 21.92 \\
\hline & Power sector & & & & & & & & & & & - & 699.26 \\
\hline \multirow[t]{2}{*}{$m^{3} / M W h$} & Water footprint of hydro plants of the Paranaíba basin ${ }^{11 ; 12}$ & & & & & & 28.742 & & & & $24,329,000$ & & 699.26 \\
\hline & Services & & & & & & & & & & & - & 38.47 \\
\hline$m^{3} / s$ & Human supply ${ }^{13}$ & & & & & & 6.10 & & & & & & 38.47 \\
\hline
\end{tabular}

Source: ${ }^{1}$ FACHINELLI and PEREIRA (2015); ${ }^{2}$ IBGE (2009); ${ }^{3}$ IBGE (2009a) ${ }^{4}$ FAO (2017); ${ }^{5}$ MEKONNEN and HOEKSTRA (2011); ${ }^{6}$ EMBRAPA (2013); ${ }^{7}$ DNPM (2009); ${ }^{8}$ EMBRAPA (2016); ${ }^{9}$ CETESB (2014); ${ }^{10}$ IPT (2013); ${ }^{11}$ GOIÁS (2010); ${ }^{12}$ Appendix XV; ${ }^{13}$ ANA (2015).

Assumptions:

- $\quad$ "The water-use coefficient used for all estimates was the average of water consumption. The choice was based on the available data and because of the purpose of the study which aims to identify the water use by the sectors of the economy. Therefore, the water use (consumption) suits better when calculating the water unavailable for other uses.

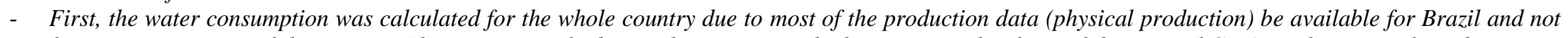
for states or regions of the country. Thus, it was applied a production ratio which represents the share of the state of Goiás in the national production, in 2008. The share used was based on both Brazilian National and Regional accounts (IBGE, 2010, 2011), which accounted for 26\% for Food, beverages and tobacco, Textile, clothes and shoes, Wood, paper and printing, Chemical and pharmaceutical products, Other industries and Metallurgy sectors. Goiás' Cement, construction and other non-metallic minerals sector accounted for 33\% of National production, in 2008 (IBGE, 2010).

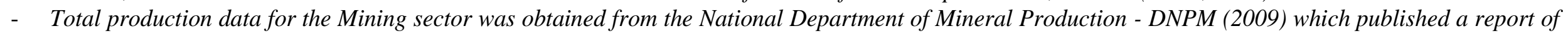
mineral sector's performance in the state of Goiás for the year 2008. 
- Data for the Oil refining, coke and ethanol was obtained from the Goiás' Energy Balance (BRAZIL, 2010). There is no refineries and coke production in the state of Goiás. Despite that, the firewood production in the IO model was allocated in the activity "Manufacture of coke". It was assumed that: It of sugarcane $=85 \mathrm{~L}$ of ethanol; 1 t of sugarcane consumes $9.1 \mathrm{~L}$ of water; $50 \%$ of processed sugarcane was used to produce ethanol in 2008. In the activity "Manufacture of coke", it was assumed that 545 toe (firewood) $=5.450 \times 10^{6} \mathrm{kcal} / 8.390=649.6 \mathrm{t}$ of coke; $1 \mathrm{~kg}$ of coke $=8,390$ kcal. Regarding biofuels production (ethanol), 968,232 t of ethanol $x 0.85 \mathrm{~g} / \mathrm{cm}^{3}$ (ethanol density) $=822,997,200 \mathrm{~L}$ of ethanol, divided by $85 \mathrm{~L} / \mathrm{t}$ of sugarcane $=9,682,320 \mathrm{t}$ of sugarcane. Finally, ITEP = $41.87 \mathrm{GJ}$; from BRAZIL (2010), 887 TEP = 37,139 GJ.

- In the Food, beverages and tobacco sector, activity "Manufacture of wine", the amount of wine declared by IBGE (2009b)-381.658m³ of wine, was multiplied by $0.742 \mathrm{~m}^{3}$ of wine by tonnes of grape (equals to 283,190 t of grape), according to EMBRAPA (2016).

- In the Textile, clothes and shoes sector, activity "Tanning and other leather preparation", and according to CETESB (2014), it was assumed that: 1 skin = $37.5 \mathrm{~kg} ; 1 \mathrm{~kg}$ of skin $=0.225 \mathrm{~kg}$ of finished leather (yield of 22.5\%); Production of 166,096 t of finished leather (IBGE, 2009b). Multiplying by 1.775 (+77.5\%) $=294,820 \mathrm{t} ;$ divided by $37.5 \mathrm{~kg}$ (average weight of one skin) $=7,861,887$ skins. 1 skin $=7.1 \mathrm{~m}^{2} ; 270,132,357 \mathrm{~m}^{2}($ IBGE, $2009 \mathrm{~b})$ divided by $7.1=38,046,810$ skins. Total $=7,861,887+38,046,810=45,908,697$ skins processed in 2008.

- In the Wood, paper and printing sector, activity "Manufacture of products of wood, cork and plaited materials, other than furniture", and according to IPT (2013), it was assumed that: The average density of 20 species used in construction sector $=682 \mathrm{~kg} / \mathrm{m}^{3}$; of 17,093 t of wood produced, it results in about $26,270 \mathrm{~m}^{3}$.

- According to BRAZIL (2010) - Energy Balance for the Goiás State, hydropower plants have produced 24,329,00 MWh in the state in 2008, accounting for $96.4 \%$ of total power production. It was assumed a water footprint of $28.742 \mathrm{~m}^{3}$ of water / MWh produced. Therefore, it was consumed $699.26 \mathrm{hm}^{3}$ of water through evaporation (see Appendices XII, XIII, XIV and XV).

- In the Services sector, activity "Human supply", it was assumed: 1 year = 31,536,000 seconds $x 6.1 \mathrm{~m}^{3}$ of water consumption per second (from ANA, 2015) $=192,369,600 \times 20 \%$ (estimated share of the commercial sector) $=38.47 \mathrm{hm}^{3}$ of water .

[Back to page 66] 


\section{Appendix XIII: Evaporation coefficients}

Net evapotranspiration in reservoirs, by month (in $\mathrm{mm}$ ).

\begin{tabular}{|c|c|c|c|c|c|c|c|c|c|c|c|c|}
\hline Hydropower reservoir & Jan & Feb & Mar & Apr & May & Jun & Jul & Aug & Sep & Oct & Nov & Dec \\
\hline UHE Batalha & 10 & 6 & 21 & 39 & 58 & 62 & 63 & 63 & 61 & 26 & 10 & 29 \\
\hline UHE Nova Ponte & 16 & 7 & 23 & 40 & 61 & 65 & 67 & 66 & 54 & 25 & 13 & 33 \\
\hline UHE Corumbá I & 2 & 1 & 17 & 37 & 53 & 56 & 58 & 54 & 55 & 21 & 8 & 21 \\
\hline UHE Barra dos Coqueiros & 12 & 7 & 22 & 42 & 64 & 70 & 68 & 68 & 67 & 20 & 6 & 25 \\
\hline UHE Salto & 12 & 8 & 23 & 42 & 64 & 70 & 68 & 69 & 66 & 19 & 5 & 25 \\
\hline UHE Emborcação & 0 & 2 & 16 & 36 & 53 & 54 & 54 & 50 & 45 & 16 & 5 & 19 \\
\hline UHE Cachoeira Dourada & 11 & 5 & 24 & 44 & 59 & 63 & 61 & 62 & 65 & 27 & 11 & 30 \\
\hline Queimado & 21 & 4 & 21 & 33 & 59 & 70 & 77 & 79 & 80 & 51 & 17 & 51 \\
\hline Corumbá IV & 19 & 8 & 19 & 32 & 56 & 64 & 73 & 84 & 86 & 53 & 13 & 44 \\
\hline Corumbá III & 12 & 11 & 19 & 32 & 57 & 63 & 68 & 72 & 72 & 42 & 21 & 37 \\
\hline Serra do Facão & 6 & 8 & 20 & 35 & 55 & 57 & 57 & 59 & 52 & 24 & 16 & 31 \\
\hline Itumbiara & 6 & 1 & 19 & 42 & 58 & 62 & 60 & 56 & 58 & 22 & 5 & 23 \\
\hline Salto Verdinho & 14 & 14 & 27 & 46 & 65 & 67 & 63 & 64 & 65 & 23 & 9 & 30 \\
\hline $\mathrm{Cacu}$ & 12 & 5 & 21 & 39 & 62 & 69 & 69 & 69 & 68 & 19 & 7 & 24 \\
\hline Espora & 10 & 5 & 24 & 37 & 55 & 61 & 64 & 75 & 71 & 25 & 19 & 28 \\
\hline Castelo Branco II & 2 & 0 & 18 & 40 & 55 & 56 & 53 & 49 & 50 & 19 & 4 & 23 \\
\hline Castelo Branco I & 2 & 0 & 18 & 38 & 51 & 51 & 48 & 46 & 45 & 18 & 6 & 25 \\
\hline Miranda & 7 & 4 & 18 & 37 & 54 & 54 & 53 & 52 & 41 & 15 & 5 & 26 \\
\hline São Simão & 13 & 11 & 25 & 46 & 67 & 72 & 68 & 66 & 64 & 22 & 4 & 25 \\
\hline
\end{tabular}

Source: ONS (2004) - Net evaporation in hydropower plants. 


\section{Appendix XIV: Net evaporation of reservoirs}

Net evaporation, monthly average (in $\mathrm{hm}^{3}$ ).

\begin{tabular}{|c|c|c|c|c|c|c|c|c|c|c|c|c|c|}
\hline Hydropower reservoir & Jan & Feb & Mar & Apr & May & Jun & Jul & Aug & Sep & Oct & Nov & Dec & $\begin{array}{c}\text { Annual } \\
\text { average }\end{array}$ \\
\hline UHE Batalha & 1.0 & 0.6 & 2.4 & 4.6 & 6.9 & 7.3 & 7.2 & 6.9 & 6.3 & 2.5 & 0.9 & 2.8 & 48.6 \\
\hline UHE Nova Ponte & 4.9 & 2.3 & 7.8 & 13.9 & 21.3 & 22.5 & 22.7 & 21.5 & 16.9 & 7.5 & 3.8 & 9.8 & 150.0 \\
\hline UHE Corumbá I & 0.1 & 0.0 & 0.9 & 2.0 & 2.8 & 2.9 & 2.9 & 2.6 & 2.5 & 0.9 & 0.3 & 0.9 & 18.7 \\
\hline UHE Barra dos Coqueiros & 0.3 & 0.2 & 0.6 & 1.1 & 1.7 & 1.9 & 1.8 & 1.8 & 1.8 & 0.5 & 0.2 & 0.7 & 12.2 \\
\hline UHE Salto & 0.7 & 0.5 & 1.4 & 2.5 & 3.9 & 4.2 & 4.1 & 4.2 & 4.0 & 1.1 & 0.3 & 1.5 & 27.7 \\
\hline UHE Emborcação & 0.0 & 0.7 & 5.8 & 13.5 & 19.8 & 19.8 & 19.2 & 16.8 & 14.2 & 4.7 & 1.4 & 5.5 & 121.3 \\
\hline UHE Cachoeira Dourada & 0.8 & 0.3 & 1.7 & 3.0 & 4.1 & 4.3 & 4.2 & 4.3 & 4.5 & 1.9 & 0.8 & 2.1 & 31.1 \\
\hline Queimado & 0.7 & 0.2 & 0.9 & 1.5 & 2.7 & 3.1 & 3.2 & 3.0 & 2.8 & 1.6 & 0.5 & 1.6 & 20.9 \\
\hline Corumbá IV & 2.9 & 1.3 & 3.0 & 5.1 & 9.0 & 10.2 & 11.5 & 13.1 & 13.2 & 8.0 & 1.9 & 6.6 & 82.9 \\
\hline Corumbá III & 0.8 & 0.7 & 1.3 & 2.2 & 3.9 & 4.3 & 4.6 & 4.8 & 4.7 & 2.7 & 1.3 & 2.4 & 32.9 \\
\hline Serra do Facão & 1.0 & 1.4 & 3.6 & 6.4 & 10.1 & 10.3 & 10.0 & 9.8 & 8.2 & 3.6 & 2.4 & 4.7 & 70.4 \\
\hline Itumbiara & 3.2 & 0.6 & 12.0 & 27.8 & 38.8 & 40.6 & 37.3 & 31.8 & 29.7 & 10.3 & 2.3 & 11.1 & 242.3 \\
\hline Salto Verdinho & 0.5 & 0.5 & 1.0 & 1.7 & 2.4 & 2.4 & 2.3 & 2.3 & 2.4 & 0.8 & 0.3 & 1.1 & 17.3 \\
\hline $\mathrm{Cacu}$ & 0.2 & 0.1 & 0.3 & 0.6 & 1.0 & 1.1 & 1.1 & 1.1 & 1.1 & 0.3 & 0.1 & 0.4 & 7.1 \\
\hline Espora & 0.3 & 0.1 & 0.7 & 1.0 & 1.5 & 1.7 & 1.7 & 2.0 & 1.8 & 0.6 & 0.5 & 0.7 & 12.3 \\
\hline Castelo Branco II & 0.1 & 0.0 & 1.0 & 2.2 & 3.0 & 3.1 & 2.9 & 2.7 & 2.7 & 1.0 & 0.2 & 1.3 & 20.0 \\
\hline Castelo Branco I & 0.1 & 0.0 & 0.6 & 1.2 & 1.6 & 1.6 & 1.5 & 1.4 & 1.4 & 0.6 & 0.2 & 0.8 & 10.7 \\
\hline Miranda & 0.3 & 0.2 & 0.9 & 1.8 & 2.6 & 2.6 & 2.6 & 2.5 & 2.0 & 0.7 & 0.2 & 1.2 & 17.4 \\
\hline São Simão & 7.3 & 6.6 & 15.8 & 28.8 & 41.4 & 43.7 & 40.4 & 37.4 & 34.9 & 11.4 & 2.1 & 13.2 & 275.7 \\
\hline Average net annual evapc & & & & & & & & & & & & & $1,219.47$ \\
\hline
\end{tabular}

$1,219.47$

Note: $E V A V=10^{-3}$. Area.$E$ EAC $i$

Area, from Appendix XI.

EVAC, from Appendix XIII. 


\section{Appendix XV: Water footprint of power plants in the region of study}

\begin{tabular}{|c|c|c|c|c|c|c|c|}
\hline \multirow[b]{2}{*}{ Hydropower station } & \multicolumn{4}{|c|}{ Power generation } & \multicolumn{2}{|c|}{ Water footprint } & \multirow[b]{2}{*}{ GJ (year) } \\
\hline & $\mathbf{M W}_{\text {average }}$ & MW(month) & MWh (year) & kWh (year) & $\mathbf{m}^{3} / \mathbf{M W h}$ & $\mathbf{m}^{3} / \mathbf{k W h}$ & \\
\hline UHE Batalha & 48.8 & 36307 & 427,488 & $427,488,000$ & 113.7 & 0.114 & $1,538,957$ \\
\hline UHE Nova Ponte & 276 & 205344 & $2,417,760$ & $2,417,760,000$ & 62.0 & 0.062 & $8,703,936$ \\
\hline UHE Corumbá I & 209 & 155496 & $1,830,840$ & $1,830,840,000$ & 10.2 & 0.010 & $6,591,024$ \\
\hline UHE Barra dos Coqueiros & 57.3 & 42631 & 501,948 & $501,948,000$ & 24.3 & 0.024 & $1,807,013$ \\
\hline UHE Salto & 63.8 & 47467 & 558,888 & $558,888,000$ & 49.5 & 0.049 & $2,011,997$ \\
\hline UHE Emborcação & 497 & 369768 & $4,353,720$ & $4,353,720,000$ & 27.9 & 0.028 & $15,673,392$ \\
\hline UHE Cachoeira Dourada & 415 & 308760 & $3,635,400$ & $3,635,400,000$ & 8.6 & 0.009 & $13,087,440$ \\
\hline Queimado & 58 & 43152 & 508,080 & $508,080,000$ & 41.2 & 0.041 & $1,829,088$ \\
\hline Corumbá IV & 76.6 & 56990 & 671,016 & $671,016,000$ & 123.5 & 0.124 & $2,415,658$ \\
\hline Corumbá III & 50.9 & 37870 & 445,884 & $445,884,000$ & 73.7 & 0.074 & $1,605,182$ \\
\hline Serra do Facão & 182.4 & 135706 & $1,597,824$ & $1,597,824,000$ & 44.1 & 0.044 & $5,752,166$ \\
\hline Itumbiara & 1015 & 755160 & $8,891,400$ & $8,891,400,000$ & 27.3 & 0.027 & $32,009,040$ \\
\hline Salto Verdinho & 58.2 & 43301 & 509,832 & $509,832,000$ & 33.9 & 0.034 & $1,835,395$ \\
\hline $\mathrm{Cacu}$ & 42.9 & 31918 & 375,804 & $375,804,000$ & 18.9 & 0.019 & $1,352,894$ \\
\hline Espora & 23.5 & 17484 & 205,860 & $205,860,000$ & 59.7 & 0.060 & 741,096 \\
\hline Castelo Branco II & 131 & 97464 & $1,147,560$ & $1,147,560,000$ & $\mathbf{1 7 . 4}$ & 0.017 & $4,131,216$ \\
\hline Castelo Branco I & 155 & 115320 & $1,357,800$ & $1,357,800,000$ & 7.9 & 0.008 & $4,888,080$ \\
\hline Miranda & 202 & 150288 & $1,769,520$ & $1,769,520,000$ & 9.8 & 0.010 & $6,370,272$ \\
\hline São Simão & 1281 & 953064 & $11,221,560$ & $11,221,560,000$ & 24.6 & 0.025 & $40,397,616$ \\
\hline Total Paranaíba basin & 4843.4 & $\mathbf{3 6 0 3 4 9 0}$ & $42,428,184$ & $42,428,184,000$ & 28.742 & 0.029 & $152,741,462$ \\
\hline
\end{tabular}

Note: Total WF = Average annual total evaporation $/ M W h($ year $)$

Average annual total, from Appendix XIV; The total estimated water footprint of hydro plants in the Paranaiba basin was $28.742 \mathrm{~m}^{3} / \mathrm{MWh}$. This indicator was applied to estimate the water use from the power sector in 2008, according to the generation of 24,329 GWh of power, consuming $699.27 \mathrm{hm}^{3}$ of water through evaporation $\left(24,329,000 \mathrm{MWh} \times 28.742 \mathrm{~m}^{3} / \mathrm{MWh}\right)$.

Source: Author's elaboration from ANEEL (2017). 


\section{Appendix XVI: GHG emissions references}

References used to determine GHG emissions in the state of Goiás, in 2008.

\begin{tabular}{|c|c|c|c|c|c|c|c|c|c|c|c|c|c|c|c|c|}
\hline \multirow{3}{*}{ Economy sectors } & \multicolumn{9}{|c|}{ Brazil } & \multicolumn{7}{|c|}{ Goiás State } \\
\hline & \multicolumn{3}{|c|}{ (1) in $G g$} & \multicolumn{5}{|c|}{ (2) in $G g$} & \multirow{2}{*}{$\begin{array}{r}\text { (3)in } G g \\
G g C O 2 e \\
G W P-A R 2 \\
\end{array}$} & \multicolumn{3}{|c|}{ (4) in $G g$} & \multicolumn{4}{|c|}{ (5) in $t$} \\
\hline & $\mathrm{Co}_{2}$ & $\mathrm{CH}_{4}$ & $\mathrm{~N}_{2} \mathrm{O}$ & $\mathrm{Co}_{2}$ & $\mathrm{CH}_{4}$ & $\mathrm{~N}_{2} \mathrm{O}$ & $\mathrm{CO}$ & $N O_{x}$ & & $\begin{array}{c}G g C O 2 e \\
\text { GWP-AR2 }\end{array}$ & $\mathrm{CH}_{4}$ & $\mathrm{~N}_{2} \mathrm{O}$ & $\begin{array}{c}G g C O 2 e \\
G W P-A R 2 \\
\end{array}$ & $\mathrm{Co}_{2}$ & $\mathrm{CH}_{4}$ & $\mathrm{~N}_{2} \mathrm{O}$ \\
\hline Agricultural & 17,296 & $12,678.1$ & 495.26 & 17,473 & $11,955.4$ & 448.06 & $5,980.4$ & 162.5 & $408,234.2$ & $34,409.55$ & $1,079.89$ & 37.84 & $34,360,642$ & & 441,107 & $1,079,89$ \\
\hline \multicolumn{17}{|l|}{ Sugarcane } \\
\hline \multicolumn{17}{|l|}{ Soybeans } \\
\hline \multirow{2}{*}{\multicolumn{17}{|c|}{$\begin{array}{l}\text { Corn } \\
\text { Beans }\end{array}$}} \\
\hline \multicolumn{15}{|l|}{ Beans } & & \\
\hline Rice crops & & 430 & & & 474.2 & & & & & & & & & & & \\
\hline Other culture & & & & & & & & & $9,958.20$ & & & & & & & \\
\hline Burning of agricultural wastes & & 169.7 & 8.37 & & 175.5 & 4.55 & $5,980.4$ & 162.5 & 5,096 & & & & & & & \\
\hline Agricultural soils & & & 472 & & & & & & 133,052 & & & & & & & \\
\hline Enteric fermentation & & $11,296.8$ & & & $10,730.3$ & 429.20 & & & $225,336.30$ & & & & & & & \\
\hline Waste management & & 760.8 & 14.31 & & 575.4 & 14.31 & & & 16,520 & & & & & & & \\
\hline \multicolumn{17}{|l|}{ Bovine } \\
\hline \multirow{2}{*}{\multicolumn{17}{|c|}{$\begin{array}{l}\text { Swine } \\
\text { Poultry }\end{array}$}} \\
\hline \multicolumn{13}{|l|}{ Poultry } & & & & \\
\hline Industrial processes & 163,285 & $11,381.64$ & 8.12 & 142,720 & 89.40 & 8.95 & $2,568.9$ & 408.50 & $153,685.07$ & & & & 382,258 & 382,258 & & \\
\hline Mining & 8,168 & 0.13 & 0.07 & 1,658 & 58.6 & & & & & & & & & & & \\
\hline Coal extraction & 1,784 & 72.34 & & & & & & & $2,888.60$ & & & & & & & \\
\hline \multicolumn{17}{|l|}{ Iron ore extraction } \\
\hline \multicolumn{17}{|l|}{ Aluminium ore extraction } \\
\hline \multicolumn{17}{|l|}{ Tin ore extraction } \\
\hline \multicolumn{17}{|l|}{ Manganese ore extraction } \\
\hline \multicolumn{17}{|l|}{ Precious metals ores extraction } \\
\hline \multicolumn{17}{|l|}{ Radioactive ores extraction } \\
\hline \multicolumn{17}{|l|}{ Non-ferrous metal ores extraction } \\
\hline \multicolumn{17}{|l|}{ Stone, sand and clay extractions } \\
\hline \multicolumn{17}{|l|}{$\begin{array}{l}\text { Extraction of minerals for the manufacture } \\
\text { of fertilizers and other chemical products } \\
\text { Sea salt extraction and refining }\end{array}$} \\
\hline $\begin{array}{l}\text { Gemstones extractions (precious and semi- } \\
\text { precious stones) }\end{array}$ & & & & & & & & & & & & & & & & \\
\hline $\begin{array}{l}\text { Extraction of non-metallic minerals not } \\
\text { previously specified }\end{array}$ & & & & & & & & & & & & & & & & \\
\hline Food, beverages and tobacco & 3,834 & 21.82 & 3.13 & & & & 230.5 & & & & & & & & & \\
\hline Slaughter of cattle except swine & & & & & & & & & & & & & & & & \\
\hline $\begin{array}{l}\text { Slaughter of swine, poultry and other small } \\
\text { animals }\end{array}$ & & & & & & & & & & & & & & & & \\
\hline
\end{tabular}




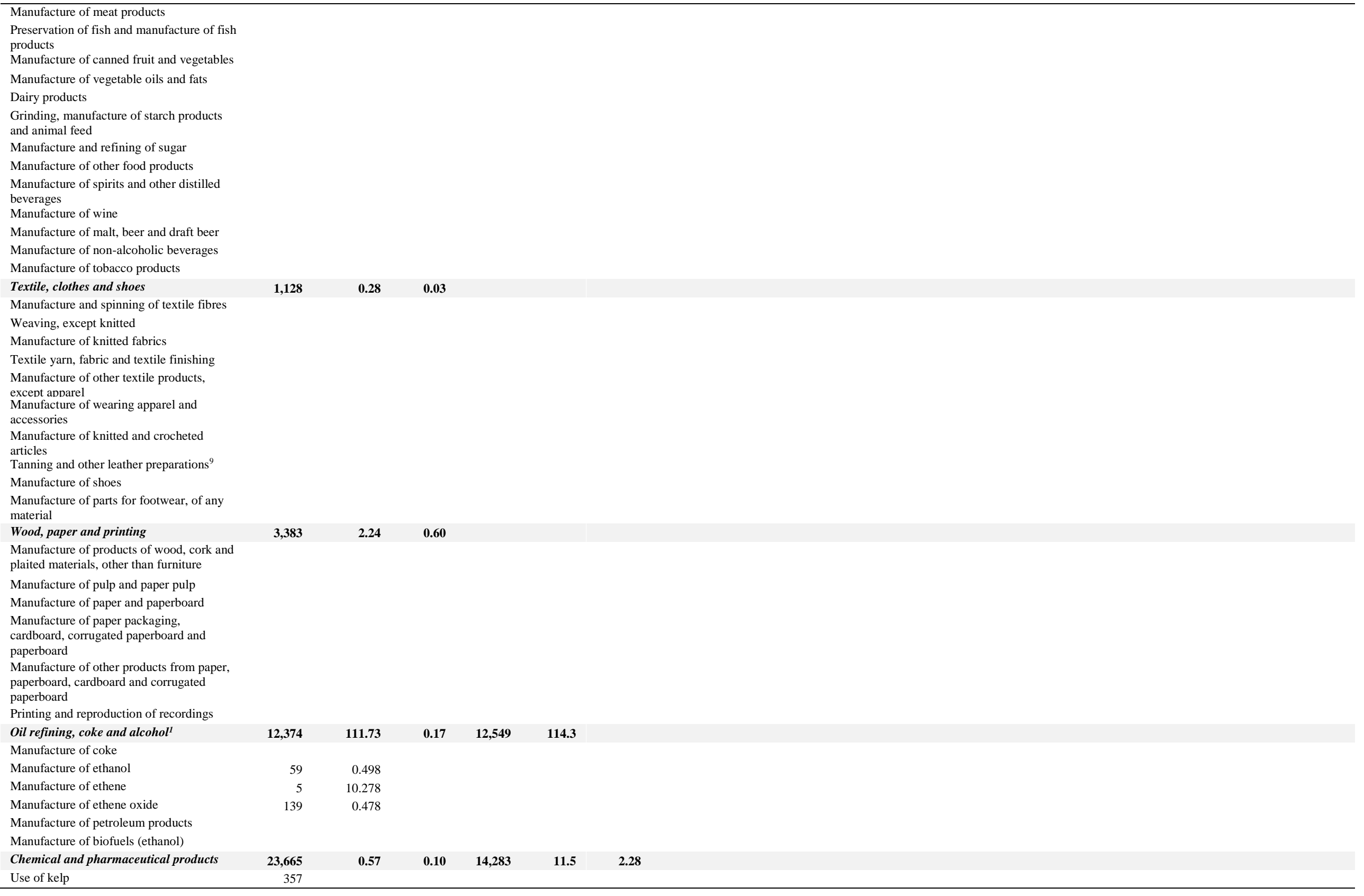




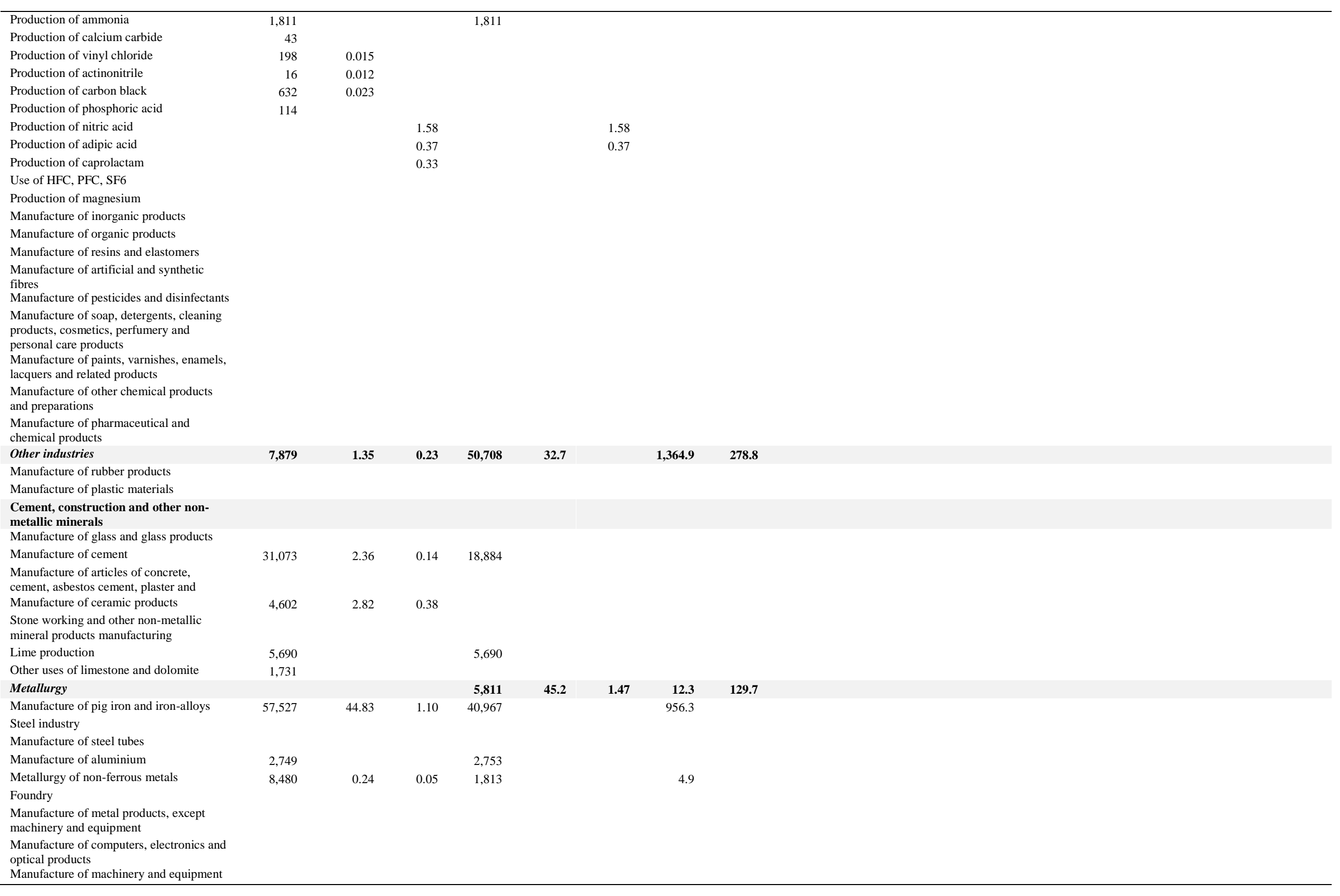


Manufacture of trucks and buses

Manufacture of parts and accessories for

\begin{tabular}{|c|c|c|c|c|c|c|c|c|c|c|c|c|c|}
\hline Power sector & 62,651 & 173.31 & 2.83 & 58,186 & 36.7 & & $1,778.4$ & 584 & $60,599.7$ & $\mathbf{9 , 3 8 5 , 5 2 0}$ & $9,178,137$ & 72,132 & 1,798 \\
\hline Integrated National System 2 & 0.0484 & & & & & & & & & & & & \\
\hline Transport & 148,416 & 12.68 & 3.32 & 150,798 & 67.9 & 13.42 & $3,065.2$ & $1,456.5$ & $156,384.10$ & & & & \\
\hline Services/commercial & 1,772 & 1.48 & 0.03 & & & & & & $1,869.70$ & & & & \\
\hline Waste treatment & 122,397 & $1,843,856$ & 14.40 & 159 & $2,277.4$ & 6.96 & & & 50,142 & $2,374,186$ & 20,123 & & 108,800 \\
\hline Solid waste & & $1,175,199$ & & & $1,266.4$ & & & & $26,755.50$ & & & & \\
\hline Effluent & & 668,657 & 14.40 & & 1,011 & & & & $23,385.50$ & & & & \\
\hline
\end{tabular}

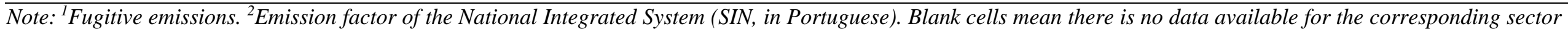
or activity, according to available sources.

Source: (1) Annual estimates of GHG emissions in Brazil (MCTI, 2014);

(2) Third National Communication of Brazil to the United Nations Framework Convention on Climate Change (MCTI, 2016);

(3) National Emissions Record System - SIRENE (SIRENE, 2017);

(4) National Emissions Record System - SIRENE, Goiás, 2008 (SIRENE, 2017) (available at: http://sirene.mcti.gov.br/web/guest/emissoes-por-unidade-federativa) ;

(5) Emission Estimating System for GHG - SEEG, Goiás, 2008 (SEEG, 2017) (available at: http://plataforma.seeg.eco.br/total_emission).

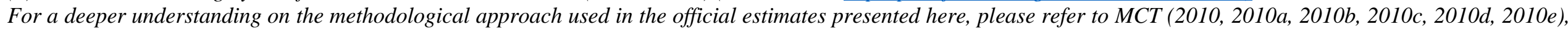
MCTI $(2014,2016)$ and SEEG $(2016,2016 a, 2016 b, 2017 b)$.

[Back to page 70$]$ 


\section{Appendix XVII: Goiás' GHG emissions}

GHG emissions in the state of Goiás, in 2008. The source SEEG (2017) has been choose due to the best available data for the state of Goiás.

\begin{tabular}{|c|c|c|c|}
\hline \multirow{2}{*}{ Economy sectors } & \multicolumn{3}{|c|}{ GHG emissions $(t)$} \\
\hline & $\mathrm{CO}_{2 e}$ GWP-AR2 & $\mathrm{CO}_{2 e}$ GWP-AR5 & $C O_{2 e} G T P-A R 5$ \\
\hline Agricultural & $\mathbf{3 5 , 7 7 6 , 8 2 8}$ & $41,674,079$ & $14,461,701$ \\
\hline Sugarcane & 484,056 & 543,872 & 211,958 \\
\hline Soybeans & 498,819 & 426,410 & 376,528 \\
\hline Corn & 257,723 & 220,311 & 194,539 \\
\hline Beans & 23,665 & 20,230 & 17,863 \\
\hline Rice crops & 49,632 & 62,112 & 14,246 \\
\hline Other crops & 103,558 & 88,526 & 78,169 \\
\hline Organic soils & 149,549 & 127,840 & 112,885 \\
\hline Synthetic fertilizers & $1,599,789$ & $1,367,562$ & $1,207,583$ \\
\hline Asinos & 4,980 & 4,943 & 2,950 \\
\hline Poultry & 282,723 & 255,615 & 196,977 \\
\hline Buffaloes & 52,508 & 61,978 & 19,475 \\
\hline Goats & 9,275 & 9,981 & 4,580 \\
\hline Equine & 429,235 & 453,304 & 222,124 \\
\hline Beef cattle & $25,067,188$ & $30,510,855$ & $8,209,345$ \\
\hline Milk cattle & $4,870,210$ & $5,554,702$ & $2,035,061$ \\
\hline Mules & 35,076 & 34,812 & 20,782 \\
\hline Sheep & 43,084 & 46,355 & 21,286 \\
\hline Swine & 508,364 & 579,645 & 212,622 \\
\hline Industrial processes & $3,973,664$ & $4,689,223$ & $2,194,165$ \\
\hline Mining & 189,469 & 189,455 & 189,238 \\
\hline Food, beverages and tobacco & 497,111 & 590,789 & 269,398 \\
\hline Dairy products & 158,476 & 211,301 & 30,185 \\
\hline Manufacture and refining of sugar & 119,775 & 159,701 & 22,814 \\
\hline Manufacture of malt, beer and draft beer & 2,767 & 3,690 & 527 \\
\hline Textile, clothes and shoes & 462 & 461 & 461 \\
\hline Wood, paper and printing & 19,488 & 25,620 & 4,596 \\
\hline Manufacture of pulp and paper pulp & 18,394 & 24,526 & 3,503 \\
\hline Oil refining, coke and alcohol & 115,463 & 153,951 & 21,993 \\
\hline Manufacture of biofuels (ethanol) & 115,463 & 153,951 & 21,993 \\
\hline Chemical and pharmaceutical products & 66,522 & 66,519 & 66,438 \\
\hline Other industries & $1,881,011$ & $2,458,324$ & 438,838 \\
\hline Cement, construction and other non-metallic minerals & 439,186 & 439,155 & 438,999 \\
\hline Manufacture of cement & 5,148 & 5,148 & 5,142 \\
\hline Manufacture of ceramic products & 51,780 & 51,749 & 51,702 \\
\hline Metallurgy & 764,947 & 764,943 & 764,096 \\
\hline Manufacture of pig iron and iron-alloys & 136,825 & 136,814 & 136,662 \\
\hline Metallurgy of non-ferrous metals & 628,122 & 628,129 & 627,434 \\
\hline Power sector & 73,586 & 73,584 & $\mathbf{7 3 , 4 9 7}$ \\
\hline Transport sector & $5,933,334$ & $5,924,289$ & $5,868,748$ \\
\hline Services / Commercial & 67,941 & 67,918 & 67,861 \\
\hline Waste & $2,374,184$ & $3,125,738$ & $\mathbf{5 0 7 , 5 9 6}$ \\
\hline Domestic effluents & 381,241 & 476,253 & 110,442 \\
\hline Industrial liquid effluents & 523,678 & 698,238 & 99,748 \\
\hline Solid waste final disposal & $1,446,915$ & $1,929,220$ & 275,602 \\
\hline Waste incineration & 22,350 & 22,027 & 21,804 \\
\hline Land-use, land-use change and forests & $47,046,802$ & $47,728,325$ & $44,541,099$ \\
\hline Land-use changes & $41,679,890$ & $41,679,890$ & $41,679,890$ \\
\hline Liming & $1,279,520$ & $1,279,520$ & $1,279,520$ \\
\hline Forestry residues & $4,087,392$ & $4,768,915$ & $1,581,689$ \\
\hline
\end{tabular}

Note: The indicator chosen for this work was the $\mathrm{CO}_{2 e}$ GWP-ARS. 
Source: SEEG (2017), Annual estimates of GHG emissions in Brazil, 2008. Available at: http://plataforma.seeg.eco.br/total_emission.

Assumptions (all the following assumptions were considered for the $\mathrm{CO}_{2 e}$ GWP-ARs indicator):

- Agricultural: 40,223,988 $t$ (from agricultural sector) $+1,305,026 t$ (from the energy used by the sector) $+145,065$ t (wasteleffluent from agricultural);

- Sugarcane: 480,778 t(from sugarcane crops) + 63,094 t (vinasse);

- Other cultures: 74,862 t (other cultures crops) + 13,664 t(cassava);

- Poultry: 240,858 t(from agricultural sector) + 14,757 t(from wasteleffluent);

- Beef cattle: 30,407,153 t(from agricultural sector) + 103,702 $t$ (from wasteleffluent);

- $\quad$ Swine: 553,039 t(from agricultural sector) + 26,606 t (wasteleffluent);

- Industrial processes: 382,258 t(from industrial processes) $+1,348,323 t$ (from the energy used by the sector) $+2,519,481$ (wasteleffluent);

- $\quad$ Food, beverages and tobacco: 216,097 $t$ (from the energy used by the sector) $+374,692 t$ (wasteleffluent);

- Dairy products: 190,303 t (wasteleffluent from the raw milk) $+20,998$ t (effluent from pasteurized milk);

- Manufacture and refining of sugar: 159,701 t (from wasteleffluent);

- Manufacture of malt, beer and draft beer: 3,690 $t$ (from wasteleffluent);

- $\quad$ Wood, paper and printing: 1,094 $t$ (from the energy used by the sector) + 24,526 t (effluent);

- Manufacture of pulp and paper pulp: 24,526 t (effluent);

- Manufacture of biofuels (ethanol): 153,951 t (wasteleffluent);

- Other industries: 52,851 $t$ (from the energy used by the sector) +476,253 $t$ (residential effluent) $+1,929,220$ (waste disposal);

- Cement, construction and other non-metallic minerals: 382,258 $t$ (industrial processes) + $5,148 t$ (from the energy used by the sector) $+51,749 t$ (energy used by the activity ceramics);

- Metallurgy: It does not consider state emissions from melting carbonates process (lack of data on state consumption of dolomite and limestone). It only considers emissions from the use of fuels (coke, coal) in the state;

- Manufacture of pig iron and iron-alloys: 97,269 t(from the energy used by pig iron activity) $+39,545$ t (energy used by iron-alloys activity);

- Power sector: 29,988 t (from public producers) + 43,596 t(from private/self-producers);

- Emissions from land-use, land-use change and forests were allocated into the Agricultural sector in the Goiás' hybrid IO model because of the origin of the emissions (i.e. land-use change, liming and forestry residues).

For a deeper understanding on the methodological approach used in the official estimates presented here, please refer to MCT (2010, 2010a, 2010b, 2010c, 2010d, 2010e), MCTI (2014, 2016) and SEEG (2016, 2016a, 2016b, 2017b).

[Back to page 70] 